\begin{abstract}
UNIVERSIDADE DE SÃO PAULO
FACULDADE DE FILOSOFIA LETRAS E CIÊNCIAS HUMANAS

DEPARTAMENTO DE LINGUÍSTICA

PROGRAMA DE PÓS-GRADUAÇÃO EM SEMIÓTICA E LINGUÍSTICA GERAL
\end{abstract}

CARINA SILVA FRAGOZO

Aquisição de Regras Fonológicas do Inglês por Falantes de Português Brasileiro

SÃO PAULO

2017 


\author{
UNIVERSIDADE DE SÃO PAULO \\ FACULDADE DE FILOSOFIA LETRAS E CIÊNCIAS HUMANAS \\ DEPARTAMENTO DE LINGUÍSTICA \\ PROGRAMA DE PÓS-GRADUAÇÃO EM SEMIÓTICA E LINGUÍSTICA GERAL
}

CARINA SILVA FRAGOZO

\title{
Aquisição de Regras Fonológicas do Inglês por Falantes de Português Brasileiro
}

Tese apresentada ao Programa de Pós-Graduação em Semiótica e Linguística Geral do Departamento de Linguística da Universidade de São Paulo, para obtenção do título de Doutor em Letras.

Área de Concentração: Semiótica e Linguística Geral

Orientadora: Prof ${ }^{-a}$ Dr ${ }^{a}$ Raquel Santana Santos

VERSÃO CORRIGIDA

De acordo: Orientadora Prof ${ }^{-}{ }^{-}{ }^{\text {a }}$ - Raquel Santana Santos

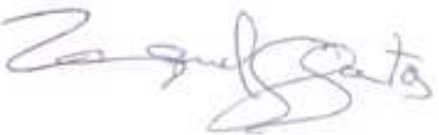

SÃO PAULO

2017 
AUTORIZO A REPRODUÇÃO E DIVULGAÇÃO TOTAL OU PARCIAL DESTE TRABALHO, POR QUALQUER MEIO CONVENCIONAL OU ELETRÔNICO, PARA FINS DE ESTUDO E PESQUISA, DESDE QUE CITADA A FONTE.

Catalogação na Publicação

Serviço de Biblioteca e Documentação

Faculdade de Filosofia, Letras e Ciências Humanas da Universidade de São Paulo

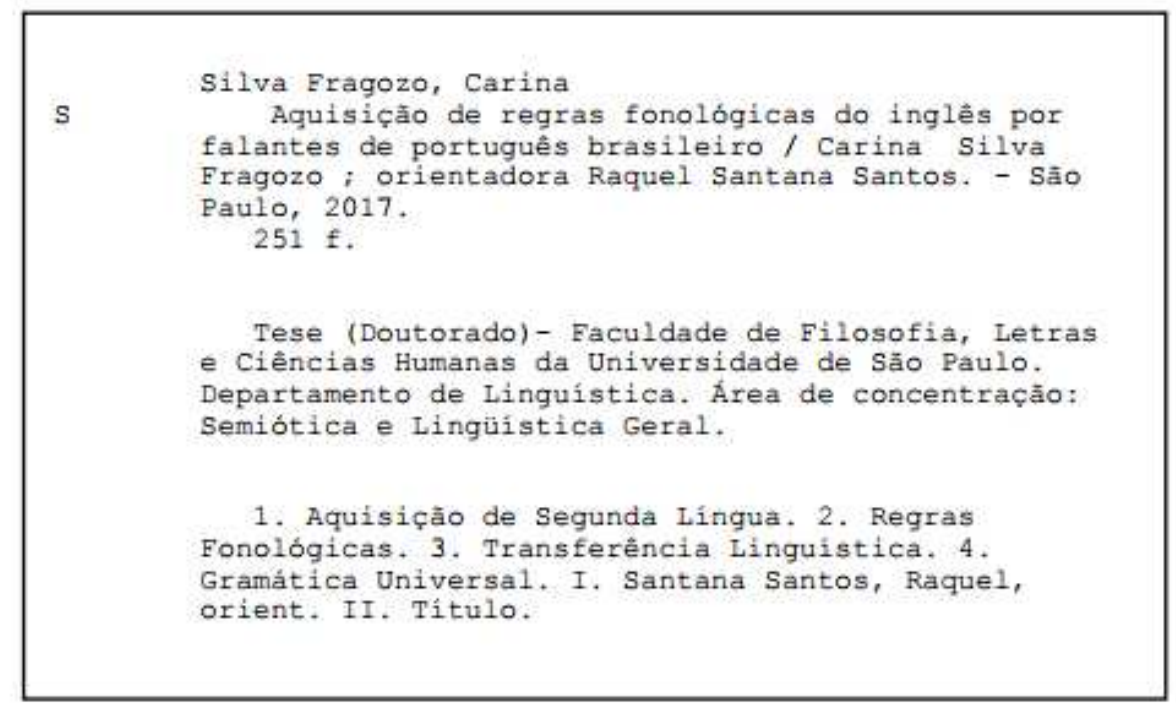




\section{FOLHA DE APROVAÇÃO}

\section{CARINA SILVA FRAGOZO \\ Aquisição de Regras Fonológicas do Inglês por Falantes de Português Brasileiro}

Tese apresentada ao Programa de Pós-Graduação em Semiótica e Linguística Geral do Departamento de Linguística da Faculdade de Filosofia, Letras e Ciências Humanas da Universidade de São Paulo como requisito para obtenção do título de Doutor em Letras.

Área de Concentração: Semiótica e Linguística Geral

Aprovada em:

BANCA EXAMINADORA

Profa. Dra. Raquel Santana Santos

Orientadora

Prof. Dr. Paulo Chagas de Sousa

(USP)

Prof. Dr. Ubiratã Kickhofel Alves

(UFRGS)

Profa. Dra. Ester Miriam Scarpa

(UNICAMP)

Profa. Dra. Eneida de Goes Leal

(PUCRS) 
Para o Anselmo. 


\section{AGRADECIMENTOS}

A realização desta tese contou com o apoio de muitas pessoas ao longo desses quatro anos, e é chegado o feliz momento de agradecer. Agradeço, portanto:

À Raquel Santana Santos, pela dedicada e cuidadosa orientação, pelo seu exemplo profissional e por se preocupar não só com a realização desta pesquisa, mas também com a minha trajetória acadêmica. Obrigada por tudo, Raquel!

Aos professores Paulo Chagas, Leo Wetzels, Cristina Altman, Eleonora Albano e Didier Demolin pelos valiosos ensinamentos durante suas aulas na USP e na UNICAMP.

Ao professor Plínio Barbosa, pelo curso de fonética acústica e por ter disponibilizado o script que utilizei nesta pesquisa.

Aos queridos colegas do grupo de estudos em Fonologia da USP, Andressa Toni, Arthur Santana, Graziela Bohn e Melanie Angelo pela acolhida, pela ajuda nos momentos de dúvida e pela amizade. Um agradecimento especial ao Arthur: vlw flw!

Ao Departamento de Linguística da USP e à CAPES, pelo auxílio financeiro.

Aos meus informantes, que gentilmente cederam seu tempo e atenção para contribuir com esta pesquisa.

Aos mais de 400 mil inscritos do canal English in Brazil, por me fazerem enxergar que é possível levar o conhecimento acadêmico para além dos muros da universidade.

Aos queridos amigos que, direta ou indiretamente, contribuíram para a realização deste trabalho, em especial: Aline Bonho Gil, Andreia Rauber, Armando Silveiro, Carolina Achutti, Fernanda Pereira Maciel, Magnun Rochel Madruga e Roberta Isolan Cury.

À minha irmã Jaqueline, por ter me inspirado a estudar a língua inglesa e por ser minha grande e eterna amiga. E ao meu cunhado Marcos, pela amizade e pelo carinho.

Aos meus amados pais, Paulo e Tânia, por terem me incentivado desde sempre a alcançar os meus objetivos. Agradeço por terem compreendido a importância dos meus momentos "vidrada no computador", mesmo quando a vontade era de me juntar à rodinha de chimarrão. Amo vocês $<3$

Ao meu esposo Anselmo, que acompanhou de perto todas as alegrias e os desafios que a vida acadêmica pode proporcionar e que sempre esteve ao meu lado para dizer: relaxa, vai dar tudo certo!

Acima de tudo, agradeço a Deus por ter guiado meu caminho até aqui. 


\section{RESUMO}

FRAGOZO, Carina. Aquisição de regras fonológicas do inglês por falantes de português brasileiro. 2017. 251f. Tese (Doutorado) - Faculdade de Filosofia, Letras e Ciências Humanas, Universidade de São Paulo, São Paulo, 2017.

Esta pesquisa investiga o papel da língua materna (L1) e da Gramática Universal (GU) na aquisição do inglês por falantes de português brasileiro através da análise de três fenômenos fonológicos: a relação entre sílaba e acento, que é totalmente diferente nas duas línguas e se dá através da marcação de parâmetros métricos; a retração de acento, que ocorre de maneira muito semelhante no inglês e no português e representa uma regra a ser transferida da L1 para a L2; e a assimilação de vozeamento, que existe em ambas as línguas, mas de maneira diferente e, portanto, trata-se de uma regra a ser modificada. Esta investigação permite compreender a influência da GU e da L1 na aquisição de L2 porque, caso os resultados mostrassem que a relação entre a sílaba e acento fosse adquirida com mais facilidade, isso seria uma evidência de que o estado inicial da aquisição é caracterizado pela GU, que permitiu a marcação do parâmetro do acento do inglês. Caso a retração de acento fosse adquirida com mais facilidade, isso significaria que o estado inicial da aquisição é caracterizado pela gramática da L1 e que haveria uma transferência (positiva) dessa regra para a L2. Por fim, caso a assimilação de vozeamento fosse adquirida com mais facilidade, isso significaria que nem a L1 e nem a GU foram fatores determinantes no processo de aquisição desses informantes. A amostra é composta por 30 falantes brasileiros de inglês divididos em três níveis de proficiência (básico, intermediário e avançado), além de 7 falantes nativos, que constituíram o grupo de controle. Para a coleta foram utilizados 3 experimentos, um para cada fenômeno, totalizando 9.248 dados. Os dados referentes à assimilação de vozeamento foram transcritos a partir da verificação acústica do vozeamento do morfema -s. A classificação dos dados referentes à sílaba e acento e à retração de acento, por sua vez, foi realizada em duas etapas: uma verificação perceptual e uma verificação acústica baseada nos principais correlatos do acento nas duas línguas: pitch e duração. Os resultados indicaram que, dentre os três fenômenos analisados, a regra de retração de acento, que se dá através da transferência da L1, e a relação entre sílaba e acento, que se dá pela marcação do parâmetro da L2, foram adquiridas com mais facilidade do que a regra de assimilação de vozeamento, que não tem apoio nem na L1 e nem na GU. Esses resultados são evidência de que o processo de aquisição fonológica de segunda língua é influenciado tanto pela Gramática Universal, que permite a marcação paramétrica a partir do input da língua alvo, quanto pela língua materna, que se manifesta na L2 através de transferência positiva ou negativa, o que faz com que regras que não contam com apoio nem da GU e nem da L1 sejam os fenômenos mais difíceis de serem adquiridos.

Palavras-Chave: Aquisição de Segunda Língua; Regras Fonológicas; Transferência; Gramática Universal 
FRAGOZO, Carina. Acquisition of phonological rules in English by speakers of Brazilian Portuguese. 2017. 251p. Doctoral Dissertation - Faculdade de Filosofia, Letras e Ciências Humanas, Universidade de São Paulo, São Paulo, 2017.

This research investigates the role of the first language (L1) and Universal Grammar (UG) in the acquisition of English by speakers of Brazilian Portuguese through the analysis of three phonological phenomena: the relation between syllable and stress, which is totally different in both languages and is given by parameter settings; stress shift, which is very similar in English and Portuguese and represents a rule to be transferred from the L1 to the target-language; and voicing assimilation, which exists in both languages, but in a different way, and, therefore, is a rule to be modified. This investigation allows us to understand the influence of UG and L1 on the acquisition of a second language because, if the results showed that the relation between syllable and stress was the easiest phenomenon to acquire, this would mean that the initial state of the acquisition is characterized by UG, which enabled the English stress parameter setting. If stress shift were more easily acquired, this would mean that the initial state of the acquisition is characterized by the grammar of the L1 and that there would be a (positive) transfer of that rule to the second language. Finally, if voicing assimilation was the easiest rule to acquire, this would mean that neither the L1 nor UG were determining factors in the acquisition process of these subjects. The sample is composed of 30 Brazilian speakers of English divided into three proficiency levels (basic, intermediate and advanced), in addition to 7 native speakers, who constituted the control group. We used 3 experiments for data collection, one for each phenomenon, totalizing 9,248 data. The data referring to voicing assimilation were transcribed based on the acoustic verification of the morpheme -s. The classification of the data related to syllable and stress and stress shift ocurred in two stages: a perceptual verification and an acoustic verification based on the main correlates of stress in the two languages: pitch and duration. The results indicated that stress shift, which occurs through the transfer of the L1, and the relation between syllable and stress, which is given by parameter settings, were more easily acquired than the voicing assimilation rule, which has no support in the L1 and in UG. These results are evidence that second language phonological acquisition is influenced both by Universal Grammar, which allows parameter (re)settings, and by first language, which means that rules that are not supported neither by GU nor L1 are the most difficult phenomena to be acquired.

Key words: Second Language Acquisition; Phonological Rules; Language Transfer; Universal Grammar 


\section{LISTA DE FIGURAS}

FIGURA 1: FRICATIVA SONORA PRODUZIDA POR UM FALANTE DE NÍVEL AVANÇADO.................................64

FIGURA 2: FRICATIVA SURDA PRODUZIDA POR UM FALANTE DE NÍVEL AVANÇADO...................................64

FIGURA 3: FRICATIVA PRODUZIDA POR UM FALANTE DE NÍVEL AVANÇADO, COM A PRIMEIRA METADE VOZEADA E A SEGUNDA METADE DESVOZEADA .65

FIGURA 4: DURAÇÃO DAS SÍLABAS DA PALAVRA CAQUI PRODUZIDA POR UMA FALANTE NATIVA DO PB .94

FiguRA 5: DURAÇÃO DAS SÍLABAS DA PALAVRA CÁQUI PRODUZIDA POR UMA FALANTE NATIVA DO PB

FIGURA 6: OSCILOGRAMA, ESPECTROGRAMA, INTENSIDADE E CURVA DE F0 DA PALAVRA RECORD PRODUZIDA COMO SUBSTANTIVO EM (A) E (B) E COMO VERBO EM (C) E (D).

FIGURA 7: PALAVRA "JORNAL" INSERIDA EM CONTEXTO QUE NÃO PERMITE A RETRAÇÃO ACENTUAL: [JORNAL] $\phi[\mathrm{HOJE}] \phi$. 100

FigURA 8: PALAVRA "JORNAL" INSERIDA EM CONTEXTO PROPÍCIO PARA A RETRAÇÃO ACENTUAL: [JORNAL HOJE] $\phi$ 101

FiguRA 9: EXEMPLO DE SEGMENTAÇÃo DE PALAVRA E DE SÍlABA No PRAAT 109 


\section{LISTA DE QUADROS}

QUADRO 1: ORDEM DE AQUISIÇÃO DOS MORFEMAS NA AQUISIÇÃO DE L1.................................................32

QUADRO 2: ORDEM DE AQUISIÇÃO DOS MORFEMAS POR CRIANÇAS APRENDIZES DE MANDARIM E

ESPANHOL COMO L2

QUADRO 3: COMPARAÇÃO ENTRE AS PROPOSTAS A RESPEITO DO PAPEL DA L1 E DA GU.........................40

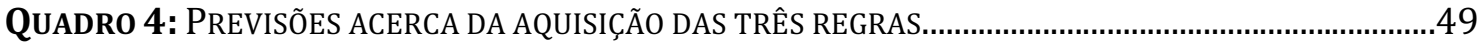

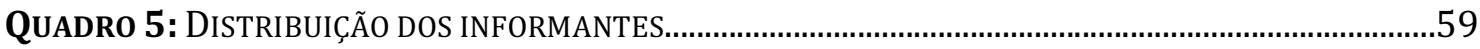

QUADRO 6: DISTRIBUIÇÃO DOS INFORMANTES POR NÍVEL DE PROFICIÊNCIA ……....................................59

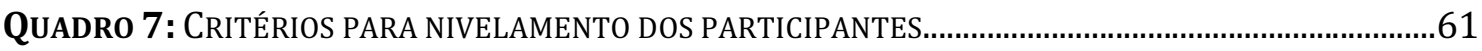

QUADRO 8: FRASES PARA A INVESTIGAÇÃO DA ASSIMILAÇÃO DE VOZEAMENTO PROGRESSIVA.................62

QUADRO 9: VARIÁVEL DEPENDENTE E VARIÁVEIS INDEPENDENTES - ASSIM. DE VOZEAMENTO............66

QUADRo 10: PAlaVRAS E SEQUÊNCIAS DE PALAVRAS PARA A VERIFICAÇÃo DA RETR. DE ACENTO...107

QUADRO 11: VARIÁVEIS CONTROLADAS - RETRAÇÃO DE ACENTO....................................................11

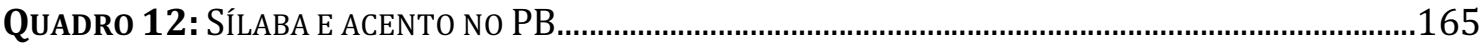

QUADRO 13: DIFERENÇAS E SEMELHANÇAS NO ACENTO DO PB E DO INGLÊS........................................170

QUADRO 14: PALAVRAS PARA AVALIAÇÃO DA RELAÇÃO ENTRE SÍLABA E ACENTO...................................174

QUADRO 15: VARIÁVEIS CONTROLADAS - SÍlABA E ACENTO...............................................................176

QUADRo 16: PALAVRAS PRODUZIDAS COM ACENTO DifERENTE Do ESPERADO - NATIVOS..................185

QUADRO 17: RESUMO DAS PRINCIPAIS PROPOSTAS SOBRE O PAPEL DA GU E DA L1 NA AQ. DE L2......215

QUADRO 18: RESUMO DAS PREVISÕES ACERCA DA AQUISIÇÃO DOS TRÊS PROCESSOS.............................217 


\section{LISTA DE GRÁFICOS}

GRÁFICO 1: APLICAÇÃO DO VOZEAMENTO POR FALANTE NATIVOS. 68

GRÁFICO 2: VOZEAMENTO DE -S POR INFORMANTE - FALANTES NATIVOS.......................................71

GRÁFICO 3: APLICAÇ̃̃O DO VOZEAMENTO POR CONTEXTO SEGUINTE - FALANTES NATIVOS.....................72

GRÁFICO 4: APLICAÇÃO DO VOZEAMENTO POR FALANTES DE INGLÊS COMO L2 $\ldots . . . . . . . . . . . . . . . . . . . . . . . . . . . . . . .73$

GRÁFICO 5: VOZEAMENTO POR NÍVEL DE PROFICIÊNCIA..........................................................................75

GRÁFICo 6: VOZEAMENTO DE -S POR INFORMANTE E NÍVEL DE PROFICIÊNCIA..........................................77

GRÁFICO 7: VOZEAMENTO DE -S POR INFORMANTE E CONTEXTO SEGUINTE: BÁSIC..................................80

GrÁFICo 8: VOZEAMENTO DE -S POR INFORMANTE E CONTEXTO SEGUINTE: INTERMEDIÁRIO................80

Gráfico 9: VOZEAMENTO DE -S POR INFORMANTE E CONTEXTO SEGUINTE: AVANÇADO.........................80

GRÁFICO 10: PROPORÇÃo DO VOZEAMENTO POR IDADE DE INÍCIO DA AQUISIÇÃO ....................................83

GRÁFICo 11: VoZEAMENTO POR IDADE DE AQUISIÇÃo E NÍVEL DE PROFICIÊNCIA....................................84

Gráfico 12: VozeAMENTO POR IDADE DE AQUiSIÇÃo E NÍVEL DE ProficiÊnCIA: CONTEXTO SEGUINTE DESVOZEADO OU PAUSA.

GRÁFICO 13: APLICAÇÃO DO VOZEAMENTO EM FRICATIVAS SEGUIDAS DE PAUSA OU DE CONSOANTE DESVOZEADA POR NÍVEL DE PROFICIÊNCIA.

GrÁFICO 14: APLICAÇÃO DA RETRAÇÃO DE ACENTO POR FALANTES NATIVOS........................................115

GRÁFICO 15: RETRAÇÃO DE ACENTO POR FALANTE NATIVO..............................................................116

GRÁFICO 16: RETRAÇÃO POR INFORMANTE SEPARADA POR CONTEXTO - NATIVOS...............................117

GRÁFICO 17: RETRAÇÃO DE ACENTO POR FALANTES DE INGLÊS COMO L2 ….......................................121

GráFICo 18: RETRAÇÃO DE ACENTO POR NÍVEL DE PROFICIÊNCIA......................................................128

GRÁFICO 19: RETRAÇÃO DE ACENTO POR INFORMANTE E NÍVEL DE PROFICIÊNCIA...............................131

GRÁFICO 20: RETRAÇÃO DE ACENTO POR INFORMANTE E POR CONTEXTO - INGLÊS COMO L2 2.............133

GRÁFICO 21: RETRAÇÃO DE ACENTO POR IDADE DE INÍ́CIO DA AQUISIÇÃO ….........................................134

GRÁFICO 22: RETRAÇÃO POR IDADE DE INÍCIO DA AQUISIÇÃO E NÍVEL DE PROFICIÊNCIA.......................134

Gráfico 23: APLICAÇão dA RETRAÇão DE ACENTO POR NATIVOS E NÃo NATIVOS..............................154

GRÁFICO 24: RETRAÇÃO DE ACENTO POR NÍVEL DE PROFICIÊNCIA ....................................................155

GRÁFICO 25: RETRAÇÃO DE ACENTO POR CONTEXTO E NÍVEL DE PROFICIÊNCIA....................................156

GRÁFICo 26: PROPORÇÃO DE ACERTOS DO ACENTO POR FALANTE NATIVOS ..........................................179

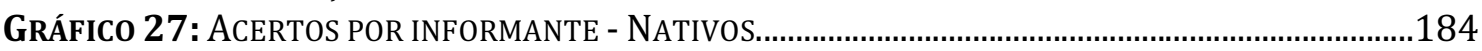

GrÁFICo 28: ACERTOS POR INFORMANTE E POR PADRÃO DA SÍlABA FINAL: FALANTES NATIVOS......184

GRÁFICO 29: PROPORÇÃO DE ACERTOS DO ACENTO POR FALANTES DE INGLÊS COMO L2 .......................186

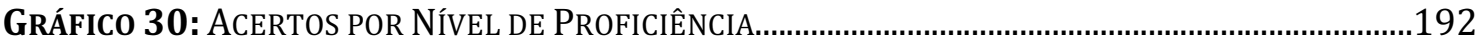

GRÁFICO 31: ACERTOS POR INFORMANTE: INGLÊS COMO L2 .............................................................194

GrÁfICo 32: ACERTOS POR INFORMANTE E PADRÃO DA SílABA FINAL: INGLÊS COMO L2..................195

Gráfico 33: ACERTOS POR INFORMANTE E TIPO DE PALAVRA: INGLÊS COMO L2 2................................195

GRÁFICO 34: ACERTOS POR NÍVEL DE PROFICIÊNCIA E TIPO DE PALAVRA: INGLÊS COMO L2................196

GráFICO 35: PROPORÇÃO DE ACERTOS POR IDADE DE INÍCIO DA AQUISIÇÃO..........................................197

GRÁFICO 36: ACERTOS POR NÍVEL DE PROFICIÊNCIA E IDADE DE INÍCIO DA AQUISIÇÃO..........................198

GráfICo 37: ACERTOS POR ACENTO ESPERADO E NÍvEL DE PROFICIÊNCIA ..........................................211

GRÁFICO 46: ACERTOS POR FALANTES DE NÍVEL AVANÇADO E FAL. NATIVOS NOS TRÊS PROCESSOS ..227 


\section{LISTA DE TABELAS}

Tabela 1: Vozeamento de -S E ConteXto Seguinte - Falantes Nativos........................................69

TABEla 2: VozeAmento DE -S E ConteXto PRECEDEnTE - FALANTES NATIVOS....................................70

TABEla 3: VOZEAMENTO POR CATEGORIA MORFolóGICA - FALANTES NATIVOS.....................................70

TABELA 4 : VOZEAMENTO DE -S POR INFORMANTE - FALANTES NATIVOS.........................................70

TABEla 5 : CRUZAMENTO ENTRE InFormante E ConteXto SEguinte - Falantes NATIVOS..............72

TABELA 6: VOZEAMENTO DE -S E CONTEXTO SEGUINTE - INGLÊS COMO L2 .............................................74

TABEla 7: VoZEAMENTO DE -S E CONTEXTO PRECEDENTE - INGLÊS COMO L2 2.......................................74

TABELA 8: VOZEAMENTO DE -S E NÍVEL DE PROFICIÊNCIA - INGLÊS COMO L2 .........................................75

TABELA 9: VOZEAMENTO DE -S POR INFORMANTE - INGLÊS COMO L2 ...................................................76

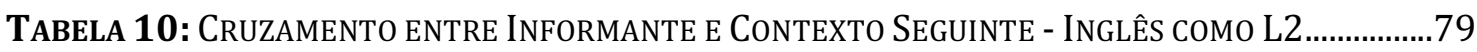

Tabela 11: CruZamento Entre Nível De ProficiênCIA E ConteXto SEguinte...............................81

TABEla 12: VOZEAMENTO POR CATEGORIA MORFOLÓGICA - INGLÊS COMO L2 .....................................82

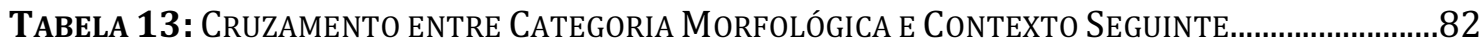

TABELA 14: VOZEAMENTO DO -S E IDADE DE INÍCIO DA AQUISIÇÃO - INGLÊS COMO L2

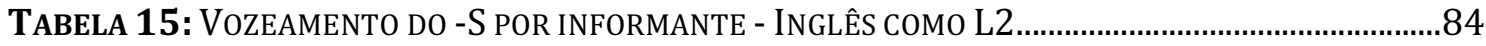

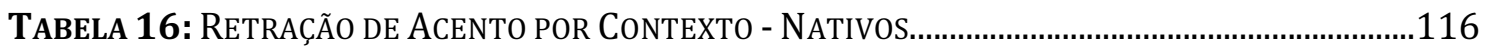

TABELA 17: RETRAÇÃO DE ACENTO POR INFORMANTE - NATIVOS.........................................................116

TABELA 18: RETRAÇÃO POR INFORMANTE SEPARADA POR CONTEXTO- NATIVOS..................................117

TABELA 19: RETRAÇÃO DE ACENTO E SEGMENTO FINAL - NATIVOS......................................................118

TABELA 20: RETRAÇÃO DE ACENTO POR PALAVRA AlVO - NATIVOS...................................................118

TABEla 21: RETRAÇÃO dE ACENTO E PADRÃo ACENTUAL EMPREGAdo - NATIVOS..............................120

TABELA 22: PADRÃo ACENTUAL APLICADO NA PALAVRA ISOLADA - INGLÊS COMO L2 .........................121

TABELA 23: RETRAÇÃO DE ACENTO POR CONTEXTO - INGLÊS COMO L2 ...............................................122

TABELA 24: RETRAÇÃO DE ACENTO POR PALAVRA ALVO - INGLÊS COMO L2

TABELA 25: RETRAÇÃO DE ACENTO E SEGMENTO FINAL - INGLÊS COMO L2 ...........................................124

TABELA 26: RETRAÇÃO DE ACENTO E PADRÃo ACENTUAL EMPREGADO - INGLÊS COMO L2................125

TABELA 27: ACENTO EMPREGADO POR PALAVRA ALVO - INGLÊS COMO L2 2...........................................126

TABELA 28: RETRAÇÃO DE ACENTO EM CASOS DE PAUSA - INGLÊS COMO L2 2.......................................127

TABELA 29: CRUZAMENTO ENTRE PAUSA E NÍVEL DE PROFICIÊNCIA - INGLÊS COMO L2 …....................127

TABELA 30: RETRAÇÃO DE ACENTO POR NívEL DE PROFICIÊNCIA - INGLÊS COMO L2

TABELA 31: RETRAÇÃO DE ACENTO POR INFORMANTE - INGLÊS COMO L2 $\ldots . . . \ldots \ldots \ldots . . . . . . . . . . . . . . . . . . . . . . . . . . . .130$

TABELA 32: RETRAÇÃO POR INFORMANTE SEPARADA POR CONTEXTO - INGLÊS COMO L2 ....................132

TABELA 33: RETRAÇÃO DE ACENTO POR IDADE DE INÍCIO DA AQUISIÇÃO .............................................133

TABELA 34: CRUZAMENTO ENTRE IDADE DE INÍCIO DA AQUISIÇÃO E CONTEXTO......................................135

TABELA 35: MÉDIAS DE DURAÇÃO NOS TRÊS CONTEXTOS ANALISADOS - NATIVOS..................................136

TABELA 36: MÉDIAS DO PICO DE F0 NOS TRÊS CONTEXTOS ANALISADOS - NATIVOS..............................139

TABELA 37: MÉDIAS DE DURAÇ̃̃O NOS TRÊS CONTEXTOS ANALISADOS - INGLÊS COMO L2 2...................141

TABELA 38: MÉDIAS DE DURAÇÃO NO NÍVEL BÁSICO - INGLÊS COMO L2 ……........................................144

TABELA 39: MÉDIAS DE DURAÇÃO NO NÍVEL INTERMEDIÁRIO - INGLÊS COMO L2 ...................................145

TABELA 40: MÉDIAS DE DURAÇÃO NO NÍVEL AVANÇADO - INGLÊS COMO L2 ...........................................147

TABELA 41: MÉDIAS DO PICO DE F0 PELOS FALANTES DE INGLÊS COMO L2

TABELA 42: RETRAÇÃo DE ACENTO POR CONTEXTO E NÍvEL DE PROFICIÊNCIA.....................................156

TABELA 43: ACERTOS POR PADRÃO ACENTUAL ESPERADO - NATIVOS..................................................180

TABELA 44: ACERTOS POR TIPO DE PALAVRA - NATIVOS..........................................................................180

TABela 45: ACERTOS POR PAdRÃo ACENTUAL ESPERAdo E TiPo de PAlaVRa - NATIVOS.................181

TABELA 46: ACERTOS POR PADRÃO DA SÍlABA FINAL - NATIVOS..........................................................181 
Tabela 47: ACERTOS POR PAdRÃo da Sílaba Final E TiPo de PALAVRa - NatiVoS..........................181

TABELA 48: ACERTOS POR SEgMENTO NA SÍlABA FinAL - NATIVOS.....................................................182

Tabela 49: ACERToS Por SEgmento na Sílaba Final E Tipo de PALAVRa - Nativos......................183

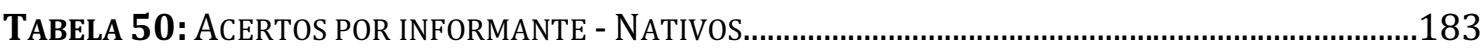

TABELA 51: ACERTOS POR PADRÃO ACENTUAL ESPERADO - INGLÊS COMO L2 ........................................187

TABELA 52: ACERTOS POR TIPO DE PALAVRA: INGLÊS COMO L2 .......................................................187

TABELA 53: PROPORÇÃO DE ACERTOS POR TIPO DE PALAVRA: INGLÊS COMO L2 .................................187

TABELA 54: ACERTOS POR SEgmENTO NA SÍlABA Final: NÃo NATIVOS.............................................188

TABELA 55: ACERTOS POR SEGMENTO FINAL E TIPO DE PALAVRA - INGLÊS COMO L2...........................189

TABELA 56: ACERTOS EM CASOS DE EPÊNTESE: INGLÊS COMO L2 …..................................................190

TABELA 57: ACERTOS POR SEGMENTO FINAL EM CASOS DE EPÊNTESE: INGLÊS COMO L2 .....................191

TABELA 58: ACENTO E PADRÃO DA SÍLABA FINAL - INGLÊS COMO L2 ……...........................................191

TABELA 59: PROPORÇão de ACERTOS POR NívEL DE PRofiCIÊNCIA......................................................192

TABELA 60: ACERTOS POR INFORMANTE - INGLÊS COMO L2

TABELA 61: ACERTOS POR IDADE DE INÍCIO DA AQUISIÇÃO...................................................................196

TABELA 62: DURAÇÃO EM PALAVRAS REAIS COM PADRÃO OXÍTONO POR NÍVEL DE PROFICIÊNCIA.......200

TABELA 63: DURAÇÃO EM LOGATOMAS COM PADRÃO OXÍTONO POR NÍVEL DE PROFICIÊNCIA...............203

TABELA 64: DURAÇÃO EM PALAVRAS REAIS COM PADRÃO PAROXÍTONO OU PROPAROXÍTONO POR NÍVEL

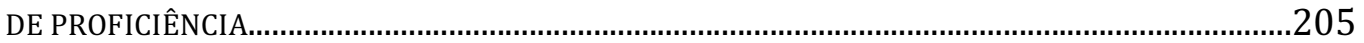

TABELA 65: DURAÇÃO EM PALAVRAS LOGATOMAS COM PADRÃO PAROXÍTONO OU PROPAROXÍTONO POR NÍVEL DE PROFICIÊNCIA...............................................................................................................207 


\section{SUMÁRIO}

INTRODUÇÃO

1. AQUISIÇÃO DE L1 E A TEORIA GERATIVA..............................................18

1.1 A Teoria de Princípios e Parâmetros...................................................................................2

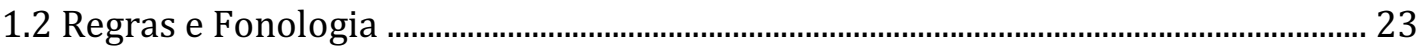

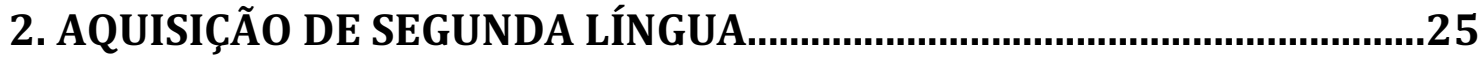

2.10 Papel da Língua Materna ………………………………………………………………25

2.20 acesso à Gramática Universal.....................................................................................29

2.30 estado inicial da gramática da L2 2............................................................................34

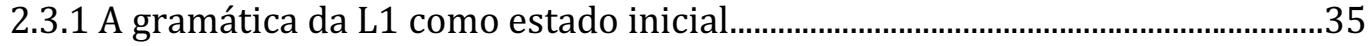

2.3.2 A GU como estado inicial......................................................................................38

2.3.3 Comparação entre as hipóteses...................................................................................39

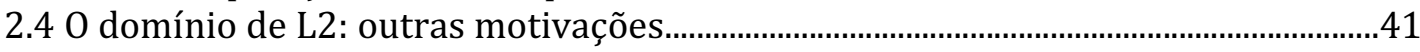

2.4.1 0 fator Idade.....................................................................................................................

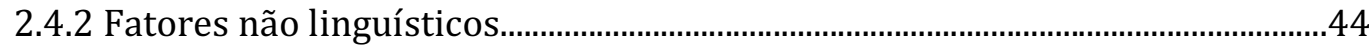

3. OBJETIVOS E HIPÓTESES........................................................................47

4. ASSIMILAÇÃO DE VOZEAMENTO.........................................................51

4.1 A regra de assimilação de vozeamento .............................................................................

4.1.1 Assimilação de vozeamento no Português Brasileiro ...........................................52

4.1.2 Assimilação de vozeamento em inglês.................................................................54

4.1.3 Assimilação de vozeamento do inglês por falantes brasileiros.........................55

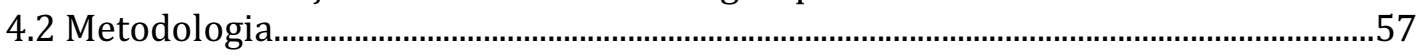

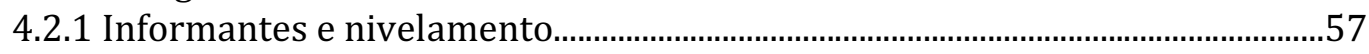

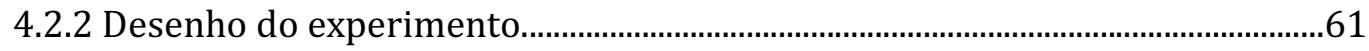

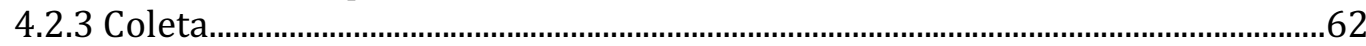

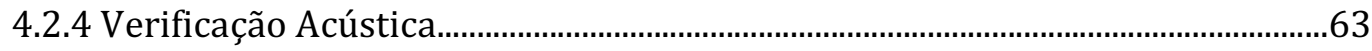

4.2.5 Classificação dos dados e Análise Estatística.........................................................65

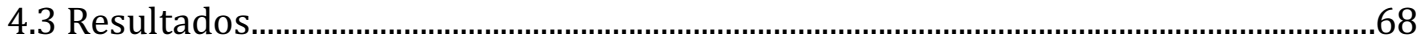

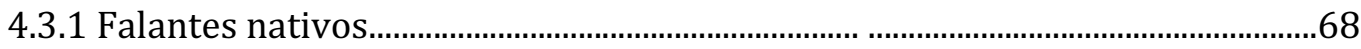

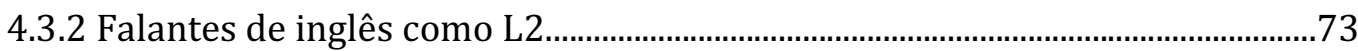

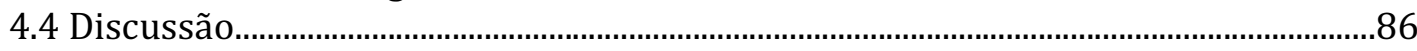

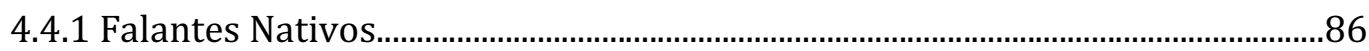

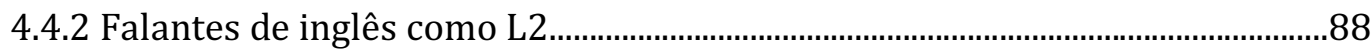

4.4.3 Aquisição da regra fonológica do inglês por falantes brasileiros .....................90

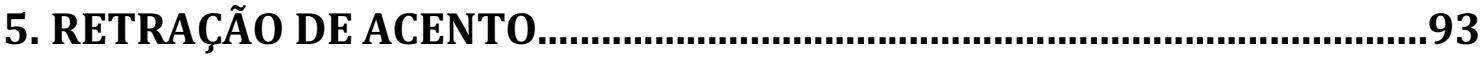

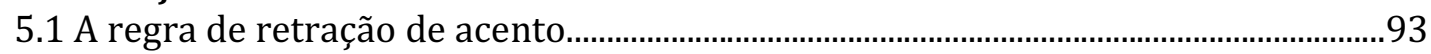

5.1.1 Retração de Acento no Português Brasileiro............................................................98

5.1.2 Retração de Acento em inglês...................................................................................101

5.1.3 Retração de acento do inglês por falantes brasileiros..........................................104

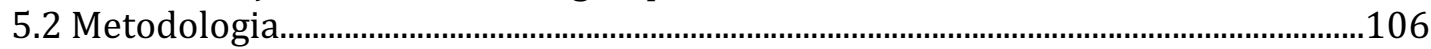




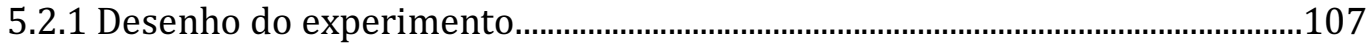

5.2.2 Critérios para verificações perceptual e acústica................................................108

5.2.3 Classificação dos dados e Metodologia Estatística ..........................................110

5.2.3.1 Verificação perceptual................................................................................110

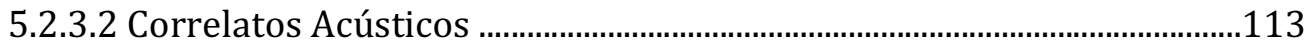

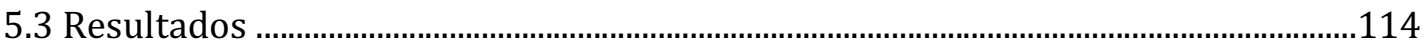

5.3.1 Verificação Perceptual......................................................................................114

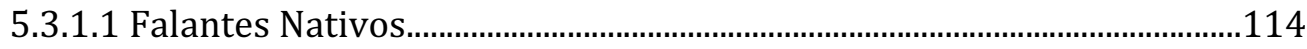

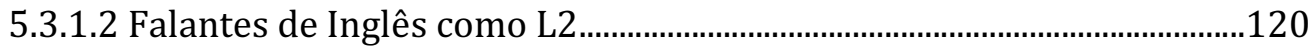

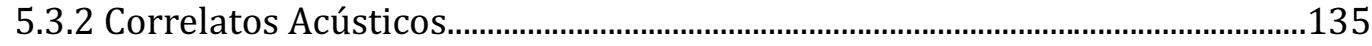

5.3.2.1 Falantes Nativos.........................................................................................136

5.3.2.1 Falantes de inglês como L2 .....................................................................141

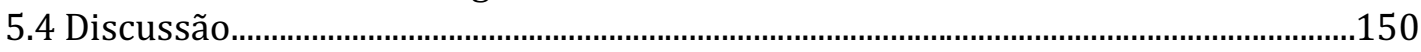

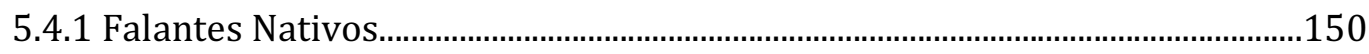

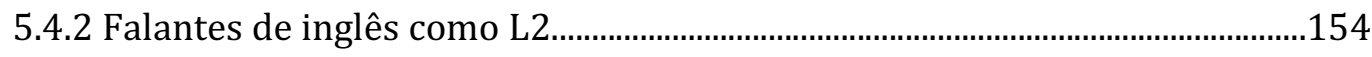

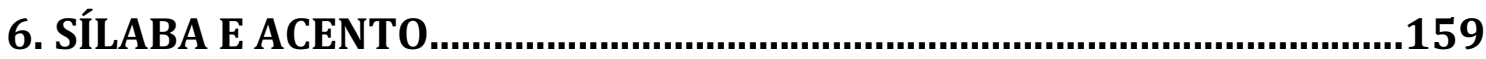

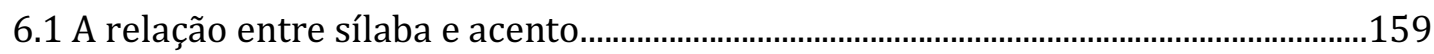

6.1.1 Sílaba e acento no Português Brasileiro..............................................................160

6.1.2 Sílaba e acento no inglês.......................................................................................165

6.1.3 Sílaba e acento do inglês por falantes brasileiros.................................................170

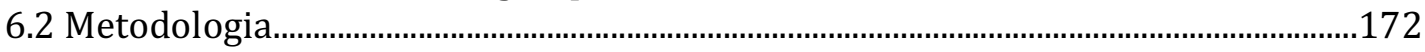

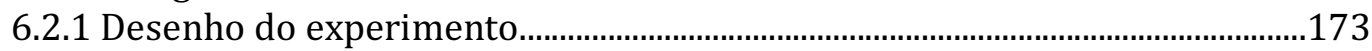

6.2.2 Critérios para verificações perceptual e acústica................................................174

6.2.3 Classificação dos dados e Metodologia Estatística ...........................................175

6.2.3.1 Verificação perceptual...............................................................................175

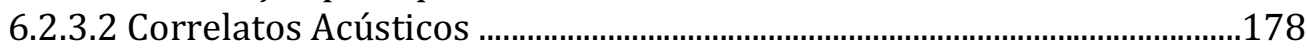

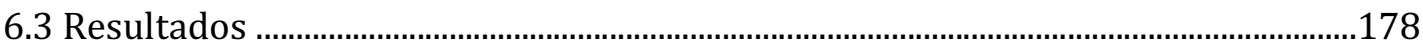

6.3.1 Verificação Perceptual.............................................................................................179

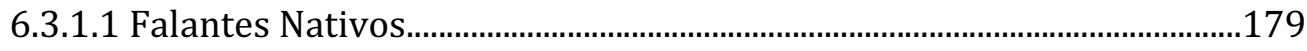

6.3.1.2 Falantes de inglês como L2 .....................................................................185

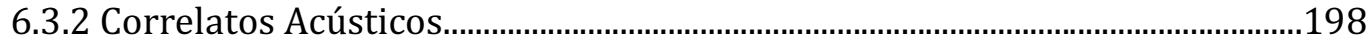

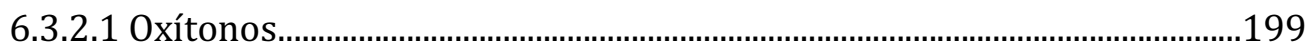

6.3.2.2 Paroxítonos e Proparoxítonos...................................................................205

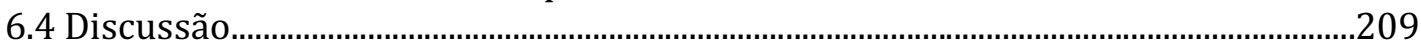

6.4.1 Falantes Nativos.......................................................................................................209

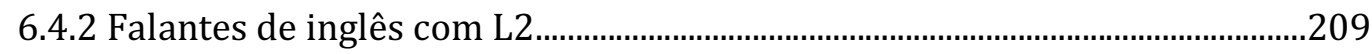

7. DISCUSSÃO

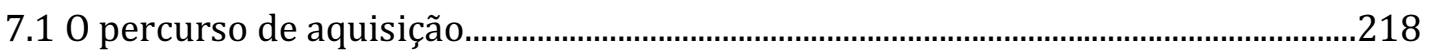

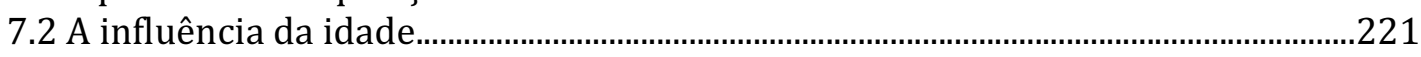

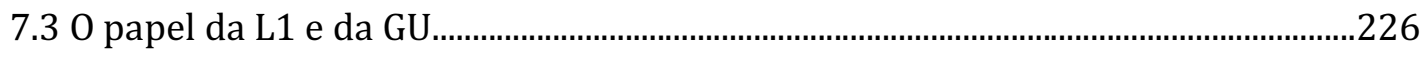

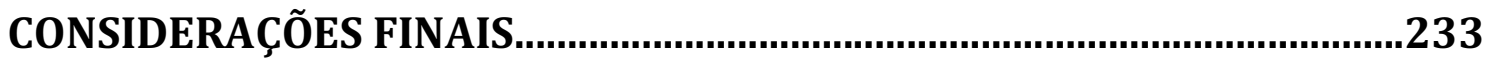

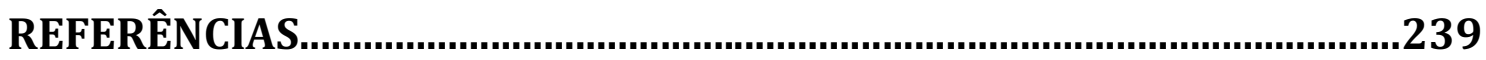

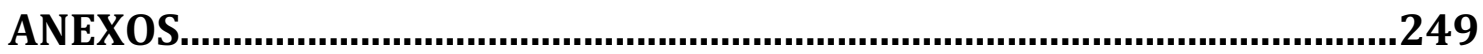




\section{INTRODUÇÃO}

Desde seus primeiros anos, a pesquisa em Aquisição de Segunda Língua (L2) tem buscado descrever possíveis semelhanças e diferenças entre a representação da gramática da língua materna (L1) e a gramática não-nativa. Se, por um lado, considerarmos o alvo a ser alcançado no processo de aquisição, as diferenças não são muitas: em ambos os casos, o objetivo é chegar a um sistema linguístico que corresponde ao input recebido, de modo que o aprendiz consiga falar e compreender a língua-alvo. Por outro lado, diferentemente das crianças, aprendizes de L2 normalmente precisam de algum tipo de instrução e levam muito mais tempo para atingir um domínio básico da língua-alvo. Além disso, ainda que o alvo a ser alcançado seja o mesmo, o estágio final da aquisição de L2 é, na maioria do casos, muito diferente daquele adquirido na L1.

No que diz respeito à aquisição de primeira língua, pesquisas vêm sendo desenvolvidas com base na hipótese de que o ser humano nasce com uma capacidade inata - a Gramática Universal (GU) - para, em condições normais, aprender qualquer língua natural a que for exposto (Chomsky, 1957, 1965). A GU é dedicada exclusivamente à linguagem e é dotada de princípios universais, que regem todas as línguas, e parâmetros, que variam entre as línguas e ocasionam tanto diferença entre as línguas quanto mudança em uma mesma língua (Chomsky, 1981). Nessa visão inatista, os valores dos parâmetros são marcados através do input durante a aquisição da língua materna.

A disponibilidade da GU na aquisição de segunda língua é bem mais discutível. Estudos em aquisição de L2 defendem que o aprendizado pode ocorrer com acesso direto à GU, sem transferência da L1 (Epstein et al, 1996), com acesso à GU, mas através da L1 (Schwartz e Sprouse, 1996, Vainikka e Young-Scholten 1994, Eubank 1993) ou sem acesso nenhum à GU (Clahsen \& Muysken, 1996), e há um intenso debate sobre a possibilidade de (re)marcar um parâmetro através do input da segunda língua (cf. White 2003, Ayoun 2005, Meisel 2011).

Na fonologia a questão é ainda mais complexa, dado que nem tudo que ocorre neste componente é interpretado como consequência de marcação paramétrica. De acordo com Bromberger \& Halle (1989), a fonologia deve investigar não apenas os 
princípios e parâmetros que fazem parte da GU, mas também regras fonológicas que são adquiridas a partir do input. Para se compreender o que é regra, faz-se necessário definir primeiro o que seja processo fonológico. Segundo Lust (2006, p. 38), um processo fonológico é diferente de uma regra fonológica:

A "phonological process" operates on sounds or features of sounds, changing them in certain ways, e.g., assimilating them to each other, substituting for them, deleting them. If such a process is regular, and generalizable, and we can specify the conditions (or contexts) under which it applies, we use the term "phonological rule.

Pode-se dizer, portanto, que um processo pode ocorrer em decorrência de uma regra fonológica ou não. Além disso, o que distingue uma regra de um processo é o fato de que regras são adquiridas e têm uma motivação fonológica. 0 trabalho de Silva (2010) mostrou, por exemplo, que o processo de vozeamento da fricativa /s/ no português brasileiro (PB) é uma regra fonológica a ser adquirida pela criança, e não um fenômeno fonético. Através da análise da fala de 46 crianças entre 2;0 e 4;1, a autora mostrou que há uma maior facilidade na produção de segmentos surdos do que sonoros e que as crianças não "nascem sabendo" aplicar a regra de vozeamento, o que seria uma evidência de que a essa é uma regra a ser adquirida no PB e que sua forma não marcada é a fricativa surda.

Tendo este cenário em mente, o objetivo desta pesquisa é verificar o papel da GU e da língua materna na aquisição de L2 através da investigação de três regras fonológicas, as quais possuem naturezas diferentes: a retração de acento, que se comporta de forma muito semelhante no português e no inglês e é uma regra a ser transferida da L1 para a L2; a assimilação de vozeamento, que existe em ambas as línguas, mas ocorre de maneira diferente e caracteriza-se, portanto, como uma regra a ser modificada; e a relação entre sílaba e acento, que é diferente nas duas línguas e se dá através da marcação de parâmetros métricos que fazem parte da GU. A partir da investigação desses três fenômenos, pretende-se avaliar se os aprendizes de L2 têm mais facilidade em adquirir uma regra fonológica semelhante, modificar uma regra fonológica que existe em ambas as línguas ou, ainda, (re)marcar um parâmetro a partir do input da língua-alvo, estudo que, até onde sabemos, ainda não foi realizado.

Esta tese está organizada da seguinte forma: o Capítulo 1 apresenta um panorama da pesquisa em aquisição de primeira língua no paradigma gerativo e aborda 
temas como o problema lógico da aquisição da linguagem, a Teoria de Princípios e Parâmetros e a aquisição de regras fonológicas.

O Capítulo 2 apresenta uma revisão dos estudos em aquisição de segunda língua e discute questões referentes ao papel da língua materna, ao acesso à gramática universal, à possibilidade de (re)marcar parâmetros, ao estado inicial da aquisição de L2, à influência da idade e a fatores não linguísticos que podem influenciar a aquisição de segunda língua.

No Capítulo 3 são apresentados os objetivos e as hipóteses que norteiam a investigação dos três fenômenos em análise nesta pesquisa.

Os Capítulos 4, 5 e 6 apresentam os estudos referentes a cada um dos três fenômenos fonológicos investigados nesta pesquisa: no Capítulo 4, o estudo referente à regra de assimilação de vozeamento; no Capítulo 5, a investigação a respeito da regra de retração de acento; e, no Capítulo 6, o estudo referente à relação entre sílaba e acento. Cada um desses capítulos inclui a descrição do fenômeno investigado, a abordagem metodológica, os resultados obtidos e uma discussão a respeito dos resultados.

A partir dos resultados apresentados e discutidos nos Capítulos 4, 5 e 6, o Capítulo 7, retoma as hipóteses estabelecidas no Capítulo 3 para discutir o papel da GU e da língua materna, o percurso de aquisição e o fator idade na aquisição de segunda língua, seguido das considerações finais. 


\section{Capítulo 1}

\section{AQUISIÇÃO DE L1 E A TEORIA GERATIVA}

Com poucos anos de vida, toda criança normal já é capaz de se comunicar naturalmente e dominar a pronúncia, a sintaxe e o vocabulário básico da sua língua materna. Qualquer criança, nascida em qualquer lugar do mundo, aprenderá a língua a que for exposta aparentemente sem muito esforço, independentemente da língua-alvo e sem qualquer tipo de instrução.

A rapidez e a facilidade que a criança adquire a língua materna há tempos tem despertado a curiosidade de linguistas e interessados no tema. Na década de 50, a maioria dos estudos em aquisição de L1 era baseada na corrente behaviorista, segundo a qual a aquisição da linguagem seria resultado de mecanismos do comportamento. Para pesquisadores behavioristas como Skinner (1957), o aprendizado linguístico seria semelhante a qualquer outro tipo de aprendizado: por meio de estímulo-resposta, imitação e reforço. Entretanto, considerar que a aquisição ocorre desse modo é problemático porque, se o aprendizado linguístico fosse resultado de reforço ou imitação, as crianças jamais produziriam exemplos do tipo "cabeu" e "fazi', no português, ou "goed" e "taked", no inglês, já que essas palavras não ocorrem na fala adulta. Além disso, caso a aquisição ocorresse exclusivamente a partir de fatos observáveis, seria impossível explicar como somos capazes de produzir e compreender sentenças nunca ouvidas, pois nem sempre as sentenças têm sua referência no contexto em que estão sendo produzidas. Há, ainda, uma outra limitação dessa proposta, relacionada à rapidez do processo: com apenas 4 anos de idade a criança já domina a maioria das regras de sua língua materna e é competente em sua língua nativa. Se o aprendizado ocorresse por imitação, seria necessário muito mais tempo de exposição à língua para que a criança adquirisse um número suficiente de frases para considerar-se que ela aprendeu, de fato, uma língua (Santos, 2002).

Para contrapor o behaviorismo vigente na época, Chomsky $(1957,1965)$ propõe uma teoria que se baseia, entre outras coisas, na rapidez do processo de aprendizagem e na criatividade linguística. A Teoria Gerativa surge num período denominado 'revolução cognitiva', época em que o foco deixa de ser o estudo do comportamento e passa para a 
investigação dos mecanismos internos envolvidos no pensamento e na ação. Segundo Chomsky (1997), os avanços nas teorias formais, aliados ao contexto da época, possibilitaram o resgate da ideia do "uso infinito de meios finitos" que já havia sido abordada por von Humboldt na época da "primeira revolução cognitiva", nos séculos 17 e 18, e a elaboração dos princípios computacionais que geram as expressões de uma língua. A teoria chomskyana busca, assim, estabelecer as regras formais necessárias para gerar todas as sentenças gramaticais de determinada língua.

As pesquisas desenvolvidas na perspectiva chomskyana têm como objetivo caracterizar o sistema de conhecimento presente na mente dos seres humanos que permite a aquisição e o desenvolvimento da linguagem. Essa investigação parte de três questões $^{1}$ fundamentais (Chomsky 1986, p. 3):

1. 0 que constitui o conhecimento da linguagem?

2. Como esse conhecimento é adquirido?

3. Como esse conhecimento é posto em uso?

A resposta para a primeira questão é dada através da existência de uma gramática gerativa, que consiste num sistema de regras recursivas capazes de gerar sentenças nunca antes proferidas. Esse sistema de regras pode ser analisado nos três principais componentes que constituem uma gramática gerativa: o componente sintático, sistema de regras que definem as sentenças permitidas em uma língua; o componente semântico, sistema de regras que definem a interpretação das sentenças produzidas pelo componente sintático; e o componente fonológico e fonético, sistema de regras que realizam as sentenças geradas pelo componente sintático a partir de uma sequência de sons (Chomsky, 1965, p. 141).

A segunda questão, conhecida como problema de Platão ou ainda problema lógico da aquisição, busca entender como o ser humano é capaz de aprender tantas coisas em tão pouco tempo de vida. Segundo Chomsky (1986), Platão buscou responder esse questionamento afirmando que o conhecimento poderia ser relembrado ou retomado de vidas passadas, ou de uma "pré-existência". Chomsky interpreta essa resposta com a visão de que certos aspectos do nosso conhecimento são inatos, geneticamente determinados, "assim como os elementos da nossa natureza de seres humanos que fazem crescer em nós pernas e braços ao invés de asas" (Chomsky 1986, p.4).

\footnotetext{
${ }^{1}$ Uma quarta questão é proposta em Chomsky (1988, p. 3): "Quais são os mecanismos físicos no cérebro do falante que servem de base para o sistema de conhecimento linguístico e para seu uso?". Segundo o autor, o linguista é capaz de buscar respostas apenas para as três primeiras perguntas, que podem, por sua vez, servir como ponto de partida para os neurocientistas investigarem essa quarta pergunta.
} 
A teoria chomskyana mostrou que, ao contrário do que defendiam as correntes linguísticas de base empirista, o aspecto criativo da linguagem não estaria relacionado à capacidade de produzir novas formas meramente por analogia. Somente a Gramática Universal (GU), capacidade inata presente na mente/cérebro dos seres humanos, poderia explicar como a criança consegue dominar a gramática de uma língua em um período tão curto a partir de um input precário, fragmentado e cheio de frases truncadas ou incompletas (Chomsky, 1981). É importante ressaltar que a afirmação de que o input é insuficiente não é feita simplesmente para negar a noção behaviorista de que a aquisição ocorre através de estímulo-resposta, ou input-output. Essa afirmação é, na verdade, baseada no fato de que as crianças aprendem determinadas propriedades da gramática que são muito sutis e não poderiam ser aprendidas somente pelo input. Em outras palavras, supõe-se que o input não oferece informações suficientemente específicas sobre a gramaticalidade e a agramaticalidade de sentenças, argumento conhecido como pobreza de estímulo (Gass e Selinker, 2009, p. 162).

Por fim, a resposta para a terceira questão seria uma teoria de como o conhecimento linguístico possibilita a comunicação e outros usos da linguagem. 0 foco da abordagem chomskyana está, no entanto, nas questões 1 e 2 , as quais serviram de base para a formulação da Teoria Gerativa (Chomsky, 1986).

A Gramática Universal foi, portanto, proposta como um sistema inato de princípios universais compartilhados por todas as línguas do mundo, o que justifica as semelhanças entre elas. Para justificar as diferenças entre as línguas, Chomsky (1981) propõe que esses princípios universais estariam relacionados a parâmetros, que variam entre as línguas e ocasionam tanto diferença entre as línguas quanto mudança em uma mesma língua. Nessa visão, o valor de um determinado parâmetro é marcado através da evidência linguística a que a criança tem acesso e, assim, a gramática é construída conforme os valores dos parâmetros são fixados no processo de aquisição, os quais geralmente têm caráter binário. A teoria de princípios e parâmetros será apresentada com mais detalhes na seção 1.1 a seguir.

\subsection{A Teoria de Princípios e Parâmetros}

Como vimos, a GU é um sistema inato dedicado exclusivamente à linguagem e dotado de princípios universais que regem todas as línguas e parâmetros que variam 
entre elas, e a marcação de parâmetros através do input gera a gramática nuclear da língua a ser adquirida. Assim, durante a aquisição, os parâmetros são marcados a partir dos dados linguísticos a que a criança tem acesso. Nas palavras de Chomsky (1981, p.7):

When the parameters of UG are fixed in one of the permitted ways, a particular grammar is determined, what I will call a "core grammar". In a highly idealized picture of language acquisition, UG is taken to be a characterization of the child's pre-linguistic state. Experience - in part, a construct based on internal state given or already attained - serves to fix the parameters of UG, providing a core grammar, guided perhaps by a structure of preferences and implicational relations among the parameters of the core theory.

Destaco, no trecho citado acima, o uso da expressão "highly idealized picture of language acquisition" (Chomsky 1981, p.7), segundo a qual a aquisição da linguagem ocorreria em um contexto "ideal". Conforme Ayoun (2005, p.7), essa visão idealizada do processo utilizada para explicar o problema lógico da aquisição não contempla as etapas do desenvolvimento, pois transmite a ideia de que a criança passa do estágio inicial ao estágio final de maneira instantânea e sem variação no output.

Sendo assim, como se dá a marcação dos parâmetros? Três hipóteses foram propostas para responder essa pergunta: a maturacional, a continuísta forte e a continuísta fraca. Segundo a hipótese maturacional, o estado inicial da gramática pode apresentar propriedades únicas, diferentes da gramática adulta. Os princípios não estão todos disponíveis no estado inicial da aquisição, mas "amadurecem" no decorrer do processo, e os parâmetros são geneticamente programados para serem, gradualmente, marcados em diferentes etapas de maturação (cf. Lightfoot 1982 e Radford 1990). A hipótese continuísta, por outro lado, propõe que a gramática da criança é basicamente a mesma gramática adulta. Segundo a versão forte da hipótese (cf. Hyams 1986), todos os princípios estão disponíveis desde o início do processo e, na versão fraca, apesar de todos os princípios estarem disponíveis, é a aprendizagem de novos itens lexicais que guia o desenvolvimento da sintaxe (cf. Pinker 1984, Clahsen 1992).

De acordo com Meisel (2011, p.37), afirmar que a gramática da criança é idêntica à do adulto como propõe a hipótese continuísta é um problema, pois, se assim fosse, não conseguiríamos explicar as diferenças entre as produções das crianças e dos adultos. 0 autor propõe, portanto, que a criança só pode acessar os princípios da gramática a partir do momento em que a GU se torna disponível por meio de "processos maturacionais", o que começaria a ocorrer um pouco antes dos dois anos de idade. Segundo o autor, 
evidências empíricas indicam que até 1:5 a criança não teria acesso a todos os princípios da GU e, a partir dos dois anos, esses princípios começariam a aparecer de maneira muito rápida. Isso seria justificado pelo fato de que antes dos dois anos a criança produz apenas palavras isoladas e, somente depois de muitos meses ela começa a unir essas palavras em sentenças. Isso também justificaria a ocorrência de variação e "erro" na fala da criança durante o processo, que não seria, necessariamente, uma variação no uso da língua, mas, de fato, uma variação gramatical. Contudo, segundo o autor, essa variação ocorre dentro de um limite, pois a criança não produzirá nada que desvie do que é oferecido pela GU:

(...) developing and mature grammar do indeed differ, but these differences fall within the variation space defined by UG. Put differently, children acquiring a language should be expected to explore all options offered by UG and only these - independently of whether they deviate from the target system (...). (Meisel, 2011, p.38)

Para dar conta do problema desenvolvimental da aquisição da linguagem, Chomsky (1995) assume que a aquisição ocorre em estágios, e que cada estágio representa uma função, ou um parâmetro a ser marcado. Essas etapas (funções) do aprendizado podem ocorrer em ordens diferentes, dependendo da criança. Independentemente da ordem, entretanto, toda criança deverá passar por todos os estágios, ou seja, deverá marcar todos os parâmetros relevantes para a língua a ser adquirida.

No caso da fonologia, estudos como o de Hayes (1984) e Halle e Vergnaud (1987), por exemplo, mostraram que a teoria de princípios e parâmetros é válida porque os sistemas fonológicos não são arbitrários, mas obedecem restrições e processos universais. Se comparados às pesquisas na área da sintaxe, entretanto, os estudos que aplicam a teoria de princípios e parâmetros para desenvolver a teoria fonológica ainda são poucos e começaram a ser explorados muito mais recentemente (cf. Ingram, 2014).

Os parâmetros fonológicos mais discutidos e aprofundados até o momento são os parâmetros métricos (ou parâmetros do acento). De acordo com Hayes (1995), além de a língua parametrizar a quantidade silábica, ou seja, se é sensível ao peso ou não, também deve ser parametrizado o que é considerado como sílaba pesada ou leve. Línguas como o inglês, por exemplo, consideram sílabas com núcleo ramificado como pesadas, enquanto sílabas com núcleo simples em final de palavra são consideradas leves, conforme veremos no Capítulo 6. 
De acordo com Dresher e Kaye (1990), as vantagens de uma abordagem baseada em princípios e parâmetros para a análise fonológica são as seguintes:

This parametrization of at least one subsystem of phonology takes us toward our ultimate goal of defining a possible phonological system. Stress is no longer the formal nightmare that created such monstrosities as [the Main Stress Rule]. It can now be defined as a core system embodying foot construction routines that is fleshed by fixing parameters appropriate to the specific stress system in question. (p. 145)

Conforme o autor, portanto, é possível simplificar as regras formais de acento a partir de um sistema composto de parâmetros que determinam o sistema acentual de determinada língua.

Segundo Ayoun (2005, p.2), apesar de ter sido alvo de críticas, a teoria de princípios e parâmetros permanece sendo desenvolvida e testada, primeiramente, porque não foi substituída por nenhuma outra proposta que desse conta do problema lógico da aquisição. A autora afirma, ainda, que a teoria foi criticada de maneira exageradamente rápida, antes mesmo de uma quantidade significativa de parâmetros ter sido proposta e testada.

Atualmente, ainda há muitas questões a serem discutidas na teoria de princípios e parâmetros, e uma delas diz respeito à possibilidade de reparametrização. Essa e outras questões serão discutidas Capítulo 2, sobre aquisição de L2, a seguir. Antes disso, falaremos sobre a aquisição de regras fonológicas.

\subsection{Regras e Fonologia}

Nesta pesquisa, adotamos a teoria de princípios e parâmetros (Chomsky, 1981), apresentada na Seção 1.1, para discutirmos a aquisição da relação entre sílaba e acento, que se dá através da marcação de parâmetros métricos. Entretanto, nem toda diferença entre duas línguas pode ser explicada através de marcações paramétricas.

Segundo Bromberger \& Halle (1989), a fonologia deve investigar não apenas os princípios e parâmetros que fazem parte da GU, mas também regras que são adquiridas a partir do input. Os autores afirmam que a natureza do componente fonológico é muito diferente daquela dos componentes sintático e semântico, já que os princípios que 
regem a fonologia, como o princípio do ordenamento de regras $^{2}$, não se aplicam aos outros componentes da gramática.

Tomemos como exemplo a regra de assimilação de vozeamento, um dos alvos deste estudo. Essa regra, que será apresentada em detalhe no Capítulo 4, consiste na extensão do vozeamento de um segmento para outro segmento adjacente. A assimilação pode ocorrer tanto de maneira progressiva, quando há uma extensão do vozeamento de um segmento para outro que o sucede, quanto regressiva, quando há uma extensão do vozeamento de um segmento para outro que o antecede. Conforme apresentado no capítulo introdutório deste trabalho, Silva (2010) mostrou que a assimilação de vozeamento é uma regra a ser adquirida pela criança, ou seja, a criança não "nasce sabendo" aplicar a regra como um adulto, pois só passa a aplicá-la a partir de determinada idade. Em outras palavras, a assimilação não é um fenômeno inato, e sim uma regra a ser adquirida.

Apesar de não descartarem a possibilidade de a fonologia lidar com princípios e parâmetros, Bromberger \& Halle (1989, p. 69) salientam que, inclusive no que diz respeito ao acento, é preciso considerar a ordenação de regras, tanto fonológicas quanto morfológicas. Para que o acento seja atribuído é necessário, por exemplo, ter informações sobre a estrutura silábica, ou seja, a regra que organiza as estruturas silábicas precede a regra de acentuação.

É importante salientar, portanto, que os fenômenos analisados nesta pesquisa possuem naturezas diferentes: a aquisição da relação entre sílaba e acento, apesar de também ser dependente de regras sobre a estrutura silábica das palavras, se dá através da marcação de parâmetros métricos e, portanto, é um fenômeno que faz parte da GU; a assimilação de vozeamento e a retração de acento, por outro lado, não são fenômenos inatos e nem parâmetros a serem marcados, mas regras a serem adquiridas. Assim, este trabalho investiga não apenas a possibilidade de (re)marcação de parâmetros na aquisição de L2, através do estudo da relação entre sílaba e acento no inglês e no PB, mas também a possibilidade de se aplicar regras existentes na L1 e que ocorrem de maneira semelhante na L2 (retração de acento) ou de maneira diferente (assimilação de vozeamento). Os fenômenos mencionados serão discutidos nos Capítulos 4, 5 e 6 a seguir.

2 Segundo esse princípio, as regras fonológicas são ordenadas e ocorrem em diferentes momentos da derivação (Bromberger \& Halle, 1989, p.158) 


\section{Capítulo 2}

\section{AQUISIÇÃO DE SEGUNDA LÍNGUA}

Vimos no Capítulo 1 que, na teoria chomskyana, o estado inicial da aquisição de língua materna é caracterizado pela Gramática Universal (Chomsky, 1986), capacidade inata comum a todos os seres humanos que explica como a criança é capaz de adquirir uma língua e toda sua complexidade em um período de tempo tão curto e a partir de um input insuficiente. Do mesmo modo que na aquisição de L1, nos deparamos com um problema lógico na aquisição de segunda língua se considerarmos a necessidade de explicar como a aquisição da língua-alvo ocorre apesar das limitações do input disponível (White, 1985).

Desde seus primeiros anos, a pesquisa em aquisição de L2 tem buscado descrever possíveis semelhanças e diferenças entre a representação da gramática nativa e da nãonativa. De acordo com Klein \& Martohardjono (1999, p.5), três questões guiaram a maior parte dos estudos em aquisição de segunda língua sob a perspectiva gerativista até hoje:

1. Os princípios da Gramática Universal restringem a aquisição de L2?

2. A reparametrização é possível em L2?

3. Qual o estado inicial da gramática da L2?

A disponibilidade da GU, a possibilidade de (re)marcar um parâmetro a partir do input da L2 e a influência da língua materna são, portanto, alvo de intenso debate na literatura em aquisição de segunda língua. 0 presente capítulo se propõe a apresentar um panorama a respeito dessas e outras questões relevantes para a pesquisa em aquisição de L2, começando pelo papel desempenhado pela língua materna.

\subsection{O Papel da Língua Materna}

Desde os primeiros trabalhos desenvolvidos na área da aquisição de L2, a transferência de aspectos da língua materna para a língua-alvo é considerada uma influência importante durante o processo. 0 conceito de transferência foi herdado da pesquisa behaviorista, segundo a qual o aprendizado de uma tarefa "A" afetaria, consequentemente, o aprendizado de uma tarefa "B", numa relação de "aprendizado 
cumulativo". No que diz respeito à aquisição de L2, essa transferência pode ser positiva (também chamada de facilitação), quando resulta em uma produção correta, ou negativa (também conhecida como interferência), quando resulta em uma produção incorreta (diferente do falar nativo) (Gass e Selinker, 2009, p. 93).

Apesar de a transferência da L1 também ter sido abordada em outras áreas da aquisição de L2 como a sintaxe, por exemplo, houve uma ênfase muito maior na fonologia, já que a transferência fonológica parece ser a mais prevalente. De acordo com Major (2008), o papel da transferência na aquisição de L2 já era mencionado no trabalho de Trubetskoy (1939), mas foram os trabalhos de Fries (1945), Weinreich (1953) e Lado (1957) que deram início ao desenvolvimento da Hipótese da Análise Contrastiva (Contrastive Analysis Hypothesis). Esses trabalhos tinham como objetivo prever e explicar os erros de pronúncia cometidos pelos aprendizes de L2, seguindo uma linha estruturalista e behaviorista. Segundo essa hipótese, os aspectos da L2 que são parecidos com a L1 seriam mais fáceis de adquirir do que os que são diferentes.

No final dos anos 50, o estruturalismo, o behaviorismo e, consequentemente, a Hipótese da Análise Contrastiva passaram a perder sua popularidade com o trabalho de Chomsky (1957), que, como vimos no Capítulo 1, mudou o foco linguística para uma abordagem mentalista. O declínio dessa hipótese ocorreu, também, porque autores como Selinker (1972) mostraram que nem todos os erros cometidos por aprendizes de L2 eram resultado de uma transferência da L1 para a língua-alvo, pois a transferência era apenas um dos fatores influenciando a produção do aprendiz.

Segundo autores como Broselow e Kang (2003), há dois problemas em afirmar que os erros cometidos por aprendizes de L2 são causados exclusivamente por transferência. O primeiro é que, em muitos casos, determinadas estruturas que não existem na L1 são mais facilmente adquiridas do que outras também inexistentes na L1, independentemente das características da L1 ou da L2. 0 segundo problema é que, apesar de a fala dos aprendizes de L2 apresentar padrões coerentes e sistemáticos, esses padrões são muitas vezes diferentes daqueles na L1 ou na L2. Segundo as autoras, esses casos são influenciados por fatores universais como a marcação, em que fenômenos marcados são mais complexos e incomuns nas línguas do mundo do que os não marcados.

A marcação, construto teórico nascido no Círculo Linguístico de Praga, foi proposta inicialmente por Trubetzkoy (1939) e Jakobson (1941) e influenciou grande 
parte dos estudos em aquisição fonológica de L1. O conceito de marcação passou a ser utilizado na aquisição de L2 a partir do trabalho de Eckman (1977), que propôs a Hipótese da Marcação Diferencial (Markedness Differential Hypothesis). Essa hipótese é uma extensão da Hipótese de Análise Contrastiva e tem como objetivo identificar o grau de dificuldade na aquisição de determinada propriedade da L2 com base na L1, o que pode ser previsto da seguinte forma:

1) as áreas da língua-alvo que diferem da língua materna e são mais marcadas do que na L1 serão mais difíceis;

2) o grau relativo de dificuldade das áreas da língua-alvo que são mais marcadas do que na L1 corresponderá ao grau relativo de marcação;

3) as áreas da língua-alvo que diferirem da língua materna, mas que não forem mais marcadas do que aquelas na L1, não serão difíceis.

(Eckman, 1977, p. 321)

Assim, é possível prever que os fenômenos não marcados são adquiridos mais facilmente do que os marcados, ainda que nenhum deles ocorra na L1. Isso também explicaria os casos em que a fala do aprendiz apresenta características que não pertencem nem à L1 e nem à L2, o que pode ser analisado como resultado de uma preferência universal por estruturas menos marcadas.

Tomemos o vozeamento de fricativas coronais, as quais serão discutidas no Capítulo 4 deste trabalho, como exemplo: neste caso, os segmentos contendo o traço [+voz] seriam classificados como marcados, enquanto os que contém o traço [-voz] seriam considerados não-marcados. A Hipótese da Marcação Diferencial permite prever, então, que um falante de uma língua como o inglês, que possui o contraste de vozeamento do /z/ em posição final (ex: ice vs. eyes), não terá dificuldade em produzir palavras no português, que não apresenta esse contraste fonológico. Um falante de português adquirindo o inglês, por outro lado, deverá aprender a fazer esse contraste, que é uma estrutura mais marcada do que na sua L1 (Gass e Selinker, 2009).

Não são apenas os traços e segmentos que podem ser transferidos de uma língua para a outra, mas também a estrutura silábica de uma língua. Quando a L2 apresenta uma estrutura silábica inexistente na L1, é previsto que o aprendiz altere essa estrutura até que consiga produzir o padrão da língua-alvo. Um falante de uma língua como o português, por exemplo, que não permite a ocorrência de consoantes plosivas em posição de coda, terá dificuldade em produzir palavras como work, no inglês. Pelo menos nos níveis iniciais, é previsto que o aprendiz adapte essa estrutura silábica através da 
inserção de uma vogal epentética, produzindo ['w3rk] como ['w3r.ki], o que veremos em detalhe no Capítulo 6.

A aquisição de estruturas silábicas também pode ser investigada com base na marcação. Espera-se, por exemplo, que falantes de uma L1 que possua apenas estruturas não marcadas (ex: consoante-vogal [CV]) tenham dificuldades de adquirir uma língua com estruturas mais marcadas (ex: consoante-vogal-consoante [CVC]), e acabem adaptando essa estrutura através de epêntese ou de apagamento (Gass e Selinker, 2009, p. 182). Além da influência da L1, há evidências de que a aquisição da sílaba também seja afetada por tendências universais de marcação. Tarone (1980) mostrou que falantes coreanos aprendendo inglês como L2 alteraram sílabas CVC do inglês por meio epêntese mesmo essa estrutura sendo permitida no coreano (ex: sack $\rightarrow$ ['sæ.kə]). Esse resultado, segundo a autora, indica uma tendência de os aprendizes preferirem a sílaba menos marcada CV não só por influência da L1, mas por uma preferência universal pelo nãomarcado.

Além da marcação, os graus de similaridade/dissimilaridade são aspectos relevantes no que diz respeito à transferência da L1 para a L2. Diferentemente do que Lado (1957) previa com a Hipótese da Análise Contrastiva, Major (2001) propõe que os sons que forem similares na L1 e na L2 são mais difíceis de serem adquiridos do que aqueles que são dissimilares. A similaridade dificultaria a tarefa do aprendiz de desenvolver novas categorias fonológicas para sons tão semelhantes nas duas línguas. Nesses casos, a tendência é que o aprendiz aplique o padrão da L1 em vez de desenvolver a categoria correspondente da L2. Um fator de extrema importância nessa proposta é, portanto, definir o conceito de similaridade. Segundo o autor, fatores como percepção, informações acústicas e articulatórias e até a intuição de falante nativo podem ser determinantes para identificar o grau de semelhança entre determinado som na L1 e na L2.

A questão da similaridade na percepção de sons não nativos também foi apontada em Flege (1995). Através do Speech Learning Model, o autor propõe que é possível prever a dificuldade na aquisição de sons não-nativos de acordo com o grau de similaridade entre os sons da L1 e da L2. O modelo prevê que sons da L2 idênticos aos da L1 serão adquiridos com facilidade, sons da L2 que são muito diferentes da L1 serão adquiridos com um pouco menos de facilidade, e os sons da L2 que são parecidos, mas não são idênticos aos da L1, serão os mais difíceis de serem adquiridos. Em outras 
palavras, é necessário um certo grau de dissimilaridade entre os sons da L1 e os da língua-alvo para que o aprendiz seja capaz de perceber o contraste já que, nos casos em que os sons são parecidos, mas não idênticos, o aprendiz tende a processar o som da L2 numa categoria perceptual da L1.

Não se pode negar, portanto, o papel da língua materna sobre a aquisição de segunda língua, sobretudo quando consideramos a aquisição de falantes adultos. Contudo, diferentemente do que a visão behaviorista previa, observa-se que a transferência da L1 não ocorre de forma automática e mecânica, mas depende de diversos fatores que determinam como ou quando essa transferência tende a ocorrer.

\subsection{0 acesso à Gramática Universal}

Como vimos em 2.1, a influência da L1 sobre a língua-alvo é considerada um fator relevante para a aquisição de segunda língua desde os primeiros estudos desenvolvidos na área. A partir dos anos 80, uma outra questão passou a ser debatida: o acesso/não acesso à GU por aprendizes de segunda língua em comparação ao acesso direto à GU por aprendizes de L1 (cf. Klein e Martohardjono, 1999; White 2003, Meisel 2011). Nesta seção, serão apresentadas duas pesquisas que buscam verificar o acesso à GU na aquisição de L2, cada uma com um argumento diferente: a proposta de White (2003), que está relacionada ao problema lógico da aquisição (cf. Capítulo 1), e a proposta de Meisel (2011), que se baseia na universalidade dos estágios a serem completados pelos aprendizes e que está, portanto, mais relacionada ao problema desenvolvimental da aquisição (cf. Seção 1.1).

Segundo White (2003), a aquisição de propriedades complexas e abstratas da gramática que não estão explícitas no input da L2 seria uma evidência de que a GU continua operante na aquisição de segunda língua. Essa evidência, contudo, não seria suficiente, já que o aprendiz poderia estar utilizando a gramática da L1 como base para a aquisição. Assim, os casos em que o aprendiz consegue adquirir propriedades que não poderiam ser adquiridas nem somente pelo input e nem a partir da gramática da L1 seriam a maior evidência a favor do funcionamento da GU na aquisição de L2.

Em busca desses exemplos, a autora discute a Restrição do Pronome Pleno (Overt Pronoun Constraint), um princípio universal a respeito das diferenças entre as línguas quanto ao fato de exigirem ou não que pronomes do caso reto (subject pronouns) sejam 
foneticamente realizados (em inglês, overt). Em línguas de sujeito nulo ou línguas prodrop como o espanhol, o italiano e o japonês, os pronomes podem ser nulos, tomando a forma de uma categoria vazia, pro. Por outro lado, em línguas de sujeito pleno (línguas [-sujeito nulo] ou [-prodrop]) como o inglês, o pronome não pode ser oculto, ou seja, deve ser foneticamente realizado. Essa diferença pode ser observada nos exemplos do inglês, em (1), e do espanhol, em (2), a seguir (cf. White 2003, p. 5):

(1) a. John $\mathrm{i}_{\mathrm{i}}$ believes that he is intelligent. [João acredita que ele é inteligente]

b. ${ }^{*}{ }^{\prime} \mathrm{hhn}_{\mathrm{i}}$ believes that _ $\mathrm{i}$ is intelligent. [João acredita que (ele) é inteligente]

(2) a. Juan cree que él $_{i}$ es inteligente [João acredita que ele é inteligente]

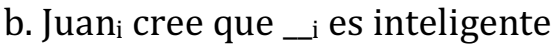
[João acredita que (ele) é inteligente]

Observa-se que, no inglês, sentenças que apresentam sujeito pleno (1a) são bem formadas, enquanto sentenças com sujeito nulo (1b) são agramaticais. 0 espanhol, por outro lado, aceita tanto sentenças com sujeito pleno (2a) quanto sentenças com sujeito nulo (2b). 0 exemplo (2), acima, também mostra que em línguas prodrop como o espanhol o sujeito não precisa, necessariamente, ser oculto. Entretanto, pronomes plenos e nulos não ocorrem nos mesmos contextos e são regidos por restrições. Em sentenças encaixadas como (2b), o sujeito poderá ser nulo a depender do que o antecede: se o pronome for precedido por um elemento referenciado como Juan, no exemplo (2b), ele poderá ser nulo ou pleno. Se o pronome for precedido por uma expressão quantificada (ex: ninguém, alguém, todos) ou uma pergunta-wh (ex: o que, qual), entretanto, o sujeito não poderá ser pleno. Essa diferença fica clara se compararmos os exemplos em (3) a seguir:

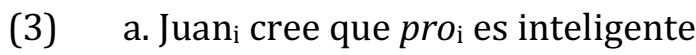
[João acredita que (ele) é inteligente]

b. Juan cree que él $_{i}$ es inteligente [João acredita que ele é inteligente]

c. $\mathrm{Nadie}_{\mathrm{i}}$ cree [que pro $_{\mathrm{i}}$ es inteligente] [Ninguém acredita que (ele) é inteligente] 
d. *Nadie ${ }_{i}$ cree [que éli es inteligente]

[Ninguém acredita que ele é inteligente]

Pode-se observar que, em (3a) e (3b), o sujeito pode ser tanto nulo quanto pleno porque há um antecedente referenciado (Juan). Na sentença (3c), entretanto, o sujeito deve, obrigatoriamente, ser oculto porque há um antecedente quantificado (nadie). Desse modo, a sentença (3d) é agramatical porque o sujeito está expresso quando precedido de um elemento quantificado.

Segundo a autora, assim como na aquisição de L1, o conhecimento desse princípio seria muito difícil de ser adquirido através do input na aquisição de L2, pois restrições como as do antecedente quantificado são muito sutis. Estudos como PérezLeroux e Glass (1997) mostram que esse aspecto da gramática não é ensinado a estudantes de espanhol nas aulas ou nos livros didáticos. Neste caso, nem o input (seja ele naturalístico ou através de instrução em sala de aula) nem o conhecimento da L1 seriam suficientes para o aprendiz de L2 chegar a essas distinções. Se um falante de inglês (uma língua não prodrop), ao adquirir uma língua como o espanhol (uma língua prodrop) mostrar conhecimento desse princípio na produção da L2, há uma forte evidência de que a Gramática Universal continua operante e que o aprendiz é capaz de mudar o parâmetro do sujeito nulo. Para verificar essa hipótese, os estudos de PérezLeroux e Glass (1997) e Kanno (1997) testaram a aquisição do espanhol e do japonês, ambas línguas de sujeito nulo, por falantes de inglês, uma língua que não permite o sujeito nulo. Os resultados das duas pesquisas mostram que os aprendizes de espanhol e de japonês como L2, em diferentes níveis de proficiência, utilizaram um número significativamente baixo de sentenças com pronome pleno com antecedentes quantificados, assim como os falantes nativos. Isso sugere que a Restrição do Pronome Pleno também opera sobre a aquisição de L2, pois os resultados mostraram que os aprendizes fazem distinções relevantes sobre o uso do pronome, as quais não poderiam ser baseadas nem gramática da L1 e nem exclusivamente no input da L2.

Vejamos agora a argumentação de Meisel (2011) a respeito do acesso à GU, com base na universalidade nos estágios da aquisição de L2. 0 autor parte do princípio de que a uniformidade é um aspecto crucial na aquisição de L1, pois o fato de haver pouca variação no desenvolvimento da gramática da língua materna e de as crianças cometerem os mesmos tipos de "erros" durante o processo sugere que o 
desenvolvimento da L1 é guiado por um mecanismo compartilhado por todos os aprendizes: a Gramática Universal. Sendo assim, investigar a existência dessa uniformidade durante a aquisição de L2 seria uma maneira de descobrir se há, também, algum tipo de conhecimento inconsciente compartilhado por todos os aprendizes guiando a aquisição de segunda língua. Segundo o autor, caso fossem encontradas evidências de que falantes de diferentes línguas maternas passam pelos mesmos estágios durante a aquisição de uma mesma L2, haveria uma forte evidência de que eles também têm acesso a uma capacidade que guia a aquisição de L2 e que a transferência da L1 não é o aspecto mais importante no processo de aquisição.

Como forma de fundamentar seu argumento, Meisel exemplifica a ordem dos morfemas. O autor aponta que tanto Brown (1973) quanto de Villiers e de Villiers (1973) chegaram a uma mesma ordem (portanto, fixa) na aquisição dos morfemas do inglês como L1, conforme o Quadro 1 a seguir:

\section{Quadro 1: Ordem de aquisição dos morfemas na aquisição de L1}

(Brown, 1973, p. 274)

\begin{tabular}{|c|c|c|c|}
\hline \multicolumn{4}{|c|}{ ORDEM DE AQUISIÇÃO DOS MORFEMAS NA AQUISIÇÃO DE L1 } \\
\hline $1^{\circ}$ presente contínuo & -ing & $8^{\circ}$ artigos & $a$, the \\
\hline $2^{\circ}$ preposição & in & 9o passado regular & -ed \\
\hline 3ํo preposição & on & $10^{\circ} 3^{\mathrm{a}}$ pessoa do sing. & $-S$ \\
\hline $4^{\circ}$ o plural & $-S$ & $11^{\mathrm{o}} 3^{\mathrm{a}}$ pessoa irregular & has \\
\hline 5o passado irregular & went, spoke & $12^{\circ}$ auxiliar sem contração & be \\
\hline $6^{0}$ caso genitivo & $-' s$ & 13o cópula contraído & be \\
\hline 7o cópula sem contração & be & 14ํa auxiliar contraído & be \\
\hline
\end{tabular}

A partir dos resultados de Brown (1973) e de Villiers e de Villiers (1973), passouse a investigar se haveria um padrão de aquisição dos morfemas durante a aquisição de L2, assim como na aquisição de L1. 0 estudo de Dulay and Burt (1973), por exemplo, investigou a aquisição de mandarim e de espanhol por 250 crianças falantes de inglês com idades entre cinco e oito anos. A conclusão dos autores foi que os aprendizes de espanhol e de mandarim como L2 passam pelos mesmos estágios na aquisição de morfemas em L2, seguindo a ordem apresentada no Quadro 2 a seguir: 


\section{Quadro 2: Ordem de aquisição dos morfemas por crianças aprendizes de Mandarim e Espanhol como L2 (Dulay e Burt, 1974)}

$\begin{array}{ll}\text { ORDEM DA AQUISIÇÃO DOS MORFEMAS POR CRIANÇAS APREN } \\ \text { 1. pronomes } & \text { 7. passado regular } \\ \text { 2. artigos } & \text { 8. passado irregular } \\ \text { 3. presente contínuo } & \text { 9. plural longo } \\ \text { 4. cópula } & \text { 10. possessivo } \\ \text { 5. plural } & \text { 11. } 3^{\text {a }} \text { pessoa regular } \\ \text { 6. auxiliar } & \end{array}$

Dois fatos podem ser observados a partir destes dados. 0 primeiro é que a ordem em L2 é a mesma inclusive para línguas bastante diferentes. 0 segundo é que a ordem de aquisição em L1 e L2 é diferente. Por exemplo, os artigos, que são o segundo elemento a ser adquirido em L2, estão no meio do processo em L1 (oitava posição). Esses resultados, segundo Meisel, foram confirmados quando pesquisas mais recentes reinterpretaram esses estudos com o objetivo de explicar as sequências de aquisição através de análises gramaticais (Zobl and Liceras $1994^{3}$ apud Meisel 2011), e mostraram que as crianças e os adultos adquirindo uma L2 passam pelos mesmos estágios, independente da L1. Para o autor, o fato de que a ordem é a mesma durante a aquisição de diferentes segundas línguas é uma evidência de que, ao menos nesses casos, a língua materna não é o elemento mais relevante para determinar a ordem de aquisição de L2, o que sugere a existência de um mecanismo regendo a aquisição de segunda língua - seja esse "mecanismo" a Gramática Universal ou não.

Portanto, com base em argumentos diferentes, tanto White (2003) quanto Meisel (2001) mostram que, assim como na aquisição de L1, parece existir um mecanismo que governa a aquisição de segunda língua.

Com base na ideia de que a aquisição de L2 é influenciada não só pela L1, mas também pela GU, uma série de estudos utilizam a teoria de princípios e parâmetros para investigar a aquisição fonológica de segunda língua. A pesquisa de Archibald (1992, 1993a, 1993b), por exemplo, tem investigado como os parâmetros métricos estipulados por Dresher e Kaye (1990, cf. Seção 1.1) se estabelecem na aquisição de uma segunda língua. 0 autor analisou a aquisição do acento do inglês por falantes de polonês (1992), de espanhol (1993a) e de húngaro (1993b), através de tarefas de percepção e de produção. Primeiramente, os aprendizes deveriam ler uma lista de palavras e sentenças,

\footnotetext{
${ }^{3}$ Zobl, H. and J. Liceras 1994. 'Functional categories and acquisition orders', Language Learning 44: 159-80.
} 
enquanto suas produções eram transcritas com relação à atribuição do acento. Então, os participantes da pesquisa ouviam as mesmas palavras e sentenças exatamente da maneira haviam produzido na tarefa anterior, numa gravação feita por um falante nativo de inglês. A tarefa, desta vez, era marcar a sílaba em que eles percebiam o acento. Os estudos mencionados apontaram que os aprendizes de espanhol, húngaro e polonês, de maneira geral, apresentaram uma boa taxa de acertos nas tarefas de atribuição do acento em palavras do inglês, apesar de também apresentarem influência de suas respectivas línguas maternas. A partir disso, o autor conclui que a gramática desses aprendizes de L2 reflete princípios da GU, marcação correta de parâmetros e marcação incorreta dos parâmetros na L1 na L2 (resultado de transferência). 0 autor defende, portanto, que a gramática de aprendizes de L2 adultos não viola os princípios métricos universais e, ainda, que os adultos são capazes de modificar os valores dos parâmetros da sua L1 através do input da L2 (Archibald, 2014).

Apesar de o acesso à GU ainda ser uma questão em debate na área de aquisição de L2, assumimos, com base na discussão apresentada na Seção 2.1 e na presente seção, que tanto a língua materna quanto a GU podem influenciar o processo de aquisição de segunda língua. Nesse sentido, concordamos com a visão de Gass (1996) de que a GU tem um papel importante durante a aquisição de L2, mas que esse processo também é influenciado pela gramática da L1. A questão, portanto, é entendermos como esses dois fatores operam no processo de aquisição.

\subsection{0 estado inicial da gramática da L2}

Assumindo-se a disponibilidade da GU na aquisição de segunda língua, ${ }^{4}$ foram propostas diversas hipóteses com relação ao estado inicial da gramática na aquisição de L2, as quais podem ser divididas em dois grupos: as hipóteses que defendem que a aquisição de L2 parte da gramática da L1 e as hipóteses que defendem que, assim como na aquisição de L1, a aquisição de L2 parte da GU. Essas propostas serão apresentadas

\footnotetext{
${ }^{4}$ Existem hipóteses que não consideram o acesso à GU. Pesquisadores como Schachter (1989), por exemplo, defendem a Hipótese do Acesso Nulo, segundo a qual a GU não está disponível para aprendizes de L2 adultos. Para o autor, o estado inicial da gramática da L2 é composto somente da gramática da L1, sem acesso direto à GU. O aprendiz adulto de L2 teria perdido o acesso aos princípios universais e às opções paramétricas disponíveis na aquisição de L1 e não seria capaz de adquirir a competência de um nativo. Como assumimos a disponibilidade da GU durante a aquisição de L2, essas hipóteses não serão abordadas neste capítulo.
} 
nas seções 2.3.1 e 2.3.2 a seguir e, na Seção 2.3.3, apresentamos uma comparação entre todas as propostas apresentadas.

\subsubsection{A gramática da L1 como estado inicial}

Há três propostas que assumem o acesso à GU e defendem que a gramática da L1 é o estado inicial da aquisição de L2: a Hipótese do Acesso Total/ Transferência Total (Full transfer/Full Access), desenvolvida por Schwartz e Sprouse (1996) e que, conforme o nome, pressupõe uma transferência total; a Hipótese das Árvores Mínimas (Minimal Tree Hypothesis), formulada por Vainikka e Young-Scholten $(1994,1996)$, que propõe uma transferência parcial; e a Hipótese dos traços sem Valor (Valueless Features Hypothesis), proposta por Eubank (1993), que assume uma transferência fraca. Vejamos cada uma delas.

Segundo a Hipótese de Transferência Total/Acesso Total (TTAT) (Schwartz e Sprouse, 1996), o estado inicial é a gramática da L1, mas há acesso total à GU. Quando a informação fornecida pela L1 é insuficiente para a aquisição de determinado aspecto da L2, o aprendiz pode recorrer à GU, que está totalmente disponível durante todo o processo de aquisição. Isso significa que é possível modificar os parâmetros da L1 para acomodar as propriedades do input da L2 e, inclusive, marcar novos parâmetros inexistentes na L1 (White, 2003, p. 61). A transferência de aspectos da L1 para a L2 possui um papel importante nessa proposta, pois faz com que o estado inicial da aquisição de L2 seja completamente diferente do estado inicial da aquisição de L1: enquanto o aprendiz inicia a aquisição sem nenhuma base na L1, o aprendiz de L2 inicia o processo a partir da gramática da L1.

Uma maneira de verificar essa hipótese é investigar o conhecimento de falantes de diferentes línguas maternas adquirindo uma mesma L2 (cf. White, 2003). Caso a hipótese em questão esteja correta, espera-se que esses aprendizes se comportem de maneira diferente, já que partem de estados iniciais diferentes. Estudos como o de White (1985) mostraram que falantes de francês e de espanhol aprendendo inglês como L2 apresentaram comportamentos diferentes na aquisição do sujeito nulo (mencionado na Seção 2.2). Em tarefas de julgamento de gramaticalidade do inglês, os falantes de espanhol aceitaram significativamente mais sentenças com sujeito nulo do que falantes de francês. Sendo o espanhol uma língua [+sujeito nulo] e o francês uma língua [-sujeito 
nulo], esse resultado seria uma evidência para a defesa da TTAT, já que a diferença nas respostas dos participantes reflete a diferença no estado inicial da L2. O estudo de Yuan (2001), por outro lado, mostrou que falantes de francês e de inglês aprendendo chinês apresentam exatamente o mesmo comportamento com relação à posição do verbo na sentença no estágio inicial da aquisição apesar de o inglês e o francês apresentarem diferenças significativas com relação a esse aspecto, o que seria uma contra-evidência à TTAT. De acordo com White (2003, p. 67), mesmo que sejam encontrados mais casos em que os aprendizes de L2 não apresentam efeitos da L1, ou, ainda, casos em que falantes de diferentes línguas maternas adquirindo uma mesma L2 se comportem da mesma maneira com relação a um determinado fenômeno na L2, isso não descartaria a validade da hipótese. Como a TTAT assume que a gramática da L2 será reestruturada a partir da interação entre a GU e o input da L2, não seria impossível que as gramáticas da L2 de falantes de diferentes línguas maternas se assemelhem em algum ponto do aprendizado. Um dos problemas desta hipótese, portanto, diz respeito à falseabilidade: se não são encontrados exemplos de transferência da L1, os defensores da hipótese podem afirmar que os aprendizes já passaram pelo estágio de transferência total. Desse modo, parece que a TTAT jamais estaria errada, pois sempre haveria uma justificativa plausível para as evidências encontradas durante o processo.

Assim como a Hipótese de Transferência Total/Acesso Total, na Hipótese das Árvores Mínimas (Minimal Trees) tanto a L1 quanto a GU estão disponíveis concomitantemente (Vanikka e Young-Scholten, 1996), mas a transferência da L1 é parcial. A gramática da L1 disponível não contém categorias funcionais (elementos gramaticais que ligam as sentenças como preposições, conjunções, etc.), apenas categorias lexicais e, como a aquisição dessas categorias funcionais não depende da L1, não há transferência. Desse modo, essas categorias funcionais emergem através do input da L2, o que significa que falantes de diferentes línguas maternas terão o mesmo desenvolvimento dessas categorias na L2. Nessa visão, o aprendiz pode atingir o estágio final da gramática da L2 ou não, dependendo do que está disponível através da L1 e da GU. Espera-se, contudo, que o aprendiz adquira completamente os aspectos relacionados às categorias funcionais.

Segundo White (2003), uma maneira de descartar essa hipótese seria encontrando dados que indiquem a influência de categorias funcionais da L1 no estado inicial da aquisição. Trabalhos como o de Schwartz e Sprouse (1996) apontam 
evidências de que há, sim, uma transferência das categorias funcionais da L1 na aquisição de L2. Segundo Meisel (2011, p.102), enquanto a TTAT acaba superestimando o papel da transferência da L1 no estado inicial da aquisição, a Hipótese das Árvores Mínimas não oferece uma explicação satisfatória para a transferência parcial. Em suma, de acordo com a Hipótese das Árvores Mínimas, o estado inicial é composto de categorias lexicais da gramática da L1 e o desenvolvimento da gramática caracteriza-se pela aquisição de categorias funcionais com base no input da L2 e na GU. Nessa visão, o aprendiz é capaz de atingir o estágio final da gramática da L2 no que diz respeito às categorias funcionais.

A Hipótese dos Traços (valores) Indeterminados (Valueless Features), proposta por Eubank (1996), propõe que a gramática da L1 influencia fortemente, mas não completamente, o estado inicial da gramática da L2. Diferentemente da Hipótese das Árvores Mínimas, e da mesma forma que na TTAT, tanto as categorias funcionais quanto as lexicais estão disponíveis a partir da L1. Entretanto, os valores dos traços das categorias funcionais não estão disponíveis, ou seja, são indeterminados. Assim como na análise da Hipótese das Árvores Mínimas, White (2003) aponta diversos problemas metodológicos que influenciaram os resultados dos proponentes da Hipótese dos Traços Indeterminados, os quais não serão detalhados na presente pesquisa porque o maior problema nessa hipótese, segundo a autora, tem caráter conceitual. Para White, não haveria razão para todas as propriedades da gramática da L1 estarem disponíveis no estado inicial exceto os traços das categorias funcionais. A autora ressalta que ambas as hipóteses foram influenciadas a partir de propostas formuladas para a aquisição de L1 (como a Hipótese Continuísta Fraca, mencionada no Capítulo 1) e que, mesmo que essas hipóteses estejam corretas com relação à aquisição de L1, não há evidências fortes para aplicá-las à aquisição de L2.

Meisel (2011, p. 105) defende que as hipóteses que propõem transferência parcial são as mais plausíveis. Para o autor, a proposta de Acesso Total/ Transferência Total não é convincente, primeiramente, porque apesar de assumir que os princípios da GU têm a mesma importância que a gramática da L1 no estado inicial, os defensores da hipótese não deixam claras as evidências para se assumir que os aprendizes têm, de fato, acesso total à GU durante os estágios iniciais da aquisição. Além disso, assumir uma transferência total significaria que, assim que uma quantidade suficiente de itens lexicais é adquirida, o aprendiz já começaria a utilizar estruturas sintáticas complexas 
transferidas diretamente da L1, mas com o léxico da L2. Entretanto, não é isso que as evidências mostram, já que as estruturas produzidas nos estágios iniciais geralmente não são idênticas às estruturas da L1. 0 autor assume, portanto, que a ideia de uma transferência parcial seria mais plausível do que uma transferência total, e conclui que, dentre as propostas apresentadas, a Hipótese dos Traços Indeterminados parece a mais adequada:

If we were to choose between the two competing hypotheses dealing with this issue, our brief review suggests that the idea of an initial grammar lacking all or even most functional elements is conceptually less plausible in L2 acquisition than in first language development. This conclusion speaks against the Minimal Trees Hypothesis, at least as an explanation of partial transfer. The notion of featural underspecification of functional categories seems to fare better in this respect. The Valueless Features Hypothesis thus seems to be the most promising of the three competing approaches. (Meisel 2011, p. 105)

0 autor acredita que a hipótese da transferência parcial é a mais adequada, principalmente, porque assume que aprendizes de L2 têm acesso indireto à GU via gramática de L1, o que explicaria a influência da L1 nos estágios iniciais da aquisição. Contudo, a maneira com que a GU é acessada, segundo ele, ainda não foi explicada de maneira satisfatória em nenhuma proposta.

\subsubsection{A GU como estado inicial}

As três hipóteses apresentadas na seção acima assumem que o estado inicial da gramática é formado pela L1, apesar de discordarem a respeito de quais aspectos da L1 estão disponíveis. Nesta seção, serão apresentadas duas hipóteses que rejeitam a ideia de que o estado inicial da gramática seja constituído de propriedades da L1 e defendem que a aquisição de L2, assim como a de L1, parte da Gramática Universal. São elas: A Hipótese Inicial da Sintaxe (Initial Hypothesis of Syntax), proposta por Platzack (1996), e a Hipótese do Acesso Total (sem transferência) (Full Access Without Transfer), formulada por Epstein et al. (1996).

De acordo com a Hipótese Inicial da Sintaxe (Platzack, 1996), assim como na aquisição de L1, o ponto inicial da aquisição de L2 é a GU. Não há transferência porque os valores dos parâmetros da L1 não fazem parte do estado inicial e, consequentemente, não há a necessidade de modificar os valores dos parâmetros. 0 valor dos traços das categorias funcionais é fraco (weak functional feature), e todo aprendiz assumirá este 
valor, pelo menos no estado inicial, mesmo que na língua-alvo esse valor seja forte. No decorrer do processo, o aprendiz estabelecerá os valores fraco ou forte a partir do input recebido da L2.

Segundo White (2003, p. 88), há evidências empíricas que geram dúvidas a respeito dessa proposta. A autora mostra que dados como os apresentados em White (1990) sugerem que os falantes de francês aprendendo inglês transferem traços fortes da L1 para a L2, o que indicaria que os aprendizes não iniciam a aquisição com a marcação de traços fracos.

Por fim, a Hipótese do Acesso Total (sem transferência), proposta por Epstein et al. (1996), advoga que, assim como na aquisição de L1, os princípios e parâmetros da GU permanecem disponíveis aos aprendizes de L2 inclusive na vida adulta, possivelmente durante todo o processo de aquisição. Nesse aspecto, essa hipótese não difere da Hipótese do Acesso total/ Transferência Total, por exemplo. 0 que distingue esta hipótese das outras é o fato de que ela rejeita a ideia de que a L1 forma o estado inicial da gramática, pois o estado inicial é constituído pela própria GU. Sendo assim, seria possível concluir que o estado inicial na L1 e na L2 é idêntico, mas Epstein et al. (1996, p. 751) rejeitam essa possibilidade. Os autores afirmam que o estado inicial não é $S_{0}$, então, possivelmente, não seria a própria GU.

As principais críticas contra esta hipótese dizem respeito à previsão de que os aprendizes de L2 adultos sempre atingiriam o nível de proficiência nativo, já que a GU estaria totalmente disponível. Sobre isso, Epstein et al. (1996) destacam a importância da distinção entre competência e desempenho pois, segundo eles, embora a proficiência nativa em L2 seja rara, isso não significa que não possa existir competência. A competência nativa na L2 não só é possível, mas é prevista pela Hipótese do Acesso Total pois, segundo os autores, é possível que o aprendiz de L2 tenha atingido o estado estável da gramática da língua-alvo sem que isso seja refletido no desempenho da gramáticaalvo. Entretanto, como White (2003, p. 89) ressalta, ficaria difícil definir o que é, de fato, o estado inicial nesta proposta, já que não seria nem a gramática da L1 e nem a GU, o que caracteriza um problema a ser resolvido.

\subsubsection{Comparação entre as hipóteses}


É possível perceber que as propostas apresentadas nas seções 2.3.1 e 2.3.1 muitas vezes se sobrepõem, o que acaba dificultando a tarefa de distinguir cada uma com evidências empíricas. Para facilitar a comparação entre as propostas apresentadas, o Quadro 3 resume o que cada uma prevê a respeito do estado inicial, do desenvolvimento e do estado estável da aquisição.

\section{Quadro 3: Comparação entre as propostas a respeito do papel da L1 e da GU (adaptado de White, 2003, p. 94)}

\begin{tabular}{|c|c|c|c|c|}
\hline BASE & PROPOSTA & ESTADO INICIAL & DESENVOLVIMENTO & $\begin{array}{c}\text { ESTADO } \\
\text { ESTÁVEL }\end{array}$ \\
\hline \multirow{4}{*}{ L1 } & $\begin{array}{l}\text { Acesso } \\
\text { Total/ } \\
\text { Transf. } \\
\text { Total }\end{array}$ & $\begin{array}{c}\text { Acesso total à GU. Estão } \\
\text { disponíveis: categorias } \\
\text { funcionais e lexicais da } \\
\text { L1, traços e força de } \\
\text { traços. }\end{array}$ & $\begin{array}{l}\text { Falantes de diferentes } \\
\text { L1's percorrem } \\
\text { caminhos diferentes. } \\
\text { É possível modificar e } \\
\text { marcar novos } \\
\text { parâmetros. }\end{array}$ & $\begin{array}{l}\text { Aquisição total } \\
\text { da gramática } \\
\text { da L2 é } \\
\text { possível, mas } \\
\text { nem sempre é } \\
\text { alcançada. }\end{array}$ \\
\hline & $\begin{array}{l}\text { Árvores } \\
\text { Mínimas }\end{array}$ & $\begin{array}{c}\text { L1). Categorias funcionais } \\
\text { da L1 não estão } \\
\text { disponíveis, somente as } \\
\text { lexicais }\end{array}$ & $\begin{array}{l}\text { Emergencla de } \\
\text { categorias funcionais } \\
\text { (disponíveis na GU) } \\
\text { em estágios, a partir } \\
\text { do input da L2. }\end{array}$ & $\begin{array}{l}\text { Aquisição da } \\
\text { gramática da } \\
\text { L2 é prevista. }\end{array}$ \\
\hline & $\begin{array}{c}\text { Traços } \\
\text { Indetermi- } \\
\text { nados }\end{array}$ & $\begin{array}{l}\text { Acesso indireto à GU (via } \\
\text { L1). Categorias funcionais } \\
\text { e lexicais da L1 estão } \\
\text { disponíveis, mas os } \\
\text { valores das categorias } \\
\text { funcionais são } \\
\text { indeterminados. }\end{array}$ & $\begin{array}{c}\text { Traços são adquiridos } \\
\text { no decorrer do } \\
\text { processo, quando } \\
\text { paradigmas } \\
\text { morfológicos são } \\
\text { adquiridos. }\end{array}$ & $\begin{array}{l}\text { Aquisição da } \\
\text { gramática da } \\
\text { L2 é prevista. }\end{array}$ \\
\hline & $\begin{array}{l}\text { Hipótese } \\
\text { Inicial da } \\
\text { Sintaxe }\end{array}$ & $\begin{array}{l}\text { Acesso total à GU. } \\
\text { O valor dos traços das } \\
\text { categorias funcionais é } \\
\text { fraco, e todo aprendiz } \\
\text { assumirá este valor. } \\
\text { Sem transferência. }\end{array}$ & $\begin{array}{c}\text { No decorrer do } \\
\text { processo, o aprendiz } \\
\text { estabelece os valores } \\
\text { fraco ou forte a partir } \\
\text { do input recebido da } \\
\text { L2. }\end{array}$ & $\begin{array}{c}\text { Estágio final } \\
\text { não é abordado } \\
\text { pela Hipótese. }\end{array}$ \\
\hline GU & $\begin{array}{c}\text { Acesso } \\
\text { Total/ Sem } \\
\text { Transf. }\end{array}$ & $\begin{array}{l}\text { Categorias funcionais e } \\
\text { lexicais da L1, traços e } \\
\text { valores dos traços. } \\
\text { Sem transferência. }\end{array}$ & $\begin{array}{l}\text { Nenhum desenvolvi- } \\
\text { mento necessário em } \\
\text { propriedades } \\
\text { abstratas de } \\
\text { categorias funcionais. }\end{array}$ & $\begin{array}{c}\text { Competência } \\
\text { na L2 idêntica } \\
\text { à de falantes } \\
\text { nativos (com } \\
\text { possíveis } \\
\text { diferenças no } \\
\text { desempenho) }\end{array}$ \\
\hline
\end{tabular}

Como vimos, todas as hipóteses apresentadas assumem que a GU continua disponível durante a aquisição de L2. As hipóteses Acesso Total/Transferência Total, Árvores Mínimas e Traços Indeterminados se assemelham porque assumem que a gramática da L2 parte da gramática da L1, mas diferem quanto aos elementos que estão 
disponíveis a partir da língua materna. As hipóteses do Acesso Total/Transferência Total, Traços Indeterminados e Acesso Total/ Sem transferência, por sua vez, se assemelham por assumirem que todas as categorias funcionais estão disponíveis no estado inicial, mas enquanto a primeira assume que há uma transferência total, a segunda assume uma transferência parcial e a última assume que não há transferência da L1.

Uma outra diferença entre as hipóteses apresentadas diz respeito ao estado estável ou "final" da aquisição. Por um lado, as hipóteses do Acesso Total/ Transferência Total, Acesso Total/ Sem transferência e a Hipótese Inicial da Sintaxe assumem que, em qualquer estágio da aquisição, a gramática do aprendiz apresenta todas as propriedades das línguas naturais (i.e. traços, categorias lexicais e funcionais), sejam essas propriedades pertencentes à L2 ou não. As hipóteses das Árvores Mínimas e dos Traços Indeterminados, por outro lado, assumem que no estágio inicial a gramática do aprendiz apresenta características diferentes do que se espera das línguas naturais, pois carecem de propriedades fundamentais como as categorias funcionais e força de traços (feature strength $)^{5}$ (White, 2003).

\subsection{0 domínio de L2: outras motivações}

Nas Seções 2.1, 2.2 e 2.3 vimos que há uma discussão sobre a possibilidade de aprendizes de L2 adquirirem um domínio nativo da língua-alvo, e que essa questão é discutida através de diferentes hipóteses sobre o acesso à GU e a influência da L1 na aquisição de L2. Além desses fatores, há outros que podem influenciar o sucesso ou o insucesso na aquisição de L2, os quais serão discutidos nas seções a seguir.

\subsubsection{0 fator Idade}

O fator idade é uma questão amplamente discutida na pesquisa em aquisição de L2. Evidências apontam para o fato de que, quanto mais tarde o aprendiz for exposto a uma segunda língua, maior será a influência da língua materna sobre a língua-alvo e

\footnotetext{
${ }^{5}$ De acordo com White (2003, p. 276), a "força" é uma propriedade dos traços sintáticos que determina quando o movimento pleno (overt movement) acontece. Segundo a autora, traços com valores fortes motivam o movimento.
} 
menores serão as chances de o falante atingir uma competência semelhante à de um falante nativo.

No que diz respeito à aquisição de L1, casos raros como o da menina Genie (Curtiss, 1977), que foi privada de qualquer input linguístico entre a idade de 1:6 até 13:7, mostram que a aquisição tardia da língua materna pode causar danos irreversíveis à linguagem. Quando, aos 13 anos, a menina finalmente passou a receber input linguístico, seu vocabulário cresceu significativamente, mas sua entonação permaneceu um tanto excêntrica. Além disso, segundo Curtiss (1977, p. 60), apesar de a menina se mostrar bastante comunicativa, não conseguia utilizar corretamente as regras gramaticais, ou seja, "tinha habilidades semânticas, mas não podia aprender a sintaxe".

As evidências encontradas na aquisição tardia de L1 suportam a existência de um "período crítico" para o desenvolvimento linguístico, após o qual a competência nativa seria inacessível a aprendizes que já ultrapassaram determinada idade. Segundo Lenneberg (1967), o fim desse período seria na puberdade, pois é nessa época que a lateralização do cérebro está finalizada, reduzindo, assim, o substrato neural necessário para o aprendizado linguístico. Com relação ao término do período crítico para a aquisição de uma segunda língua, Long (1990) afirma que a aquisição da sintaxe e da morfologia nativa parece ser possível apenas para quem inicia a aprendizagem da L2 até os 15 anos. No que concerne à fonologia, o período seria ainda mais curto:

The ability to attain native-like phonological abilities in an SL begins to decline by age 6 in many individuals and to be beyond anyone beginning later than age 12 , no matter how motivated they might be or how much opportunity they might have (Long 1990, p.280).

Segundo o autor, portanto, a fonologia é o primeiro aspecto a ser afetado pelo período crítico, e fatores como motivação e quantidade de input não são suficientes para o desenvolvimento de uma fala similar à nativa. Pesquisas como a de Bongaerts, Mermen e Van der Slik (2000, p. 299), por sua vez, sugerem que a fonologia é o único fator a ser comprometido pela idade, pois é o único aspecto do desempenho linguístico que envolve fatores neuromusculares e que, portanto, tem uma realidade física.

Birdsong (1999) apresenta diversas possíveis explicações para o fato de que a maioria dos adultos não consegue alcançar a proficiência nativa na aquisição de L2. Um dos motivos é a perda da plasticidade no cérebro, já que, com o passar dos anos, há uma 
lateralização das funções cerebrais que impede o adulto de utilizar o cérebro da mesma maneira que as crianças em tarefas de aprendizado linguístico.

Autores como Fromkin, Rodman e Hyams (2003, p.383) e Bialystok e Hakuta (1999, p. 164) preferem o termo "período sensível” para a aquisição da linguagem, em vez do já mencionado "período crítico". Segundo eles, um "período sensível" pressupõe uma diminuição da capacidade de adquirir línguas mais gradual. Assim como Long (1990), Gass e Selinker (2009, p. 405) enfatizam que o período sensível mais curto é o da aquisição da fonologia, e destacam que isso ocorre especialmente na aquisição de aspectos suprassegmentais, o que já foi apontado em estudos como o de Moyer (1999), por exemplo. 0 autor investigou a pronúncia de falantes de inglês como L1 fluentes em alemão que iniciaram a aquisição na idade adulta, e os resultados mostraram que, apesar de todos os participantes estarem altamente motivados e serem altamente proficientes na L2, suas produções eram, ainda, diferentes da pronúncia nativa.

De acordo com Kuhl (2004, p. 832), a aquisição dos padrões da primeira língua acaba interferindo na aquisição de novos padrões - como aqueles de uma segunda língua - porque eles são diferentes do "filtro mental" já estabelecido na aquisição da língua materna. A autora explica que, até os 5 meses de idade, os bebês são capazes de distinguir praticamente todas as unidades fonéticas possíveis nas línguas do mundo (cerca de 600 consoantes e 200 vogais), e que, aos poucos, essa habilidade começa a dar lugar a uma capacidade de distinguir os sons específicos da língua materna. No decorrer da aquisição a criança aprende a agrupar essa variedade de unidades fonéticas possíveis em categorias fonológicas da língua a que forem expostas, computando estatisticamente o input recebido para determinar a estrutura da língua materna. E é justamente a fixação dessas categorias fonológicas da L1 que acaba dificultando a percepção e, consequentemente, a produção dos sons de uma segunda língua.

Além dos fatores biológicos mencionados nesta seção, Bongaerts et al, (1995) ressaltam que aspectos sociais como motivação e identificação com a língua-alvo também podem influenciar o sucesso ou insucesso na aquisição de uma L2 por falantes mais velhos. Esses fatores serão discutidos na Seção 2.3 .2 a seguir. 


\subsubsection{Fatores não linguísticos}

Segundo Selinker (1972), em média apenas 5\% dos aprendizes conseguem adquirir a mesma competência de um falante nativo (o que seria uma contra-evidência para a Hipótese do Acesso Total/ Sem Transferência, por exemplo, pois a hipótese prevê que o aprendiz é capaz de adquirir a competência de um falante nativo). Na maioria das vezes, de acordo com o autor, há uma estabilização no aprendizado assim que os aprendizes adquirem apenas algumas estruturas diferentes da L2, o que ele chama de fossilização. Segundo o autor, fenômenos fossilizáveis são:

(...) linguistic items, rules and subsystems which speakers of a particular NL [native language] will tend to keep in their IL [interlanguage $=$ their L2 grammar] relative to a particular TL [target language], no matter what the age of the learner or amount of explanation and instruction he receives in the TL (Selinker 1972, p.215).

Segundo Long (2005, p.492) um dos problemas relacionados à fossilização proposta em Selinker (1972) é o fato de que esta é assumida, e não demonstrada. Segundo o autor, muitos dos erros frequentes caracterizados por alguns pesquisadores como itens fossilizados podem ser explicados de outras formas, e podem não ter nenhuma relação com fossilização (Long 2005, p.493).

Há diversos fatores não-linguísticos que podem influenciar a aquisição de uma L2. Um deles é a aptidão, que se refere à habilidade, ou facilidade, para aprender outras línguas além da L1. De acordo com Gass e Selinker (2009, p.417), a aptidão para a aquisição de L2 nem sempre foi incluída no estudo da aquisição de L2, principalmente pelo fato de que não é fácil mensurá-la. Com o objetivo de definir o que é, de fato, essa aptidão, Carroll (1989, p. 26) destaca quatro características: 1) A habilidade de discriminar sons estrangeiros; 2) A habilidade de reconhecer as funções das palavras nas sentenças; 3) A habilidade de inferir regras ou generalizações de determinada língua a partir do input; e 4) A capacidade de memorizar informações. Segundo Gass e Selinker (2009), essas quatro habilidades parecem ser um bom indicativo para sucesso na aquisição de L2, pois o domínio dessas habilidades representa uma vantagem para o aprendizado.

Outra questão que ainda não discutimos está relacionada à quantidade e a qualidade do input na aquisição de L2. Corder (1967) fez uma distinção entre o que ele 
chama de input e intake, definindo input como o que está disponível para o aprendiz, e intake como aquilo que é internalizado por ele. Em uma situação de contato com uma língua estrangeira, por exemplo, muitas vezes o aprendiz não consegue compreender o que ouve. Toda informação que estiver disponível ao aprendiz e não for compreendida será input, e não intake.

De acordo com Ferguson (1971), a língua usada pelos professores ou por falantes nativos da língua-alvo para se comunicar com aprendizes menos proficientes geralmente apresenta algumas características semelhantes à linguagem utilizada com as crianças (motherese). O foreign talk, ou "fala para estrangeiros", apresenta características de simplificação do input, tais como: registro de fala mais lento, pausas mais longas, vocabulário simplificado (por exemplo, poucas expressões idiomáticas ou phrasal verbs, no caso do inglês) e repetições. Mas será que esse input simplificado realmente ajuda no aprendizado de uma segunda língua? Gass e Selinker (2009, p. 308) afirmam que facilitar a compreensão do input pode, sim, facilitar o aprendizado, mas a compreensão não é o único aspecto envolvido na aquisição de uma L2.

Além da qualidade do input, há, também, a questão da quantidade. Krashen (1985) afirma que a quantidade insuficiente do input recebido por aprendizes de L2 em contextos não-naturalistas é um fator determinante para o insucesso na aquisição de uma L2. Mattos (2000, p.68), por outro lado, propõe que, por maior que seja a quantidade de input que o aprendiz receba, a língua-alvo sempre será sua segunda língua, o que explicaria o fato de a maior parte dos aprendizes jamais atinge a mesma proficiência de um nativo. Segundo a autora:

(...) pode-se supor que os aprendizes de L2 não cheguem a níveis avançados de proficiência na segunda língua porque continuam usando sua língua materna em seus processos cognitivos de alto nível, quando não estão em contato direto com a L2, ou seja, quando não estão realizando alguma tarefa na L2.

A autora salienta que, enquanto o ser humano usa sua língua materna de maneira involuntária em qualquer situação em que se encontre, o uso da L2 é restrito a situações em que há algum tipo de necessidade específica.

De acordo com Krashen (1985, p.3), a quantidade e a qualidade do input são importantes para a aquisição, mas não são suficientes devido à existência do que o autor denomina "filtro afetivo": um "bloqueio mental que impede os aprendizes de utilizar completamente o input compreensível recebido para a aquisição da linguagem". De 
acordo com o autor, fatores como falta de motivação, baixa autoconfiança e ansiedade caracterizam um "filtro afetivo alto" e seriam os principais motivos para as diferenças individuais no processo de aquisição, inclusive se compararmos crianças e adultos. Desse modo, os aprendizes terão mais facilidade em adquirir a L2 se tiverem atitudes positivas com relação à língua-alvo pois apresentarão um filtro afetivo mais baixo (ou fraco), o que possibilita a busca por uma maior quantidade de input compreensível. A hipótese do filtro afetivo foi criticada principalmente por não considerar a importância do output no processo de aquisição e por razões metodológicas, já que demonstrar a relação entre fatores psicológicos e o processo de aquisição de línguas não é algo simples de ser realizado (Ellis, 1985; McLaughlin, 1987, Callegari, 2006).

Assim, é possível que aspectos como aptidão para o aprendizado de línguas, motivação e características relacionadas ao input também tenham um papel relevante no processo de aquisição de L2. Contudo, não é fácil mensurar esses aspectos a fim de investigá-los na pesquisa em aquisição de L2. 


\section{Capítulo 3}

\section{OBJETIVOS E HIPÓTESES}

Conforme mencionado na introdução desta pesquisa, o nosso objetivo é verificar a influência da L1 e da GU na aquisição de segunda língua. Especificamente, discutiremos esta questão através da análise de três fenômenos no inglês produzido por falantes brasileiros: ${ }^{6}$ a regra de retração de acento, que ocorre de maneira semelhante no inglês e no português brasileiro (em um encontro de acentos primários, move-se o primeiro acento para uma sílaba anterior); a regra de assimilação de vozeamento, que existe em ambas as línguas mas ocorre de maneira diferente (em português a regra é regressiva, em inglês é progressiva); e a relação entre sílaba e acento, que ocorre de maneira diferente nas duas línguas e representa um parâmetro a ser marcado pelo aprendiz (assumindo Bisol, a sílaba pesada por coda atrai acento quanto em posição final; em inglês, a sílaba com núcleo ramificado atrai acento). ${ }^{7}$

Com esta pesquisa, busca-se investigar se é mais fácil adquirir uma regra igual, uma regra semelhante ou, ainda, marcar um parâmetro existente na língua materna. Essa investigação permite compreender a influência da GU e da L1 na aquisição de L2 porque, caso os resultados mostrem que a relação entre a sílaba e acento é adquirida com mais facilidade, isso seria uma evidência de que o estado inicial da aquisição é caracterizado pela GU, que permitiu a parametrização do acento a partir do input da L2. Caso a retração de acento seja adquirida com mais facilidade, isso significaria que o estado inicial da aquisição é caracterizado pela gramática da L1 e que haveria uma transferência (positiva) dessa regra para a L2. Por fim, caso a assimilação de vozeamento seja adquirida com mais facilidade, isso significaria que nem a L1 e nem a GU foram fatores facilitadores no processo de aquisição desses informantes, já que não

\footnotetext{
${ }^{6}$ Para facilitar a argumentação, os três fenômenos estão sendo descritos separadamente (Capítulos 4, 5 e 6), juntamente com os experimentos. Aqui, apenas salientamos os pontos relevantes para o estabelecimento das hipóteses e predições.

7 Conforme veremos no Capítulo 6, sílabas finais pesadas por coda também atraem o acento em verbos e adjetivos no inglês (cf. Hayes, 1982). Entretanto, enquanto no PB apenas um segmento nesta posição conta como sílaba pesada, no inglês somente coda ramificada ou núcleo ramificado constituem o peso.
} 
se trata de um caso de marcação paramétrica ou de transferência (positiva) da L1 para a L2.

Listando alvos específicos, pretende-se observar:

I. Se os aprendizes aplicarão a regra de assimilação de vozeamento regressiva, característica do português, ou progressiva, característica do inglês e, nesse caso, com os condicionamentos morfológicos relevantes.

II. Se os falantes brasileiros de inglês como L2 aplicarão a regra de retração de acento da mesma forma que um falante nativo da língua (i.e., tanto na aplicação da regra quanto no parâmetro acústico envolvido).

III. Se os aprendizes aplicarão a regra de acento do inglês ou do português ao se depararem com palavras reais e logatomas que possuem características de palavras existentes na língua inglesa com estruturas silábicas diferentes do português.

IV. Se os falantes de nível avançado apresentarão uma taxa de acertos maior do que os falantes de nível básico e intermediário, o que permitirá analisar o estado inicial, o desenvolvimento e o estágio final da gramática dos aprendizes com relação a cada um dos fenômenos em questão.

V. Se a idade de início da aquisição da L2 tem alguma influência na produção dos fenômenos estudados.

A partir dos objetivos propostos acima e da discussão sobre o papel da GU e da L1 na aquisição de segunda língua no Capítulo 2, as hipóteses que norteiam esta pesquisa são as seguintes:

I. A GU continuará disponível durante a aquisição de L2 (cf. White, 2003, Meisel, 2011), mas a aquisição partirá da gramática da L1, o que explicaria a forte influência da L1 sobre a L2, principalmente nos níveis iniciais;

Esta hipótese nos leva à predição de que a modificação de uma regra (i.e., assimilação de vozeamento) será mais difícil de ser adquirida do que uma regra existente de maneira semelhante nas duas línguas (i.e., retração de acento) ou que a marcação de um parâmetro (i.e. sílaba e acento) pois, nesse caso, não há apoio nem na L1 e nem na GU.

II. O nível de proficiência é um fator relevante na aquisição de L2.

Nossa segunda hipótese nos leva à predição de que os falantes de nível avançado apresentarão produções mais semelhantes ao falar nativo do que os falantes dos níveis básico e intermediário. Espera-se que, no nível avançado, os aprendizes tenham sido 
capazes de adquirir as duas regras mencionadas e, ainda, tenham conseguido (re)marcar o parâmetro do acento.

III. Existe um período crítico que afeta a aquisição de L2 (Lenneberg, 1967).

A terceira hipótese, por fim, nos leva à predição de que os falantes que iniciaram a aquisição da L2 antes dos 12 anos apresentarão produções mais semelhantes ao modo de falar nativo.

Levando em conta os três fenômenos em análise, nossas hipóteses levam às seguintes previsões a respeito do papel da L1 e da GU no processo de aquisição dos fenômenos estudados:

\section{Quadro 4: Previsões acerca da aquisição das três regras}

\section{POSSIBILIDADES DE} AQUISIÇÃO

Retração de acento mais fácil de adquirir do que assimilação de vozeamento e relação entre sílaba e acento

Relação entre sílaba e acento mais fácil de adquirir do que retração de acento e assimilação de vozeamento

Assimilação de Vozeamento mais fácil de adquirir do que retração de acento e relação entre sílaba e acento.

Retração de Acento e relação entre sílaba e acento mais fáceis de adquirir do que assimilação de vozeamento.

Retração de Acento e assimilação de vozeamento mais fáceis de adquirir do que relação entre sílaba e acento.

Assimilação de vozeamento e relação entre sílaba e acento mais fáceis de adquirir do que retração de acento

Retração de acento e relação entre sílaba e acento mais fáceis que assimilação de vozamento

\section{PAPEL DA GU E DA L1}

Aquisição parte da língua materna, que permite a transferência da regra de retração da L1 para a L2.

Aquisição parte da GU, que permite que a parametrização do acento ocorra antes da transferência da retração de acento da L1 e da modificação da regra de assimilação de vozeamento.

Nem a L1 e nem a GU são as principais influências no processo de aquisição, já que a regra de assimilação de vozeamento progressiva é o único caso em que nem a L1 e nem a GU têm papel facilitador.

A GU permite a marcação do parâmetro do acento e a L1 permite a transferência da regra de retração de acento, enquanto assimilação de vozeamento não tem apoio nem na GU e nem na L1.

Transferência da L1 para aquisição da retração de acento e de outros fatores que não envolvem nem a L1 e nem a GU para modificar uma regra fonológica.

Não há transferência da L1. A GU permite a parametrização do acento e a assimilação de vozeamento é adquirida por outros fatores que não envolvem, necessariamente, a GU ou a L1.

A aquisição é guiada pela GU e a L1, o que permite a parametrização e a transferência. 
Os três processos são adquiridos de forma semelhante, não há mais fácil ou mais difícil.
A GU e a L1 exercem o mesmo nível de influência durante a aquisição, mas fatores como instrução explícita, motivação e input também exercem uma forte influência sobre a aquisição.

Os Capítulos 4, 5 e 6 a seguir apresentam os estudos referentes à aquisição da regra de assimilação de vozeamento, da retração de acento e da relação entre sílaba e acento. As hipóteses e predições aqui apresentadas serão retomadas no Capítulo 7, que discute os resultados obtidos nesta pesquisa. 


\section{Capítulo 4}

\section{ASSIMILAÇÃO DE VOZEAMENTO}

Este capítulo apresenta o estudo referente à regra de assimilação de vozeamento, que existe tanto no inglês quanto no Português, mas de maneira diferente. A Seção 4.1 caracteriza a regra nas duas línguas e apresenta dois trabalhos desenvolvidos sobre o tema. A Seção 4.2 apresenta a metodologia empregada no desenvolvimento desta pesquisa. Os resultados são apresentados em 4.3 e, por fim, a Seção 4.4 apresenta uma discussão a respeito dos resultados referentes à aquisição da regra.

\subsection{A regra de assimilação de vozeamento}

O processo de assimilação consiste na extensão de uma propriedade (como a nasalidade e o vozeamento) de um segmento para outro segmento adjacente, e esse processo pode ocorrer de forma progressiva ou regressiva. A assimilação progressiva consiste no espraiamento de um ou mais traços de um segmento para outro que o sucede. No inglês, por exemplo, como veremos na Seção 4.1 .1 a seguir, o vozeamento do morfema -s em final de palavra é nfluenciado pelo contexto precedente (ex: cat[s]; $\operatorname{dog}[z]$ ), o que caracteriza a assimilação progressiva. A assimilação regressiva, por sua vez, caracteriza-se pela extensão de um ou mais traços de um segmento para outro que o antecede. No PB, por exemplo, a fricativa /s/ em posição de coda sofre um processo de assimilação regressiva diante de segmento vozeado (ex: pe[s]te; de[z]de), conforme veremos em 4.1.2.

De acordo com Lombardi (1999, p. 6), a assimilação progressiva é um processo raro e geralmente restrito a contextos morfológicos ou fonológicos específicos:

Progressive voicing assimilation always has additional morphological or phonological restrictions, showing the activity of additional constraints; there are no languages where we can simply say that whenever two obstruents come together, they show progressive voicing assimilation.

Segundo a autora, em línguas como o inglês, o iídiche e o holandês a assimilação progressiva está sempre condicionada a restrições morfológicas ou fonológicas. Essas 
restrições também foram encontradas em casos de assimilação progressiva no japonês, conforme os dados apresentados em Mester e Ito $(1986)^{8}$ e no grego, de acordo com a pesquisa de Nespor e Vogel (1986, p.23) ${ }^{9}$.

A assimilação regressiva, por outro lado, é descrita por Lombardi (1999) como um processo "normal", comum nas línguas do mundo, e que ocorre de forma sistemática. No português, regras como assimilação de vozeamento, harmonia vocálica, palatalização e nasalização ocorrem de forma regressiva, já que é o contexto seguinte que desencadeia esses processos. ${ }^{10}$ As Seções 4.1.1 e 4.1.2 a seguir descrevem a regra de assimilação de vozeamento no PB e no inglês.

\subsubsection{Assimilação de Vozeamento no Português Brasileiro}

No Português Brasileiro, a fricativa /s/ em posição de coda sofre um processo de assimilação de vozeamento quando seguida de vogal ou consoante vozeada, conforme os exemplos a seguir:
a. a[s]pas
b. po[s]te
c. $\mathrm{a}[\mathrm{s}]$ casas
d. de[z]de
e. pa[z]ma
f. o[z] animais

Pode-se observar em (4) que a assimilação de vozeamento se dá de forma regressiva no $\mathrm{PB}$, pois há um espraiamento do traço [voz] de um segmento para outro que o antecede. Nos exemplos (a), (b) e (c), a fricativa /s/ é seguida das consoantes

\footnotetext{
${ }^{8}$ Os autores observam que o processo ocorre apenas em compostos. Ex: iro (cor) + kami (papel) $\rightarrow$ irogami (papel colorido)

${ }^{9}$ Em Grego, a assimilação progressiva ocorre entre palavras, dentro de palavra ou entre morfemas apenas se a primeira palavra for um artigo e a segunda for um nome.

10 Alguns exemplos de processos que ocorrem na direção oposta do que é esperado no português brasileiro, ou seja, da esquerda para a direita, foram registrados na literatura. Magalhães (2014) apresenta casos de assimilação progressiva pós apagamento da vogal átona não final em palavras como pê[s]e[g]o, que se torna pê[s].[k]o e có[s]e[g]as, que se torna co[s].[k]as. Hora (1990), por sua vez, mostra os casos de palavras como "doido" e "muito", as quais, segundo o autor, são produzidas como do[dz]o e mu[t]]o por influência do [i] que antecede as consoantes que sofreram a palatalização. Esses casos são bastante específicos e confirmam a observação de Lombardi (1996) de que, nas línguas do mundo, o processo de assimilação regressiva é mais comum e a assimilação progressiva é rara e mais restrita.
} 
surdas [p], [t] e [k] e, portanto, ocorre de maneira desvozeada. Nos exemplos (d), (e) e (f), por outro lado, o /s/ é produzido de maneira vozeada, por ser adjacente aos segmentos vozeados [d], [m] e [a]. Assim, quando a fricativa antecede uma consoante não vozeada, é produzida como [s] (ou seu alofone [S], em dialetos como o carioca), quando antecede uma consoante vozeada ocorre como [z] (ou seu alofone [3]), e quando antecede uma vogal ocorre sistematicamente como [z], tanto dentro de palavras (cf. (d) e (e)) quanto entre palavras (cf. (f)).

A assimilação de vozeamento, assim como a assimilação de outros traços, tem forte motivação fonética. Entretanto, também existem condicionamentos fonológicos específicos de cada língua que determinam de que maneira esse processo irá acontecer. No grego, por exemplo, a regra de vozeamento ocorre apenas no domínio do sintagma entoacional, enquanto no espanhol ocorre apenas no domínio do enunciado fonológico (cf. Nespor e Vogel, 1986). Já no caso da regra do PB, que é consenso nos estudos em fonologia do português (Bisol, 2005; Câmara Jr., 1972), não há um condicionamento prosódico específico. A regra ocorre tanto dentro de palavras (ex: me[z]mo, de[z]de) quanto entre palavras (ex: o[z] animais) e é evitada apenas em situações de pausa silenciosa (ex: o[s]... animais). Pode-se dizer, portanto, que o único som obstruinte possível de ser produzido antes de uma pausa no PB é a fricativa [s] (ou seu alofone [J]). Sendo este um som não vozeado, pode-se afirmar que nenhuma obstruinte vozeada é produzida em final de palavra no PB quando seguida de uma pausa (Zimmer, Silveira e Alves 2009).

Para verificar as características acústicas do /s/ em posição final no português, Zanfra (2013) realizou uma análise acústica dessa fricativa seguida de palavra iniciada em vogal, em consoante vozeada, em consoante desvozeada e seguida de pausa na fala de 23 brasileiros. Os resultados mostraram que o /s/ foi produzido como [s] em 100\% dos casos de fricativa seguida de pausa ou consoante desvozeada, e como [z] em 96,88\% dos casos de fricativa seguida de vogal ou consoante vozeada. Segundo a autora, os casos em que a fricativa não foi vozeada quando seguida de contexto sonoro $(3,12 \%$ dos dados) podem ter sido influenciados pelo próprio método de coleta, que se deu através da leitura de frases. Neste tipo de tarefa é comum que os participantes falem de maneira mais cuidadosa e mais lenta, o que pode ter resultado em pequenas inserções de pausas entre a palavra alvo e o contexto seguinte. Desse modo, o trabalho de Zanfra (2013) traz 
evidências acústicas de que a assimilação de vozeamento regressiva é, de fato, uma regra categórica no PB.

\subsubsection{Assimilação de vozeamento em inglês}

Diferentemente do que ocorre no PB, a produção de [s] ou [z] em final de palavra possui caráter fonológico no inglês, pois caracteriza a distinção de significado, conforme os pares mínimos a seguir:
a. bus [b/s] ônibus buzz [bız] zumbido
b. fence [fEns] cerca fens [fEnz] brejo
c. his [hiz] dele hiss [his] assovio

No que diz respeito à assimilação de vozeamento, o inglês apresenta dois tipos de processo: a assimilação regressiva e a progressiva. A assimilação regressiva ocorre na língua quando fricativas sofrem desvozeamento diante de obstruintes surdas, como nos exemplos a seguir:

(6) a. [faiv] five (cinco)

b. [faif tons] five tons (cinco toneladas)

Pode-se observar em (6b) que o [v] perde o traço [+voz] diante de [t] por assimilar o vozeamento do contexto seguinte, o que caracteriza a assimilação regressiva (Roca e Johnson, 1999).

A assimilação progressiva, por sua vez, ocorre quando a fricativa /z/ é precedida de um segmento desvozeado. Nos exemplos em (7), extraídos de Yavas (2006, p. 63), podemos observar que o morfema de plural, do caso genitivo e da $3^{\underline{a}}$ pessoa do Presente Simples pode ser produzido como [s], [z] ou [iz], dependendo do segmento precedente:

$\begin{array}{ll} & \text { Plural } \\ \text { a. }[\mathrm{s}] & \text { cats [kæts] } \\ \text { b. }[\mathrm{z}] & \text { dogs [dəgz] } \\ \text { c. }[\mathrm{iz}] & \text { buses [b [bzə] }\end{array}$

\section{Caso Genitivo}

[s] Jack's

[z] John's

[iz] George's

\section{Presente Simples}

[s] s/he jumps

[z] s/he runs

[iz] s/he catches

Os exemplos mostram que o morfema é produzido como [s] quando precedido de segmentos não vozeados (ex.: cat[s]) e como [z] quando precedido de segmentos 
vozeados (ex.: $\operatorname{dog}[z])$, o que caracteriza a assimilação progressiva. Por fim, quando tal morfema é precedido de uma sibilante, realiza-se como [iz] (ex.:bus[iz]).

Para mostrar que no inglês a assimilação de vozeamento do morfema -s é determinada pelo segmento precedente e não pelo seguinte, Silva (2010, p. 34) apresenta os exemplos a seguir, nos quais as palavras cats, cat's, watches, dogs e laws mantêm sua sonoridade determinada pelo segmento anterior mesmo quando seguidas de um segmento que difere de sua característica quanto ao traço [voz]. Observa-se que em (8a) e (8b) as fricativas permanecem surdas, apesar de estarem seguidas de segmentos vozeados. Em (9c), (9d) e (9e), por outro lado, a fricativa permanece sonora mesmo quando seguida de elementos surdos.
a. cat[s] on the roof
(gatos no telhado)
b. cat' $[\mathrm{s}]$ ball
(bola do gato)
c. she wa[tyz] TV
(ela assiste TV)
d. $\operatorname{dog}[\mathrm{z}]$ painting
(pintura de cachorro)
e. law $[\mathrm{z}]$ court
(tribunal de justiça)

É importante salientar, por fim, que enquanto a assimilação regressiva ocorre de maneira generalizada na língua (cf. (6)), o vozeamento progressivo é restrito ao domínio da palavra fonológica e aos três contextos morfológicos mencionados.

\subsubsection{Aquisição da regra do inglês por falantes brasileiros}

Vimos em 4.1.1 e 4.1.2 que o processo de assimilação de vozeamento do ocorre tanto no PB quanto no inglês, mas de maneira diferente. Enquanto no PB a assimilação ocorre de maneira regressiva, pois é influenciada pelo vozeamento do contexto seguinte, no inglês a regra ocorre de maneira progressiva, pois a fricativa torna-se desvozeada em decorrência do contexto precedente. Além disso, vimos que, enquanto no PB essa regra não é condicionada por nenhum contexto morfológico ou fonológico específico, em inglês ela ocorre somente nos morfemas de plural, de $3^{a}$ pessoa do singular e no caso genitivo, sob o domínio da palavra fonológica.

Há poucos estudos sobre a aquisição de fricativas vozeadas em posição final do inglês por falantes do PB. Dentre eles, destacamos as pesquisas de Zanfra (2013), sob a 
perspectiva da produção, e de Mendes (2017), que investigou a percepção dessas fricativas.

Zanfra (2013) analisou a aquisição de /s/ e /z/ em final de palavras do inglês por aprendizes brasileiros considerando o papel do nível de proficiência, do contexto fonológico seguinte e da ortografia. Sua pesquisa investigou a produção dessas fricativas por 23 falantes adultos de nível intermediário e avançado em diferentes contextos fonológicos: seguidas de pausa, de consoante desvozeada, de vogal e de consoante vozeada. A influência da ortografia foi investigada através da inserção de palavras terminadas com a letra "e" (ex: these, lose) e terminadas com a letra "s" (ex: does, moves) no instrumento de coleta, que continha 54 sentenças em inglês. A hipótese era de que o vozeamento seria mais frequente em palavras terminadas com o grafema "e" do que naquelas terminadas em "s". Os resultados mostraram que a ortografia teve um papel significativo na produção dos informantes, já que houve mais vozeamento do -s em palavras que continham o grafema "e" no final de palavra. 0 contexto fonológico também se mostrou relevante: em palavras como $b u / s /$, por exemplo, em que a fricativa não é vozeada no inglês, os informantes brasileiros aplicaram o vozeamento quando o contexto seguinte era sonoro e não aplicaram quando o contexto seguinte era uma pausa ou uma consoante surda. Os resultados também mostraram que o nível de proficiência dos participantes não foi significativo, já que tanto os sujeitos de nível intermediário quanto de nível avançado transferiram a regra de vozeamento do português para o inglês.

O trabalho de Mendes (2017), por sua vez, investigou a percepção do morfema -s do inglês por brasileiros falantes de inglês como L2, levando em consideração o papel do contexto fonológico seguinte, o tempo de tarefa, o nível de confiança e o nível de proficiência dos sujeitos. Os dados foram coletados através de um teste de percepção com 120 frases, cada uma com uma palavra-alvo com as diferentes realizações do -s: [s], [z], e [Iz]. O material de áudio foi gravado por um falante nativo de inglês e 33 aprendizes de inglês, divididos em três níveis de instrução formal, foram submetidos ao teste. Os resultados encontrados pelo autor mostraram que, dentre os três alomorfes testados ([s], [z] e [Iz]), o [z] foi o que apresentou a taxa de acertos mais baixa (39\%), sobretudo nos casos de fricativa seguida por contexto desvozeado ou pausa. Seus resultados mostram, deste modo, que o contexto seguinte parece desempenhar um papel importante na percepção do morfema -s, pois o percentual de acertos na 
identificação do [z] foi mais alto nos casos de fricativa seguida de consoante sonora ou vogal.

Assim como na pesquisa de Zanfra (2013), pretendemos investigar a produção de fricativas vozeadas em posição de final de palavra no inglês por falantes brasileiros. Contudo, enquanto o trabalho da autora inclui casos em que o /z/ pertence ao radical da palavra (ex: these, lose) e não controla o papel do contexto morfológico sobre o vozeamento, nos dedicamos exclusivamente aos casos em que o vozeamento é resultado de assimilação progressiva, quando a fricativa se encontra em fronteira morfológica (-s de $3^{\text {a }}$ pessoa do singular, de plural e do caso genitivo). Devido à importância do segmento que antecede a fricativa para a aplicação da regra progressiva, também investigamos o papel do contexto precedente, o que não foi controlado em nenhum dos dois estudos mencionados. Desse modo, pretendemos analisar não apenas os contextos fonológicos que influenciam a aplicação da regra do inglês, mas também o papel do contexto morfológico.

\subsection{Metodologia}

Esta seção apresenta a metodologia empregada nesta pesquisa para investigar a aquisição da regra de assimilação de vozeamento progressiva do inglês por falantes brasileiros. Nas seções a seguir, serão abordados os seguintes aspectos: os participantes da pesquisa e o teste de nivelamento em 4.2.1; o desenho do experimento em 4.2.2; os procedimentos da coleta em 4.2.3; os critérios e métodos para a verificação acústica em 4.2.4 e, finalmente, as variáveis consideradas para a análise dos dados e a metodologia estatística em 4.2.5.

\subsubsection{Informantes e nivelamento}

Esta pesquisa foi registrada e aprovada pelo Comitê de Ética do Instituto de Psicologia da Universidade de São Paulo sob o título "Aquisição Fonológica de Segunda Língua", número CAAE 46139815.1.0000.5561.

Os informantes são 30 falantes brasileiros de inglês como L2 e 7 falantes nativos da língua. Antes do início da gravação, todos os sujeitos foram entrevistados com base nas seguintes informações solicitadas na Ficha Social (Anexo 1): nome, idade, cidade de 
nascimento, escolaridade, profissão e, no caso dos falantes não-nativos, tempo de experiência com a L2, idade em que começou a aprender inglês, experiência em país falante de língua inglesa, quantidade de exposição à língua inglesa no cotidiano, experiência em aulas de pronúncia do inglês e domínio de outra(s) língua(s) estrangeira(s).

Os informantes são todos ex-alunos ou conhecidos da pesquisadora. Os critérios para a seleção dos 30 falantes não-nativos nesta pesquisa foram os seguintes:

- Não ter morado em país falante de inglês por mais de um mês

- Ser filho de pais brasileiros monolíngues

- Não falar nenhuma outra língua estrangeira além do inglês

- Ter concordado e assinado o Termo de Consentimento Livre e Esclarecido (Anexo 2).

Além desses informantes, esta pesquisa conta com um grupo de 7 falantes nativos de inglês que viveram a maior parte da vida em seus países de origem, cujos dados foram utilizados como uma amostra de controle. Dentre esses falantes nativos, dois são ingleses e vivem no Brasil há cerca de 15 anos, dois são australianos e vivem no Brasil há cerca de 8 anos e três são estadunidenses e nunca vieram ao Brasil.11

A amostra analisada é do tipo aleatória estratificada, quando a população é dividida em subgrupos (estratos) e uma subamostra é selecionada a partir de cada estrato da população (Levin e Fox, 2004). Dois fatores foram considerados para a escolha dos sujeitos: o nível de proficiência (básico, intermediário e avançado) e a idade do início do contato formal com a L2, de modo a verificar se os participantes que iniciaram a aquisição até os 12 anos apresentam uma produção mais próxima à nativa com base na Hipótese do Período Crítico (cf. Seção 2.4.1).

No caso dos falantes brasileiros, foi determinado o número de 5 participantes por célula, totalizando 30 informantes, além dos 7 falantes nativos já mencionados, conforme o Quadro 5 a seguir:

\footnotetext{
${ }^{11}$ Até onde sabemos, para o estudo dos fenômenos em questão, as diferentes variantes da língua inglesa não apresentam qualquer tipo de influência.
} 
Quadro 5: Distribuição dos informantes

\begin{tabular}{|c|c|c|}
\hline $\begin{array}{c}\text { NÍVEL DE } \\
\text { PROFICIÊNCIA }\end{array}$ & $\begin{array}{c}\text { INÍCIO DO CONTATO } \\
\text { FORMAL COM A L2 }\end{array}$ & $\begin{array}{c}\text { No DE } \\
\text { INFORMANTES }\end{array}$ \\
\hline \multirow{2}{*}{ Básico } & Antes dos 12 anos. & 5 \\
& Após os 12 anos & 5 \\
\hline \multirow{2}{*}{ Intermediário } & Antes dos 12 anos. & 5 \\
& Após os 12 anos & 5 \\
\hline \multirow{2}{*}{ Avançado } & Antes dos 12 anos. & 5 \\
& Após os 12 anos & 5 \\
\hline Controle & Falantes Nativos de inglês & 7 \\
\hline
\end{tabular}

O nivelamento dos informantes nos três grupos (básico, intermediário e avançado) foi realizado com base no Common European Framework of Reference for Languages (CEFRL ${ }^{12}$ ), documento elaborado pelo Conselho Europeu que permite a avaliação do conhecimento linguístico de aprendizes de qualquer idioma (Council of Europe, 2001). Atualmente, seus seis níveis de referência são amplamente aceitos para avaliar o conhecimento dos aprendizes de L2 não só na Europa, mas em diversos países. No CEFRL o conhecimento do falante é dividido em três categorias, cada uma com duas subdivisões, conforme o Quadro 6 a seguir:

\section{Quadro 6: Distribuição dos informantes por nível de proficiência}

\begin{tabular}{|c|c|c|}
\hline A: Falante Básico & B: Falante IndePEndente & C: FAlAnTE PRoficientE \\
\hline $\begin{array}{c}\text { A1 Iniciante } \\
\text { A2 Básico }\end{array}$ & B1 Intermediário & $\begin{array}{c}\text { C1 Proficiência eficaz } \\
\text { C2 Domínio pleno }\end{array}$ \\
\hline
\end{tabular}

Para avaliar o desenvolvimento dos fenômenos analisados nesta pesquisa, foram determinados três níveis de proficiência: básico (A2), intermediário (B1) e avançado (C1). A escolha desses três níveis se deu por acreditarmos que no nível A1 os participantes não teriam conhecimento suficiente para realizar as tarefas propostas neste estudo e, além disso, por haver uma distância significativa entre cada nível.

Os participantes foram nivelados em duas etapas: um teste online baseado em questões de múltipla escolha e um teste de proficiência oral, ambos oferecidos

\footnotetext{
${ }^{12}$ Quadro Europeu Comum de Referência para Línguas
} 
gratuitamente no site de Cambridge ${ }^{13}$. Optou-se pela combinação desses dois testes porque um teste escrito poderia indicar o nível de conhecimento gramatical do participante, mas não a sua habilidade oral.

0 teste online contém 25 perguntas de múltipla escolha sobre gramática, vocabulário e uso da língua inglesa e indica, automaticamente, uma estimativa do nível do participante de acordo com o CEFRL. 0 resultado desse teste serviu de base para a escolha do teste oral, que avalia aspectos como a habilidade interagir com o examinador, a pronúncia e o vocabulário do aprendiz. Assim, se o teste online indicava que o nível do participante era B1, por exemplo, era aplicado um teste oral relativo a esse nível.

Originalmente, os testes orais de Cambridge são conduzidos com dois ou três candidatos ao mesmo tempo e na presença de dois examinadores: um interlocutor, que conduz o teste, e um assessor, que não participa da interação e avalia a produção dos candidatos. Os testes têm a duração de cerca de 15 minutos e são divididos em quatro partes. A primeira é uma entrevista rápida na qual os candidatos respondem perguntas simples sobre a cidade onde vivem, família, estudos e planos futuros. Na segunda parte, cada participante fala individualmente por cerca de 1 minuto sobre um determinado assunto proposto pelo examinador. Na terceira, os dois (ou três) candidatos devem interagir e demonstrar capacidade de sustentar suas opiniões e tomar decisões. Por fim, na quarta parte, os candidatos devem concordar ou discordar dos temas propostos pelo examinador de maneira mais aprofundada do que nas partes anteriores do teste. A nota do teste oral varia de 0 a 5 pontos, conforme o exemplo no Anexo 3.

Nesta pesquisa, os testes foram conduzidos individualmente e, portanto, não incluíram a Parte 3, que envolve a interação entre os candidatos. Além disso, foram conduzidos por apenas uma "examinadora", a pesquisadora, que já tinha experiência neste tipo de avaliação. Como o objetivo dos testes nesta pesquisa não era atribuir uma nota e sim dividir os participantes em três níveis de proficiência, a avaliação foi feita da seguinte forma: se o participante apresentasse um desempenho oral inferior ao esperado para o nível indicado pelo teste de múltipla escolha, era considerado o nível do teste oral, e não do teste online. Por exemplo, se o teste online indicava nível intermediário (B1) e o participante obtinha nota 1 (a mais baixa) no teste oral, consideramos que seu nível era básico (A1). Caso ele apresentasse um desempenho oral acima do esperado para o nível indicado pelo teste online, por outro lado, consideramos

\footnotetext{
${ }^{13}$ www.cambridgeenglish.org
} 
que o nível do participante era o avançado (C1). Os critérios para o nivelamento dos participantes são resumidos no Quadro 7 a seguir.

Quadro 7: Critérios para nivelamento dos participantes

\begin{tabular}{|c|c|c|c|}
\hline $\begin{array}{c}\text { RESULTADO D0 } \\
\text { TESTE ONLINE }\end{array}$ & $\begin{array}{c}\text { TESTE ORAL } \\
\text { APLICADO }\end{array}$ & $\begin{array}{c}\text { DESEMPENHO NO TESTE } \\
\text { ORAL }\end{array}$ & $\begin{array}{c}\text { RESULTADO DO } \\
\text { NIVELAMENTO }\end{array}$ \\
\hline A2 & A2 & $\begin{array}{c}\text { Nota de } 1 \text { a } 4 \\
\text { Nota } 5 \text { com ótimo } \\
\text { desempenho }\end{array}$ & $\begin{array}{c}\text { Básico } \\
\text { Intermediário }\end{array}$ \\
\hline B2 & B2 & $\begin{array}{c}\text { Nota } 1 \\
\text { Nota de } 2 \text { a } 4 \\
\text { Nota } 5 \text { com ótimo } \\
\text { desempenho }\end{array}$ & $\begin{array}{c}\text { Básico } \\
\text { Intermediário } \\
\text { Avançado }\end{array}$ \\
\hline C1 & C1 & Nota 1 & Intermediário \\
Nota de 2 a 5 & Avançado \\
\hline
\end{tabular}

\subsubsection{Desenho do experimento}

Como dissemos em 4.1, neste trabalho lidamos com casos de assimilação de vozeamento progressiva do inglês, que afeta a fricativa /z/ em posição de final de palavra. A ideia inicial para a coleta dos dados para assimilação de vozeamento seria a contação de uma história (pela pesquisadora) e a recontação dessa história (pelos participantes), contendo palavras com exemplos de assimilação progressiva, para evitar ao máximo a influência da escrita. Entretanto, o procedimento foi alterado por acreditarmos que os falantes de nível básico não teriam conhecimento suficiente para recontar a história de memória.

Optou-se, portanto, pela leitura de 28 frases que incluem 60 palavras com contexto para regra de assimilação progressiva, característica da língua inglesa, isto é, palavras com um segmento sonoro precedendo o morfema -s nas quais a fricativa deveria ser vozeada. As palavras analisadas foram incluídas em dois tipos de contexto: em 14 frases incluímos 30 palavras seguidas de segmentos vozeados, nas quais o vozeamento do -s poderia ser influenciado pela regra de assimilação regressiva do PB (ex: Jack live[z] in the countryside); nas 14 frases restantes, foram incluídas 30 palavras seguidas de consoantes desvozeadas ou de pausas, nas quais o vozeamento do -s não poderia ser resultado da regra do PB (ex: Susan read Pam'[z] paper[z]). Nesses casos, o 
vozeamento do -s seria um indicativo da aquisição da regra de assimilação progressiva do inglês.

As frases criadas para a verificação da assimilação de vozeamento são apresentadas no Quadros 8 seguir.

Quadro 8: Frases para a investigação da assimilação de vozeamento progressiva ASSIMILAÇÃO PROGRESSIVA SEGUIDA DE SEGMENTO VOZEADO

1. Jack live[z] in the countryside with hi[z] brother.

2. John'[z] uncle love[z] drinking wine.

3. Jack love[z] everything related to storie[z] now.

4. Mary love[z] all kind[z] of animal[z] in the world.

5. John has three $\operatorname{dog}[\mathrm{z}]$ and one cat.

6. He open[z] all the window[z] of the house and ha[z] breakfast.

7. He feed[z] the dog[z] and the cat.

8. She wa[z] extremely tired, but wa[z] very happy.

9. Mary' $[\mathrm{z}]$ book i[z] very interesting.

10. The kid[z] were playing with John'[z] ball.

11. Paul' $[z]$ afraid of bug[z] and crie[z] when he see[z] one.

12. Many time[z] the brother[z] argue.

13. Jack leave[z] all his thing $[\mathrm{z}]$ around the house.

14. John' $[\mathrm{z}]$ videogame is an old one.

\section{ASSIMILAÇÃO PROGRESSIVA SEGUIDA DE SEGMENTO DESVOZEADO OU PAUSA}

1. I saw two little bird[z] playing with the kid[z].

2 . The boy[z] play game[z] together everyday.

3. My brother' $[\mathrm{z}]$ friend bought new shoe[z].

4. Yesterday I gave bird[z]' food to the $\operatorname{dog}[\mathrm{z}]$.

5. She leave[z] tomorrow to see her sister[z].

6. I read only the first page[z].

7. She run[z] ten kilometer[z] per hour.

8. Susan read Pam'[z] paper[z].

9. The girl[z] pointed out that they love movie[z].

10. My boyfriend' $[\mathrm{z}]$ father love[z] playing the piano.

11. I disagree with those price[z].

12. She believe[z] Peter'[z] cousin love[z] Cathy.

13. I bought apple[z], tomatoe[z], potatoe[z], pear[z]...

14. Here is what we need: jean[z], coral shoe[z], purple windbreaker[z].

\subsubsection{Coleta}

As gravações foram realizadas na cidade de São Paulo em locais silenciosos como salas de aula da universidade e a casa dos participantes por meio do software Audacity. 
Foi utilizado um microfone de baixa impedância da marca Behringer, um pedestal de mesa e uma placa acústica Roland Quad-capture ${ }^{14}$.

As sentenças do experimento foram apresentadas através de slides no Microsoft Power Point, em ordem aleatória. Os participantes controlavam através de cliques a velocidade e a alternância das ocorrências, de modo que cada palavra e cada frase fosse apresentada individualmente, evitando-se, assim, qualquer tipo de "desconfiança" por parte do informante sobre quais seriam os fenômenos investigados. ${ }^{15}$

Todos os participantes foram instruídos a ler cada uma das ocorrências da maneira mais natural possível. Em casos de erro na leitura, na altura da voz, na distância do microfone ou de pausas excessivas durante a produção das frases, solicitou-se que os participantes repetissem a ocorrência uma ou mais vezes, até que o problema fosse corrigido.

\subsubsection{Verificação Acústica: Assimilação de Vozeamento}

A verificação acústica de todos os dados investigados neste trabalho foi conduzida por meio do software Praat, versão 5.4.06, desenvolvido por Paul Boersma e David Weenink, do Institute of Phonetic Sciences da Universidade de Amsterdã.

Para a análise da assimilação de vozeamento, é preciso que observemos as características das consoantes fricativas, as quais são produzidas através de uma constrição estreita no trato vocal que gera o som da fricção. Essa energia produzida aparece no espectrograma em um padrão irregular, sem linhas horizontais ou verticais regulares. De modo geral, observa-se que as fricativas surdas possuem maior duração do que as sonoras (Reetz e Jongman 2009, p. 192).

Frequência e duração são, portanto, correlatos acústicos relevantes para a distinção entre fricativas surdas e sonoras. Contudo, o correlato mais importante neste trabalho é o vozeamento. Assim como Silva (2010), optamos por determinar a

\footnotetext{
${ }^{14}$ Com exceção dos 3 falantes nativos de inglês, que moram nos Estados Unidos. Nesses casos, os dados foram coletados a distância, com o gravador Olympus VN-120 Digital Rec.Bulk, mas obedecendo os mesmos critérios estabelecidos para os outros 34 participantes da pesquisa.

${ }^{15}$ Salientamos que a coleta dos dados referentes aos três fenômenos investigados nesta pesquisa (assimilação de vozeamento, retração de acento e sílaba e acento) se deu através de uma única gravação. As palavras e frases referentes aos três fenômenos foram apresentados em ordem aleatória utilizando-se uma única apresentação de slides. Após a coleta, os arquivos de áudio foram separados para que a análise dos dados pudesse ser desenvolvida. As palavras e frases referentes à Retração de Acento e a Sílaba e Acento serão apresentadas nos Capítulos 5 e 6 a seguir.
} 
sonoridade da fricativa na verificação acústica através da observação da faixa de vozeamento localizada na parte inferior do espectrograma e, além disso, a presença de pulsos glotais durante a produção da fricativa. Enquanto as fricativas vozeadas apresentam pulsos periódicos, as fricativas desvozeadas apresentam apenas um ruído contínuo caracterizado pela passagem de ar. Utilizamos, ainda, uma terceira evidência para determinar a sonoridade das fricativas: a curva de F0 (Frequência Fundamental), que nas fricativas sonoras se mostra contínua e nas fricativas surdas é interrompida.

A Figura 1 a seguir mostra o espectrograma de uma fricativa sonora produzida por um falante de nível avançado. É possível observar a barra de sonoridade, os pulsos glotais e a curva de F0.

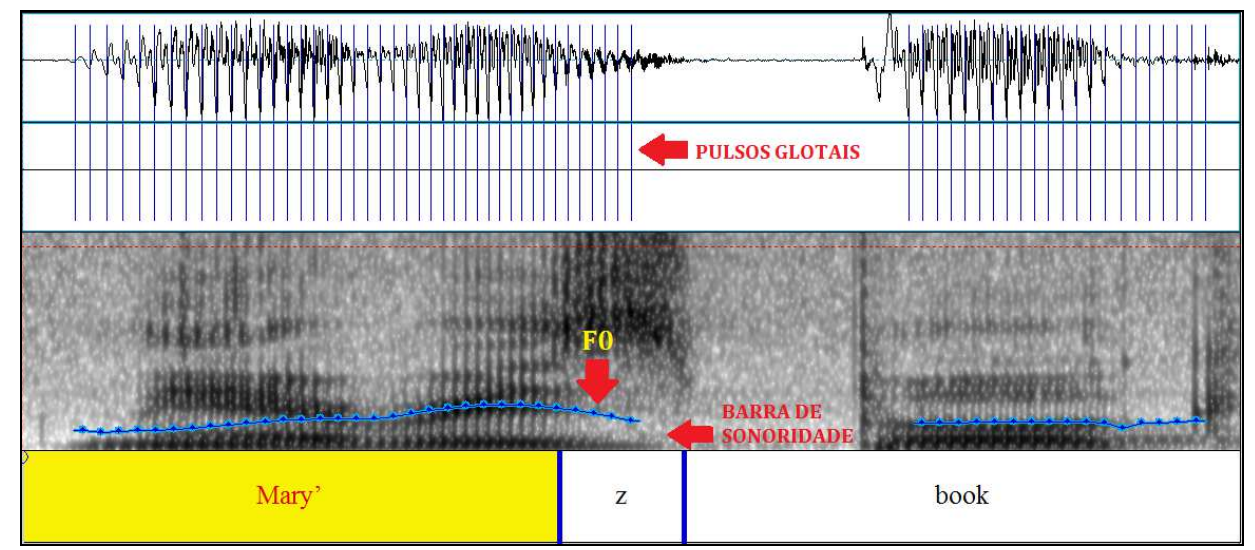

Figura 1: Fricativa sonora produzida por um falante de nível avançado

A Figura 2, por sua vez, mostra o espectrograma de uma fricativa surda produzida pelo mesmo falante. É possível observar a ausência da barra de sonoridade, dos pulsos glotais e a interrupção da curva de F0.

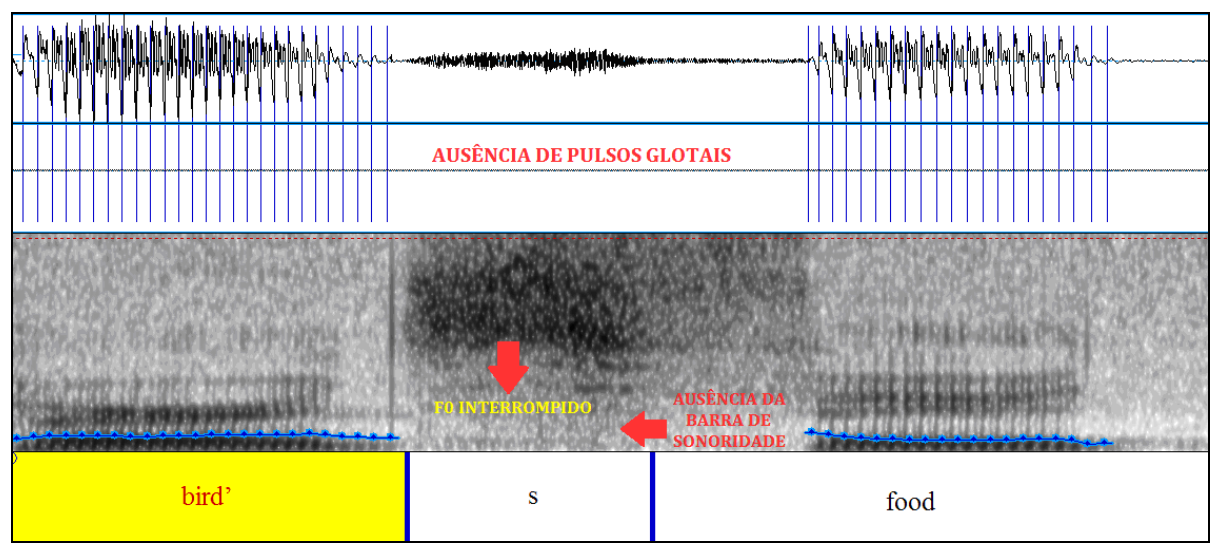

Figura 2: Fricativa surda produzida por um falante de nível avançado. 
Portanto, os correlatos acústicos utilizados para a distinção de uma fricativa surda de uma sonora neste trabalho são: a barra de vozeamento localizada na parte inferior do espectrograma, a presença ou ausência de pulsos glotais e a curva de F0, que é contínua nas fricativas vozeadas, e interrompida nas desvozeadas.

Em alguns casos, entretanto, a distinção entre fricativas vozeadas e desvozeadas de acordo com esses critérios não ficou tão clara, já que os participantes produziram metade da consoante vozeada e a outra metade desvozeada. Em outras palavras, a barra de vozeamento, os pulsos glotais e o F0 foram identificados apenas na primeira metade do -s, como podemos observar na Figura 3 a seguir:

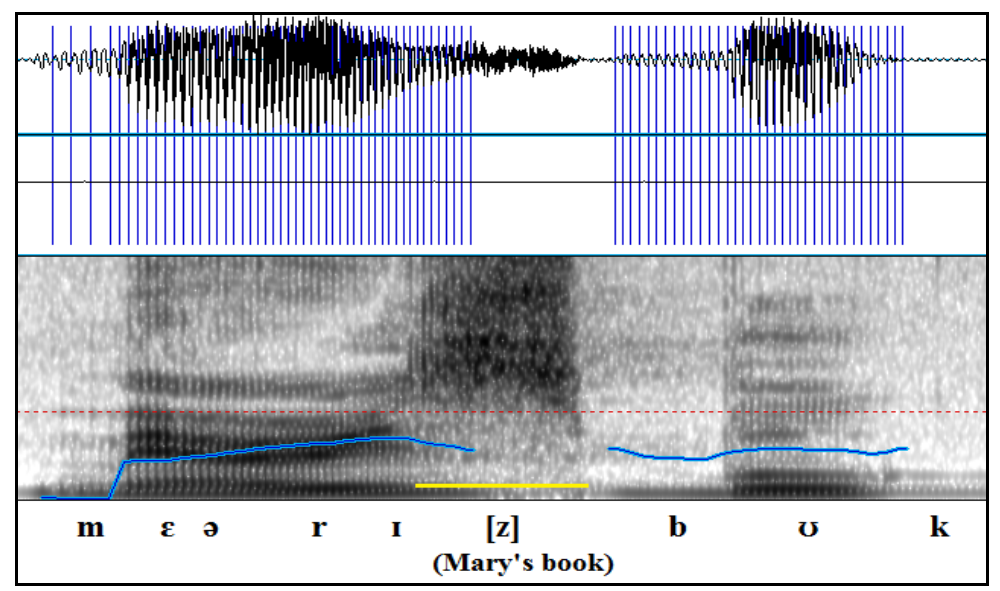

Figura 3: Fricativa produzida por um falante de nível avançado, com a primeira metade vozeada e a segunda metade desvozeada.

Apesar de o vozeamento ocorrer apenas na primeira metade da consoante, as fricativas produzidas dessa forma foram, perceptualmente, identificadas como vozeadas. Portanto, optou-se por classificar essas ocorrências como "vozeadas" por dois motivos: 1) há uma indicação de vozeamento, ainda que parcial; 2) essas fricativas foram percebidas como vozeadas.

\subsubsection{Classificação dos dados e Análise Estatística}

Após definirmos o vozeamento do -s com base nos critérios descritos em 4.2.4, os dados foram codificados para que a análise estatística pudesse ser realizada. Tendo em vista o discutido sobre assimilação de vozeamento, foram controladas as variáveis apresentadas no Quadro 9 a seguir. A variável dependente, que é o conjunto de formas 
em competição com o mesmo valor de verdade (cf. Tarallo 1994, p.8) é, neste caso, a aplicação do vozeamento (vozeado [z] vs. não vozeado [s]). Também são apresentadas a seguir as variáveis independentes, que são aspectos linguísticos ou extralinguísticos que podem condicionar a variável dependente, e os fatores para as formas que cada variável pode adotar.

Quadro 9: Variável Dependente e Variáveis Independentes - Assimilação de Vozeamento

\begin{tabular}{|c|c|c|}
\hline $\begin{array}{c}\text { VARIÁVEL } \\
\text { DEPENDENTE }\end{array}$ & Vozeamento do -s & $\begin{array}{l}{[\mathrm{s}]} \\
{[\mathrm{z}]}\end{array}$ \\
\hline \multirow{6}{*}{$\begin{array}{c}\text { VARIÁVEIS } \\
\text { INDEPENDENTES }\end{array}$} & Contexto Precedente & $\begin{array}{l}\text { Plosiva } \\
\text { Nasal } \\
\text { Fricativa } \\
\text { Vogal }\end{array}$ \\
\hline & Contexto Seguinte & $\begin{array}{l}\text { Consoante Vozeada } \\
\text { Vogal } \\
\text { Consoante Desvozeada } \\
\text { Pausa }\end{array}$ \\
\hline & $\begin{array}{c}\text { Categoria morfológica } \\
\text { do }-s\end{array}$ & $\begin{array}{l}\text { Plural } \\
\text { Caso Genitivo } \\
\text { 3a pessoa do Presente S. }\end{array}$ \\
\hline & Nível de Proficiência & $\begin{array}{l}\text { Básico } \\
\text { Intermediário } \\
\text { Avançado } \\
\text { Falante Nativo }\end{array}$ \\
\hline & $\begin{array}{c}\text { Início da } \\
\text { Aquisição da L2 }\end{array}$ & $\begin{array}{l}\text { Antes dos } 12 \text { anos } \\
\text { Depois dos } 12 \text { anos }\end{array}$ \\
\hline & Informante & $\begin{array}{l}1 \\
2 \\
\cdots \\
30\end{array}$ \\
\hline
\end{tabular}

Ainda que neste trabalho todos os contextos precedentes propostos pelo experimento de coleta sejam de segmentos vozeados (já que o objetivo é verificar a regra de assimilação progressiva), incluímos a variável Contexto Precedente com o 
objetivo de observar a influência do tipo de segmento que antecede a fricativa sobre o vozeamento. Os fatores para essa variável são os seguintes: plosiva (ex: dogs), nasal (ex: John's), fricativa (ex: lives) e vogal (ex: tomatoes).

A variável Contexto Seguinte busca verificar a influência do vozeamento do segmento que sucede a fricativa e é composta pelos seguintes fatores: consoante vozeada (ex: John's dog), vogal (ex: opens all), consoante desvozeada (ex: kids playing) e pausa (boys). Através desta variável, pretende-se observar os casos em que os falantes aplicarão a regra de assimilação de vozeamento regressiva, característica do português, em vez da assimilação progressiva, do inglês.

Com a variável Categoria Morfológica espera-se observar se o fato de o -s corresponder à marca de plural (ex: dogs), ao caso genitivo (John's) ou à terceira pessoa do Presente Simples (reads) influencia, de alguma forma, o vozeamento da fricativa.

A variável Nível de Proficiência tem como objetivo verificar a hipótese de que os falantes de níveis mais avançados apresentarão uma taxa de aplicação da regra mais alta, e é composta por três fatores: básico, intermediário e avançado.

Para verificar o papel da Hipótese do Período Crítico (cf. Seção 2.4), foi incluída a variável Idade do início da aquisição, e os fatores que compõem esta variável são: antes dos 12 anos e depois dos 12 anos.

Com a variável Informante, por fim, pretende-se observar a aplicação da regra por cada participante da pesquisa. Destacamos que esta variável tem caráter descritivo, ou seja, não faz parte da modelagem estatística empregada para a análise de cada fenômeno.

Com relação à assimilação de vozeamento, observa-se a aplicação de dois fenômenos variáveis: a produção de fricativas vozeadas e de fricativas desvozeadas. Para que fosse possível estabelecer quais variáveis influenciam a aplicação do vozeamento, foi utilizado o modelo de regressão logística binomial para medidas repetidas, dado que cada participante do estudo respondeu 28 frases (e pelo menos uma palavra por frase analisada) e a resposta é binária (vozeamento/não vozeamento das fricativas). Para isso, foi utilizado o programa computacional GoldVarb- $\mathrm{X}^{16}$, baseado no pacote Varbrul 25, que parte de uma lista de tokens (ocorrências) codificados para determinado número de fatores. Através da codificação dos fatores, a análise

${ }^{16} \mathrm{O}$ programa pode ser obtido gratuitamente em:

http://individual.utoronto.ca/tagliamonte/goldvarb.htm. 
multidimensional oferecida pelo programa contabiliza de maneira precisa o número de ocorrências, as porcentagens e os pesos relativos, que indicam a probabilidade de aplicação da regra. Os valores dos pesos relativos são sempre números entre 0,00 e 1,00: um valor próximo a 1,00 indica favorecimento à aplicação da regra, um valor próximo a 0,00, pouco favorecimento à aplicação da regra e um valor próximo a 0,50, o ponto neutro, ou seja, o fator em questão não tem efeito sobre a regra.

\subsection{Resultados}

Nesta seção serão apresentados os resultados referentes à assimilação de vozeamento progressiva. A partir dos procedimentos metodológicos explicitados na Seção 4.2 foram obtidos 2.220 dados referentes à regra, incluindo o grupo de controle. Os resultados dos 7 falantes nativos de inglês, que constituem o grupo de controle, são apresentados na Seção 4.3.1 a seguir. Na Seção 4.3.2, são apresentados os resultados referentes aos 30 falantes de inglês como L2.

\subsubsection{Falantes nativos de inglês (grupo de controle)}

A taxa de aplicação do vozeamento pelos sete falantes nativos que constituem a amostra de controle nesta pesquisa pode ser observada no Gráfico 1 a seguir - todos casos em que o vozeamento seria obrigatório em inglês, por influência do contexto precedente.

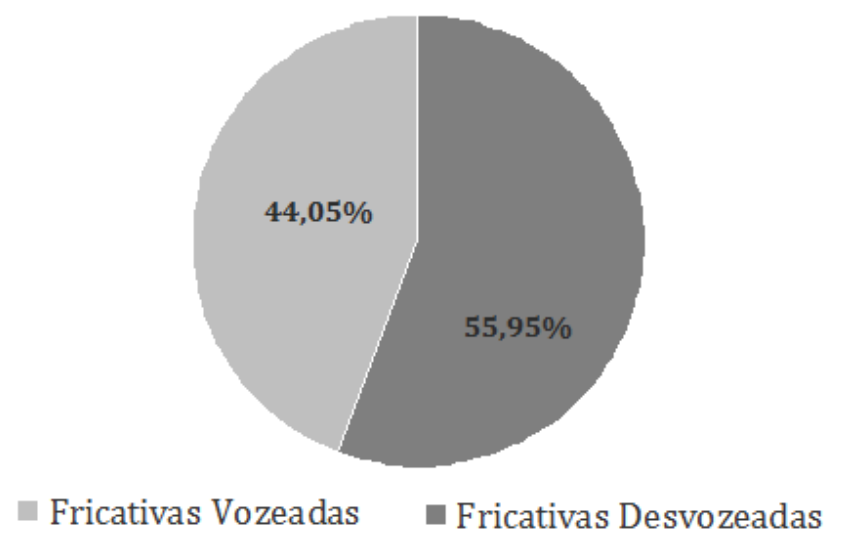

Gráfico 1: Aplicação do vozeamento por falante nativos 
Pode-se observar que os falantes nativos produziram fricativas vozeadas em $44,05 \%$ dos casos (185/420) e fricativas desvozeadas em 55,95\% dos casos (235/420). Dentre as três variáveis testadas, a análise estatística apontou evidências de que apenas Contexto Seguinte influencia o vozeamento. Categoria Morfológica e Contexto Precedente, portanto, não se mostraram estatisticamente significantes nos dados dos falantes nativos desta pesquisa.

A variável Contexto Seguinte, que observa a influência de vogais (ex: loves everything), consoantes vozeadas (ex: Mary's book), consoantes desvozeadas (ex: boys play) e pausas (He bought new shoes. ) sobre o vozeamento, indicou que a aplicação do vozeamento é favorecida quando o contexto seguinte é vozeado. Pode-se observar na Tabela 1 a seguir que os contextos que favoreceram a aplicação do vozeamento foram as vogais e as consoantes vozeadas, com pesos relativos de 0,68 e 0,67, respectivamente. Consoantes desvozeadas e pausas, por outro lado, desfavoreceram a aplicação da regra, com pesos relativos de 0,40 e 0,31, respectivamente, e apresentaram taxas de aplicação do vozeamento significativamente mais baixas, de $35 \%$ e $12,5 \%$.

Tabela 1: Vozeamento de -s e Contexto Seguinte - Falantes Nativos

\begin{tabular}{cccccc}
\hline \multirow{2}{*}{ Contexto Seguinte } & \multicolumn{2}{c}{ Vozeado } & \multicolumn{2}{c}{ Desvozeado } & PESO \\
\cline { 2 - 5 } & $\mathbf{n}$ & $\mathbf{\%}$ & $\mathbf{n}$ & $\mathbf{\%}$ & REL. \\
\hline Vogal & 76 & 61,29 & 48 & 38,71 & 0,68 \\
Consoante Vozeada & 51 & 60,71 & 33 & 39,29 & 0,67 \\
Consoante Desvozeada & 49 & 35,00 & 91 & 65,00 & 0,40 \\
Pausa & 9 & 12,50 & 63 & 87,50 & 0,31 \\
\hline
\end{tabular}

Vejamos, então, as porcentagens de aplicação do vozeamento nos resultados referentes à variável Contexto Precedente, que não se mostrou estatisticamente significante nos dados dos falantes nativos. A Tabela 2 a seguir mostra que vogal (ex: potatoes) foi o contexto que apresentou a maior taxa de aplicação do vozeamento, de $47,83 \%$. As líquidas (ex: brothers ), por sua vez, foram o segundo contexto com maior aplicação do vozeamento (47,14\%), seguidas das nasais (ex: runs ), com 46,03\% e, por fim, das plosivas (ex: dogs) e das fricativas (ex: loves), com aplicação de 36,9\% e 35,71\%, respectivamente. 
Tabela 2: Vozeamento de -s e Contexto Precedente - Falantes Nativos

\begin{tabular}{ccccc}
\hline \multirow{2}{*}{ Contexto Precedente } & \multicolumn{2}{c}{ Vozeado } & \multicolumn{2}{c}{ Desvozeado } \\
\cline { 2 - 5 } & $\mathbf{n}$ & $\mathbf{\%}$ & $\mathbf{N}$ & $\mathbf{\%}$ \\
\hline Vogal & 77 & 47,83 & 84 & 52,17 \\
Líquida & 33 & 47,14 & 37 & 52,86 \\
Nasal & 29 & 46,03 & 34 & 53,97 \\
Plosiva & 31 & 36,90 & 53 & 63,10 \\
Fricativa & 15 & 35,71 & 27 & 64,29
\end{tabular}

Assim como a variável Contexto Precedente, Categoria Morfológica também não foi selecionada como estatisticamente relevante nos dados dos falantes nativos. Como vimos na seção 7.5.1, essa variável testava os seguintes fatores: $3^{a}$ pessoa do singular (ex: leaves), caso genitivo (ex: John's) e plural (ex: dogs ). Na Tabela 3 a seguir podemos observar que a categoria morfológica que apresentou a maior porcentagem de aplicação do vozeamento por falantes nativos de inglês foi a de verbos na $3^{\underline{a}}$ pessoa do singular, com $48,3 \%$ de fricativas vozeadas, seguida do caso genitivo, com taxa de vozeamento de $47,62 \%$ e, por fim, do plural, com $40 \%$ de vozeamento.

Tabela 3: Vozeamento por Categoria Morfológica - Falantes Nativos

\begin{tabular}{ccccc}
\hline \multirow{2}{*}{ Categoria Morfológica } & \multicolumn{2}{c}{ Vozeado } & \multicolumn{2}{c}{ Desvozeado } \\
\cline { 2 - 5 } & $\mathbf{n}$ & $\mathbf{\%}$ & $\mathbf{n}$ & $\mathbf{\%}$ \\
\hline 3 Pessoa & 71 & 48,30 & 76 & 51,70 \\
Genitivo & 30 & 47,62 & 33 & 52,38 \\
Plural & 84 & 40,00 & 126 & 60,00
\end{tabular}

Vejamos a aplicação do vozeamento por informante. Pode-se observar na Tabela 4 a seguir que o Falante Nativo 4 foi o que mais produziu o vozeamento, com $73,3 \%$ de aplicação, enquanto o Falante Nativo 6 foi o que apresentou menos casos de vozeamento, com apenas 8,3\% de aplicação.

Tabela 4 : Vozeamento de -s por Informante - Falantes Nativos

\begin{tabular}{c|c|c}
\hline & Casos/Total & Porcentagem \\
\hline Nativo 1 & $43 / 60$ & $71 \%$ \\
Nativo 2 & $30 / 60$ & $50 \%$ \\
Nativo 3 & $38 / 60$ & $63,3 \%$ \\
Nativo 4 & $44 / 60$ & $73,3 \%$ \\
Nativo 5 & $10 / 60$ & $16,6 \%$ \\
Nativo 6 & $5 / 60$ & $8,3 \%$ \\
Nativo 7 & $15 / 60$ & $25 \%$ \\
\hline TOTAL & $\mathbf{1 8 5 / 4 2 0}$ & $\mathbf{4 4 \%}$ \\
\hline
\end{tabular}


A aplicação do vozeamento por informante também pode ser visualizada no Gráfico 2 a seguir. 0 Gráfico evidencia uma diferença na porcentagem de aplicação entre os nativos 1, 2, 3 e 4, que apresentaram taxas de aplicação do vozeamento mais altas (71\%, 50\%, 63,3\% e 73,3\%, respectivamente), e os nativos 5 , 6 e 7, com taxas bem mais baixas $(16,6 \%, 8,3 \%$ e $25 \%$, respectivamente). Interessantemente, ao contrário dos nativos 1, 2, 3 e 4, que vivem no Brasil, os nativos 5, 6 e 7 são os únicos que nunca saíram dos Estados Unidos.

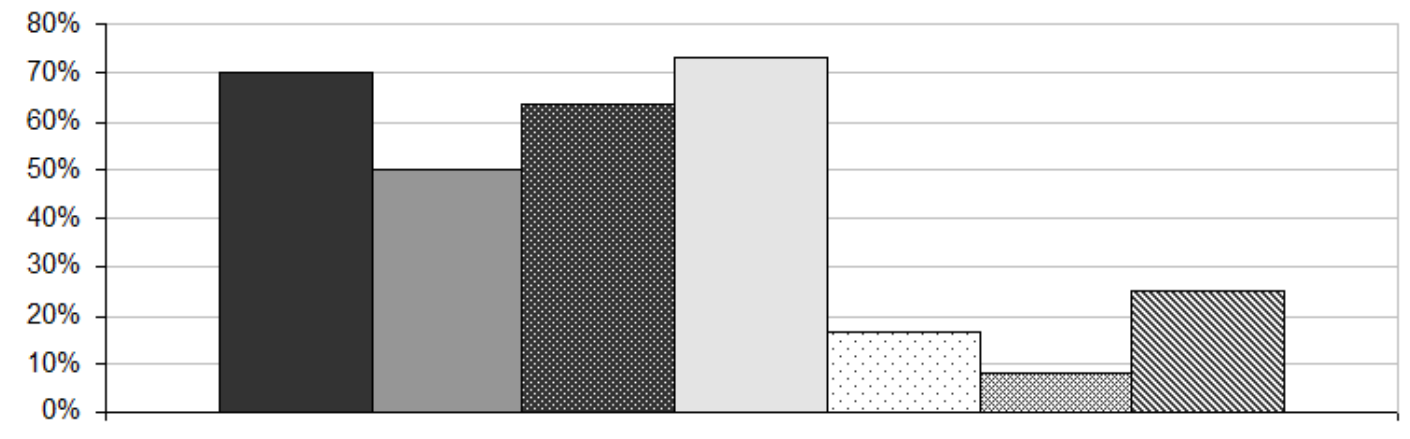

Nativo $1 \square$ Nativo 2 圆 Nativo $3 \square$ Nativo $4 \square$ Nativo 5 Nativo $6 \mathbb{8}$ Nativo 7

Gráfico 2: Vozeamento de -s por Informante - Falantes Nativos

Para verificar a influência do contexto seguinte sobre a aplicação do vozeamento pelos informantes do grupo de controle foi realizado um cruzamento entre as variáveis Informante e Contexto Seguinte.

Os resultados mostram que o falante Nativo 1 aplicou o vozeamento em $100 \%$ dos casos de fricativa seguida de vogal e em 100\% dos casos de consoante vozeada no contexto seguinte (destacados em cinza). Nos casos de contexto seguinte desvozeado ou pausa, nenhum falante nativo aplicou $100 \%$ do vozeamento. Destaca-se em cinza que os falantes Nativos 2 e 5 não produziram nenhum vozeamento em casos de fricativa seguida de pausa e que os Nativos 6 e 7 produziram apenas uma fricativa vozeada nos casos de consoante desvozeada no contexto seguinte, conforme a Tabela 5 a seguir. 
Tabela 5 : Cruzamento entre Informante e Contexto Seguinte - Falantes Nativos

\begin{tabular}{|c|c|c|c|c|c|c|c|c|}
\hline & \multicolumn{4}{|c|}{$\begin{array}{l}\text { VOZEAMENTO EM CONTEXTO } \\
\text { SEGUINTE VOZEADO }\end{array}$} & \multicolumn{4}{|c|}{$\begin{array}{l}\text { VOZEAMENTO EM CONTEXTO } \\
\text { SEGUINTE DESVOZEADO/PAUSA }\end{array}$} \\
\hline & \multicolumn{2}{|c|}{ Vogal } & \multicolumn{2}{|c|}{ Cons. Vozeada } & \multicolumn{2}{|c|}{ Cons. Desvoz, } & \multicolumn{2}{|c|}{ Pausa } \\
\hline & $\begin{array}{c}\text { Casos/ } \\
\text { Total }\end{array}$ & $\%$ & $\begin{array}{c}\text { Casos/ } \\
\text { Total }\end{array}$ & $\%$ & $\begin{array}{c}\text { Casos/ } \\
\text { Total }\end{array}$ & $\%$ & $\begin{array}{c}\text { Casos/ } \\
\text { Total }\end{array}$ & $\%$ \\
\hline Nativo 1 & $18 / 18$ & 100 & $12 / 12$ & 100 & $11 / 20$ & 55 & $2 / 10$ & 20 \\
\hline Nativo 2 & $16 / 18$ & 88 & $8 / 12$ & 66 & $6 / 20$ & 30 & $0 / 10$ & 0 \\
\hline Nativo 3 & $14 / 18$ & 77 & $11 / 12$ & 91 & $12 / 20$ & 60 & $1 / 10$ & 10 \\
\hline Nativo 4 & $16 / 18$ & 88 & $10 / 12$ & 83 & $15 / 20$ & 75 & $3 / 10$ & 30 \\
\hline Nativo 5 & $4 / 18$ & 22 & $3 / 12$ & 25 & $3 / 20$ & 15 & $0 / 10$ & 0 \\
\hline Nativo 6 & $2 / 18$ & 11 & $1 / 12$ & 8 & $1 / 20$ & 5 & $1 / 10$ & 10 \\
\hline Nativo 7 & $6 / 18$ & 33 & $6 / 12$ & 50 & $1 / 20$ & 5 & $2 / 10$ & 20 \\
\hline TOTAL & $94 / 126$ & 74 & $51 / 84$ & 60 & $49 / 140$ & 35 & $9 / 70$ & 12 \\
\hline
\end{tabular}

O Gráfico 3 a seguir apresenta a taxa de aplicação do vozeamento em cada um dos quatro tipos de contexto seguinte e mostra o favorecimento de contextos seguintes sonoros (vogais e consoantes vozeadas) sobre o vozeamento do -s em todos os falantes, exceto o Nativo 6.

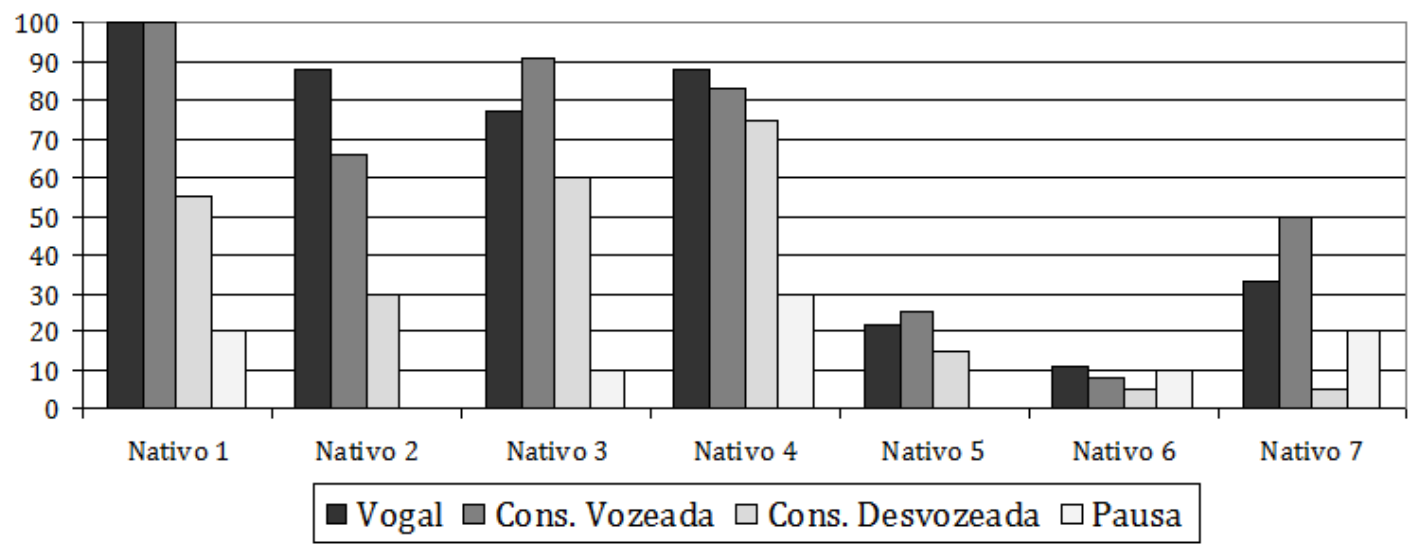

Gráfico 3: Aplicação do vozeamento por contexto seguinte - Falantes Nativos

Pode-se observar, portanto, que a taxa de aplicação do vozeamento é superior quando o contexto seguinte é sonoro (vogal ou consoante vozeada) e que esse resultado foi estatisticamente significante no grupo de falantes nativos. Observou-se, também, que há mais vozeamento com vogais, líquidas e nasais no contexto precedente do que com plosivas e fricativas e mais aplicações de vozeamento no -s de $3^{\underline{a}}$ pessoa do que no de caso genitivo e de plural, ainda que esses resultados não tenham sido estatisticamente significantes. 


\subsubsection{Falantes de inglês como L2}

A taxa de aplicação do vozeamento do morfema -s por todos os aprendizes de inglês como L2 pode ser visualizada no Gráfico 4 a seguir - todos casos em que o vozeamento seria obrigatório em inglês.

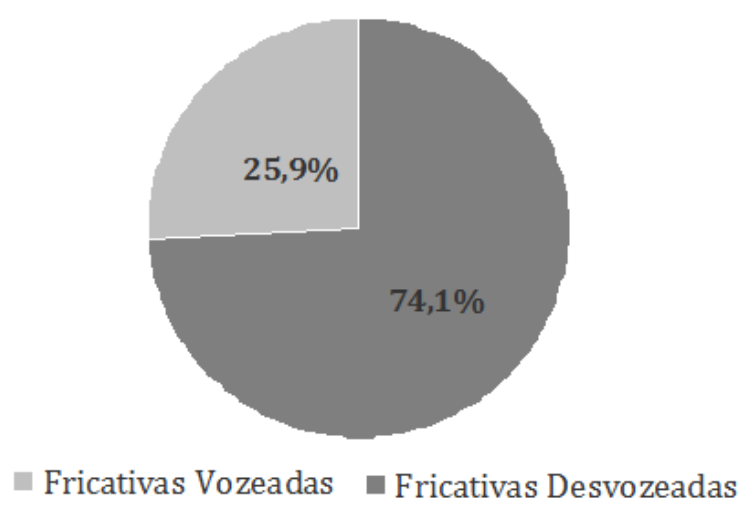

Gráfico 4: Aplicação do vozeamento por falantes de inglês como L2

Pode-se observar que os participantes produziram fricativas vozeadas em 25,9\% das ocorrências (466/1800) e fricativas não vozeadas em 74,1\% dos casos (1334/1800). É importante ressaltar que o Gráfico 4 inclui tanto contextos de fricativa seguida por um segmento sonoro, quando o vozeamento poderia ser resultado de

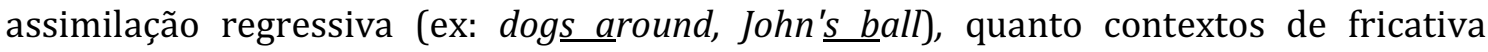
seguida de uma consoante surda (ex: John's cousin) ou pausa (ex: new shoes ), quando o vozeamento seria, de fato, uma evidência da aquisição da regra do inglês.

A análise estatística apontou evidências de que as variáveis Contexto Seguinte, Contexto Precedente e Nível de Proficiência influenciam no vozeamento. Dentre as variáveis testadas, portanto, Categoria Morfológica e Idade de Início da Aquisição não se mostraram relevantes para a aplicação da regra.

A variável Contexto Seguinte, que tem por objetivo verificar a influência do contexto fonológico que sucede a fricativa na aplicação do vozeamento, foi a primeira selecionada como estatisticamente relevante. Como vimos em 4.2.5, as categorias investigadas foram pausa (ex: I bought pears. ), consoante desvozeada (ex: boyfriend's father), consoante vozeada (ex: Mary' $\underline{s}$ book) e vogal (ex: Jack lives in the countryside). Os resultados mostraram que, assim como no grupo de controle, as vogais e as consoantes vozeadas foram os contextos que mais favoreceram a aplicação do vozeamento, ambos 
com peso relativo de 0,93 . As consoantes desvozeadas, por sua vez, tiveram um peso relativo de 0,16 e, portanto, não favoreceram a aplicação da regra. Por fim, contextos de pausa foram os que menos favoreceram o vozeamento da fricativa. A aplicação da regra neste contexto ocorreu em apenas 3 ocorrências e apresentou peso relativo de 0,07, conforme a Tabela 6 a seguir:

Tabela 6: Vozeamento de -s e Contexto Seguinte - Inglês como L2

\begin{tabular}{cccccc}
\hline \multirow{2}{*}{ Contexto Seguinte } & \multicolumn{2}{c}{ Vozeado } & \multicolumn{2}{c}{ Desvozeado } & PESO \\
\cline { 2 - 5 } & $\mathbf{n}$ & $\mathbf{\%}$ & $\mathbf{n}$ & $\mathbf{\%}$ & REL. \\
\hline Cons. Vozeada & 200 & 58,82 & 140 & 41,18 & 0,93 \\
Vogal & 254 & 58,12 & 183 & 41,88 & 0,93 \\
Cons. Desvozeada & 9 & 1,66 & 532 & 98,34 & 0,16 \\
Pausa & 3 & 0,62 & 479 & 99,38 & 0,07
\end{tabular}

A variável Contexto Precedente, que tem por objetivo verificar a influência do contexto fonológico que antecede a fricativa, também se mostrou significativa para a aplicação da regra no grupo de falantes de inglês como L2. Como vimos na Seção 4.2.2, todos os contextos precedentes nas palavras do experimento são vozeados (já que são os contextos em que o -s é produzido como /z/ no inglês). já que são os contextos de aplicação da regra em inglês). São eles: vogais (ex: tomatoes [tə'meitouz]), nasais (ex: opens

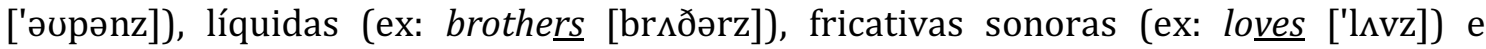
plosivas sonoras (ex: dogs [djgz]). Dentre esses contextos, vogal foi o que mais favoreceu o vozeamento, com peso relativo de 0,64 . As fricativas e as nasais, com peso relativo de 0,50 e 0,47 , respectivamente, ficaram próximas do ponto neutro, o que significa que não tiveram papel significativo sobre a aplicação do vozeamento. As plosivas e as líquidas, por fim, não favoreceram a aplicação da regra, com peso de 0,39 e 0,34 , respectivamente, conforme a Tabela 7 a seguir.

Tabela 7: Vozeamento de -s e Contexto Precedente - Inglês como L2

\begin{tabular}{cccccc}
\hline Contexto & \multicolumn{2}{c}{ Vozeado } & \multicolumn{2}{c}{ Desvozeado } & PESO \\
\cline { 2 - 5 } Precedente & n & \% & n & \% & REL. \\
\hline Vogal & 218 & 34,6 & 412 & 65,4 & 0,64 \\
Fricativa & 73 & 34,8 & 137 & 65,2 & 0,50 \\
Nasal & 59 & 21,7 & 211 & 78,1 & 0,47 \\
Plosiva & 84 & 23,3 & 276 & 76,7 & 0,39 \\
Líquida & 33 & 10 & 330 & 90 & 0,34
\end{tabular}


A última variável que se mostrou estatisticamente relevante para a aplicação do vozeamento por falantes brasileiros foi Nível de Proficiência, que divide os informantes entre os níveis Básico, Intermediário e Avançado. Pode-se observar na Tabela 8 que os falantes de nível avançado apresentaram uma taxa de aplicação do vozeamento inferior à dos falantes de nível intermediário, com 27,33\% e 33,83\%, respectivamente. Os falantes de nível básico, por sua vez, apresentaram a menor porcentagem de fricativas vozeadas, de 16,5\%. Observa-se, também, que o nível Intermediário foi o único que favoreceu a aplicação da regra, com peso relativo de 0,59, enquanto Básico e Avançado não foram favorecedores, com pesos 0,44 e 0,45, respectivamente.

Tabela 8: Vozeamento de -s e Nível de Proficiência - Inglês como L2

\begin{tabular}{cccccc}
\hline \multirow{2}{*}{ Nível de Proficiência } & \multicolumn{2}{c}{ Vozeado } & \multicolumn{2}{c}{ Desvozeado } & PESO \\
\cline { 2 - 5 } & $\mathbf{n}$ & $\mathbf{\%}$ & $\mathbf{n}$ & $\mathbf{\%}$ & REL. \\
\hline Básico & 99 & 16,50 & 501 & 83,50 & 0,44 \\
Intermediário & 203 & 33,83 & 397 & 66,17 & 0,59 \\
Avançado & 164 & 27,33 & 436 & 72,67 & 0,45
\end{tabular}

A proporção de acertos por nível de proficiência pode ser visualizada no Gráfico 5 a seguir, que apresenta também a taxa de aplicação do grupo de controle (nativos), já apresentada na Seção 4.3.1.

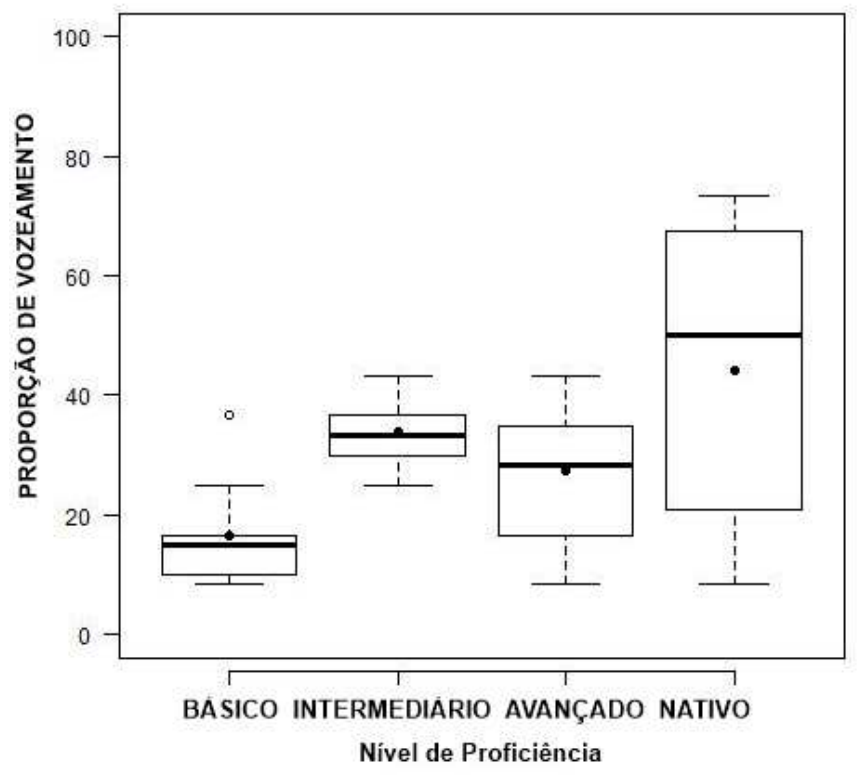

Gráfico 5: Vozeamento por nível de proficiência

Com o objetivo de verificar a aplicação do vozeamento por cada participante desta pesquisa, a Tabela 8 a seguir apresenta uma descrição dos dados por Informante. 
Lembramos aqui que eram 30 informantes, 10 em cada nível de proficiência. Os informantes que produziram a maior porcentagem de fricativas vozeadas foram o Informante 18, do nível intermediário, e o Informante 27, do nível avançado, ambos com 43,33\% de aplicação, seguidos dos informantes 20 e 28, do nível intermediário e avançado, respectivamente, ambos com aplicação de 41,66\% (todos destacados em cinza escuro). Os informantes que apresentaram a porcentagem mais baixa foram o Informante 4, do nível básico, e 30, do nível avançado, ambos com apenas 8,33\% de vozeamento. Os Informantes 2 e 6 do nível Básico também apresentaram uma porcentagem baixa de aplicação, com 10\% de fricativas vozeadas, assim como os Informantes 1, 3 e 10, do nível básico, com 15\% de vozeamento, todos destacados em cinza claro na Tabela 9 a seguir.

Tabela 9: Vozeamento de -s por Informante - Inglês como L2

\begin{tabular}{|c|c|c|c|}
\hline NÍVEL & INFORMANTE & CASOS/TOTAL & PORCENTAGEM \\
\hline \multirow{10}{*}{ Básico } & Inf. 1 & $9 / 60$ & $15 \%$ \\
\hline & Inf. 2 & $6 / 60$ & $10 \%$ \\
\hline & Inf. 3 & $9 / 60$ & $15 \%$ \\
\hline & Inf. 4 & $5 / 60$ & $8,33 \%$ \\
\hline & Inf. 5 & $22 / 60$ & $36,66 \%$ \\
\hline & Inf. 6 & $6 / 60$ & $10 \%$ \\
\hline & Inf. 7 & $15 / 60$ & $25 \%$ \\
\hline & Inf. 8 & $8 / 60$ & $13,33 \%$ \\
\hline & Inf. 9 & $10 / 60$ & $16,66 \%$ \\
\hline & Inf. 10 & $9 / 60$ & $15 \%$ \\
\hline \multirow{10}{*}{ Interm. } & Inf. 11 & $22 / 60$ & $36,66 \%$ \\
\hline & Inf. 12 & $18 / 60$ & $30 \%$ \\
\hline & Inf. 13 & $18 / 60$ & $30 \%$ \\
\hline & Inf. 14 & $22 / 60$ & $36,66 \%$ \\
\hline & Inf. 15 & $15 / 60$ & $25 \%$ \\
\hline & Inf. 16 & $17 / 60$ & $28,33 \%$ \\
\hline & Inf. 17 & $21 / 60$ & $35 \%$ \\
\hline & Inf. 18 & $26 / 60$ & $43,33 \%$ \\
\hline & Inf. 19 & $19 / 60$ & $31,66 \%$ \\
\hline & Inf. 20 & $25 / 60$ & $41,66 \%$ \\
\hline \multirow{11}{*}{ Avançado } & Inf. 21 & $10 / 60$ & $16,66 \%$ \\
\hline & Inf. 22 & $19 / 60$ & $31,66 \%$ \\
\hline & Inf. 23 & $16 / 60$ & $26,66 \%$ \\
\hline & Inf. 24 & $18 / 60$ & $30 \%$ \\
\hline & Inf. 25 & $14 / 60$ & $23,33 \%$ \\
\hline & Inf. 26 & $21 / 60$ & $35 \%$ \\
\hline & Inf. 27 & $26 / 60$ & $43,33 \%$ \\
\hline & Inf. 28 & $25 / 60$ & $41,66 \%$ \\
\hline & Inf. 29 & $10 / 60$ & $16,66 \%$ \\
\hline & Inf. 30 & $5 / 60$ & $8,33 \%$ \\
\hline & TOTAL & $466 / 1800$ & $25,89 \%$ \\
\hline
\end{tabular}


De forma a facilitar observar a relação entre o nível de proficiência e o informante, o Gráfico 6 a seguir mostra a porcentagem de aplicação do vozeamento por cada informante, separados por nível de proficiência.

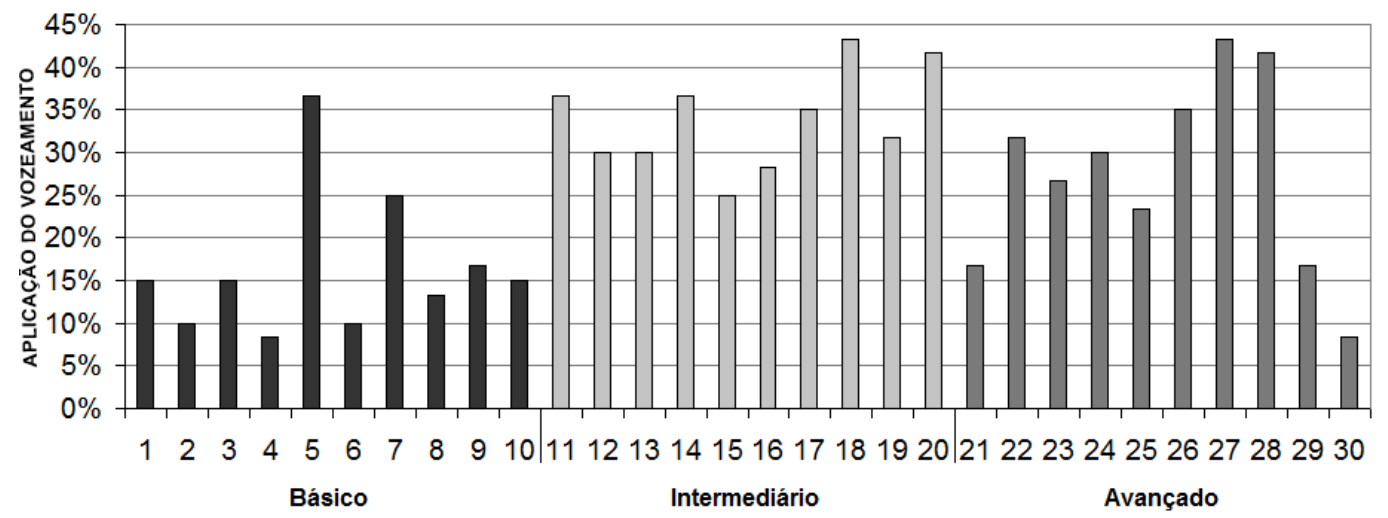

Gráfico 6: VOZEAMENTO DE -S POR Informante e Nível de Proficiência

É possível observar que, de maneira geral, os resultados dos falantes de nível intermediário são os mais homogêneos, pois todos variam entre $25 \%$ e 43,33\% de aplicação do vozeamento. Destacam-se, no nível intermediário, os informantes 18 e 20, que apresentaram as maiores taxas de aplicação entre os falantes deste nível $(43,33 \%$ e 41,66\%, respectivamente). No caso do nível avançado, observa-se uma variação muito maior: enquanto os informantes 27 e 28 se destacam com as maiores taxas de aplicação, os informantes 21, 25, 29 e 30 apresentam taxas de vozeamento mais baixas do que qualquer falante de nível intermediário, o que contribui para a taxa geral dos informantes de nível avançado ter sido mais baixa que a dos de nível intermediário (cf. Tabela 7, Gráfico 5). Dentre os falantes de nível básico, o Informante 5 apresentou a maior taxa de aplicação do vozeamento (36,66\%), superando 8 dos 10 participantes de nível avançado. Entretanto, os outros 9 informantes de nível básico apresentaram taxas bastante inferiores às da maioria dos informantes dos outros dois níveis.

Esses resultados, contudo, não significam que a maior taxa de aplicação do vozeamento representa, de fato, uma maior taxa de aplicação da regra de assimilação de vozeamento progressiva, característica do inglês. A alta taxa de aplicação do vozeamento por determinados informantes pode ter ocorrido por terem produzido menos pausas entre as palavras do que outros informantes e, consequentemente, aplicado a regra de assimilação regressiva, característica do português. Para verificar a aplicação do vozeamento da fricativa por informante em contextos que não favoreceriam a 
assimilação regressiva, ou seja, casos de fricativa seguida de consoante desvozeada (ex: John's cousin) ou pausa (ex: movies ), realizou-se um cruzamento entre as variáveis Informante e Contexto Seguinte.

Os resultados apontaram que a grande maioria dos informantes aplicou o vozeamento apenas quando a fricativa era seguida de um segmento vozeado. Nos casos em que o contexto seguinte era uma vogal (ex: dogs around), o Informante 7, do nível básico, aplicou 87,5\% de vozeamento, enquanto o Informante 2, também do nível básico, aplicou apenas em 1 caso neste contexto (1,66\%). No caso de fricativas seguidas de consoante vozeada (ex: John's videogame), os Informantes 12 e 28, de nível intermediário e avançado, respectivamente, aplicaram o vozeamento em 91,66\% dos casos (11/12), e todos os outros informantes aplicaram o vozeamento em pelo menos uma das ocorrências neste contexto.

Nos casos de fricativa seguida por consoante desvozeada (ex: kids playing) ou pausa (ex: I bought pears $)$, quase não houve casos de vozeamento. Pode-se observar na Tabela 10 a seguir que apenas os Informantes 1, 3 e 6, de nível básico, os informantes 11, 14, 17 e 20, de nível intermediário, e o Informante 22, de nível avançado, apresentaram algum caso de vozeamento quando o contexto seguinte era uma consoante desvozeada (destacados em cinza escuro). Nos contextos de fricativa seguida de pausa, ${ }^{17}$ o vozeamento ocorreu em ainda menos casos: somente o Informante 20 , do nível intermediário, apresentou 3 casos de vozeamento (destacado em cinza).

\footnotetext{
${ }^{17}$ Os falantes de nível básico apresentaram mais casos de pausa do que os falantes dos outros níveis de proficiência porque, muitas vezes, não conseguiram produzir as frases do experimento de maneira contínua, mesmo quando solicitados para repeti-las sem a inserção de pausas.
} 
Tabela 10: Cruzamento entre Informante e Contexto Seguinte - Inglês como L2

\begin{tabular}{|c|c|c|c|c|c|c|c|c|}
\hline & \multicolumn{4}{|c|}{$\begin{array}{l}\text { CONTEXTO SEGUINTE } \\
\text { VOZEADO }\end{array}$} & \multicolumn{4}{|c|}{$\begin{array}{l}\text { CONTEXTO SEGUINTE } \\
\text { DESVOZEADO/PAUSA }\end{array}$} \\
\hline & \multicolumn{2}{|c|}{ VOGAL } & \multicolumn{2}{|c|}{ CONS. VOZEADA } & \multicolumn{2}{|c|}{ PAUSA } & \multicolumn{2}{|c|}{ CONS. DESVOZ. } \\
\hline & Casos/Tot. & $\%$ & Casos/Tot. & $\%$ & Casos/Tot. & $\%$ & Casos/Tot. & $\%$ \\
\hline Inf. 1 & $4 / 5$ & 80 & $4 / 7$ & 57,14 & $0 / 38$ & 0 & $1 / 10$ & 10 \\
\hline Inf. 2 & $1 / 6$ & 1,66 & $5 / 10$ & 50 & $0 / 32$ & 0 & $0 / 12$ & 0 \\
\hline Inf. 3 & $3 / 10$ & 30 & $5 / 10$ & 50 & $0 / 27$ & 0 & $1 / 13$ & 7,69 \\
\hline Inf. 4 & $2 / 5$ & 40 & $3 / 9$ & 33,33 & $0 / 32$ & 0 & $0 / 14$ & 0 \\
\hline Inf. 5 & $12 / 14$ & 85,71 & $10 / 11$ & 90,9 & $0 / 20$ & 0 & $0 / 15$ & 0 \\
\hline Inf. 6 & $1 / 10$ & 10 & $4 / 12$ & 33,33 & $0 / 20$ & 0 & $1 / 18$ & 5,55 \\
\hline Inf. 7 & $7 / 8$ & 87,5 & $8 / 12$ & 66,66 & $0 / 26$ & 0 & $0 / 14$ & 0 \\
\hline Inf. 8 & $2 / 6$ & 33,33 & $6 / 11$ & 54,54 & $0 / 28$ & 0 & $0 / 15$ & 0 \\
\hline Inf. 9 & $5 / 8$ & 62,5 & $5 / 9$ & 55,55 & $0 / 28$ & 0 & $0 / 15$ & 0 \\
\hline Inf. 10 & $3 / 5$ & 60 & $6 / 9$ & 66,66 & $0 / 31$ & 0 & $0 / 15$ & 0 \\
\hline Inf. 11 & $13 / 18$ & 72,22 & $8 / 12$ & 66,66 & $0 / 10$ & 0 & $1 / 20$ & 5 \\
\hline Inf. 12 & $7 / 18$ & 38,88 & $11 / 12$ & 91,66 & $0 / 10$ & 0 & $0 / 20$ & 0 \\
\hline Inf. 13 & $9 / 18$ & 50 & $9 / 12$ & 75 & $0 / 10$ & 0 & $0 / 20$ & 0 \\
\hline Inf. 14 & $10 / 18$ & 55,55 & $10 / 12$ & 83,33 & $0 / 10$ & 0 & $2 / 20$ & 10 \\
\hline Inf. 15 & 8/18 & 44,44 & $7 / 12$ & 58,33 & $0 / 10$ & 0 & $0 / 20$ & 0 \\
\hline Inf. 16 & $10 / 18$ & 55,55 & $7 / 12$ & 58,33 & $0 / 10$ & 0 & $0 / 20$ & 0 \\
\hline Inf. 17 & $12 / 18$ & 66,66 & $9 / 12$ & 75 & $0 / 10$ & 0 & $1 / 20$ & 10 \\
\hline Inf. 18 & $15 / 18$ & 83,33 & $10 / 12$ & 83,33 & $0 / 10$ & 0 & $0 / 20$ & 0 \\
\hline Inf. 19 & $11 / 18$ & 61,11 & $8 / 12$ & 66,66 & $0 / 10$ & 0 & $0 / 20$ & 0 \\
\hline Inf. 20 & $15 / 18$ & 83,33 & $6 / 12$ & 50 & $3 / 10$ & 30 & $1 / 20$ & 5 \\
\hline Inf. 21 & $7 / 18$ & 38,88 & $3 / 12$ & 25 & $0 / 10$ & 0 & $0 / 20$ & 0 \\
\hline Inf. 22 & $10 / 18$ & 55,55 & $9 / 12$ & 75 & $0 / 10$ & 0 & $1 / 20$ & 10 \\
\hline Inf. 23 & $11 / 18$ & 61,11 & $5 / 12$ & 41,66 & $0 / 10$ & 0 & $0 / 20$ & 0 \\
\hline Inf. 24 & $12 / 18$ & 66,66 & $6 / 12$ & 50 & $0 / 10$ & 0 & $0 / 20$ & 0 \\
\hline Inf. 25 & $9 / 18$ & 50 & $5 / 12$ & 41,66 & $0 / 10$ & 0 & $0 / 20$ & 0 \\
\hline Inf. 26 & $14 / 18$ & 77,77 & $7 / 12$ & 58,33 & $0 / 10$ & 0 & $0 / 20$ & 0 \\
\hline Inf. 27 & $16 / 18$ & 88,88 & $10 / 12$ & 83,33 & $0 / 10$ & 0 & $0 / 20$ & 0 \\
\hline Inf. 28 & $14 / 18$ & 77,77 & $11 / 12$ & 91,66 & $0 / 10$ & 0 & $0 / 20$ & 0 \\
\hline Inf. 29 & $7 / 18$ & 38,88 & $3 / 12$ & 25 & $0 / 10$ & 0 & $0 / 20$ & 0 \\
\hline Inf. 30 & $4 / 18$ & 22,22 & $1 / 12$ & 8,33 & $0 / 10$ & 0 & $0 / 20$ & 0 \\
\hline TOTAL & $254 / 437$ & 58,12 & $201 / 340$ & 59,11 & $3 / 482$ & 0,62 & $9 / 541$ & 1,66 \\
\hline
\end{tabular}

A taxa de aplicação por informante e por nível de proficiência distribuída em cada contexto seguinte também pode ser visualizada nos Gráficos 7, 8 e 9 a seguir. Fica bastante claro que o vozeamento ocorreu majoritariamente nos casos de contexto seguinte vozeado (vogal ou consoante vozeada) nos três níveis de proficiência. 


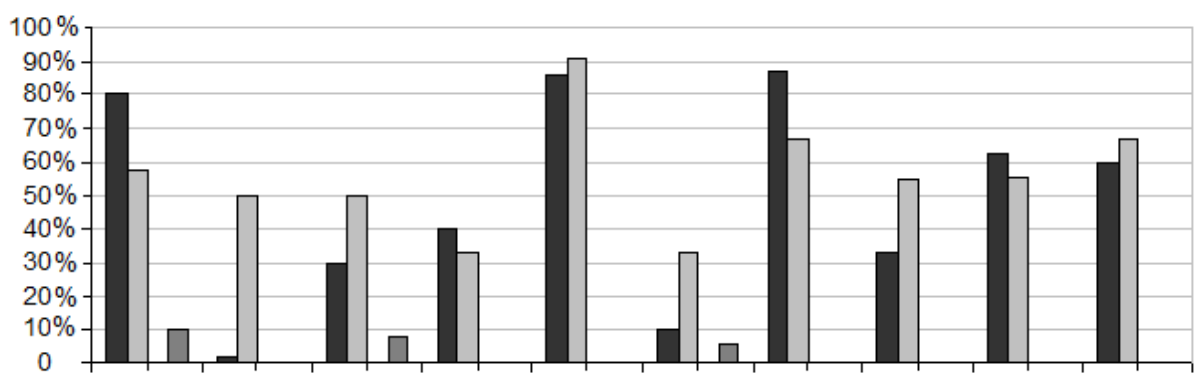

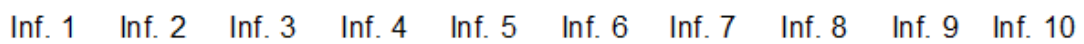

$\square$ VOGAL $\square$ CONS. VOZEADA OPAUSA $\square$ CONS. DESVOZEADA

Gráfico 7: Vozeamento de -s por Informante e Contexto Seguinte: Básico

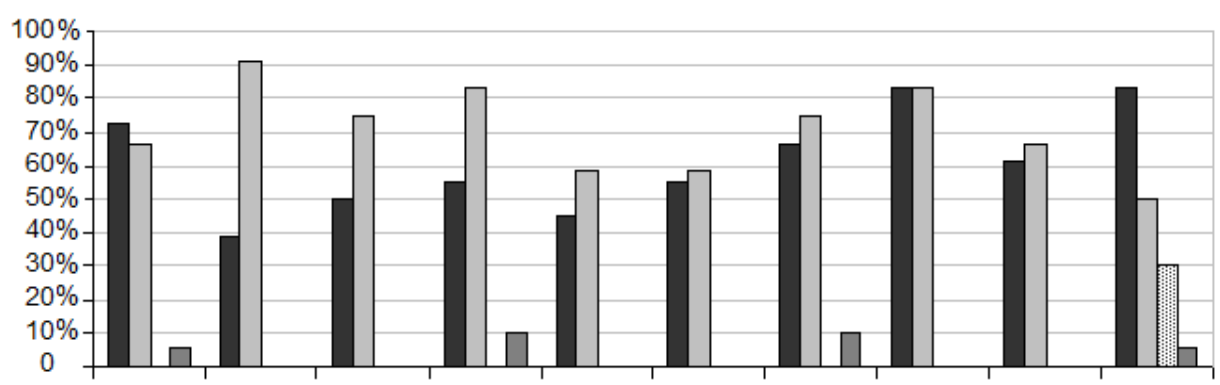

Inf. 11 Inf. 12 Inf. 13 Inf. $14 \quad$ Inf. $15 \quad$ Inf. 16 Inf. 17 Inf. 18 Inf. 19 Inf. 20

$\square$ VOGAL $\square$ CONS. VOZEADA 圈 PAUSA $\square$ CONS. DESVOZEADA

Gráfico 8: Vozeamento de -s por Informante e Contexto Seguinte: Intermediário

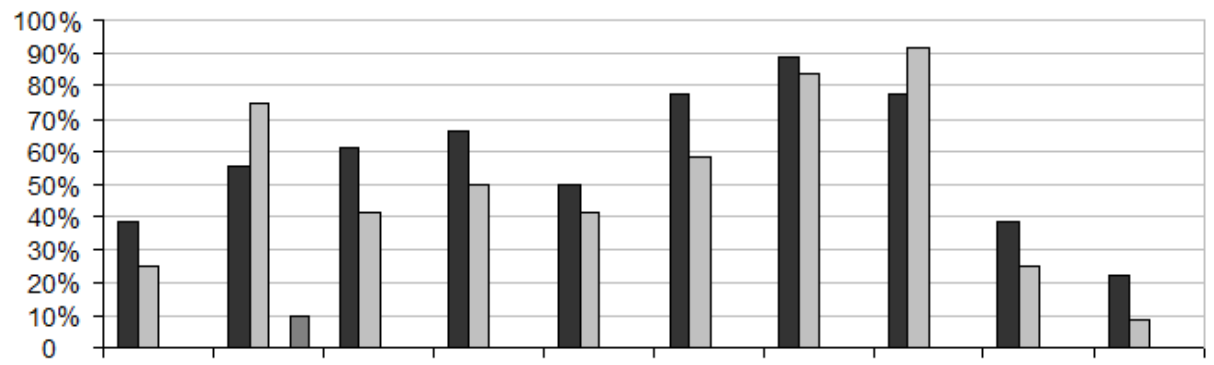

Inf. 21 Inf. 22 Inf. 23 Inf. 24 Inf. 25 Inf. 26 Inf. 27 Inf. 28 Inf. 29 Inf. 30

$\square$ VOGAL $\square$ CONS. VOZEADA 圈 PAUSA $\square$ CONS. DESVOZEADA

Gráfico 9: Vozeamento de -s por Informante e Contexto Seguinte: Avançado

Portanto, os resultados apresentados nesta seção mostram que, apesar de os informantes terem aplicado o vozeamento em 25,9\% das ocorrências (466/1800), ele ocorreu em apenas 1,17\% (12/1023) dos casos em que o contexto seguinte era um segmento desvozeado (9/541) ou uma pausa (3/482). Isso mostra que, na grande maioria dos casos, a regra foi aplicada por influência do vozeamento do contexto seguinte, e não do contexto precedente. 
Para verificar o percurso de aquisição da regra nos contextos que não permitiam a assimilação regressiva, realizou-se o cruzamento entre as variáveis Nível de Proficiência e Contexto Seguinte. Se observarmos na Tabela 11 apenas os casos de fricativa seguida de consoante desvozeada, que não permitem o vozeamento pela aplicação da regra do português, verificamos apenas 3 aplicações da regra no nível básico, 5 no nível intermediário e 1 no nível avançado. Nos casos de fricativa seguida de pausa, que também bloqueia a assimilação regressiva, há ainda menos aplicações do vozeamento: somente os informantes do nível intermediário apresentaram 3 casos de vozeamento. Esse resultado mostra que os casos de vozeamento foram fortemente influenciados por contextos seguintes sonoros (vogal e consoante vozeada) nos três níveis de proficiência. Se observarmos os poucos casos de aplicação do vozeamento com consoantes desvozeadas no contexto seguinte, percebemos que há mais aplicação da regra no nível básico do que no nível avançado. Nos contextos seguidos de pausa, encontramos aplicações apenas no nível intermediário.

Tabela 11: Cruzamento entre Nível de Proficiência e Contexto Seguinte

\begin{tabular}{c|c|c|c|c|c|c|c|c}
\hline \multirow{4}{*}{ Nível } & \multicolumn{3}{|c|}{ VOZEAMENTO EM } & \multicolumn{3}{c}{ VOZEAMENTO EM CONTEXTO } \\
\cline { 2 - 8 } & \multicolumn{2}{|c|}{ CONTEXTO SEGUINTE VOZEADO } & \multicolumn{2}{c}{ SEG. DESVOZEADO OU PAUSA } \\
\cline { 2 - 9 } & VOGAL & CONS. VOZEADA & CONS. DESVOZ. & \multicolumn{2}{c}{ PAUSA } \\
\cline { 2 - 9 } & Casos/ & $\%$ & $\begin{array}{c}\text { Casos/ } \\
\text { Total }\end{array}$ & $\%$ & $\begin{array}{c}\text { Casos/ } \\
\text { Total }\end{array}$ & $\%$ & $\begin{array}{c}\text { Casos/ } \\
\text { Total }\end{array}$ & $\%$ \\
\hline Básico & $41 / 86$ & 48 & $55 / 110$ & 50 & $3 / 145$ & 2 & $0 / 276$ & 0 \\
Interm. & $115 / 190$ & 61 & $82 / 110$ & 75 & $5 / 200$ & 2,5 & $3 / 200$ & 1,5 \\
Avanç & $106 / 190$ & 56 & $52 / 93$ & 56 & $1 / 200$ & 0,5 & $0 / 100$ & 0
\end{tabular}

Os resultados indicam, portanto, que a aquisição da regra de assimilação progressiva do inglês não ocorreu em nenhum nível de proficiência, pois a taxa de aplicação do vozeamento em contextos que não permitiam a assimilação regressiva foi extremamente baixa nos três níveis de proficiência testados.

Vejamos, por fim, as taxas de aplicação do vozeamento nas duas variáveis que não foram selecionadas como estatisticamente relevantes, a começar por Categoria Morfológica. Dentre as três categorias testadas ( $3^{\mathrm{a}}$ pessoa do singular (ex: leaves), caso genitivo (ex: John's) e plural (ex: dogs)), o -s de $3^{\circ}$ pessoa do singular foi o que apresentou a maior taxa aplicação do vozeamento, assim como no grupo de controle, com uma porcentagem de $42,8 \%$ de fricativas vozeadas, seguido do caso genitivo, com 
$26,3 \%$ de vozeamento e do plural, com $14,6 \%$ de vozeamento, conforme a Tabela 12 a seguir.

Tabela 12: Vozeamento por Categoria Morfológica - Inglês como L2

\begin{tabular}{ccccc}
\hline Categoria & \multicolumn{2}{c}{ Vozeado } & \multicolumn{2}{c}{ Desvozeado } \\
\cline { 2 - 5 } Morfológica & $\mathbf{n}$ & $\mathbf{\%}$ & $\mathbf{N}$ & $\mathbf{\%}$ \\
\hline 3 Pessoa & 257 & 42,8 & 343 & 57,2 \\
Genitivo & 79 & 26,3 & 221 & 73,7 \\
Plural & 131 & 14,6 & 769 & 85,4
\end{tabular}

Para verificar a aplicação do vozeamento nos morfemas de plural, de $3^{\underline{a}}$ pessoa e do caso genitivo nos contextos que não favoreciam a assimilação regressiva, realizamos o cruzamento entre as variáveis Categoria Morfológica e Contexto Seguinte. Pode-se observar na Tabela 13 a seguir que as aplicações de vozeamento nas três categorias morfológicas se concentram nos casos de contexto seguinte vozeado. Nos casos de consoante desvozeada no contexto seguinte, há apenas 7 aplicações de vozeamento na categoria plural e 2 na categoria genitivo. Nos casos de fricativa seguida de pausa, houve apenas 3 casos de vozeamento na categoria plural. 0 resultado desse cruzamento evidencia que o vozeamento foi, de fato, influenciado pelo contexto seguinte, e não pela categoria morfológica.

Tabela 13: Cruzamento entre Categoria Morfológica e Contexto Seguinte

\begin{tabular}{|c|c|c|c|c|c|c|c|c|}
\hline \multirow{3}{*}{$\begin{array}{l}\text { Categ. } \\
\text { Morfol. }\end{array}$} & \multicolumn{4}{|c|}{$\begin{array}{l}\text { VOZEAMENTO EM CONTEXTO } \\
\text { SEGUINTE VOZEADO }\end{array}$} & \multicolumn{4}{|c|}{$\begin{array}{l}\text { VOZEAMENTO EM CONT. } \\
\text { SEGUINTE DESVOZ. OU PAUSA }\end{array}$} \\
\hline & \multicolumn{2}{|c|}{ VOGAL } & \multicolumn{2}{|c|}{ CONS. VOZEADA } & \multicolumn{2}{|c|}{ CONS. DESVOZ. } & \multicolumn{2}{|c|}{ PAUSA } \\
\hline & $\begin{array}{c}\text { Casos/ } \\
\text { Total }\end{array}$ & $\%$ & $\begin{array}{c}\text { Casos/ } \\
\text { Total }\end{array}$ & $\%$ & $\begin{array}{c}\text { Casos/ } \\
\text { Total }\end{array}$ & $\%$ & $\begin{array}{l}\text { Casos/ } \\
\text { Total }\end{array}$ & $\%$ \\
\hline $3 \stackrel{a}{ } P e$ & $151 / 224$ & 67 & $106 / 163$ & 61 & $0 / 147$ & 0 & $0 / 56$ & 0 \\
\hline Plural & $95 / 217$ & 44 & $21 / 30$ & 70 & $7 / 267$ & 2 & $3 / 386$ & 1 \\
\hline Genitivo & $16 / 25$ & 64 & $62 / 110$ & 56 & $2 / 131$ & 1 & $0 / 34$ & 0 \\
\hline
\end{tabular}

A variável Idade de Início da Aquisição, que também não foi estatisticamente significativa, mostrou que o vozeamento foi realizado por falantes que iniciaram a aquisição antes dos 12 anos em 26\% dos casos e por falantes que iniciaram a aquisição após os 12 anos em 25,78\% das ocorrências, conforme a Tabela 14: 
Tabela 14: Vozeamento do -s e Idade de Início da Aquisição - Inglês como L2

\begin{tabular}{ccccc}
\hline Idade da & \multicolumn{2}{c}{ Vozeado } & \multicolumn{2}{c}{ Desvozeado } \\
\cline { 2 - 5 } Aquisição & $\mathbf{n}$ & $\mathbf{\%}$ & $\mathbf{N}$ & $\mathbf{\%}$ \\
\hline Antes dos 12 & 234 & 26,00 & 666 & 74,00 \\
Depois dos 12 & 232 & 25,78 & 668 & 74,22
\end{tabular}

Para facilitar a observação da taxa de aplicação por Idade de Início da Aquisição, o Gráfico 10 a seguir apresenta a taxa de aplicação do vozeamento entre os dois grupos de idade em comparação com a taxa de vozeamento dos falantes nativos, apresentada na Seção 4.3.1. Percebe-se que a proporção do vozeamento se encontra muito próxima nos dois grupos, mas a média de vozeamento no grupo que iniciou a aquisição antes dos 12 anos é um pouco mais alta.

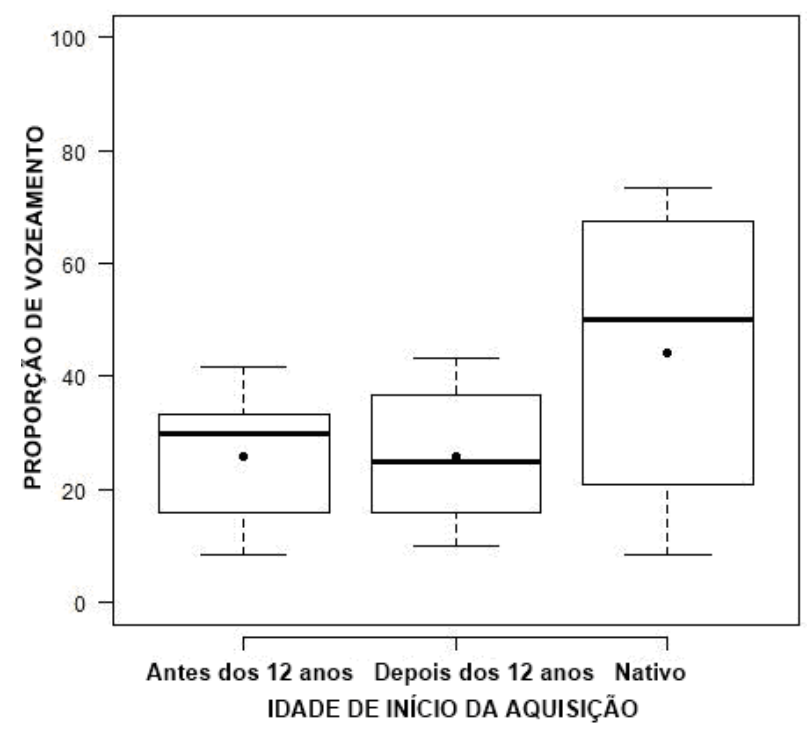

Gráfico 10: Proporção do vozeamento por Idade de início da aquisição

Para verificar a relação entre Idade de Início da Aquisição e a taxa de aplicação da regra por informante, foi realizado um cruzamento entre essas duas variáveis. A Tabela 15 a seguir mostra que, dentre os informantes que iniciaram a aquisição antes dos 12 anos, o Informante 4, de nível básico, e o Informante 30, do nível avançado, apresentaram a menor taxa de aplicação do vozeamento, de 8,33\% (destacados em cinza claro), e o informante que mais aplicou a regra foi o Informante 20, de nível intermediário, com 41,66\% de aplicação (destacado em cinza escuro). Dentre os informantes que iniciaram a aquisição depois dos 12 anos, os Informantes 2 e 6, do nível básico, foram os que apresentaram as menores taxas de aplicação, de 10\%. As maiores 
porcentagens de aplicação ocorreram nos Informantes 20, de nível intermediário, e 24 e 28, de nível avançado, todos com aplicação de 41,66\% (destacados em cinza escuro).

Tabela 15: Vozeamento do -s e Idade por informante - Inglês como L2

\begin{tabular}{c|c|c|c|c|c|c}
\hline & \multicolumn{3}{|c|}{ ANTES DOS 12 ANOS } & \multicolumn{3}{c}{ DEPOIS DOS 12 ANOS } \\
\hline Nível & Inform. & Casos/Total & $\mathbf{\%}$ & Inform. & Casos/Total & \% \\
\hline \multirow{5}{*}{ Básico. } & Inf. 3 & $9 / 60$ & $15 \%$ & Inf. 1 & $9 / 60$ & $15 \%$ \\
& Inf. 4 & $6 / 60$ & $8,33 \%$ & Inf. 2 & $6 / 60$ & $10 \%$ \\
& Inf. 7 & $15 / 60$ & $25 \%$ & Inf. 5 & $22 / 60$ & $36,66 \%$ \\
& Inf. 9 & $10 / 60$ & $16,66 \%$ & Inf. 6 & $6 / 60$ & $10 \%$ \\
& Inf. 10 & $9 / 60$ & $15 \%$ & Inf. 8 & $8 / 60$ & $13,33 \%$ \\
\hline \multirow{5}{*}{ Interm. } & Inf. 11 & $22 / 60$ & $36,66 \%$ & Inf. 12 & $18 / 60$ & $30 \%$ \\
& Inf. 13 & $18 / 60$ & $30 \%$ & Inf. 14 & $22 / 60$ & $36,66 \%$ \\
& Inf. 17 & $21 / 60$ & $35 \%$ & Inf. 15 & $15 / 60$ & $25 \%$ \\
& Inf. 19 & $19 / 60$ & $31,66 \%$ & Inf. 16 & $17 / 60$ & $28,33 \%$ \\
& Inf. 20 & $25 / 60$ & $41,66 \%$ & Inf. 18 & $25 / 60$ & $41,66 \%$ \\
\hline \multirow{5}{*}{ Avançado } & Inf. 22 & $19 / 60$ & $31,66 \%$ & Inf. 21 & $10 / 60$ & $16,66 \%$ \\
& Inf. 23 & $16 / 60$ & $26,66 \%$ & Inf. 25 & $14 / 60$ & $23,33 \%$ \\
& Inf. 24 & $18 / 60$ & $30 \%$ & Inf. 27 & $25 / 60$ & $41,66 \%$ \\
\cline { 2 - 6 } & Inf. 26 & $21 / 60$ & $35 \%$ & Inf. 28 & $25 / 60$ & $41,66 \%$ \\
& Inf. 30 & $6 / 60$ & $8,33 \%$ & Inf. 29 & $10 / 60$ & $16,66 \%$ \\
\hline & TOTAL & $\mathbf{2 3 4 / 9 0 0}$ & $\mathbf{2 6 \%}$ & TOTAL & $\mathbf{2 3 2 / 9 0 0}$ & $\mathbf{2 5 , 7 \%}$ \\
\hline
\end{tabular}

O Gráfico 11 compara a taxa de aplicação do vozeamento por nível de proficiência e por idade de início da aquisição. Pode-se observar que, de modo geral, os falantes de nível básico em ambos os grupos de idade de aquisição apresentaram uma taxa de vozeamento inferior aos de nível básico e avançado.

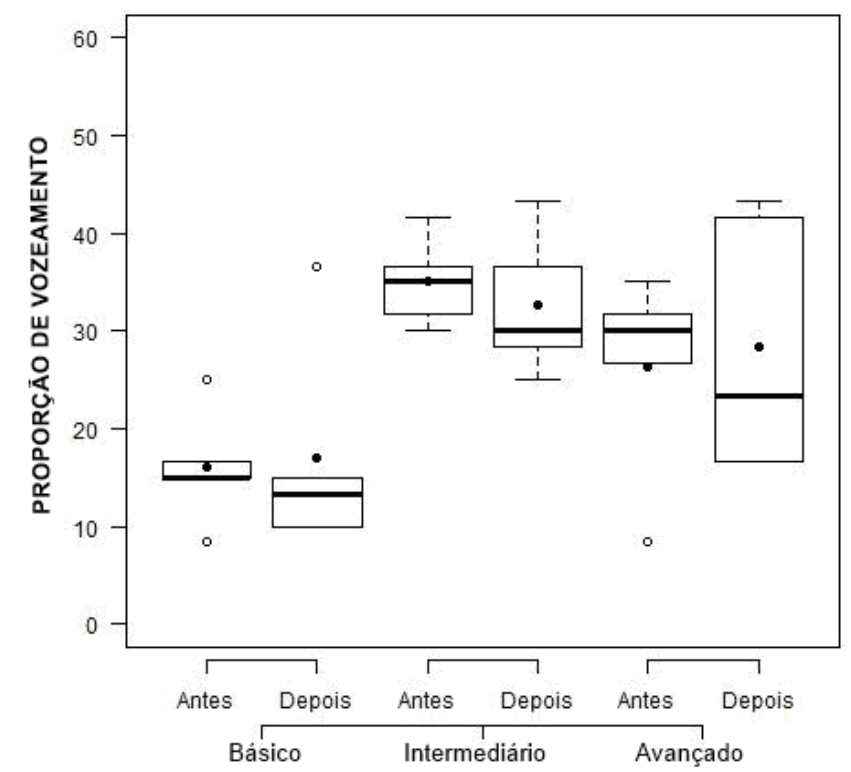

Gráfico 11: Vozeamento por Idade de aquisição e Nível de Proficiência 
Pode-se observar que, nos três níveis de proficiência, a média de vozeamento pelos informantes que iniciaram o aprendizado da língua-alvo antes dos 12 anos é mais alta que a dos que iniciaram após os 12 anos. Observa-se, também, que a variação na proporção de vozeamento dentre os falantes de nível avançado que iniciaram a aquisição depois dos 12 anos foi maior do que nos outros níveis. Isso se justifica porque, dentre os falantes de nível avançado que iniciaram a aquisição depois dos 12 anos se encontram os Informantes 21 e 29, que apresentaram as taxas de aplicação muito baixas (ambos de 16,66\%), e os informantes 27 e 28, que apresentaram as maiores taxas de aplicação neste nível (ambos de 41,66\%).

0 Gráfico 12, por fim, apresenta a proporção de vozeamento por idade de início da aquisição e por nível de proficiência nos casos de fricativa seguida de pausa ou consoante desvozeada, quando a regra regressiva do português não poderia ser aplicada. Como vimos na Tabela 13, houve apenas 12 aplicações de vozeamento nesses contextos: três no nível básico, oito no nível intermediário e uma no avançado.

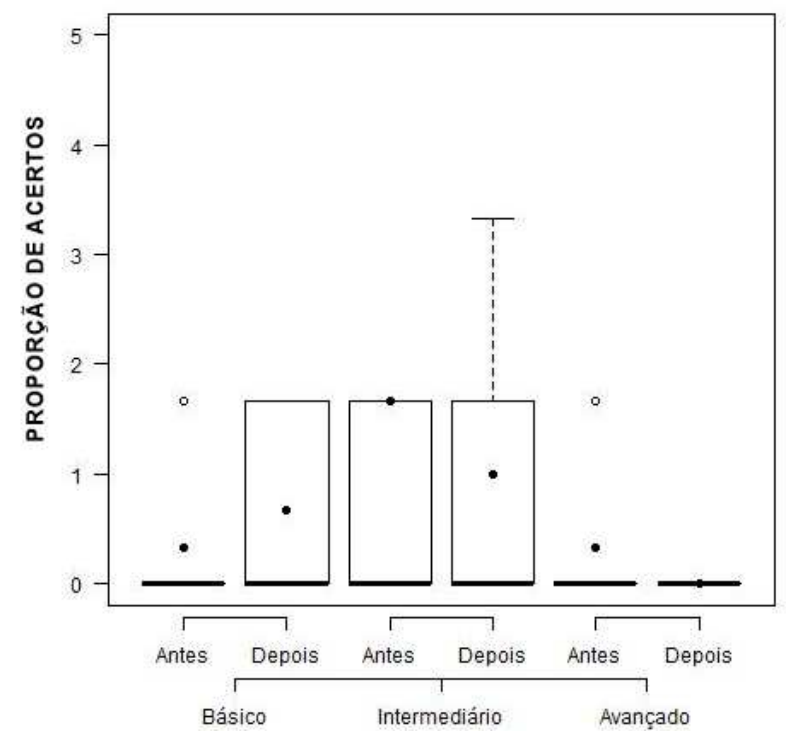

\section{Gráfico 12: Vozeamento por Idade de aquisição e Nível de Proficiência: contexto seguinte desvozeado ou pausa}

No nível básico, o gráfico mostra mais aplicações dentre os informantes que iniciaram a aquisição depois dos 12 anos. Se observarmos a Tabela 9, que apresenta a proporção de vozeamento por informante em cada contexto seguinte, vemos que, dos três casos de vozeamento no nível básico nesses contextos, um foi aplicado pelo Informante 1, que iniciou a aquisição antes dos 12 anos e os outros dois foram aplicados pelos informantes 3 e 6, que iniciaram a aquisição após os 12 anos. No nível 
intermediário, dentre os 8 casos de vozeamento nesses contextos, observa-se uma aplicação maior no grupo que iniciou a aquisição depois dos 12 anos mas, de maneira geral, os dois grupos apresentam uma proporção de vozeamento muito semelhante. No nível avançado, por fim, a única aplicação de vozeamento nesses contextos foi produzida pelo Informante 22, que iniciou a aquisição antes dos 12 anos.

\subsection{Discussão}

Esta seção discute os resultados referentes à regra de assimilação de vozeamento do inglês apresentados em 4.3.

\subsubsection{Falantes Nativos}

Os resultados referentes aos falantes nativos, apresentados em 4.3.1, mostraram que o vozeamento foi aplicado em apenas $44,05 \%$ dos casos, ainda que todos os contextos favorecessem a produção de fricativas vozeadas. Acreditamos que dois fatores possam estar influenciando esse resultado: a o desvozeamento do contexto precedente e o desvozeamento ${ }^{18}$ da fricativa em posição final, influenciada pelo contexto seguinte.

De acordo com Yavas (2008, p. 57) a dessonorização de plosivas e fricativas em posição final é um fenômeno bastante comum no inglês. No que diz respeito às plosivas, o autor afirma que /b, d, g/ só apresentam o vozeamento completo em posição intervocálica (ex: aboard, adore, eager) e, em posição inicial (ex: $\underline{b} a y, \underline{d} a y$, gay) e final (ex: $c a \underline{b} s a \underline{d} s a g$ ), o vozeamento tende a ser parcial ou praticamente inexistente. ${ }^{19} 0$ mesmo se observa no caso das fricativas: de acordo com o autor, o vozeamento só é completo em posição intervocálica (ex: reșume) e, em posição inicial (ex: zilp) e final (ex: buzz) esse vozeamento tende a ser parcial.

Se observarmos os resultados apresentados na Tabela 2, referentes à influência do contexto precedente sobre o vozeamento na produção dos falantes nativos desta pesquisa, percebemos que houve menos aplicações de vozeamento nos casos em que o

\footnotetext{
18 Neste trabalho, utilizamos os termos desvozeamento e dessonorização para nos referirmos ao mesmo fenômeno.

19 É importante salientar que, de acordo com o autor, as características acústicas de /b, d, g/ desvozeados não são as mesmas de /p, t, k/, ou seja, o contraste não é perdido após o processo de desvozeamento. Além disso, o autor salienta que desvozeamento em posição final (ex: cab́) tende a ser maior do que o desvozeamento em posição inicial (ex: $\underline{\text { bay }}$ ).
} 
contexto precedente era uma fricativa ou uma plosiva -justamente as consoantes que poderiam sofrer algum tipo de dessonorização. Por isso, verificamos acusticamente o contexto precedente de todas as palavras em que a fricativa não foi vozeada pelos falantes nativos e observamos que a fricativa /v/ foi produzida como surda em $0,7 \%$ dos casos, nas palavras loves e leaves, e as plosivas /b/ e /g/ em 31\% dos casos, nas palavras dogs, bird's, kids e boyfriend's. Nesses casos, o desvozeamento do contexto precedente resulta na aplicação da regra de assimilação de vozeamento progressiva, na qual o morfema -s é produzido como [s] quando antecedido por uma consoante surda. Assim, pelo menos nesses contextos, a baixa taxa de vozeamento pode ser explicada por esse processo de assimilação.

A baixa taxa de aplicação do vozeamento do morfema -s pelos falantes nativos nos casos que não permitiam a dessonorização do contexto precedente pode ser explicada pelo mesmo processo de desvozeamento. Vimos que a produção de fricativas plenamente vozeadas tende a ocorrer somente no meio de palavra. Em posição de final de palavra, o vozeamento tende a ser reduzido, sobretudo quando a fricativa se encontra diante de pausa ou de consoante surda (cf. Yavas 2008, p. 58). Nos casos de fricativa seguida de contexto vozeado, esse desvozeamento é bloqueado e a fricativa tende a manter-se sonora. Isso é exatamente o que se observa nos resultados apresentados na Tabela 1, que apresenta a influência do contexto seguinte sobre o vozeamento nos dados dos falantes nativos. Observa-se que o vozeamento do -s foi favorecido quando o contexto seguinte era sonoro (vogal ou consoante vozeada) e desfavorecido quando o contexto seguinte era surdo ou pausa.

Os casos de desvozeamento de fricativa seguida de consoante surda, segundo Smith (1997), podem ser vistos como um processo de assimilação regressiva, pois o fato de a consoante seguinte ser desvozeada favorece o desvozeamento da fricativa anterior. Como vimos na Seção 4.1.2, a assimilação regressiva ocorre no inglês quando fricativas sofrem dessonorização diante de plosivas surdas, como no exemplo five tons já mencionado, em que o [v] de five perde o traço [+voz] diante do $[\mathrm{t}]$ de tons por assimilar o vozeamento do contexto seguinte (cf. Roca e Johnson, 1999). No que diz respeito aos casos de desvozeamento da fricativa seguida de pausa, a autora afirma que a explicação mais comum é o fato de que produzir o vozeamento e, ao mesmo tempo, a fricção característica das fricativas, é difícil neste contexto (cf. Ohala, 1983), pois o esforço articulatório tende a ser reduzido em posição final. 
Acreditamos, portanto, que a dessonorização do contexto precedente, que bloqueia a assimilação progressiva, e o desvozeamento da fricativa em posição de final de palavra, processo comum no inglês (cf. Yavas 2008, Smith 1997, Ohala, 1983), são fatores que justificam a baixa taxa de vozeamento do morfema -s pelos falantes nativos neste trabalho. Cabe salientar, também, que, nesta pesquisa, nos propusemos a verificar acusticamente apenas o vozeamento das fricativas (cf. 4.2.4), pois é o principal correlato acústico para a distinção entre fricativas surdas e sonoras. Entretanto, a vibração das pregas vogais não é o único fator que determina o contraste de vozeamento nas fricativas. Além da barra de sonoridade, da curva de F0 e dos pulsos glotais que caracterizam o vozeamento, frequência e duração são correlatos acústicos relevantes para a diferenciar o vozeamento dessas consoantes. Faz-se necessário verificar, portanto, o papel de outros correlatos acústicos para a distinção entre [s] e [z] nos casos em que o vozeamento não foi constatado no tipo de verificação acústica realizado nesta pesquisa.

\subsubsection{Falantes de inglês como L2}

Vejamos os resultados referentes aos falantes brasileiros de inglês como segunda língua, apresentados em 4.3.2. Vimos que o vozeamento foi aplicado em $25,9 \%$ dos dados, incluindo tanto contextos de fricativa seguida por um segmento sonoro quanto contextos de fricativa seguida de consoante surda ou pausa.

Observou-se que a aplicação do vozeamento foi favorecida por segmentos vozeados no contexto seguinte e que, nos casos de fricativa seguida de consoante desvozeada ou de pausa, o vozeamento foi aplicado em apenas 0,6\% dos dados (cf. Tabela 5). Os resultados também indicaram que a produção de fricativas vozeadas foi favorecida por vogais no contexto precedente (Cf. Tabela 6). Apesar de as fricativas serem precedidas de segmentos vozeados em todas as palavras do experimento, isso poderia indicar que, sendo a vogal o elemento mais sonoro na escala de sonoridade, ela teria uma maior influência sobre o vozeamento do segmento seguinte. Entretanto, como vimos, além de aplicação do vozeamento ter sido favorecida por segmentos vozeados no contexto seguinte, a taxa de aplicação do vozeamento em contextos que não permitiam a assimilação regressiva foi quase inexistente. Fica claro, portanto, que foi o vozeamento do contexto seguinte que 
influenciou a produção de fricativas vozeadas nos contextos em análise, e não o do contexto precedente.

Os resultados também apontaram que a variável nível de proficiência foi estatisticamente relevante e que os falantes de nível intermediário foram os que apresentaram mais casos de vozeamento (cf. Gráfico 5). Entretanto, é importante salientar que o nível de proficiência foi estatisticamente significante apenas porque foi considerada a taxa de aplicação geral do vozeamento pelos informantes - a qual inclui os contextos em que o vozeamento poderia ser resultado de assimilação regressiva, e não progressiva. Isso se confirma quando observamos a taxa de aplicação do vozeamento especificamente no casos que não permitiam a aplicação da assimilação regressiva, do português. 0 Gráfico 13 a seguir apresenta a proporção de vozeamento somente nos casos de fricativa seguida de pausa ou consoante desvozeada, separada por nível de proficiência. Pode-se observar que, nesses contextos específicos, não há um aumento na aplicação do vozeamento no decorrer do processo de aprendizagem, já que todos os níveis apresentam uma taxa de aplicação muito baixa e muito aproximada.

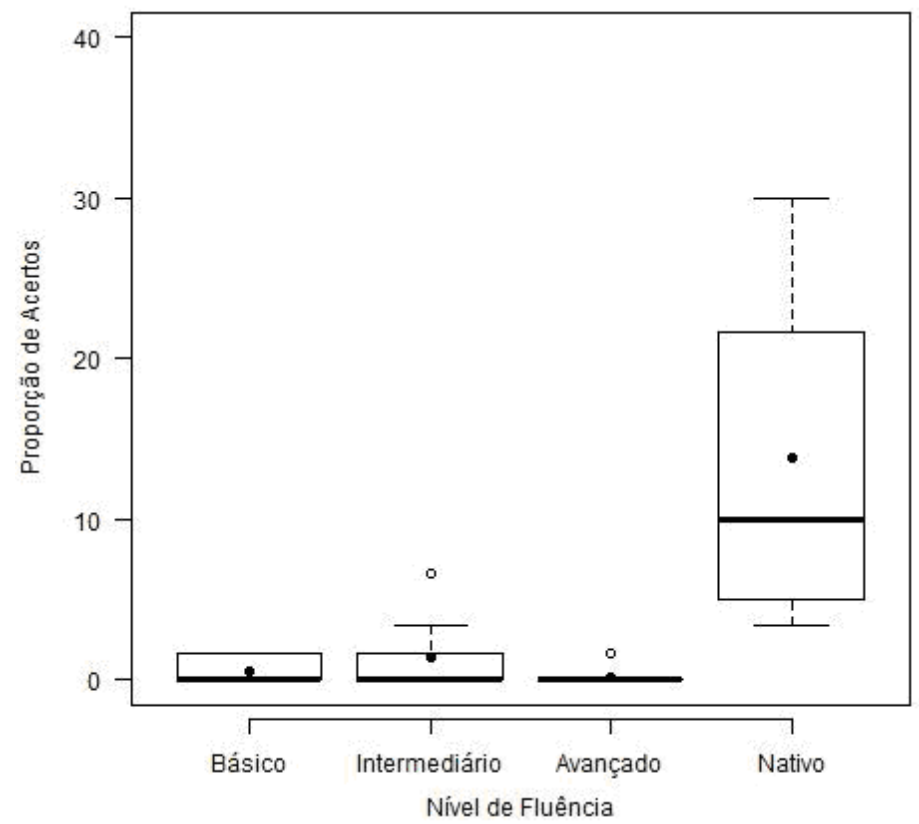

Gráfico 13: Aplicação do vozeamento em fricativas seguidas de pausa ou de consoante desvozeada por nível de proficiência

Portanto, ainda que o nível intermediário tenha apresentado mais aplicações de vozeamento do que os informantes dos outros dois níveis, não podemos afirmar que a regra do inglês foi adquirida em nenhum nível de proficiência se olharmos somente para 
os casos que não permitiam a assimilação regressiva. Percebe-se, assim, uma transferência da regra fonológica da L1 para a L2 nos três níveis de proficiência.

Dentre as variáveis testadas, Categoria Morfológica e Idade de Início da Aquisição não foram estatisticamente relevantes nos resultados referentes aos falantes de inglês como L2. Observou-se que o vozeamento da fricativa pelos falantes brasileiros não foi influenciado pela categoria do morfema -s, mas pelo contexto fonológico que favorecia a aplicação da regra do português (cf. Tabela 12). A variável Idade de Início da Aquisição, por fim, indicou uma tendência de os falantes que iniciaram a aquisição antes dos 12 anos aplicarem mais o vozeamento nos três níveis de proficiência (cf. Gráfico 11). Contudo, essa diferença não é constatada se considerarmos apenas os casos em que o vozeamento não poderia ser influenciado pelo contexto seguinte, pois, como vimos, a proporção de vozeamento foi extremamente baixa nesses contextos (cf. Gráfico 12).

Os resultados indicam, portanto, que a assimilação de vozeamento progressiva do /s/ no inglês não foi adquirida em nenhum nível de proficiência. A Seção 4.4.3 a seguir discute as razões que podem ter impedido a aquisição da regra pelos falantes brasileiros.

\subsubsection{Aquisição da regra fonológica do inglês por falantes brasileiros}

Para analisarmos a baixa taxa de aplicação da assimilação progressiva pelos falantes brasileiros, retomemos o que se sabe a respeito da direção da assimilação. Vimos na Seção 4.1 que, nas línguas em que a assimilação progressiva ocorre, sempre há um condicionamento morfológico ou fonológico específico. No inglês, como vimos em 4.1.1, há exemplos de assimilação de vozeamento progressiva e regressiva mas, enquanto a assimilação progressiva é restrita aos morfemas de plural, de terceira pessoa do singular e do caso genitivo (ex: bug[z], live[z], John'[z]), a assimilação regressiva não é restrita a nenhum contexto específico e ocorre de maneira generalizada na língua (ex: fai[f] tons). Pode-se dizer, portanto, que a assimilação progressiva do inglês é mais marcada do que a regressiva por ser mais restrita e mais complexa, características relevantes para a definição de marcação (cf. Rice 2007, p. 80).

Vimos, também, que o inglês apresenta pares mínimos como since [sins] $X$ sins [sınz] e peace [pi:s] X peas [pi:z], em que o traço [voz] na obstruinte em posição final é o único responsável pela mudança de significado. De acordo com Rice (2007, p. 82), nas 
línguas que apresentam esse contraste em posição final, a obstruinte sonora é considerada um elemento marcado, pois apresenta uma tendência à neutralização, enquanto a obstruinte surda é considerada um elemento não marcado, pois é o que emerge nos casos em que a neutralização ocorre.

Como vimos no Capítulo 2, o termo "marcação" é utilizado na pesquisa em aquisição de L2 com o objetivo identificar o grau de dificuldade na aquisição de determinada propriedade da língua-alvo. Segundo Eckman (1977), os aspectos da L2 que forem diferentes da L1 e forem mais marcados do que na língua materna serão mais difíceis de serem adquiridos. No caso do vozeamento do -s analisado neste capítulo, além de a direção da assimilação ser diferente no inglês e no $\mathrm{PB}$, a regra progressiva do inglês é mais marcada, o que caracteriza uma dificuldade maior para o aprendiz brasileiro (cf. a Hipótese da Marcação Diferencial (Eckman, 1977)). Além disso, diferentemente do inglês, o PB não apresenta contraste fonológico de vozeamento em obstruintes em posição final, o que também representa uma dificuldade para o aprendiz de inglês como L2.

Outro fator que merece atenção é o fato de que os contrastes alofônicos (aqueles que não modificam o significado das palavras) tendem a ser menos salientes perceptualmente do que os contrastes fonológicos (Peperkamp, 2011). Para os falantes de português, o contraste entre /s/ e /z/ em posição de onset (ex: /s/elo X /z/elo), que causa mudança de significado, é mais saliente do que o contraste em final de palavra (casa[s] X casa[z] amarelas), que não distingue significado. Sendo assim, o sistema perceptual do aprendiz brasileiro está programado para não perceber o contraste entre [s] e [z] em final de palavra, o que, por hipótese, dificulta o processamento e, consequentemente, a produção desse contraste no inglês, que tem caráter fonológico.

Os resultados da pesquisa de Mendes (2017) mostram evidências de que a percepção pode, de fato, ser um fator relevante para a aquisição de fricativas vozeadas em posição final no inglês. Como vimos em 4.1.3, o autor investigou a percepção dos alomorfes [s], [z] e [Iz] em final de palavra no inglês por falantes brasileiros. Seus resultados indicaram que o [z] apresentou a taxa de acertos mais baixa, principalmente nos casos de fricativa seguida de consoante desvozeada ou de pausa, em que o vozeamento não existe no português.

Segundo Flege (1995), para adquirir um som da L2 que não ocorre na L1 é preciso que o som não apenas seja detectado através de uma percepção acústica, mas 
que uma nova categoria acústica seja formada no sistema sonoro do aprendiz. Através do Speech Learning Model (Flege, 1995), o autor propõe que é possível prever a dificuldade na aquisição de sons não-nativos de acordo com o grau de similaridade entre os sons da L1 e da L2. 0 modelo prevê que sons da L2 idênticos aos da L1 serão adquiridos com facilidade, sons da L2 que são muito diferentes da L1 serão adquiridos com um pouco menos de facilidade, e os sons da L2 que são parecidos, mas que não são idênticos aos da L1, serão os mais difíceis de serem adquiridos. Em outras palavras, é necessário um certo grau de dissimilaridade entre os sons da L1 e os da língua-alvo para que o aprendiz seja capaz de perceber o contraste. Assim, nos casos em que os sons são parecidos, mas não idênticos, o aprendiz tende a processar o som da L2 numa categoria perceptual da L1.

Segundo autores como Hallé, Best e Levitt (1999), determinados contrastes são muito difíceis de serem percebidos e, mesmo com muito treino e exposição à língua-alvo, continuam sendo processados de maneira não-nativa, inclusive nos casos de aprendizes que iniciaram a aquisição na infância. De acordo com Peperkamp (2011, p.6), a aquisição de segmentos, suprassegmentos, estrutura silábica e fonotaxe na L1 ocorre muito cedo, já que, com um ano de idade, a criança já apresenta uma capacidade perceptual muito parecida com a de seus pais. Segundo a autora, ainda que seja possível desenvolver a percepção de uma L2 em falantes que iniciaram a aquisição após a primeira infância, o desempenho idêntico ao de um falante nativo é, aparentemente, inalcançável. Isso vai ao encontro dos resultados obtidos nesta pesquisa, já que, ao contrário do esperado, nem mesmo os aprendizes que iniciaram a aquisição antes da puberdade apresentaram uma proporção de vozeamento significativa nos contextos que não permitiam a aplicação da regra do português.

Em suma, o fato de a assimilação progressiva ser uma regra marcada e de o contraste entre [s] e [z] em posição de final de palavra ser alofônico no português e, portanto, pouco saliente para os falantes brasileiros, parecem ser fatores relevantes para explicar os resultados descritos neste capítulo. 


\section{Capítulo 5}

\section{RETRAÇÃO DE ACENTO}

Este capítulo apresenta o estudo referente à regra de retração de acento, que ocorre de maneira muito semelhante no inglês e no português. A Seção 5.1 a seguir caracteriza a regra nas duas línguas. A metodologia empregada no desenvolvimento deste estudo é apresentada na Seção 5.2. Na Seção 5.3, são apresentados os resultados e, por fim, na Seção 5.4, é apresentada uma discussão a respeito dos resultados referentes à aquisição desta regra.

\subsection{A regra retração de acento}

Para se discutir a retração acentual, é necessário primeiro caracterizar o que seja acento lexical, já que, como veremos, nas duas línguas a retração ocorre quando há um choque de acentos primários.

De acordo com Roach (2000, p.93), o acento pode ser estudado foneticamente de duas maneiras: sob o ponto de vista da produção ou da percepção. No que concerne à produção, em termos articulatórios, o acento de uma sílaba depende de mais energia muscular e mais atividade respiratória do que se observa em uma sílaba átona. No que diz respeito à percepção, todas as sílabas acentuadas possuem como característica a proeminência, isto é, as sílabas acentuadas são reconhecidas como tais por serem mais proeminentes do que as sílabas átonas. 0 acento é, portanto, visto como uma propriedade relacional, pois uma sílaba só pode ser considerada acentuada se comparada a outras sílabas não acentuadas.

Acusticamente, os quatro principais correlatos do acento são a frequência fundamental (F0 ou pitch), a duração, a intensidade e, menos comumente, os formantes, e as línguas podem apresentar comportamentos diferentes com relação a esses correlatos (Reetz e Jongman, 2009, p. 210). No português, embora no passado Câmara Jr. (1972) apontasse o F0 como o principal correlato acústico do acento, com o desenvolvimento de novas tecnologias para a verificação acústica diversos estudos mais 
atuais apontam a duração como o parâmetro acústico mais importante para a definição do acento lexical (Major, 1992; Massini, 1992; Barbosa, 2000; Ferreira, 2008).

Para ilustrar o papel da duração na atribuição do acento em português, apresentamos nas Figuras 4 e 5 a seguir a duração das sílabas das palavras caqui (fruta) e cáqui (cor), que se diferem apenas pela posição do acento. A Figura 4 apresenta o espectrograma da palavra caqui $\left(c^{2} Q U^{20}\right)$, produzida pela pesquisadora na frase-veículo Diga caqui berrando. Observe-se que a duração na sílaba ca- é de 0,174 s, enquanto que qui é 0,301652s. Mesmo tendo em conta a duração intrínseca dos segmentos, a sílaba final apresenta o dobro de duração que a primeira.

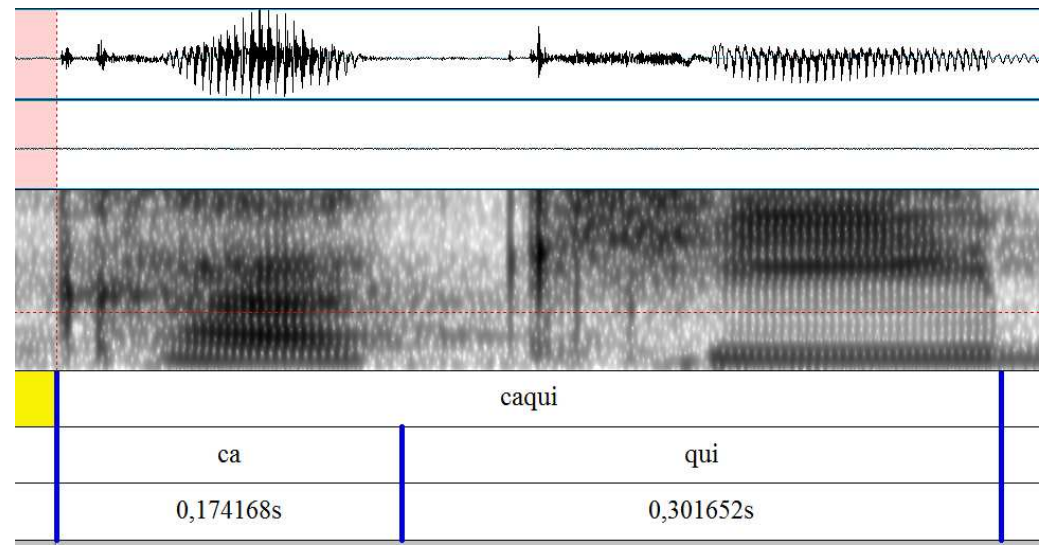

Figura 4: Duração das sílabas da palavra caqui produzida por uma falante nativa do PB

O Espectrograma 5, por sua vez, apresenta a produção da palavra cáqui (CAqui), na qual a sílaba $c a$ - é a mais forte, produzida pela pesquisadora na mesma frase-veículo. Percebe-se que a duração desta sílaba acentuada é de 0,231s, valor apenas ligeiramente superior ao -qui, com 0,198851s. Quando comparamos a sílaba nas palavras diferentes, percebe-se também esta diferença: o $c a$-átono apresentado na Figura 4, é pouco menor do que o ca- tônico (cf. Figura 5); o mesmo ocorre com o -qui: esta sílaba átona é 50\% mais curta do que sua contraparte tônica (0,198851s vs. 0,301652s). Através da comparação entre duas sílabas que possuem os mesmos segmentos e diferem apenas pela atribuição do acento, podemos observar que sílabas tônicas são, de fato, mais longas do que sílabas átonas no PB.

\footnotetext{
${ }^{20}$ Neste trabalho, as letras em caixa alta representam as sílabas acentuadas.
} 


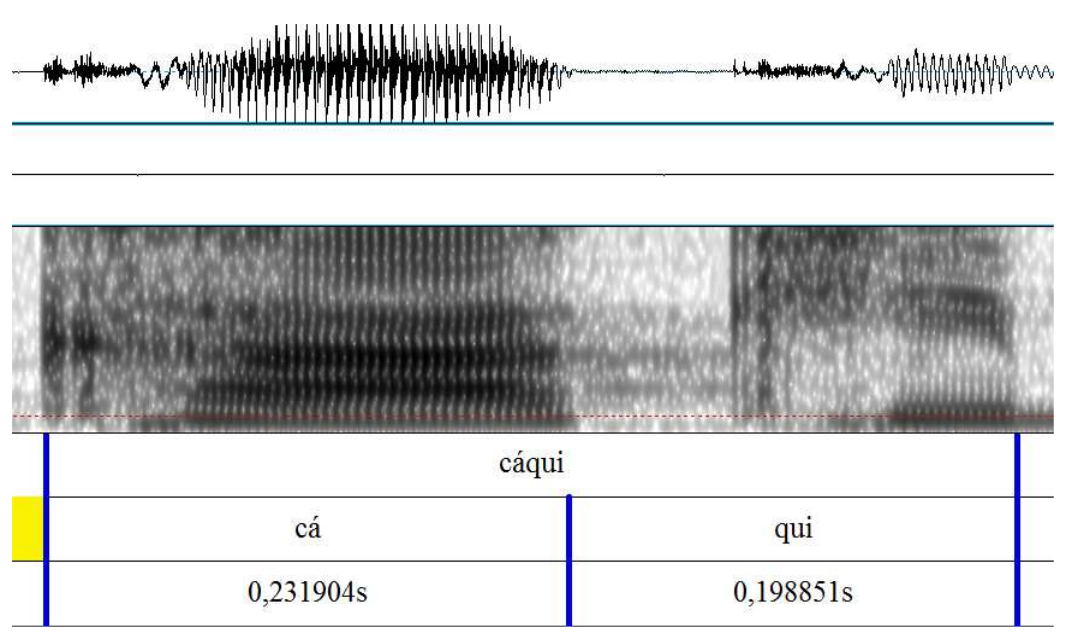

Figura 5: Duração das sílabas da palavra cáqui produzida por uma falante nativa do PB

No caso do inglês, uma sílaba acentuada apresenta tipicamente frequência fundamental (F0 ou pitch) mais alta, maior duração e maior intensidade em comparação com sílabas átonas. Fry (1958) e Bolinger (1986) afirmam que o correlato mais importante para a definição de uma sílaba acentuada no inglês é o pitch.

A Figura 6 a seguir, extraída de Reetz e Jongman (2009, p. 212), mostra os oscilogramas, os espectrogramas e os contornos de pitch e de intensidade referentes à palavra record produzida como substantivo (REcord) em (a) e (b) e como verbo (reCORD) em (c) e (d) por um falante nativo de inglês.

Observa-se que, nas sílabas tônicas (em (a) e (b) re- e em (c) e (d) -cord), a frequência fundamental (F0) e a intensidade são mais altas e as sílabas são mais longas. Segundo os autores, estudos de percepção baseados na fala sintética, isto é, quando os segmentos produzidos são os mesmos, mas os correlatos do acento são alterados, indicam que o F0 (pitch) e a duração são correlatos mais importantes para a identificação do acento no inglês do que a intensidade (cf. Reetz e Jongman 2009, p. 212). 

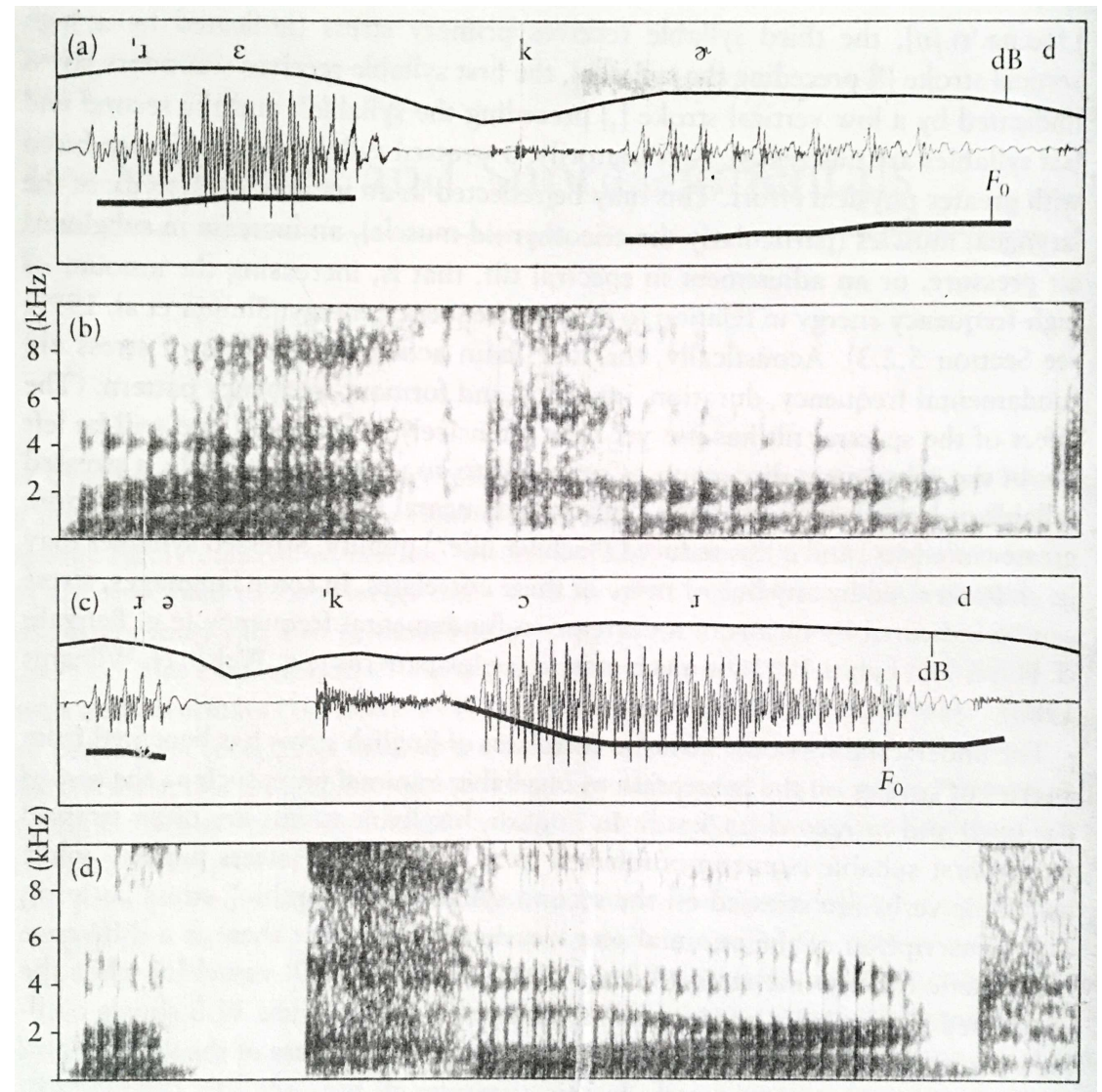

Figura 6: Oscilograma, espectrograma, intensidade e curva de $\mathrm{FO}$ da palavra record produzida como substantivo em (a) e (b) e como verbo em (c) e (d) (Reetz e Jongman 2009, p. 212)

Além dos parâmetros acústicos de acento, as línguas também diferem com relação ao ritmo. Há línguas que apresentam ritmo acentual, as quais apresentam intervalos regulares entre os acentos independentemente do número de sílabas entre eles, como o inglês, o russo e o árabe, e outras que possuem ritmo silábico, nas quais os intervalos entre acentos aumentam de acordo com o número de sílabas entre eles, como o espanhol, o francês e o italiano (Massini, 1992, p.11).

Diferentemente do inglês, cujo ritmo é normalmente caracterizado como acentual, o PB gera discussões com relação a esse aspecto. Segundo Massini (1992, p.11), por exemplo, a língua apresenta características tanto do ritmo acentual quanto do silábico. De acordo com a autora, enquanto o falar gaúcho é detentor de um ritmo mais silábico, o falar paulistano é mais acentual, já que as sílabas apresentam durações muito diferentes entre si. Similarmente, Abaurre-Gnerre (1981, p. 39) afirma que o ritmo do PB não pode ser considerado absolutamente silábico ou absolutamente acentual devido à variação dialetal, sendo as variantes da Bahia e do Rio Grande do Sul detentoras de um 
ritmo mais silábico e as variantes do Rio de Janeiro e do Espírito Santo, de um ritmo mais acentual. De acordo com a autora, mesmo dentro da mesma região uma língua pode apresentar padrões acentuais diferentes, a depender do estilo de fala: enquanto a fala formal e lenta caracteriza um ritmo mais silábico, a fala informal e rápida caracteriza um ritmo mais acentual. Barbosa (2000), por fim, afirma que a dicotomia ritmo silábico/acentual deve ser vista apenas como um rótulo indicativo de tendências nas línguas estudadas.

Um fenômeno rítmico comum a todas as línguas é a preferência por uma alternância entre sílabas fortes (acentuadas) e sílabas fracas (com acento mais fraco ou sem acento), o que Selkirk (1984, p.52) chamou de Princípio de Alternância Rítmica (Principle of Rythmic Alternation). Esse princípio, também chamado de euritmia por Nespor e Vogel (1986), explica a tendência de se evitar duas sílabas acentuadas em sequência, o que causa um choque acentual.

À luz da Fonologia Métrica, Liberman \& Prince (1977) foram os primeiros a abordar a noção de choque acentual, caracterizando o fenômeno através de relações de proeminência relativa internas às palavras. Segundo os autores, o choque acentual não se caracteriza por qualquer sequência fonética de acentos fortes, pois apenas acentos adjacentes em uma mesma linha da grade métrica são considerados como acentos em colisão sujeitos a fenômenos de reajuste rítmico.

Os estudos de Nespor e Vogel (1986), sobre o italiano, de Selkirk (1984), sobre o inglês, e de Abousalh (1997) e Santos (2001), sobre o português, apontam que a estratégia de retração de acento é utilizada por falantes dessas línguas para a resolução de choques acentuais. A retração, que ocorre dentro do domínio da frase fonológica nessas línguas, faz com que o acento da primeira palavra que constitui o choque seja deslocado para a esquerda. No inglês, por exemplo, em uma sequência de choque acentual como thirTEEN MEN, o acento na última sílaba de thirteen é transferido para a sílaba anterior, o que resulta em THIRteen MEN, de modo a privilegiar a alternância entre sílabas fortes e fracas.

A regra de retração de acento no inglês e no PB é apresentada nas seções a seguir. 


\subsubsection{Retração de Acento no Português Brasileiro}

No português, o acento primário pode ocorrer na última (ex: $c a F E ́$ ), na penúltima (ex: meNIno) ou na antepenúltima sílaba (ex: MÉdico). De acordo com Abousalh (1997) e Gayer e Collischonn (2007), várias são as estratégias de resolução do choque acentual na língua: o deslocamento de um dos acentos, a desacentuação de uma das proeminências, a inserção de uma pausa e a retração de acento, foco neste trabalho.

Gayer e Collischonn (2007), que analisaram as estratégias utilizadas por falantes de Porto Alegre e de São Borja (RS) em situações de choque acentual através de uma análise de oitiva, verificaram que, de 803 ocorrências de choque acentual, a retração (ex: LAvar ROUpa) ocorreu em 60 casos (7\%), a inserção de pausa (ex: enTÃo (...) MInha mãe) em 146 casos (20\%), a desacentuação de uma das proeminências, comum em monossílabos (ex: faz VINte anos), em 493 casos (61\%), a posposição (ex: minha irMÃ $m o R A$ ) em 36 casos (4\%) e a permanência do choque acentual (ex: funÇÃO TOda) em 68 casos (8\%). Apesar de as ocorrências de retração de acento não apresentarem um número expressivo nesse estudo, a pesquisa confirma a ocorrência dessa estratégia em tais variantes do PB.

Segundo o estudo de Abousalh (1997), desenvolvido à luz da interface entre sintaxe e fonologia, se o condicionamento para a retração de acento fosse apenas rítmico, seria esperado que os choques acentuais fossem sempre desfeitos, pois trata-se de uma violação da regra de alternância rítmica. Como a retração acentual é variável, a autora se propôs a investigar quais fatores influenciam na escolha entre desfazer ou não desfazer o choque no PB. Seu estudo revela que, para que um choque acentual seja desfeito, ele precisa estar dentro de uma mesma frase fonológica. Em outras palavras, choques de acento em fronteiras de frase fonológica não precisam ser necessariamente desfeitos, e a retração ou apagamento de acento para evitar choques só se manifestam sistematicamente quando o choque é interno a uma frase fonológica.

A importância do contexto prosódico para a resolução do choque acentual pode ser observada no exemplo (9) a seguir (exemplo de Tenani (2017, p.117). Observa-se que, em (9a), Jornal Hoje é o nome de um conhecido telejornal brasileiro, enquanto que em (9b), hoje refere-se ao dia em que um determinado jornal foi visto. Segundo as regras de mapeamento prosódico, Jornal Hoje (9a) constitui uma única frase fonológica, enquanto que jornal hoje (9b) são mapeados como duas frases fonológicas diferentes. 
(9) a. [Você] $\phi$ [viu] $\phi$ [o Jornal Hoje?] $\phi$

b. [Você] $\phi[\mathrm{viu}] \phi[$ o jornal $] \phi[$ hoje?] $\phi$

O diferente mapeamento prosódico em domínios explica porque a retração acentual ocorre apenas na sentença (9a), pois as duas palavras que constituem o choque se encontram na mesma frase fonológica. Na sentença (9b), a regra é bloqueada porque cada palavra pertence a uma frase fonológica distinta, o que não permite o movimento do acento.

No entanto, o estudo de Sandalo e Truckenbrodt (2002) defende que o fato de o choque acentual estar dentro de uma mesma frase fonológica não é suficiente para justificar o reajuste do acento. Para os autores, a retração ocorre quando as frases fonológicas têm o mesmo tamanho prosódico, ou seja, quando possuem o mesmo número de palavras fonológicas. Assim, a retração é permitida no exemplo (10a) porque as frases fonológicas possuem o mesmo tamanho, mas não é permitida em (10b) porque as frases fonológicas possuem tamanhos diferentes:

(10) a. [caFÉ QUENte] $\phi$ [queima a boca] $\phi \rightarrow$ [CAfé QUENte] $\phi$ [queima a boca] $\phi$ b. [caFÉ QUENte] $\phi$ [queima] $\phi \quad$ \#[CAfé QUENte] $\phi[$ queima] $\phi$

A pesquisa de Santos (2002), que também investigou a relação entre sintaxe e fonologia, mostra que "categorias sintáticas foneticamente vazias influenciam na organização rítmica dos enunciados" (p. 68). A autora discute a possibilidade de um pronome foneticamente nulo ( $p r o$ ) impedir a retração de acento em casos de choque acentual entre verbo e advérbio. 0 estudo mostra que em (11a), por exemplo, o choque acentual pode ser evitado através da retração de acento. Em (11b), por outro lado, a retração causaria estranhamento:

a. o josé maria canTOU HOje $\rightarrow$ o josé maria CANtou HOje

b. o josé maria conTOU HOje $\rightarrow$ \# o josé maria CONtou HOje

Segundo a autora, a retração de acento não pode ocorrer em (11b) porque há estruturalmente uma posição preenchida por um pronome foneticamente nulo (pro) entre o verbo e o advérbio no papel de objeto. 0 exemplo (11a), por outro lado, não 
possui essa categoria vazia, pois não há estruturalmente nenhum elemento entre o verbo intransitivo (ou "usado intransitivamente") e o advérbio. Assim, seu estudo mostra que características sintático-semânticas também são relevantes no estudo de padrões acentuais, e que o tamanho da frase fonológica não é o único determinante para a retração de acento, já que as frases fonológicas em (11a) e (11b) possuem o mesmo tamanho.

Para verificar o caráter fonético da retração de acento no $\mathrm{PB}$, os estudos de Barbosa (2002) e Madureira (2002) investigaram se as estratégias de desfazimento do choque acentual demonstradas fonologicamente na língua também ocorriam numa perspectiva fonético-acústica. Os resultados do estudo de Barbosa (2002), que analisou o acento a partir do parâmetro da duração, mostram que, em vez de retração de acento, houve um aumento na duração da sílaba oxítona da primeira palavra do choque, ou seja, um favorecimento para a ocorrência de choque acentual. 0 estudo de Madureira (2002), que analisou, além da duração, a frequência fundamental (F0), também mostrou que a retração acentual não foi a estratégia escolhida pelos informantes.

As Figuras 7 e 8 a seguir ilustram a palavra "jornal" na frase Você viu o jornal hoje? (cf. exemplo 9) produzida pela pesquisadora em dois contextos: quando "jornal" e

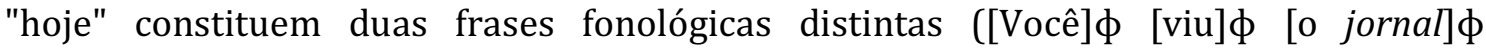
[hoje?]ф) (Figura 7), e quando "Jornal Hoje" se refere ao telejornal brasileiro e as duas

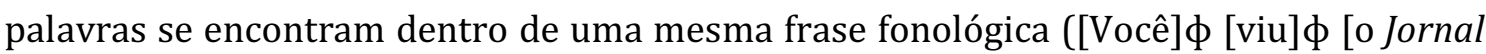
Hoje?]ф) (Figura 8).

Na Figura 7, observa-se que, enquanto a duração da sílaba jor- é 0,218732s e a duração da sílaba -nal é de 0,332s.

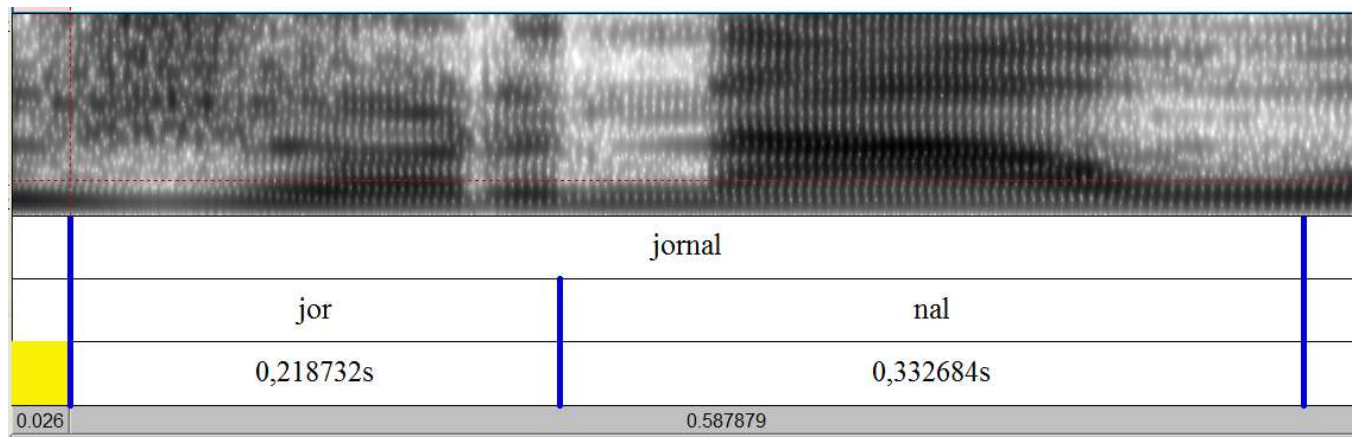

Figura 7: palavra "jornal" inserida em contexto que não permite a retração acentual: [jornal] $\phi$ [hoje] $\phi$ 
Na Figura 8, a duração da sílaba jor- é de 0,210s e da sílaba -nal é de 0,213s. Muito embora a duração da primeira sílaba seja parecida nos dois casos, há uma diminuição significativa na duração da última sílaba da primeira palavra, exatamente aquela que constitui choque acentual, conforme apontado por Barbosa (2002). Observe que a duração das duas sílabas da palavra "jornal" no espectograma segue exatamente o mesmo padrão duracional encontrado no Espectograma 6 para palavras dissílabas paroxítonas, a saber, a duração das sílabas é muito parecida.

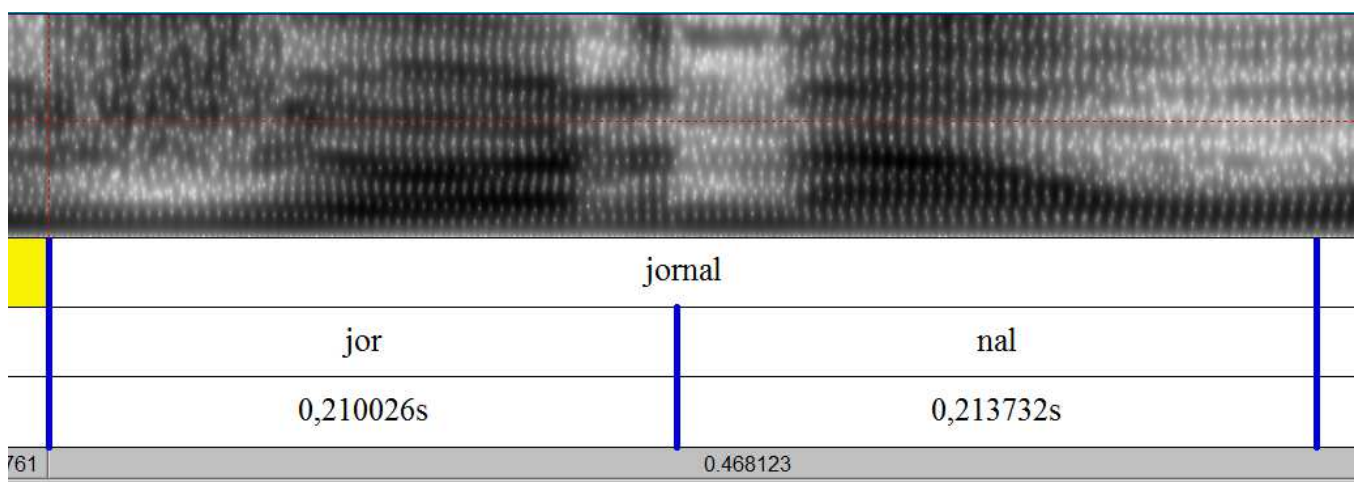

Figura 8: palavra "jornal" inserida em contexto propício para a retração acentual: [Jornal Hoje] $\phi$

Por fim, observa-se que a retração de acento no PB tende a ocorrer especificamente em choques entre sílabas com acento primário, conforme o exemplo (12) a seguir:
a. caFÉ QUENte $\rightarrow$ CAfé QUENte
b. jeSUS CRISto $\rightarrow$ JEsus CRISto
c. caFÉ requenTAdo $\rightarrow{ }^{*}$ CAfé requenTAdo
d. jeSUS ressusciTAdo $\rightarrow$ *JEsus ressusciTAdo

Enquanto a retração em (12a) e (12b) é possível porque há um choque entre dois acentos primários, a retração causaria estranhamento em sequências como (12c) e (12d), em que os acentos primários são não-adjacentes.

\subsubsection{Retração de Acento em Inglês}

Diferentemente do acento do português que, como vimos na Seção 5.1.1, pode ocorrer apenas nas três primeiras sílabas (ex: caFÉ, saPAto, LÁpide), o acento do inglês 
pode ocorrer numa janela de quatro sílabas, como mostram os exemplos kangaROO, toMAto, ARticle e CAtegory.

Segundo Selkirk (1984, p.52), a alternância entre sílabas fracas e fortes define uma organização rítmica ideal para o inglês, o que explica a tendência em evitarem-se duas sílabas acentuadas em sequência. Assim como o PB, o inglês também apresenta a retração de acento como um recurso para evitar o choque acentual, conforme podemos observar nos exemplos de Hayes (1984, p. 33):
a. fourTEEN - FOURteen WOmen
b. MissiSSIppi - MIssissippi LEgislature
c. seventy-SEven - SEventy-seven SEals

É possível observar que em (13a), devido ao choque entre os acentos da última sílaba da primeira palavra e da primeira sílaba da segunda palavra, há uma retração do acento, que passa de -teen para four-. 0 exemplo (13b), por sua vez, mostra que a retração é possível mesmo quando não há uma adjacência de acentos lexicais. Um processo semelhante ocorre em (13c), quando o acento de palavra seven é transferido para a palavra anterior, seventy, para privilegiar a alternância entre sílabas fortes e fracas $^{21}$. Hayes (1984), que utiliza tanto grades métricas quanto árvores métricas para analisar as regras de ritmo do inglês, explica que em exemplos como Mississipi Mabel, o choque de acento é reorganizado, pois um intervalo quadrissilábico é favorável a um intervalo dissilábico, conforme o exemplo a seguir (p. 45):

a.

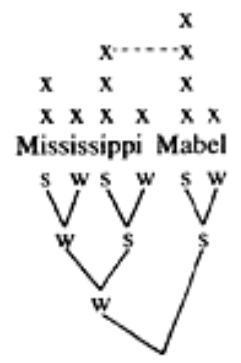

b.

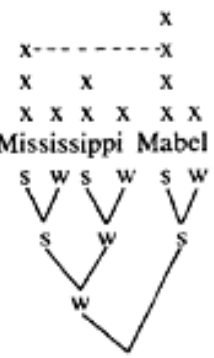

\footnotetext{
21 Segundo Hayes (1984), na presença de um acento de pitch no início do enunciado é possível haver a retração de acento, mesmo sem o choque. Para exemplificar o conceito de acento de pitch, Selkirk (1995) utiliza a frase LEgumes are a good source of vitamins. Nessa frase, a sílaba acentuada le- carrega o acento de pitch, pois apresenta o pico mais alto de $F 0$ no enunciado, e a ausência de um acento de pitch em vitamins indica que o predicado dessa sentença não representa uma informação nova. Nesse sentido, a presença de um acento de pitch na sílaba mais forte da primeira palavra da frase indica que essa não é uma frase declarativa comum, pois há a intenção de enfatizar tal palavra.
} 
0 autor mostra que choques acentuais reorganizam-se de maneira gradativa, sendo que acentos adjacentes são rigorosamente evitados e acentos próximos, mas nãoadjacentes, tendem a ocorrer com menos rigor por obedecer uma sequência acentual forte-fraco.

Há casos, entretanto, em que o choque acentual é mantido no inglês. 0 reajuste do acento não ocorre, por exemplo, quando as duas palavras estão separadas pelo limite entre duas frases fonológicas (cf. Hayes, 1989) pois, assim como no PB, a retração de acento ocorre apenas dentro de uma mesma frase fonológica (ex: ([I] $\phi$ [saw] $\phi$ [THIRteen MEN] $\phi$ [in the park] $\phi)$. 0 choque também é mantido quando a vogal da sílaba que receberia o acento em caso de retração é um schwa, como na sequência maroon coat (/məRU:N KOvT/), em que o acento na sílaba -roon não pode recair sobre ma-porque a vogal reduzida não pode receber o acento (cf. Levey 1999).

Para verificar se há uma preferência pela alternância entre sílabas fortes e fracas sob o ponto de vista fonético, Cooper e Eady (1986) mediram a duração e o pitch de sílabas em sequência de choque acentual do inglês, mas não observaram nenhum indício de mudança desses correlatos neste contexto. ${ }^{22}$ Segundo os autores, é difícil identificar os correlatos acústicos que influenciam a ocorrência do choque acentual porque os valores absolutos de uma sílaba isolada nem sempre podem indicar alguma tendência de mudança de ritmo na sentença como um todo.

Através da combinação entre uma análise perceptual e uma análise acústica, Levey (1999) também buscou investigar as características fonéticas do choque acentual por falantes de inglês, com base em três possibilidades: a) o acento primário da última sílaba da primeira palavra do choque seria movido para a sílaba anterior, caracterizando a retração acentual (ex: RACoon COAT); b) o acento primário na sílaba final seria reduzido; e c) o choque acentual seria evitado através do uso de acento de pitch em uma sílaba que antecede ou sucede o choque na frase. A autora analisou o acento de palavras oxítonas produzidas por 10 falantes nativos da língua inglesa em contextos de choque acentual (seguidas de uma sílaba acentuada) e em contextos sem choque (seguidas de uma sílaba não acentuada). A verificação perceptual mostrou que a resolução do choque acentual ocorreu em menos de 30\% dos casos, inclusive em sequências onde não havia o

\footnotetext{
${ }^{22}$ Resultados semelhantes foram encontrados no estudo de Schreuder e Gilbers (2002), para o holandês. Os autores analisaram a duração, o pitch e a intensidade em sequências que foram perceptualmente identificadas como casos de retração acentual e não encontraram diferenças significativas quanto a esses correlatos.
} 
choque. A verificação acústica, por sua vez, apontou que a frequência fundamental foi a única pista que poderia influenciar percepção da retração de acento, mas não foram encontradas evidências suficientes para afirmar que o F0 é, de fato, o correlato acústico responsável pela retração.

Autores como Grabe e Warren (1995) sugerem que a retração de acento é, na verdade, um fenômeno de natureza perceptual, e não acústica. Os autores desenvolveram um experimento de percepção em que os participantes deveriam apontar a sílaba acentuada em uma série de palavras. Quando solicitados para identificar o acento em sequências de choque acentual como thirTEEN MEN, os participantes perceberam uma retração acentual, ou seja, THIRteen MEN. Quando a mesma palavra THIRteen foi apresentada isoladamente, entretanto, os participantes identificaram o acento como thirTEEN. Segundo Kimball e Cole (2014), esse resultado sugere que os falantes de inglês estão condicionados a perceber uma alternância entre sílabas fortes e fracas, mesmo que uma verificação acústica indique que essa alternância não tenha sido, de fato, produzida.

Em suma, os estudos apresentados na Seção 5.1.1, sobre o PB, e nesta seção, sobre o inglês, mostram que a regra de retração de acento ocorre de maneira muito semelhante nas duas línguas, já que, em ambos os casos, trata-se de um fenômeno variável para a resolução de choque acentual, assim como outras estratégias como a inserção de pausa e a manutenção do choque, que ocorre somente dentro de frase fonológica (cf. Abousalh (1997), Tenani (2017), e Sandalo e Truckenbrodt (2002) para o PB e Hayes (1989) para o inglês). Do ponto de vista fonético, a retração de acento não foi constatada nem no PB e nem no inglês. Em ambas as línguas, os estudos apontam que a retração de acento é uma regra que tende a ser percebida, e não mensurada acusticamente através de correlatos como pitch e duração (cf. Barbosa (2002) e Madureira (2002) para o PB e Cooper e Eady (1986) e Levey (1999) para o inglês).

\subsubsection{Retração de acento do inglês por falantes brasileiros}

Na Seção 5.1 mostramos que a retração de acento não pode ser estudada apenas do ponto de vista rítmico, pois, se assim fosse, o choque acentual seria sempre desfeito, por ser uma violação da regra de alternância rítmica. Como vimos, a retração pode estar condicionada ao contexto prosódico e, tanto no PB (Abousalh 1997, Sandalo e 
Truckenbrodt 2002, Santos 2002) quanto no inglês (Hayes 1984, 1989), tal fenômeno ocorre sob o domínio da frase fonológica.

O trabalho de Silva Jr. (2013) é o único, até onde sabemos, que comparou a produção de sequências de choque acentual nas duas línguas em questão. 0 autor buscou investigar se o ritmo do PB influenciaria a produção do inglês como L2 através da análise de sequências de choque acentual inseridas no domínio da frase fonológica no inglês e no PB por falantes de português como L1. Seu objetivo foi verificar quais estratégias de resolução do choque de acento seriam aplicadas pelos informantes brasileiros nas duas línguas dentre movimento de batida, que indica retração acentual, e inserção de batida silenciosa, que indica a não retração.

A pesquisa investigou as produções de cinco informantes: três brasileiros falantes de inglês como L2 (grupo experimental) e dois norte-americanos falantes de português como L2 (grupo de controle). Os informantes brasileiros foram divididos em três níveis de proficiência: C1 (advanced), B2 (high intermediate) e B1 (low intermediate), com base nos resultados do Oxford Online Placement Test ${ }^{23}$. 0 corpus foi composto de 20 sentenças, nove assertivas e uma interrogativa em inglês e oito assertivas e duas exclamativas em português, todas contendo alguma sequência de palavras com choque acentual em inglês (ex: thirTEEN BALLS) ou em português (ex: muLHER Ótima). Através de uma verificação dos correlatos acústicos empregados por cada informante, de modo individual os resultados mostraram que, em vez de retração acentual, a inserção de um curto pulso rítmico silencioso - ou, de acordo com Selkirk (1984), uma "batida silenciosa" (silent demibeat) - foi a estratégia mais empregada pelos falantes brasileiros para a resolução do choque em ambas as línguas. Os falantes norteamericanos, por outro lado, preferiram a estratégia de movimento de batida, ou seja, preferiram a retração de acento.

Após a análise acústica de todas as sequências de choque acentual, o autor solicitou que um norte-americano falante do PB como L2 e um brasileiro falante do inglês como L2, ambos não-informantes da tese, ouvissem cada uma das sequências e indicassem a sílaba acentuada. Apesar de não ter apresentado uma comparação estatística entre os resultados da percepção dos dois ouvintes e os resultados obtidos através de análise acústica, o autor conclui que há, definitivamente, diferenças entre a percepção da retração acentual e a retração acentual detectada no sinal acústico. Em

\footnotetext{
${ }^{23}$ www.oxfordenglishtesting.com
} 
outras palavras, os ouvintes tendem a perceber os intervalos acentuais como sendo mais regulares do que eles realmente são quando analisados acusticamente.

Dado que o estudo de Silva Jr. (2013) é o único que encontramos sobre a produção de frases com choque acentual do inglês por falantes brasileiros, acreditamos que o presente estudo poderá trazer contribuições relevantes a respeito da aplicação da regra de retração de acento no inglês por falantes brasileiros. Diferentemente do autor, que avaliou a produção de apenas três falantes de inglês como L2 e não apresentou uma combinação de resultados obtidos através de verificação acústica e através de verificação perceptual, a presente pesquisa se propõe a analisar acústica e perceptualmente a produção de 30 falantes de inglês como L2 nos níveis básico, intermediário e avançado, e compará-la com a produção de 7 falantes nativos de inglês. Espera-se observar se, do ponto de vista perceptual, os falantes não nativos aplicam a retração de acento nos mesmos contextos que os nativos e, do ponto de vista acústico, quais são os correlatos que sofrem algum tipo de alteração em contextos de choque acentual, sem choque acentual e de palavra isolada.

\subsection{Metodologia}

Esta seção a apresenta os procedimentos metodológicos utilizados para investigar a retração de acento do inglês por falantes do PB. Os critérios para a seleção e o nivelamento dos 37 informantes, incluindo o grupo de controle, são os descritos em 4.2.1, já que se tratam dos mesmos informantes na análise dos três fenômenos em análise (assimilação de vozeamento, retração de acento e sílaba e acento). Os procedimentos de coleta também são os mesmos descritos em 4.2.3, já que o registro dos dados referentes aos três fenômenos investigados se deu através de uma única gravação, por meio de uma única apresentação de slides que apresentava as palavras e frases a serem investigadas em ordem aleatória.

Esta seção apresenta, portanto, o desenho do experimento para a coleta dos dados referentes à retração de acento, em 5.2.1, os procedimentos para as verificações perceptual e acústica em 5.2.2 e os critérios para a classificação dos dados e verificação estatística em 5.2.3. 


\subsubsection{Desenho do experimento}

Para a investigação da retração de acento, desenvolvemos um experimento contendo 21 palavras oxítonas em três contextos: isoladas (ex: thirTEEN), inseridas em frases com sequência de choque acentual (ex: thirTEEN MEN) e inseridas em frases sem sequência de choque acentual (ex: thirTEEN poTAtoes). Como vimos em 5.1, diferentemente do $\mathrm{PB}$, em que a retração não ocorre entre acentos não-adjacentes (ex: ${ }^{*}$ CAfe requenTAdo), o inglês permite a retração nesses casos (ex: MIssissipi MAbel). Através da inserção de sequências com choque acentual (dois acentos primários adjacentes), de sequências sem choque acentual (uma sílaba átona entre os dois acentos primários) e de palavras isoladas no experimento de coleta, pretende-se observar como os falantes nativos e não nativos aplicarão o acento nas mesmas palavras em cada um desses contextos.

As palavras e as sequências de palavras com choque e sem choque acentual são apresentadas no Quadro 10 a seguir.

Quadro 10 - Palavras e Sequências de Palavras para a Verificação da Retração de Acento

\begin{tabular}{|c|c|c|}
\hline $\begin{array}{l}\text { PALAVRA } \\
\text { ISOLADA }\end{array}$ & $\begin{array}{c}\text { SEQUENCIAS DE } \\
\text { CHOQUE ACENTUAL }\end{array}$ & $\begin{array}{c}\text { SEQUÊNCIAS SEM } \\
\text { CHOQUE ACENTUAL }\end{array}$ \\
\hline $\begin{array}{ll}\text { 1. } & \text { thirTEEN } \\
\text { 2. } & \text { fourTEEN } \\
\text { 3. } & \text { fifTEEN } \\
\text { 4. } & \text { sixTEEN } \\
\text { 5. } & \text { sevenTEEN } \\
\text { 6. } & \text { eighTEEN } \\
\text { 7. } & \text { nineTEEN } \\
\text { 8. } & \text { unKIND } \\
\text { 9. } & \text { kangaROO } \\
\text { 10. } & \text { TenneSSEE } \\
\text { 11. } & \text { groTESQUE } \\
\text { 12. } & \text { roBUST } \\
\text { 13. } & \text { disLIKE } \\
\text { 14. } & \text { bamBOO } \\
\text { 15. } & \text { poLICE } \\
\text { 16. } & \text { disCRETE } \\
\text { 17. } & \text { comPLETE } \\
\text { 18. } & \text { Bel-AIR } \\
\text { 19. } & \text { U2 } \\
\text { 20. } & \text { reTAKE (v.) } \\
\text { 21. } & \text { exPRESS }\end{array}$ & $\begin{array}{ll}\text { 1. } & \text { thirTEEN PENcils } \\
\text { 2. } & \text { fourTEEN WOmen } \\
\text { 3. } & \text { fifTEEN GIRLS } \\
\text { 4. } & \text { sixTEEN CHAIRS } \\
\text { 5. } & \text { sevenTEEN YEARS } \\
\text { 6. } & \text { eighTEEN CHILdren } \\
\text { 7. } & \text { nineTEEN BOYS } \\
\text { 8. } & \text { unKIND COmment } \\
\text { 9. } & \text { kangaROO KIM } \\
\text { 10. } & \text { TenneSSEE PEOPLE } \\
\text { 11. } & \text { groTESQUE PICtures } \\
\text { 12. } & \text { roBUST BAbies } \\
\text { 13. } & \text { disLIKE CHOcolate } \\
\text { 14. } & \text { disLIKE POWer } \\
\text { 15. } & \text { disLIKE PROblems } \\
\text { 16. } & \text { bamBOO BRAcelets } \\
\text { 17. } & \text { poLICE OFFICER } \\
\text { 18. } & \text { disCRETE AREAS } \\
\text { 19. } & \text { comPLETE PAper } \\
\text { 20. } & \text { Bel-AIR BOY } \\
\text { 21. } & \text { U2 SONG } \\
\text { 22. } & \text { reTAKE COURSE } \\
\text { 23. } & \text { exPRESS TRAIN }\end{array}$ & $\begin{array}{ll}\text { 1. } & \text { thirTEEN poTAtos } \\
\text { 2. } & \text { fourTEEN baNAnas } \\
\text { 3. } & \text { fifTEEN toMAtos } \\
\text { 4. } & \text { sixTEEN imiTAtions } \\
\text { 5. } & \text { sevenTEEN paPAYas } \\
\text { 6. } & \text { eighTEEN adVENtures } \\
\text { 7. } & \text { nineTEEN eXAMples } \\
\text { 8. } & \text { unKIND reVENge } \\
\text { 9. } & \text { kangaROO MeLIssa } \\
\text { 10. } & \text { TenneSSEE volCAno } \\
\text { 11. groTESQUE deCEPtion } \\
\text { 12. } \text { roBUST umBRElla } \\
\text { 13. disLIKE perFECtionism } \\
\text { 14. disLIKE conFUsion } \\
\text { 15. disLIKE poliTIcians } \\
\text { 16. } \text { bamBOO maTErials } \\
\text { 17. poLICE conVENtion } \\
\text { 18. } \text { disCREET beGInning } \\
\text { 19. } \text { comPLETE comPUters } \\
\text { 20. } \text { Bel-AIR ceLEbrity } \\
\text { 21. U2 celeBRAtion } \\
\text { 22. } \text { reTAKE examiNATION } \\
\text { 23. } \text { exPRESS transforMAtions }\end{array}$ \\
\hline
\end{tabular}


Para evitar qualquer influência do contexto sintático ou prosódico sobre a retração de acento, todas as sequências de palavras foram inseridas em frases fonológicas do mesmo tamanho e no mesmo tipo de frase veículo, conforme os exemplos em (15):
a) [I saw] [grotESQUE PICtures] [in the park].
b) [I have] [thirTEEN poTAtoes] [at home].
c) [I saw] [kangaROO KIM] [last night].
d) [I saw] [bamB00 BRAcelets [last night].

As frases e palavras foram apresentadas em ordem aleatória na mesma apresentação de slides que apresentava as palavras e frases que investigavam os outros dois fenômenos analisados nesta pesquisa (assimilação de vozeamento (cf. Cap. 4) e sílaba e acento (cf. Cap. 6)), com o objetivo de evitar que os informantes percebessem quais fenômenos estavam sendo investigados.

\subsubsection{Critérios para verificações Perceptual e Acústica}

A classificação dos dados referentes à retração de acento foi realizada em duas etapas: uma verificação perceptual e uma verificação acústica. Optou-se pela combinação entre esses dois tipos de verificação porque, conforme mencionado em 5.2.1, muitas vezes a retração de acento é percebida ainda que não haja evidências acústicas que indiquem a aplicação da regra. Como vimos, estudos como o de Grabe e Warren (1995) e Levey (1999) indicam que os correlatos acústicos nem sempre acusam a alternância entre sílabas fortes e fracas percebida em casos de choque, o que torna essencial a combinação entre os dois tipos de verificação para a análise da retração de acento.

Para a verificação perceptual, foram utilizados os mesmos procedimentos aplicados por Levey (1999) e Stander (2007): primeiramente, a própria pesquisadora sinalizou o acento em cada palavra do corpus e, para assegurar a confiabilidade dessa classificação, solicitou-se que outra avaliadora, também brasileira, com extenso conhecimento dos aspectos fonético-fonológicos da língua, realizasse o mesmo procedimento. Após essa etapa, comparou-se as duas transcrições e, nos casos de discordância, as palavras eram ouvidas novamente até que se chegasse a um consenso a 
respeito das sílabas acentuadas. As transcrições perceptuais foram organizadas em tabelas e, então, iniciaram-se os procedimentos de verificação acústica.

Para verificar se haveria alguma alteração nos correlatos acústicos das palavras em análise em contextos de frase com choque acentual (ex: fifTEEN MEN), de frase sem choque acentual (ex: fifTEEN poTAtoes) e de palavra isolada (ex: fifTEEN), foi utilizado um script do Praat desenvolvido pelo professor Plínio Barbosa ${ }^{24}$ (Unicamp), o qual aponta, entre outras informações, as medidas de duração (em milissegundos) e do pico de F0 (pitch) de cada sílaba. Para o funcionamento do script, cada palavra e cada sílaba foi segmentada manualmente através da criação de textgrids no Praat: primeiramente, segmentava-se a palavra alvo na primeira camada do textgrid; então, na segunda camada, eram segmentadas as sílabas; na terceira camada, por fim, indicava-se a sílaba classificada perceptualmente como acentuada, conforme o exemplo na Figura 9 seguir:

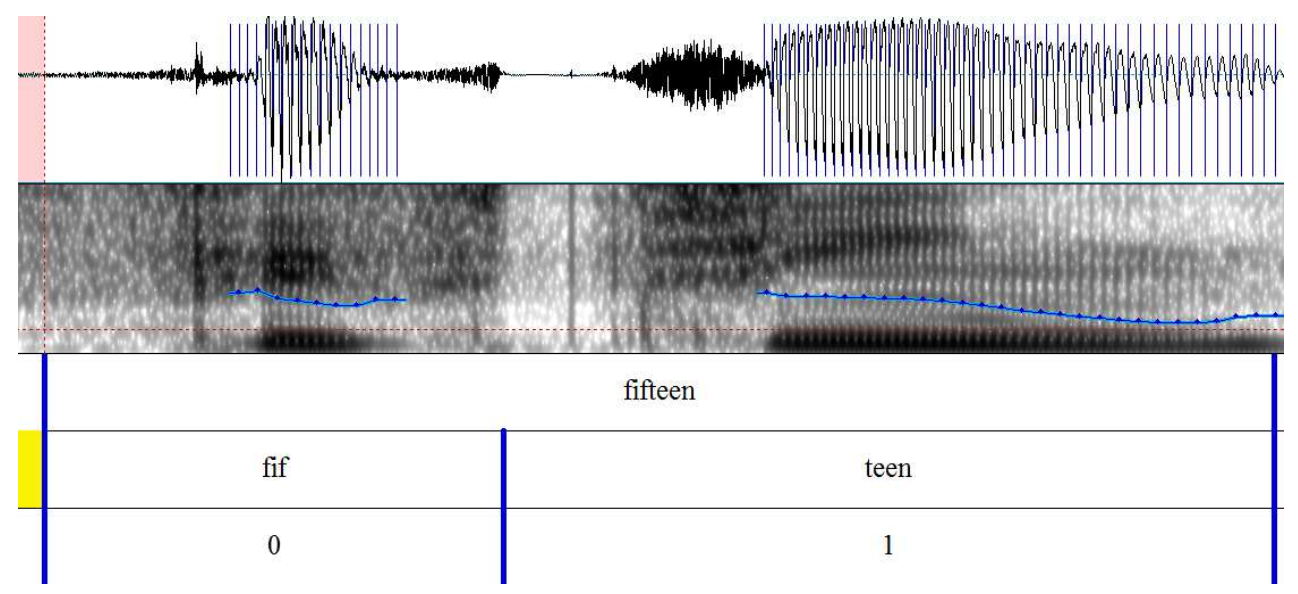

Figura 9: Exemplo de segmentação de palavra e de sílaba no Praat

A segmentação foi realizada através da inspeção visual da forma de onda no espectro, considerando o espectrograma de banda larga como referência, conforme os critérios estabelecidos em Barbosa e Madureira (2015, p. 170-171). Buscou-se empregar os procedimentos de segmentação com consistência, isto é, utilizando sempre o mesmo procedimento em todas as palavras: partindo da observação da forma de onda e das características no espectrograma, estabeleceu-se, primeiramente, um limite aproximado da sílaba ou palavra analisada; então, a segmentação foi determinada conforme o

\footnotetext{
${ }^{24}$ Agradecemos ao professor Plínio Barbosa por ter gentilmente cedido o script que ajudou na realização desta pesquisa.
} 
primeiro e último pulsos regulares de sua forma de onda no oscilograma, com o recorte realizado no centro do vale desse primeiro ou último pulso sonoro.

Após a segmentação dos 37 arquivos de áudio, o script gerou automaticamente os valores correspondentes à duração (em milissegundos) e ao pico de F0 (em Hz) de cada sílaba.

\subsubsection{Classificação dos dados e Metodologia Estatística}

A Seção 5.2.3.1 a seguir apresenta as variáveis estabelecidas para a investigação dos dados classificados através de julgamento perceptual e o tipo de verificação estatística empregada na análise desses dados. Na Seção 5.2.3.2, é apresentada a metodologia estatística empregada na análise dos correlatos acústicos (pitch e duração).

\subsubsection{Verificação perceptual}

A variável dependente, neste caso, é a ocorrência de retração de acento. Os fatores para esta variável são: houve retração, quando a retração foi aplicada (ex: THIRteen MEN) e não houve retração, quando a retração não foi aplicada (ex: thirTEEN $M E N)$.

Para que a ocorrência da retração acentual fosse contabilizada, foi necessário relacionar a variável dependente com a variável contexto, que indica se a palavra foi produzida em uma frase com choque acentual, em uma frase sem choque acentual ou isolada. Uma palavra como fifTEEN, por exemplo, poderia ser produzida isoladamente como FIFteen, por influência da regra de acento de PB. Nesse caso, a atribuição do acento na sílaba fif- em uma sequência como FIFteen MEN pelo mesmo informante não indicaria uma ocorrência de retração de acento, pois não houve mudança no padrão acentual empregado no contexto de palavra isolada e no caso de choque acentual. Sendo assim, a ocorrência de retração só foi considerada quando o falante produziu o padrão oxítono na palavra isolada (ex: fifTEEN) e o padrão paroxítono ou proparoxítono nas frases com choque (ex: FIFteen MEN) ou sem choque (ex: FIFteen poTAtoes).

O Quadro 11 a seguir apresenta os fatores da variável dependente e, também, das variáveis independentes linguísticas e extralinguísticas que foram controladas na análise desta regra. 


\section{Quadro 11: Variáveis Controladas - Retração de Acento}

\begin{tabular}{|c|c|c|}
\hline $\begin{array}{l}\text { VARIÁVEL } \\
\text { DEPENDENTE }\end{array}$ & $\begin{array}{c}\text { Ocorrência da } \\
\text { Retração de Acento }\end{array}$ & $\begin{array}{l}\text { Houve retração } \\
\text { Não houve retração }\end{array}$ \\
\hline \multirow{8}{*}{$\begin{array}{l}\text { VARIÁVEIS } \\
\text { INDEPENDENTES }\end{array}$} & Contexto & $\begin{array}{l}\text { Palavra Isolada } \\
\text { Frase Com Choque } \\
\text { Frase Sem Choque }\end{array}$ \\
\hline & Palavra Alvo & $\begin{array}{l}\text { Cada uma das } 21 \text { palavras } \\
\text { oxítonas que poderia sofrer } \\
\text { retração }\end{array}$ \\
\hline & $\begin{array}{l}\text { Padrão Acentual } \\
\text { Empregado }\end{array}$ & $\begin{array}{l}\text { Oxítono } \\
\text { Paroxítono } \\
\text { Proparoxítono } \\
\end{array}$ \\
\hline & $\begin{array}{l}\text { Segmento na } \\
\text { Sílaba Final }\end{array}$ & $\begin{array}{l}\text { Vogal Longa } \\
\text { Vogal Longa + nasal } \\
\text { Vogal Longa + obstruinte }\end{array}$ \\
\hline & Pausa & $\begin{array}{l}\text { Com Pausa } \\
\text { Sem Pausa }\end{array}$ \\
\hline & $\begin{array}{c}\text { Nível de } \\
\text { Proficiência }\end{array}$ & $\begin{array}{l}\text { Básico } \\
\text { Intermediário } \\
\text { Avançado } \\
\text { Falante Nativo }\end{array}$ \\
\hline & $\begin{array}{c}\text { Idade de Início da } \\
\text { Aquisição da L2 }\end{array}$ & $\begin{array}{l}\text { Antes dos } 12 \text { anos } \\
\text { Depois dos } 12 \text { anos }\end{array}$ \\
\hline & Informante & $\begin{array}{l}1 \\
2 \\
\cdots \\
30\end{array}$ \\
\hline
\end{tabular}

A variável Contexto, como vimos, possibilita a comparação entre o padrão acentual empregado pelos informantes nas palavras em frases com choque acentual, em frases sem choque acentual e isoladas, para verificar se houve alguma modificação no acento da mesma palavra em cada um desses contextos.

A variável Palavra Alvo, por sua vez, foi incluída para verificar o padrão acentual empregado pelos informantes em cada palavra que poderia sofrer a retração de acento. Os fatores desta variável são as 21 palavras oxítonas que poderiam sofrer retração em caso de choque acentual: bamboo, Bel-Air, complete, discrete, dislike, eighteen, express, fifteen, fourteen, grotesque, kangaroo, nineteen, police, retake, robust, seventeen, sixteen, 
Tennessee, thirteen, U2 (youTWO) e unkind. É importante salientar que, apesar de a retração não ser possível em palavras como police e complete na fala de nativos por conterem a vogal reduzida schwa [ə] na sílaba que receberia o acento em caso de retração ([kəm'plist], [pə'li:s]), incluímos esses exemplos no experimento porque os falantes brasileiros, sobretudo no nível básico, tendem a produzir vogais plenas nesses contextos (complete: [kom'pli:t] - ['kom.plit]; police: [po'li:s] - ['po.li:s]), o que possibilita a análise da retração nesses casos.

A variável Padrão Acentual Empregado tem como objetivo verificar o padrão acentual produzido pelos falantes nos casos em que houve retração e nos casos em que não houve retração. Os fatores desta variável são Oxítono, Paroxítono e Proparoxítono, que são os padrões acentuais mais comuns no PB e no inglês.

A variável Pausa, por sua vez, foi incluída para controlar os casos em que o informante fez uma pausa entre as duas palavras nas sequências com choque e sem choque acentual (ex: thirteen ... men). Durante a coleta, solicitamos que os informantes realizassem a leitura das frases sem interrupções e da forma mais natural possível, pois a fala cuidadosa e/ou com taxa de elocução mais lenta gera mais fronteiras de frase fonológica e pode bloquear a retração que ocorreria na fala natural (cf. Sandalo e Truckenbrodt, 2002). Entretanto, houve casos em que os informantes não conseguiram realizar a leitura das frases sem a inserção de pausa, mesmo quando solicitados para repetir a leitura sem interrupções, principalmente no nível básico. Por isso, controlamos essas ocorrências de pausa através desta variável, cujos fatores são Com Pausa e Sem Pausa. ${ }^{25}$

A variável Segmento na Sílaba Final foi incluída para verificar a influência do padrão silábico da sílaba final da primeira palavra do choque sobre a aplicação da regra. Os fatores analisados foram: vogal longa (ex: bamBOO, kangaROO), nasal (ex: thirTEEN, fourTEEN) e obstruinte (ex: japaNESE, conCRETE26).

Além dessas variáveis linguísticas, as variáveis sociais Nível de Proficiência, Idade de Início da Aquisição e Informante, que já foram descritas na Seção 4.2.5, foram controladas na análise da retração de acento.

\footnotetext{
${ }^{25}$ O julgamento das ocorrências de pausas se deu, principalmente, com base na percepção da pesquisadora e da juíza que ajudou na realização da verificação perceptual de todos os dados. Após registrarmos todas as frases em que percebemos a ocorrência de pausa entre as duas palavras do choque, medimos a duração de cada um desses intervalos. A média de duração das pausas foi de $0,53 \mathrm{~s}$, sendo o intervalo mais curto de $0,25 \mathrm{~s}$ e o mais longo de $1,34 \mathrm{~s}$.

${ }^{26}$ Nessas palavras há a possibilidade de inserção de epêntese na sílaba final, principalmente no nível básico, o que bloquearia o choque acentual (ex: com.PLE.te PApers).
} 
A verificação estatística dos dados classificados através de julgamento perceptual foi realizada através do programa GoldVarb-X, que já foi descrito na Seção 4.2.5, sobre a assimilação de vozeamento. A aplicação da regra de retração de acento, assim como no caso da assimilação de vozeamento, tem caráter binário (aplicou/não aplicou a retração). Portanto, também é condizente com o tipo de teste estatístico oferecido pelo programa mencionado, que permite ao pesquisador total autonomia para a realização de cruzamentos entre variáveis e possibilita verificar a probabilidade de aplicação da regra em cada fator analisado através dos valores dos pesos relativos.

\subsubsection{Correlatos Acústicos}

Para a comparação das médias de duração e de F0 das sílabas produzidas pelos informantes nos três contextos analisados (palavra isolada, em frase com choque acentual e em frase sem choque acentual), foram utilizados dois testes estatísticos. 0 primeiro é o teste não paramétrico de Wilcoxon, utilizado na estatística para a comparação entre dois grupos - no caso desta pesquisa, os dois grupos referentes à idade de aquisição da L2 (antes dos 12 anos e depois dos 12 anos) e os grupos de nativos vs. não nativos. Este teste é utilizado para testar a hipótese nula de que os grupos possuem funções de distribuição iguais contra a hipótese alternativa de que ao menos dois grupos possuem funções de distribuição diferentes. 0 segundo teste é o KruskalWallis, utilizado na estatística para a comparação entre três ou mais grupos - no caso do presente estudo, os três níveis de proficiência analisados (básico, intermediário e avançado) e os três contextos em que as palavras foram inseridas (isolada, com choque e sem choque). ${ }^{27} 0$ teste de Kruskal-Wallis testa a hipótese nula de que os grupos foram tomados de uma mesma população, contra a hipótese alternativa de que pelo menos dois grupos vêm de populações distintas. Estes testes foram feitos através da PROC WILCOXON do software SAS. As análises foram realizadas no software estatístico SAS 9.4. Foi fixado o nível de significância $\alpha=0,05$ para todas as análises.

\subsection{Resultados}

\footnotetext{
${ }^{27} \mathrm{O}$ tratamento estatístico aplicado a todos os dados referentes aos correlatos acústicos analisados nesta pesquisa
} foi conduzido pela doutoranda em Estatística Andressa Kutschenko Nahas, registrada sob o CONRE 39066 - A. 
Nesta seção serão apresentados os resultados referentes à regra de retração de acento. Foram obtidos 2.645 dados relacionados à regra, incluindo o grupo de controle. Os resultados referentes à verificação perceptual são apresentados na Seção 5.3.1 a seguir e, na Seção 5.3.2, são apresentados os resultados referentes aos correlatos acústicos empregados pelos informantes.

\subsubsection{Verificação Perceptual}

Esta seção apresenta os resultados obtidos através de julgamento perceptual, seguindo os critérios metodológicos descritos em 5.2.4. Lembramos que foram consideradas ocorrências de retração os casos em que o informante apresentou o padrão oxítono na palavra isolada (ex: fifTEEN, sevenTEEN) e o padrão paroxítono (ex: FIFteen MEN) ou proparoxítono (ex: SEventeen MEN) na mesma palavra em frases com ou sem sequência de choque acentual. Ressaltamos, portanto, que os resultados referentes aos falantes nativos e não nativos apresentados nas seções 5.3.1.1 e 5.3.1.2 a seguir incluem somente as ocorrências de palavras inseridas em frases (com choque e sem choque), já que as palavras produzidas isoladamente foram utilizadas apenas como um parâmetro para controlar os casos em que houve retração.

\subsubsection{Falantes nativos}

Das 21 palavras oxítonas incluídas no experimento, apenas três foram classificadas como paroxítonas quando lidas isoladamente na fala de nativos: discrete, classificada como DIScrete na produção do Informante 3; nineteen, classificada como NINEteen nas produções dos Informantes 4 e 2; e thirteen, classificada como THIRteen na produção do Informante 4. Nesses casos, ainda que essas palavras também tenham sido produzidas como paroxítonas em frases com choque e sem choque, a ocorrência de retração de acento não foi contabilizada, já que não houve mudança na posição do acento nos diferentes contextos analisados.

A taxa de aplicação da retração de acento pelos sete falantes nativos que constituem a amostra de controle nesta pesquisa pode ser observada no Gráfico 14 a 
seguir, que inclui tanto as palavras inseridas em frases com sequência de choque quanto aquelas inseridas em frases sem sequência de choque acentual.

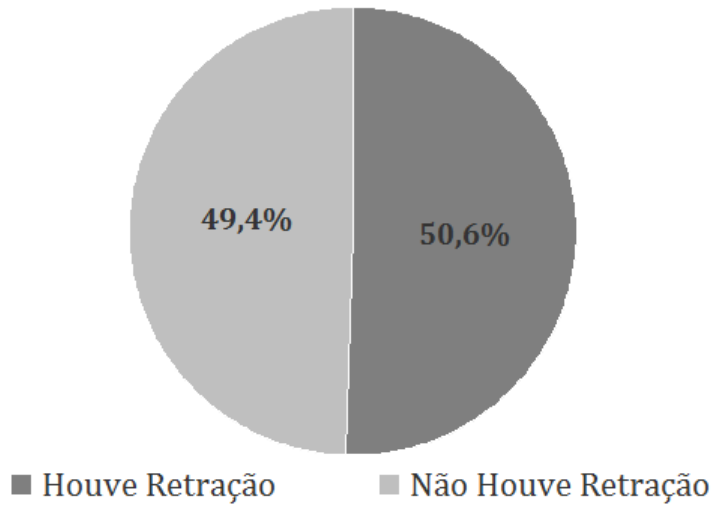

Gráfico 14: Aplicação da Retração de Acento por Falantes Nativos

Pode-se observar que os falantes nativos aplicaram a retração de acento em $50,06 \%$ dos casos (133/322) e não aplicaram em 49,4\% dos dados (159/322).

$\mathrm{Na}$ primeira rodada estatística, as variáveis Palavra e Acento Empregado apresentaram knockout ${ }^{28}$, isto é, a aplicação categórica da regra (100\%) ou a sua nãoaplicação (0\%). Por isso, realizou-se uma nova rodada, excluindo-se essas duas variáveis da análise multidimensional. Dentre as variáveis restante testadas nos dados dos falantes nativos, Segmento Final foi selecionada como estatisticamente significativa e Contexto não foi significativa. Os resultados a seguir não serão necessariamente apresentados conforme a ordem de seleção do programa estatístico.

A variável Contexto, que controla se a palavra está em contexto de encontro acentual ou não, não foi estatisticamente significativa para a aplicação da retração de acento pelos falantes nativos. A Tabela 16 mostra que 49,7\% dos casos de retração ocorreram em frases com uma sequência de choque acentual (ex: sixTEEN CHAIRS) e 51,6\% ocorreu em frases sem choque acentual (ex: sixTEEN imiTAtions). Houve, portanto, mais casos de retração de acento em frases sem choque acentual, mas a proporção de aplicação da regra nos dois grupos foi bastante aproximada.

\footnotetext{
${ }^{28} \mathrm{Na}$ análise realizada pelo programa GoldVarb, knockout é "um fator que, num dado momento da análise, corresponde a uma frequência de $0 \%$ ou $100 \%$ para um dos valores da variável dependente" (Guy e Zilles, 2007, p. 158). As ocorrências de knockout são um problema analítico no processamento dos dados pelo programa, pois não há variação e, portanto, não há a possibilidade de atribuir-se pesos e frequências para cada fator. Dentre as possibilidades de correção, optamos por excluir as variáveis em questão e realizar uma nova rodada.
} 
Tabela 16: Retração de Acento por Contexto - Nativos

\begin{tabular}{ccccc}
\hline \multirow{2}{*}{ Contexto } & \multicolumn{2}{c}{ Retração } & \multicolumn{2}{c}{ Sem retração } \\
\cline { 2 - 5 } & $\mathbf{N}$ & $\mathbf{\%}$ & $\mathbf{n}$ & $\mathbf{\%}$ \\
\hline Frase Com Choque & 80 & $49,7 \%$ & 81 & $50,3 \%$ \\
Frase Sem Choque & 83 & $51,6 \%$ & 78 & $48,4 \%$
\end{tabular}

A Tabela 17 a seguir apresenta a taxa de aplicação da retração de acento por informante, tanto em contextos com choque quanto em contextos sem choque. Pode-se observar que o Falante Nativo 6 foi o que aplicou a maior taxa de retração acentual, de $69,6 \%$, seguido do Nativo 3, que aplicou a regra em 60\% das frases.

Tabela 17: Retração de Acento por informante - Nativos

\begin{tabular}{ccc}
\hline \multirow{2}{*}{ Informante } & \multicolumn{2}{c}{ Proporção de Retração Acentual } \\
\cline { 2 - 3 } & Casos/Total & Porcentagem \\
\hline Nativo 1 & $20 / 46$ & $43,5 \%$ \\
Nativo 2 & $17 / 46$ & $37 \%$ \\
Nativo 3 & $28 / 46$ & $60 \%$ \\
Nativo 4 & $20 / 46$ & $43,5 \%$ \\
Nativo 5 & $21 / 46$ & $43,7 \%$ \\
Nativo 6 & $32 / 46$ & $69,6 \%$ \\
Nativo 7 & $25 / 46$ & $54,3 \%$ \\
\hline TOTAL & $\mathbf{1 6 3 / 3 2 2}$ & $\mathbf{5 0 , 6 \%}$ \\
\hline
\end{tabular}

A aplicação da retração de acento por informante também pode ser visualizada no Gráfico 15 a seguir. Percebe-se que os falantes 1, 5 e 6 apresentaram a mesma taxa de aplicação da regra, de 43\%, que as taxas mais altas foram aplicadas pelos nativos 3, 6 e 7 e que o falante 2 foi o que apresentou a menor taxa, de $37 \%$.

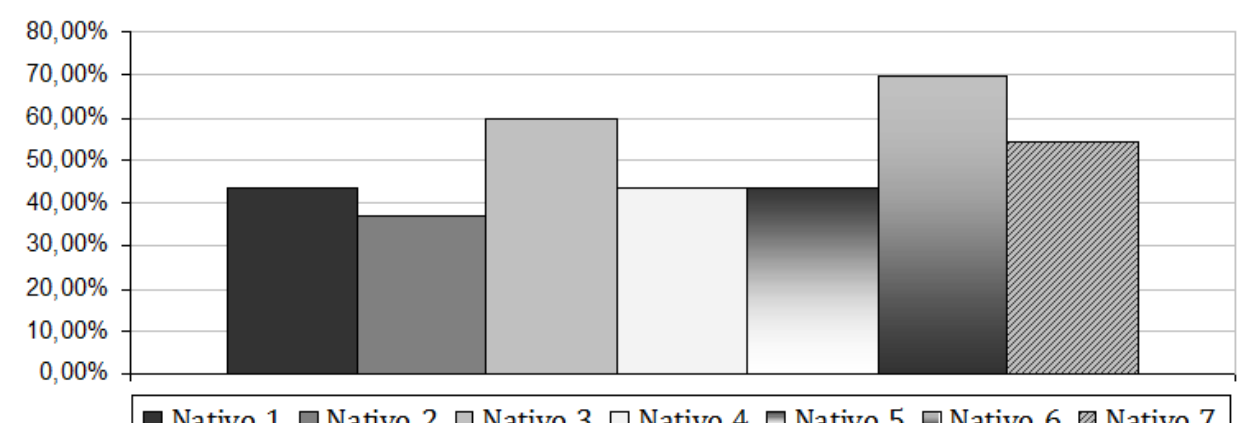

Gráfico 15: Retração de Acento por Falante Nativo

A Tabela 18 a seguir apresenta a aplicação da retração de acento em cada tipo de contexto, isto é, frases com choque (ex: fourTEEN PEOple) e frases sem choque (ex: fourTEEN baNAnas) por informante. Pode-se observar que a maioria dos informantes 
apresentou uma proporção de retração bastante aproximada nos dois contextos, exceto o Nativo 6, que aplicou $74 \%$ de retração em frases com choque e $65 \%$ em frases sem choque, e o Nativo 7, que aplicou 43\% de retração em frases com choque e $65 \%$ em frases sem choque

Tabela 18: Retração por informante separada por Contexto- Nativos

\begin{tabular}{ccccc}
\hline \multirow{2}{*}{ Informante } & \multicolumn{3}{c}{ Retração por Contexto } \\
\cline { 2 - 5 } & $\begin{array}{c}\text { Frase com } \\
\text { Choque }\end{array}$ & \multicolumn{2}{c}{$\begin{array}{c}\text { Frase sem } \\
\text { Choque }\end{array}$} \\
\cline { 2 - 5 } & N/Total & $\%$ & N/Total & $\%$ \\
\hline Nativo 1 & $10 / 23$ & $43 \%$ & $10 / 23$ & $43 \%$ \\
Nativo 2 & $9 / 23$ & $39 \%$ & $8 / 23$ & $35 \%$ \\
Nativo 3 & $14 / 23$ & $61 \%$ & $14 / 23$ & $61 \%$ \\
Nativo 4 & $10 / 23$ & $43 \%$ & $10 / 23$ & $43 \%$ \\
Nativo 5 & $10 / 23$ & $43 \%$ & $10 / 23$ & $43 \%$ \\
Nativo 6 & $17 / 23$ & $74 \%$ & $15 / 23$ & $65 \%$ \\
Nativo 7 & $10 / 23$ & $43 \%$ & $15 / 23$ & $65 \%$ \\
\hline TOTAL & $\mathbf{8 0 / 1 6 1}$ & $\mathbf{5 0}$ & $\mathbf{8 3 / 1 6 1}$ & $\mathbf{5 2}$ \\
\hline
\end{tabular}

A taxa de aplicação da retração de acento por informante e por contexto também pode ser visualizada no Gráfico 16 a seguir. Pode-se perceber que não houve diferença na aplicação da retração em frases com choque e sem choque na produção de quase todos os nativos.

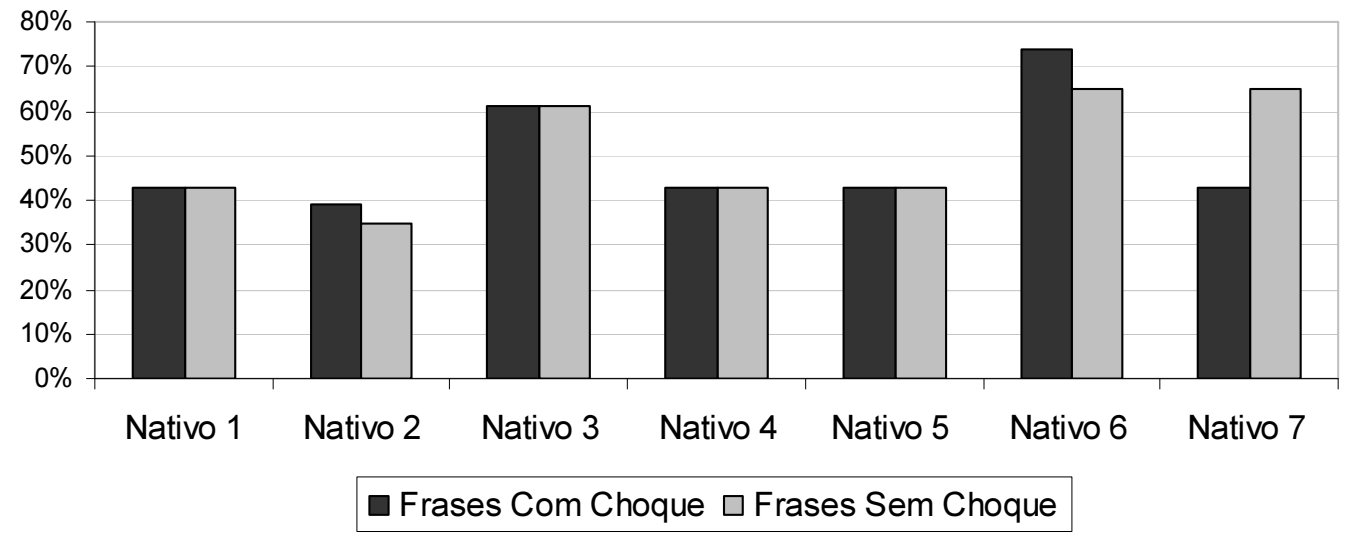

Gráfico 16: Retração por informante separada por Contexto - Nativos

A Tabela 19 a seguir apresenta os resultados referentes à variável Segmento Final, a única que se mostrou estatisticamente relevante para a aplicação da retração de acento pelos falantes nativos. Como vimos em 5.2.5, o objetivo desta variável era verificar se o padrão da última sílaba da primeira palavra do choque (todas oxítonas) 
teria alguma influência sobre a retração. Os fatores desta variável são Vogal Longa (ex: bamboo, kangaroo), Nasal (ex: thirteen, eighteen) e Obstruinte (ex: retake, complete).

Tabela 19: Retração de Acento e Segmento Final - Nativos

\begin{tabular}{ccccccc}
\hline \multirow{2}{*}{ Segmento Final } & \multicolumn{2}{c}{ Retração } & \multicolumn{2}{c}{ Sem retração } & PESO \\
\cline { 2 - 5 } & $\mathbf{n}$ & $\mathbf{\%}$ & $\mathbf{n}$ & $\mathbf{\%}$ & REL. \\
\hline Nasal & 78 & $79,6 \%$ & 20 & $20,4 \%$ & 0,80 \\
Vogal Longa & 42 & $75 \%$ & 14 & $25 \%$ & 0,75 \\
Obstruinte & 43 & $25,6 \%$ & 125 & $74,4 \%$ & 0,23
\end{tabular}

Pode-se observar que palavras terminadas em nasal foram as que mais favoreceram a aplicação da regra, com peso relativo de 0,80. Palavras terminadas com vogal longa também favoreceram a retração de acento, com peso relativo de 0,75. Palavras terminadas em uma consoante obstruinte, por fim, desfavoreceram a aplicação da regra, com peso relativo de 0,23 .

A Tabela 20 a seguir apresenta a taxa de aplicação da regra por Palavra Alvo, variável que não pôde ser incluída na análise multidimensional por causa da ocorrência de knockouts.

Tabela 20: Retração de Acento por Palavra Alvo - Nativos

\begin{tabular}{ccccc}
\hline \multirow{2}{*}{ Palavra Alvo } & \multicolumn{2}{c}{ Retração } & \multicolumn{2}{c}{ Sem retração } \\
\cline { 2 - 5 } & $\mathbf{n}$ & $\mathbf{\%}$ & $\mathbf{n}$ & $\mathbf{\%}$ \\
\hline eighteen & 14 & $100 \%$ & 0 & 0 \\
seventeen & 14 & $100 \%$ & 0 & 0 \\
sixteen & 12 & $85,7 \%$ & 2 & $14,3 \%$ \\
Tennessee & 12 & $85,7 \%$ & 2 & $14,3 \%$ \\
bamboo & 12 & $85,7 \%$ & 2 & $14,3 \%$ \\
kangaroo & 12 & $85,7 \%$ & 2 & $14,3 \%$ \\
fourteen & 11 & $78,6 \%$ & 3 & $21,4 \%$ \\
retake & 11 & $78,6 \%$ & 3 & $21,4 \%$ \\
thirteen & 11 & $78,6 \%$ & 3 & $21,4 \%$ \\
nineteen & 9 & $64,3 \%$ & 5 & $35,7 \%$ \\
unkind & 9 & $64,3 \%$ & 5 & $35,7 \%$ \\
fifteen & 7 & $50 \%$ & 7 & $50 \%$ \\
U2 & 6 & $42,9 \%$ & 8 & $57,1 \%$ \\
dislike & 16 & $38,1 \%$ & 23 & $61,9 \%$ \\
Bel-Air & 5 & $35,7 \%$ & 9 & $64,3 \%$ \\
robust & 2 & $14,3 \%$ & 12 & $85,7 \%$ \\
grotesque & 0 & 0 & 14 & $100 \%$ \\
complete & 0 & 0 & 14 & $100 \%$ \\
discrete & 0 & 0 & 14 & $100 \%$ \\
police & 0 & 0 & 14 & $100 \%$ \\
express & 0 & 0 & 14 & $100 \%$
\end{tabular}


Pode-se observar que as palavras eighteen e seventeen foram as únicas que apresentaram $100 \%$ de aplicação da regra. Isso significa que todos os falantes nativos aplicaram o padrão oxítono quando produziram essas palavras individualmente (eighTEEN, fourTEEN) e, em frases com choque (eighTEEN CHILdren, fourTEEN WOmen) e sem choque (eighTEEN adVENtures, fourTEEN baNAnas) aplicaram o padrão paroxítono (EIGHteen, FOURteen).

As palavras sixteen, Tennessee, bamboo e kangaroo apresentaram a mesma taxa de aplicação, de 85,7\%. Fourteen, retake e thirteen também apresentaram a mesma proporção de aplicação da regra, de 78,6\%, seguidas de nineteen e unkind, com 64,7\%, fifteen, com 50\%, e da palavra composta U2 (youTWO) com $42 \%$ de aplicação. A palavra dislike, que foi a única incluída em mais de uma frase com choque (disLIKE CHOcolate, disLIKE POWer e disLIKE PROblems) e sem choque (disLIKE perFECtionism, disLIKE conFUsion e disLIKE poliTIcians), apresentou taxa de retração de 38,1\%, seguida de BelAir, com 35,7\%. Dentre as palavras que apresentaram alguma ocorrência de retração, robust (ex: roBUST BAbies) foi a que apresentou a taxa mais baixa, de 14,3\%.

Por fim, as palavras grotesque (ex: groTESQUE PICtures), complete (ex: comPLETE PApers), discrete (ex: disCRETE Areas), express (ex: exPRESS TRAINS) e police (ex: poLICE Officers) não apresentaram nenhum caso de retração. Conforme mencionado em 5.2.3.1, era previsto que a retração não ocorresse em palavras como complete [kəm'plist] e [pə'li:s] na fala dos nativos, pois, nesses casos, a primeira sílaba da palavra contém a vogal reduzida schwa [ə], que não poderia receber o acento.

Percebe-se, portanto, que o fato de palavras terminadas em consoante nasal terem favorecido a retração (cf. Tabela 15) está relacionado ao fato de as palavras eighteen, seventeen e sixteen, todas terminadas em consoante nasal, terem apresentado as maiores taxas de aplicação da regra (cf. Tabela 16). Já o fato de palavras terminadas em vogal longa também terem favorecido a aplicação da regra pode ser explicado pelo fato de as palavras Tennessee, bamboo e kangaroo, terminadas em vogal longa, terem apresentado altas taxas de aplicação da retração. Palavras terminadas em obstruinte, por fim, desfavoreceram a aplicação da regra porque este é o padrão silábico encontrado nas palavras grotesque, complete, discrete, police e express, que não apresentaram nenhuma ocorrência de retração de acento.

A Tabela 21 a seguir apresenta os resultados referentes à variável Padrão Acentual Empregado, que não foi incluída nas rodadas estatísticas mas serve para 
observarmos qual foi o padrão acentual aplicado pelos falantes nativos nos casos em que houve retração e nos casos em que não houve. Observa-se que em 95,4\% dos casos, a retração ocorreu em palavras oxítonas que se tornaram paroxítonas quando inseridas em frases (ex: fiftEEN $\rightarrow$ FIFteen). Em 95\% a retração ocorreu em palavras oxítonas que se tornaram proparoxítonas em contexto de choque (ex: kangaROO $\rightarrow$ KANgaroo). Os 6 casos em que os informantes aplicaram o padrão paroxítono e os 2 casos em que empregaram o padrão proparoxítono nas frases em que a retração não foi contabilizada ocorreram porque os falantes empregaram esse mesmo padrão acentual nas palavras produzidas individualmente (ex: FIFteen, KANgaroo), o que não caracteriza a aplicação da regra. Por fim, as palavras em que os informantes aplicaram o padrão oxítono apresentam $0 \%$ de aplicação da regra porque isso significa que a palavra era oxítona e continuou oxítona em contexto de frases com choque, o que não caracteriza a retração.

\section{Tabela 21: Retração de Acento e Padrão Acentual Empregado - Nativos}

\begin{tabular}{ccccc}
\hline Padrão Acentual & \multicolumn{2}{c}{ Retração } & \multicolumn{2}{c}{ Sem retração } \\
\cline { 2 - 5 } Empregado & $\mathbf{n}$ & $\mathbf{\%}$ & $\mathbf{n}$ & $\mathbf{\%}$ \\
\hline Paroxítona & 125 & $95,4 \%$ & 6 & $4,6 \%$ \\
Proparoxítona & 38 & $95 \%$ & 2 & $5 \%$ \\
Oxítona & 0 & 0 & 151 & $100 \%$
\end{tabular}

Com relação aos dados referentes aos falantes nativos observou-se, portanto, que o fato de a palavra estar inserida em uma sequência com choque acentual ou sem choque acentual não teve papel significativo para a ocorrência da retração de acento. Além disso, observou-se que o padrão da última sílaba da primeira palavra do choque foi estatisticamente significativo para a aplicação da retração de acento e que palavras terminadas em vogal longa e em vogal longa seguida de nasal favoreceram a aplicação da regra, enquanto palavras terminadas em obstruinte não favoreceram.

\subsubsection{Falantes de inglês como L2}

Antes de apresentarmos os resultados referentes à aplicação da retração de acento em frases com choque e sem choque acentual, vejamos o padrão acentual empregado pelos falantes não nativos nas palavras individuais, as quais, conforme já mencionado, foram utilizadas como um parâmetro para controlar os casos em que houve retração nas frases. A Tabela 22 a seguir apresenta o padrão acentual aplicado em 
cada palavra lida isoladamente ${ }^{29}$. Percebe-se que em 11 palavras (ex: Bel-Air, dislike, retake) a porcentagem de aplicação do padrão oxítono, que era o padrão esperado no contexto de palavra isolada, foi bem mais alta do que os outros dois padrões. Nas outras 10 palavras, entretanto, a aplicação do padrão paroxítono (ex: eighteen, fifteen, fourteen) ou proparoxítono (kangaroo, seventeen) foi quase a mesma do padrão oxítono. Nesses casos, a ocorrência do padrão paroxítono ou proparoxítono nas palavras inseridas em frases com ou sem choque não foi classificada como retração de acento, já que não houve modificação no padrão acentual empregado nos diferentes contextos.

Tabela 22: Padrão Acentual Aplicado na Palavra Isolada - Inglês como L2

\begin{tabular}{|c|c|c|c|c|c|c|}
\hline \multirow{3}{*}{$\begin{array}{c}\text { Palavra } \\
\text { Alvo }\end{array}$} & \multicolumn{6}{|c|}{ ACENTO APLICADO NA PALAVRA ISOLADA } \\
\hline & \multicolumn{2}{|c|}{ Oxítono } & \multicolumn{2}{|c|}{ Paroxítono } & \multicolumn{2}{|c|}{ Proparoxítono } \\
\hline & Casos/Tot. & $\%$ & Casos/Tot. & $\%$ & Casos/Tot. & $\%$ \\
\hline bamboo & $24 / 30$ & 80 & $6 / 30$ & 20 & & \\
\hline Bel-Air & $26 / 30$ & 86,6 & $4 / 30$ & 13,4 & & \\
\hline complete & $25 / 30$ & 83,3 & $5 / 30$ & 16,7 & & \\
\hline discrete & $23 / 30$ & 76,6 & $7 / 30$ & 23,4 & & \\
\hline dislike & $26 / 30$ & 86,6 & $4 / 30$ & 13,4 & & \\
\hline eighteen & $16 / 30$ & 53,3 & $14 / 30$ & 46,6 & & \\
\hline express & $28 / 30$ & 93,3 & $2 / 30$ & 7,7 & & \\
\hline fifteen & $13 / 30$ & 43,3 & $17 / 30$ & 56,5 & & \\
\hline fourteen & $18 / 30$ & 60 & $12 / 30$ & 40 & & \\
\hline grotesque & $23 / 30$ & 76,6 & $7 / 30$ & 23,4 & & \\
\hline kangaroo & $15 / 30$ & 50 & $1 / 30$ & 3,3 & $14 / 30$ & 46,6 \\
\hline nineteen & $16 / 30$ & 53,3 & $14 / 30$ & 46,7 & & \\
\hline police & $15 / 30$ & 50 & $15 / 30$ & 50 & & \\
\hline retake & $29 / 30$ & 86,7 & $1 / 30$ & 3,3 & & \\
\hline robust & $18 / 30$ & 60 & $12 / 30$ & 40 & & \\
\hline seventeen & $17 / 30$ & 56,6 & $0 / 30$ & 0 & $13 / 30$ & 43,4 \\
\hline sixteen & $18 / 30$ & 60 & $12 / 30$ & 40 & & \\
\hline Tennessee & $17 / 30$ & 56,6 & $3 / 30$ & 10 & $10 / 30$ & 33,4 \\
\hline thirteen & $14 / 30$ & 46,6 & $16 / 30$ & 53,3 & & \\
\hline U2 & $26 / 30$ & 86,6 & $4 / 30$ & 13,4 & & \\
\hline unkind & $23 / 30$ & 76,6 & $7 / 30$ & 23,4 & & \\
\hline
\end{tabular}

Vejamos, então, a taxa de aplicação da retração de acento pelos trinta falantes de inglês como segunda língua pode ser observada no Gráfico 17 a seguir, que inclui palavras inseridas em frases com choque e sem choque acentual.

\footnotetext{
${ }^{29}$ Cada palavra foi lida isoladamente apenas uma vez.
} 


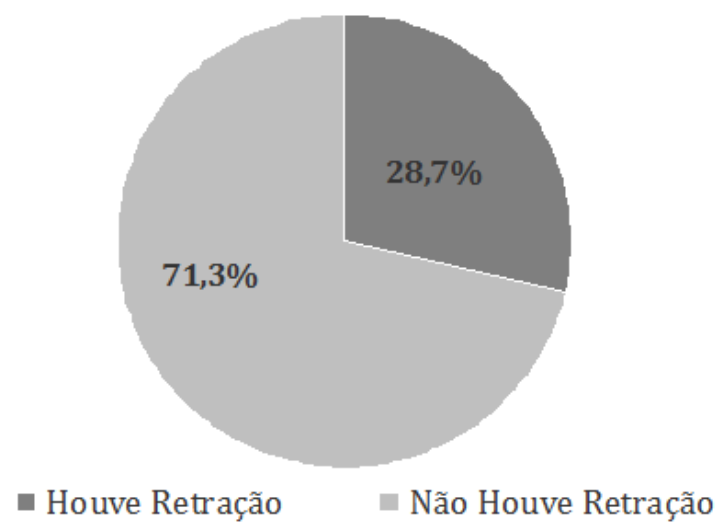

Gráfico 17: Retração de Acento por falantes de inglês como L2

Observa-se que a retração de acento foi aplicada em 28,7\% dos casos (396/1378) e não foi aplicada em 71,3\% dos dados dos falantes não nativos (982/1378). A análise estatística selecionou, nesta ordem, as variáveis Nível de Proficiência, Idade de Início da Aquisição e Palavra Alvo como estatisticamente relevantes. As variáveis Segmento Final, Contexto e Pausa, portanto, não foram consideradas estatisticamente significativas.

Os resultados nesta seção não serão necessariamente apresentados conforme a ordem de seleção do programa estatístico. Para privilegiar o desenvolvimento da discussão proposta neste trabalho, apresentaremos primeiramente as variáveis linguísticas (Contexto, Palavra, Segmento Final, e Pausa) e, em seguida, as variáveis extralinguísticas (Nível de Proficiência, Idade de Início da Aquisição e Informante).

A Tabela 23 a seguir apresenta os resultados referentes à variável Contexto, que, assim como nos dados dos falantes nativos, não foi estatisticamente significativa para a aplicação da retração de acento.

Tabela 23: Retração de Acento por Contexto - Inglês como L2

\begin{tabular}{ccccc}
\hline \multirow{2}{*}{ Contexto } & \multicolumn{2}{c}{ Retração } & \multicolumn{2}{c}{ Sem retração } \\
\cline { 2 - 5 } & $\mathbf{n}$ & $\mathbf{\%}$ & $\mathbf{n}$ & $\mathbf{\%}$ \\
\hline Frases com Choque & 206 & $29,9 \%$ & 483 & $70,1 \%$ \\
Frases sem Choque & 190 & $27,6 \%$ & 499 & $72,4 \%$
\end{tabular}

Pode-se observar que em 29,9\% dos casos a retração ocorreu em frases com uma sequência de choque acentual (ex: SixTEEN CHAIRS) e em 27,6\% dos casos a regra foi aplicada em frases sem choque acentual (ex: sixTEEN imiTAtions). Houve, portanto, mais casos de retração de acento em frases com choque acentual, mas a diferença entre esses dois tipos de frase não foi estatisticamente significativa. 
Dentre as variáveis linguísticas testadas, apenas Palavra Alvo mostrou-se estatisticamente relevante na produção dos falantes de inglês como L2. Os resultados referentes a esta variável são apresentados na Tabela 24 a seguir, que inclui contextos de frase com choque e sem choque. ${ }^{30}$

Tabela 24: Retração de Acento por Palavra Alvo - Inglês como L2

\begin{tabular}{cccccc}
\hline Palavra & \multicolumn{2}{c}{ Retração } & \multicolumn{2}{c}{ Sem retração } & PESO \\
\cline { 2 - 5 } Alvo & $\mathbf{n}$ & $\mathbf{\%}$ & $\mathbf{n}$ & $\mathbf{\%}$ & REL. \\
\hline U2 & 31 & $51,7 \%$ & 29 & $48,3 \%$ & 0,75 \\
seventeen & 30 & $50 \%$ & 30 & $50 \%$ & 0,74 \\
sixteen & 29 & $48,3 \%$ & 31 & $51,7 \%$ & 0,72 \\
nineteen & 26 & $43,3 \%$ & 34 & $56,7 \%$ & 0,68 \\
fourteen & 24 & $40 \%$ & 36 & $60 \%$ & 0,64 \\
unkind & 21 & $35 \%$ & 39 & $65 \%$ & 0,64 \\
Tennessee & 23 & $38,3 \%$ & 37 & $61,7 \%$ & 0,63 \\
thirteen & 23 & $38,3 \%$ & 37 & $61,7 \%$ & 0,63 \\
fifteen & 23 & $38,3 \%$ & 37 & $61,7 \%$ & 0,63 \\
kangaroo & 22 & $36,7 \%$ & 38 & $63,3 \%$ & 0,61 \\
eighteen & 22 & $36,7 \%$ & 38 & $63,3 \%$ & 0,61 \\
robust & 18 & $30 \%$ & 42 & $70 \%$ & 0,58 \\
bamboo & 20 & $33,3 \%$ & 40 & $66,7 \%$ & 0,57 \\
grotesque & 15 & $25,9 \%$ & 43 & $74,1 \%$ & 0,52 \\
express & 12 & $20 \%$ & 48 & $80 \%$ & 0,43 \\
police & 12 & $20 \%$ & 48 & $80 \%$ & 0,43 \\
Bel-Air & 11 & $18,3 \%$ & 40 & $81,7 \%$ & 0,41 \\
discrete & 9 & $15 \%$ & 51 & $85 \%$ & 0,35 \\
retake & 8 & $13,3 \%$ & 52 & $86,7 \%$ & 0,31 \\
complete & 7 & $11,7 \%$ & 53 & $88,3 \%$ & 0,28 \\
dislike & 10 & $5,6 \%$ & 170 & $94,4 \%$ & 0,14
\end{tabular}

Pode-se observar que, dentre todas as palavras testadas, a palavra composta $U 2$, nome de uma famosa banda irlandesa, foi a maior favorecedora da retração de acento entre os falantes não nativos, com taxa de aplicação de 51,7\% e peso relativo de 0,75. Isso significa que, em $51,7 \%$ dos casos, os falantes brasileiros aplicaram o padrão oxítono nesta palavra produzida isoladamente (youTWO) e, em frases com choque (youTWO SONGS) e sem choque (youTWO celeBRAtions) aplicaram o padrão paroxítono (YOUtwo).

\footnotetext{
${ }^{30}$ Dentre as 1380 palavras produzidas pelos falantes de inglês como L2 nas frases em análise, apenas duas produções tiveram que ser excluídas: a palavra grotesque produzida pela Informante 9, do nível básico, nas frases com choque acentual e sem choque acentual. A informante não conseguiu produzir esta palavra, mesmo quando solicitada para repetir a leitura. Sendo assim, todos os informantes produziram 46 palavras cada, exceto a Informante 9, que produziu 44.
} 
As palavras seventeen e sixteen também favoreceram a aplicação da retração de acento e apresentaram pesos relativos bastante aproximados, de 0,74 e 0,72, respectivamente. As palavras nineteen, fourteen, unkind, Tennessee, thirteen, fifteen, kangaroo, eighteen, robust e bamboo também se mostraram favoredoras à aplicação da regra, com pesos relativos entre 0,68 e 0,57. A palavra grotesque, por sua vez, mostrou um peso relativo de 0,52 , o que significa que não teve papel significativo sobre a aplicação da regra de retração. Por fim, as palavras express, police, Bel-Air, discrete, retake, complete e dislike não favoreceram a aplicação da retração, sendo dislike a palavra menos favorecedora (peso relativo de 0,14). Conforme previsto na Seção 5.2.3.1, os casos de retração em palavras como police $(20 \%)$ e complete $(7 \%)$ indicam que os brasileiros podem ter produzido vogais plenas nas sílabas po- e com-, o que possibilitou a aplicação do acento paroxítono.

A Tabela 25 a seguir apresenta os resultados referentes à variável Segmento Final, cujo objetivo era verificar se o padrão da última sílaba da primeira palavra do choque teria alguma influência sobre a aplicação da regra. Os fatores para esta variável, que não se mostrou estatisticamente significativa para a aplicação da retração de acento pelos falantes de inglês como L2, são Vogal Longa (ex: bamboo, kangaroo), Nasal (ex: thirteen, eighteen) e Obstruinte (ex: retake, express).

Tabela 25: Retração de Acento e Segmento Final - Inglês como L2

\begin{tabular}{ccccc}
\hline \multirow{2}{*}{ Segmento Final } & \multicolumn{2}{c}{ Retração } & \multicolumn{2}{c}{ Sem retração } \\
\cline { 2 - 5 } & $\mathbf{N}$ & $\mathbf{\%}$ & $\mathbf{n}$ & $\mathbf{\%}$ \\
\hline Nasal & 177 & $42,1 \%$ & 243 & $57,9 \%$ \\
Vogal Longa & 96 & $40 \%$ & 144 & $60 \%$ \\
Obstruinte & 123 & $17,1 \%$ & 595 & $82,9 \%$
\end{tabular}

$\mathrm{O}$ fato de vogais longas seguidas de nasal terem apresentado a maior taxa de aplicação do vozeamento está relacionado ao fato de que as palavras seventeen, sixteen, nineteen e fourteen apresentaram taxas de retração bastante altas (entre 40\% e 50\%). Palavras terminadas em vogal longa também apresentaram uma taxa de aplicação alta porque a palavra que apresentou mais casos de retração foi $U 2$, cuja sílaba final apresenta uma vogal longa. Por fim, o fato de palavras terminadas em obstruinte terem apresentado a taxa de aplicação mais baixa está relacionado ao fato de palavras como discrete, retake, complete e dislike terem apresentado as taxas mais baixas de aplicação da regra (cf. Tabela 20). 
A Tabela 26 a seguir apresenta o padrão acentual empregado pelos falantes brasileiros nos casos de retração de acento. Lembramos que esta variável tem caráter descritivo, ou seja, não foi incluída na análise multidimensional por causa da ocorrência de knockout. 0 objetivo com esta variável é observarmos qual foi o padrão acentual empregado pelos falantes nos casos em que houve retração e nos casos em que não houve aplicação da regra.

Tabela 26: Retração de Acento e Padrão Acentual Empregado - Inglês como L2

\begin{tabular}{ccccc}
\hline Padrão Acentual & \multicolumn{2}{c}{ Retração } & \multicolumn{2}{c}{ Sem retração } \\
\cline { 2 - 5 } Empregado & $\mathbf{n}$ & $\mathbf{\%}$ & $\mathbf{n}$ & $\mathbf{\%}$ \\
\hline Paroxítona & 320 & $54,4 \%$ & 268 & $45,5 \%$ \\
Proparoxítona & 76 & $53,9 \%$ & 65 & $46 \%$ \\
Oxítona & 0 & 0 & 649 & $100 \%$
\end{tabular}

Observa-se que 54,4\% dos casos em que os informantes aplicaram o padrão paroxítono foram ocorrências de retração de acento (ex: FIFteen MEN) e que em 45,5\% dos casos os informantes aplicaram o padrão paroxítono tanto nas palavras produzidas individualmente (ex: FIFteen) quanto nas palavras inseridas em frases, o que não caracteriza a retração. Resultados semelhantes foram encontrados quando o padrão empregado foi o proparoxítono: 53,9\% foram casos de retração (ex: KANgaroo KIM) e $46 \%$ foram casos em que esse mesmo padrão foi empregado tanto na palavra isolada (ex: KANgaroo) quanto na palavra inserida em frases com choque (ex: KANgaroo KIM) e sem choque (ex: KANgaroo meLIssa). Por fim, as aplicações do padrão Oxítono (ex: kangaROO) indicam os casos em que a retração não foi aplicada.

A Tabela 27 a seguir apresenta o cruzamento entre as variáveis Padrão Acentual Empregado e Palavra Alvo e deve ser lida da seguinte forma: a palavra dislike, por exemplo, foi produzida como oxítona 171 vezes nas frases com choque e sem choque (disLIKE), o que significa que a retração não ocorreu em nenhum desses casos. Essa mesma palavra foi produzida com o padrão paroxítono em 9 casos (DISlike), dos quais 8 foram ocorrências de retração de acento e um não foi (porque o padrão paroxítono também foi aplicado na palavra isolada). A palavra $U 2$, por sua vez, foi produzida como oxítona nas frases com choque e sem choque em 26 casos e como paroxítona em 36 casos, dos quais 29 foram ocorrências de retração de acento, e assim sucessivamente. 
Tabela 27: Acento empregado por palavra alvo - Inglês como L2

\begin{tabular}{ccccccc}
\hline \multirow{2}{*}{ Palavra } & \multicolumn{5}{c}{ ACENTO APLICADO EM CASOS DE RETRAÇÃO } \\
\cline { 2 - 7 } Alvo & \multicolumn{2}{c}{ Oxítono } & \multicolumn{2}{c}{ Paroxítono } & \multicolumn{2}{c}{ Proparoxítono } \\
\cline { 2 - 6 } & n/Total & $\%$ & n/Total & $\%$ & n/Total & $\%$ \\
\hline dislike & $0 / 171$ & 0 & $8 / 9$ & $89 \%$ & 0 & 0 \\
U2 & $0 / 26$ & 0 & $29 / 36$ & $81 \%$ & 0 & 0 \\
bamboo & $0 / 35$ & 0 & $20 / 25$ & $80 \%$ & 0 & 0 \\
retake & $0 / 50$ & 0 & $8 / 10$ & $80 \%$ & 0 & 0 \\
express & $0 / 45$ & 0 & $12 / 15$ & $80 \%$ & 0 & 0 \\
unkind & $0 / 32$ & 0 & $21 / 28$ & $75 \%$ & 0 & 0 \\
Bel-Air & $0 / 45$ & 0 & $11 / 15$ & $73 \%$ & 0 & 0 \\
discrete & $0 / 46$ & 0 & $9 / 14$ & $64 \%$ & 0 & 0 \\
sixteen & $0 / 8$ & 0 & $29 / 52$ & $56 \%$ & 0 & 0 \\
grotesque & $0 / 30$ & 0 & $15 / 28$ & $54 \%$ & 0 & 0 \\
complete & $0 / 47$ & 0 & $7 / 13$ & $54 \%$ & 0 & 0 \\
fourteen & $0 / 14$ & 0 & $24 / 46$ & $52 \%$ & 0 & 0 \\
nineteen & $0 / 6$ & 0 & $26 / 54$ & $48 \%$ & 0 & 0 \\
eighteen & $0 / 12$ & 0 & $22 / 48$ & $46 \%$ & 0 & 0 \\
robust & $0 / 19$ & 0 & $18 / 41$ & $44 \%$ & 0 & 0 \\
thirteen & $0 / 7$ & 0 & $23 / 53$ & $43 \%$ & 0 & 0 \\
fifteen & $0 / 4$ & 0 & $23 / 56$ & $41 \%$ & 0 & 0 \\
police & $0 / 25$ & 0 & $12 / 35$ & $34 \%$ & 0 & 0 \\
Tennessee & $0 / 13$ & 0 & $1 / 6$ & $17 \%$ & $22 / 41$ & $54 \%$ \\
seventeen & $0 / 4$ & 0 & $0 / 2$ & 0 & $30 / 54$ & $56 \%$ \\
kangaroo & $0 / 12$ & 0 & $0 / 2$ & 0 & $22 / 46$ & $48 \%$ \\
\hline ToTAL & $\mathbf{0} / \mathbf{6 4 9}$ & $\mathbf{0}$ & $\mathbf{3 1 7} / \mathbf{5 8 8}$ & $\mathbf{5 4 \%}$ & $\mathbf{7 4 / 1 4 1}$ & $\mathbf{5 2 \%}$ \\
\hline
\end{tabular}

Pode-se destacar na Tabela 27 que a ocorrência do padrão oxítono nos numerais sixteen, nineteen, thirteen e fifteen foi bastante baixa (destacados em cinza claro) e que a aplicação do padrão paroxítono foi alta em todas essas palavras (destacadas em cinza escuro). Observa-se que boa parte dos casos em que o padrão paroxítono foi aplicado nessas palavras não foram casos de retração, o que revela uma tendência de os falantes brasileiros aplicarem o padrão paroxítono nessas palavras tanto em contexto isolado quanto inseridas em frases. 0 mesmo pode ser observado no numeral seventeen, que foi produzido de maneira oxítona em apenas 4 casos (sevenTEEN) e de maneira proparoxítona (SEventeen) em 54 casos, dos quais apenas 30 foram casos de retração.

A última variável linguística considerada na análise da regra de retração de acento foi Pausa, a qual, como vimos na Seção 5.2.3, controla a ocorrência de pausas entre a primeira e a segunda palavra do choque (ex: fifTEEN ... MEN). Se compararmos a aplicação da retração nos casos com pausa e sem pausa a diferença não é muito significativa $(11,1 \%$ e $29,3 \%$, respectivamente). Entretanto, se observarmos a aplicação 
da retração nos casos de pausa em comparação com os casos em que não houve retração, essa diferença é bastante significativa $(11,1 \%$ e $88,9 \%$, respectivamente), conforme a Tabela 28 a seguir.

Tabela 28: Retração de Acento em casos de Pausa - Inglês como L2

\begin{tabular}{ccccc}
\hline \multirow{2}{*}{ Pausa } & \multicolumn{2}{c}{ Retração } & \multicolumn{2}{c}{ Sem retração } \\
\cline { 2 - 5 } & $\mathbf{n}$ & $\mathbf{\%}$ & $\mathbf{n}$ & $\mathbf{\%}$ \\
\hline Com Pausa & 5 & $11,1 \%$ & 40 & $88,9 \%$ \\
Sem Pausa & 391 & $29,3 \%$ & 942 & $70,7 \%$
\end{tabular}

Observa-se que as ocorrências de pausa foram pouco numerosas, se considerarmos o total de dados obtidos nesta pesquisa (45/1338). Isso ocorreu porque, como dito em 5.2.3.1, solicitamos que os informantes realizassem a leitura das frases de maneira natural e sem interrupções, de modo a evitar a influência de pausas sobre as sequências de choque acentual. ${ }^{31}$ Entretanto, sobretudo no nível básico, alguns informantes não conseguiram realizar a leitura das frases sem interrupções. Isso fica evidente nos resultados apresentados na Tabela 29 a seguir, que apresenta as ocorrências de pausa por nível de proficiência. Pode-se observar que, das 45 pausas, 39 ocorreram no nível básico, e a retração ocorreu em apenas 4 casos (10\%). No nível intermediário, foram registradas 5 ocorrências de pausa, e em nenhum desses casos a regra de retração de acento foi aplicada. Por fim, no nível avançado, registramos apenas um caso de pausa, o qual não impediu a aplicação da regra.

Tabela 29: Cruzamento entre pausa e nível de proficiência - Inglês como L2

\begin{tabular}{|c|c|c|c|c|}
\hline \multirow{3}{*}{$\begin{array}{c}\text { Nível de } \\
\text { Proficiência }\end{array}$} & \multicolumn{4}{|c|}{ Pausa } \\
\hline & \multicolumn{2}{|c|}{ Com Pausa } & \multicolumn{2}{|c|}{ Sem Pausa } \\
\hline & $\mathrm{n} /$ Total & $\%$ & $\mathrm{n} /$ Total & $\%$ \\
\hline Básico & $4 / 39$ & $10 \%$ & $76 / 419$ & $18 \%$ \\
\hline Intermediário & $0 / 5$ & 0 & $114 / 455$ & $25 \%$ \\
\hline Avançado & $1 / 1$ & $100 \%$ & $201 / 459$ & $44 \%$ \\
\hline TOTAL & $5 / 45$ & $11 \%$ & $391 / 1333$ & $29 \%$ \\
\hline
\end{tabular}

Vejamos, então, os resultados referentes às variáveis extralinguísticas. A variável Nível de Proficiência, conforme já mencionado, foi a primeira selecionada como estatisticamente relevante. Os resultados da Tabela 30 a seguir mostram que a aplicação

\footnotetext{
${ }^{31} \mathrm{O}$ mesmo procedimento foi aplicado nos casos de pausa em frases cujo objetivo era verificar a assimilação de vozeamento, pois a pausa poderia bloquear a assimilação regressiva (cf. Cap. 5).
} 
da regra foi favorecida pelos falantes de nível avançado, com peso relativo de 0,69 e taxa de aplicação de 43,9\%. Os falantes de nível intermediário apresentaram um peso relativo próximo do ponto neutro, de 0,45 , e taxa de $24,8 \%$ de aplicação da regra. Os informantes de nível básico, por fim, não favoreceram a aplicação da regra, pois apresentaram peso relativo de 0,34 e a menor porcentagem de aplicação da retração, de $17,5 \%$.

Tabela 30: Retração de Acento por Nível de Proficiência - Inglês como L2

\begin{tabular}{cccccc}
\hline Nível de & \multicolumn{2}{c}{ Retração } & \multicolumn{2}{c}{ Sem retração } & PESO \\
\cline { 2 - 5 } Proficiência & $\mathbf{n}$ & $\mathbf{\%}$ & $\mathbf{n}$ & $\mathbf{\%}$ & REL. \\
\hline Básico & 80 & $17,5 \%$ & 378 & $82,5 \%$ & 0,34 \\
Intermediário & 114 & $24,8 \%$ & 346 & $75,2 \%$ & 0,45 \\
Avançado & 202 & $43,9 \%$ & 258 & $56,1 \%$ & 0,69
\end{tabular}

A aplicação da retração de acento por nível de proficiência também pode ser visualizada no Gráfico 18 a seguir, que também apresenta a taxa de aplicação do grupo de controle (cf. Seção 5.3.11) para fins de comparação.

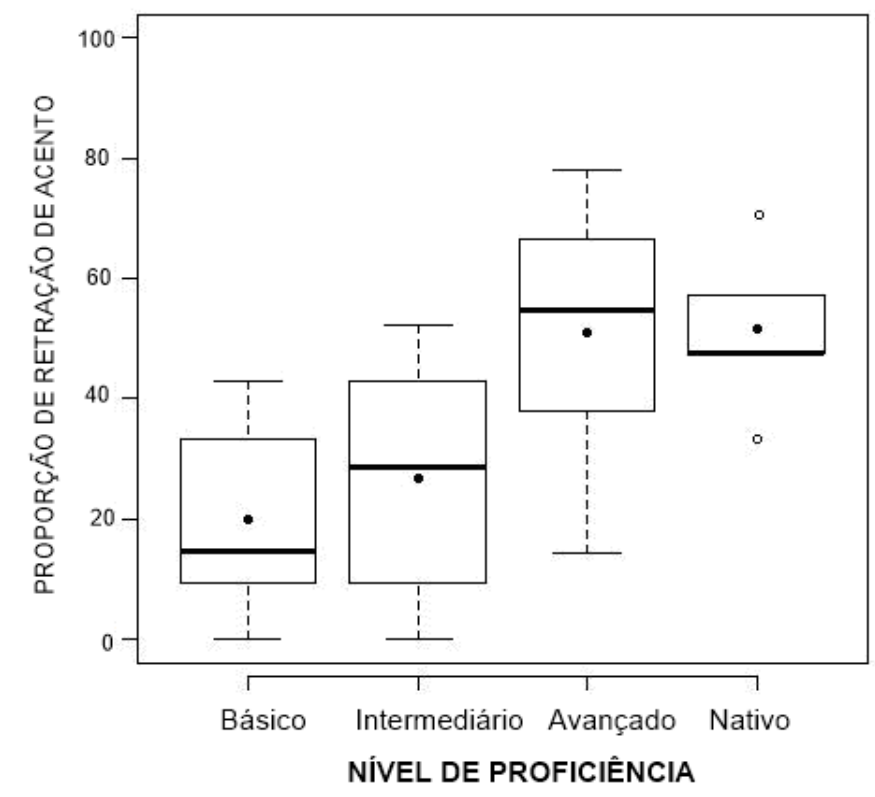

Gráfico 18: Retração de Acento por Nível de Proficiência

Pode-se observar que a média de aplicação da regra aumenta conforme o nível de proficiência e que os falantes de nível avançado apresentam, em média, uma proporção de retração mais alta do que os falantes nativos. Percebe-se, também, que há bastante 
variação na proporção de retração de acento nos três níveis de proficiência, e que essa variação é menor no grupo de falantes nativos.

Com o objetivo de verificar a taxa de aplicação da regra por cada participante da pesquisa, a Tabela 31 a seguir apresenta a taxa de aplicação da regra por Informante.

Dentre os falantes de nível básico, observa-se que os informantes 1 e 8 apresentaram as taxas mais baixas, de 4,3\% e 2,2\%, respectivamente (destacados em cinza claro). Os informantes 4 e 6 , por outro lado, apresentaram as taxas mais altas neste nível de proficiência, de 34,8\% e 32,6\%, respectivamente (destacados em cinza escuro). No nível intermediário, os informantes que apresentaram as taxas mais altas foram o 11 e o 13 , de 41,3\% e 50\%, respectivamente (em cinza escuro). Os falantes 18 e 19 apresentaram taxas bem mais baixas, de 10,9\% e 4,3\%, e o Informante 16 foi o único de todos os participantes que não apresentou nenhum caso de retração de acento (em cinza claro). Por fim, dentre os informantes do nível avançado, os informantes 28 e 30 foram os que apresentaram as taxas mais baixas, de 17,4\% e 21,7\%, respectivamente (em cinza escuro). Os informantes 21 e 22, por outro lado, apresentaram taxas bastante altas, de $58,7 \%$ e 56,5\%, respectivamente, e o Informante 28 apresentou a taxa mais alta de todos os participantes, de $80,4 \%$, superando inclusive as taxas dos 7 falantes nativos do grupo de controle (cf. Tabela 17). 
Tabela 31: Retração de Acento por Informante - Inglês como L2

\begin{tabular}{|c|c|c|c|}
\hline NÍVEL & INFORMANTE & CASOS/TOTAL & PORCENTAGEM \\
\hline \multirow{10}{*}{ Básico } & Inf. 1 & $2 / 46$ & $4,3 \%$ \\
\hline & Inf. 2 & $4 / 46$ & $8,7 \%$ \\
\hline & Inf. 3 & $4 / 46$ & $8,7 \%$ \\
\hline & Inf. 4 & $16 / 46$ & $34,8 \%$ \\
\hline & Inf. 5 & $5 / 46$ & $10,9 \%$ \\
\hline & Inf. 6 & $15 / 46$ & $32,6 \%$ \\
\hline & Inf. 7 & $7 / 46$ & $15,2 \%$ \\
\hline & Inf. 8 & $1 / 46$ & $2,2 \%$ \\
\hline & Inf. 9 & $11 / 44$ & $25 \%$ \\
\hline & Inf. 10 & $15 / 46$ & $32,6 \%$ \\
\hline \multirow{10}{*}{ Interm. } & Inf. 11 & $19 / 46$ & $41,3 \%$ \\
\hline & Inf. 12 & $17 / 46$ & $37 \%$ \\
\hline & Inf. 13 & $23 / 46$ & $50 \%$ \\
\hline & Inf. 14 & $9 / 46$ & $19,6 \%$ \\
\hline & Inf. 15 & $8 / 46$ & $17,4 \%$ \\
\hline & Inf. 16 & $0 / 46$ & 0 \\
\hline & Inf. 17 & $16 / 46$ & $34,8 \%$ \\
\hline & Inf. 18 & $5 / 46$ & $10,9 \%$ \\
\hline & Inf. 19 & $2 / 46$ & $4,3 \%$ \\
\hline & Inf. 20 & $15 / 46$ & $32,6 \%$ \\
\hline \multirow{11}{*}{ Avançado } & Inf. 21 & $27 / 46$ & $58,7 \%$ \\
\hline & Inf. 22 & $26 / 46$ & $56,5 \%$ \\
\hline & Inf. 23 & $22 / 46$ & $47,8 \%$ \\
\hline & Inf. 24 & $22 / 46$ & $47,8 \%$ \\
\hline & Inf. 25 & $37 / 46$ & $80,4 \%$ \\
\hline & Inf. 26 & $21 / 46$ & $45,7 \%$ \\
\hline & Inf. 27 & $17 / 46$ & $37 \%$ \\
\hline & Inf. 28 & $8 / 46$ & $17,4 \%$ \\
\hline & Inf. 29 & $12 / 46$ & $26,1 \%$ \\
\hline & Inf. 30 & $10 / 46$ & $21,7 \%$ \\
\hline & TOTAL & $396 / 1378$ & $28,7 \%$ \\
\hline
\end{tabular}

Para a facilitar a observação da relação entre o nível de proficiência e o informante, o Gráfico 19 a seguir mostra a porcentagem de aplicação da retração de acento por cada sujeito, separados por nível de proficiência.

Pode-se observar que as taxas de aplicação da regra apresentam bastante variação entre os informantes. Percebe-se, por exemplo, que os informantes 4, 6, 9 e 10 do nível básico apresentam taxas mais altas que os informantes 14, 15, 16, 18 e 19 do nível intermediário e que os informantes 28, 29 e 30, do nível avançado. Observa-se, também que a taxa de retração pelo nível intermediário foi mais alta que a do nível básico por causa dos informantes 11,12,13, 17 e 20, que apresentaram taxas de 
aplicação mais altas. Por fim, no nível avançado, observa-se que as taxas de aplicação foram, de modo geral, mais altas que a dos outros dois níveis, exceto no que diz respeito aos informantes 28, 29 e 30. Percebe-se também que o informante 25 apresentou a taxa de aplicação mais alta entre todos os informantes, o que ajudou a aumentar a média dos falantes de nível avançado.

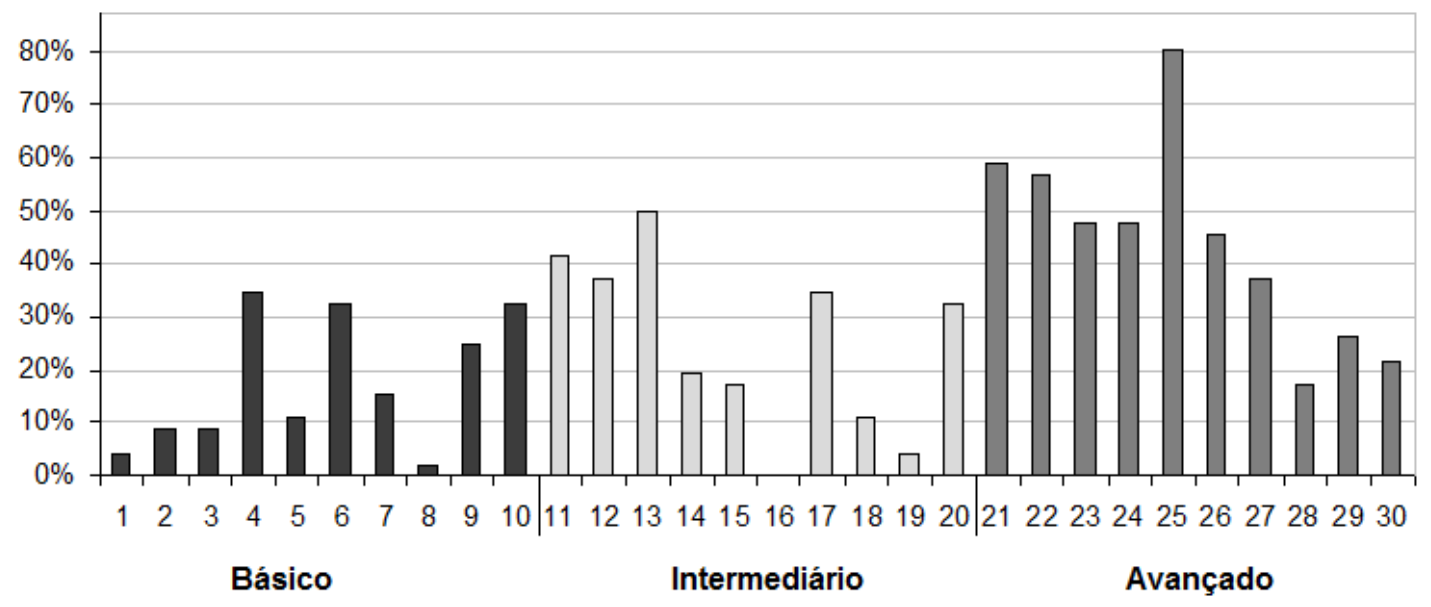

Gráfico 19: Retração de Acento por informante e nível de proficiência

A Tabela 32 a seguir apresenta a aplicação da retração de acento em frases com choque (ex: bamBOO BRAcelet) e frases sem choque (ex: bamBOO maTErials). Pode-se observar que, dos 30 falantes de inglês como L2, 8 apresentaram a mesma proporção de retração de acento nos dois contextos: os informantes 1, 2, 3 e 4, do nível básico, 15 e 19, do intermediário, e 22 e 30, do avançado. Metade dos informantes apresentaram uma taxa de retração mais alta nos casos de frase com choque acentual: os informantes 6, 7 e 9, do nível básico, 11, 12, 13 e 14, do nível intermediário, e todos do nível avançado, exceto o informante 28. 
Tabela 32: Retração por Informante separada por Contexto - Inglês como L2

\begin{tabular}{|c|c|c|c|c|c|}
\hline \multirow{3}{*}{$\begin{array}{c}\text { Nível de } \\
\text { Proficiência }\end{array}$} & \multirow{3}{*}{ Informante } & \multicolumn{4}{|c|}{ Contexto } \\
\hline & & \multicolumn{2}{|c|}{$\begin{array}{c}\text { Frase com } \\
\text { Choque }\end{array}$} & \multicolumn{2}{|c|}{$\begin{array}{c}\text { Frase sem } \\
\text { Choque }\end{array}$} \\
\hline & & N/Total & $\%$ & N/Total & $\%$ \\
\hline \multirow{10}{*}{ Básico } & Inf. 1 & 1 & $4 \%$ & 1 & $4 \%$ \\
\hline & Inf. 2 & 2 & $9 \%$ & 2 & $9 \%$ \\
\hline & Inf. 3 & 2 & $9 \%$ & 2 & $9 \%$ \\
\hline & Inf. 4 & 8 & $35 \%$ & 8 & $35 \%$ \\
\hline & Inf. 5 & 2 & $9 \%$ & 3 & $13 \%$ \\
\hline & Inf. 6 & 8 & $35 \%$ & 7 & $30 \%$ \\
\hline & Inf. 7 & 6 & $26 \%$ & 1 & $4 \%$ \\
\hline & Inf. 8 & 0 & 0 & 1 & $4 \%$ \\
\hline & Inf. 9 & 6 & $27 \%$ & 5 & $23 \%$ \\
\hline & Inf. 10 & 7 & $30 \%$ & 8 & $35 \%$ \\
\hline \multirow{10}{*}{ Intermed. } & Inf. 11 & 10 & $43 \%$ & 9 & $39 \%$ \\
\hline & Inf. 12 & 9 & $39 \%$ & 8 & $35 \%$ \\
\hline & Inf. 13 & 12 & $52 \%$ & 11 & $48 \%$ \\
\hline & Inf. 14 & 5 & $22 \%$ & 4 & $17 \%$ \\
\hline & Inf. 15 & 4 & $17 \%$ & 4 & $17 \%$ \\
\hline & Inf. 16 & 0 & 0 & 0 & 0 \\
\hline & Inf. 17 & 7 & $30 \%$ & 9 & $39 \%$ \\
\hline & Inf. 18 & 2 & $9 \%$ & 3 & $13 \%$ \\
\hline & Inf. 19 & 1 & $4 \%$ & 1 & $4 \%$ \\
\hline & Inf. 20 & 7 & $30 \%$ & 8 & $25 \%$ \\
\hline \multirow{10}{*}{ Avançado } & Inf. 21 & 14 & $61 \%$ & 13 & $57 \%$ \\
\hline & Inf. 22 & 13 & $57 \%$ & 13 & $57 \%$ \\
\hline & Inf. 23 & 12 & $52 \%$ & 10 & $43 \%$ \\
\hline & Inf. 24 & 12 & $52 \%$ & 10 & $43 \%$ \\
\hline & Inf. 25 & 20 & $87 \%$ & 17 & $74 \%$ \\
\hline & Inf. 26 & 11 & $48 \%$ & 10 & $43 \%$ \\
\hline & Inf. 27 & 9 & $39 \%$ & 8 & $35 \%$ \\
\hline & Inf. 28 & 3 & $13 \%$ & 5 & $22 \%$ \\
\hline & Inf. 29 & 8 & $35 \%$ & 4 & $17 \%$ \\
\hline & Inf. 30 & 5 & $22 \%$ & 5 & $22 \%$ \\
\hline
\end{tabular}

A taxa de aplicação da retração de acento por informante e por contexto também pode ser visualizada no Gráfico 20 a seguir. Pode-se perceber que a grande maioria dos informantes ou apresentou uma proporção igual nos dois contextos ou aplicou mais a retração nos contextos de choque. Apenas o informante 10, do nível básico, e os informantes 17 e 18, do nível intermediário, apresentaram uma proporção de retração um pouco mais alta nos contextos sem choque. 


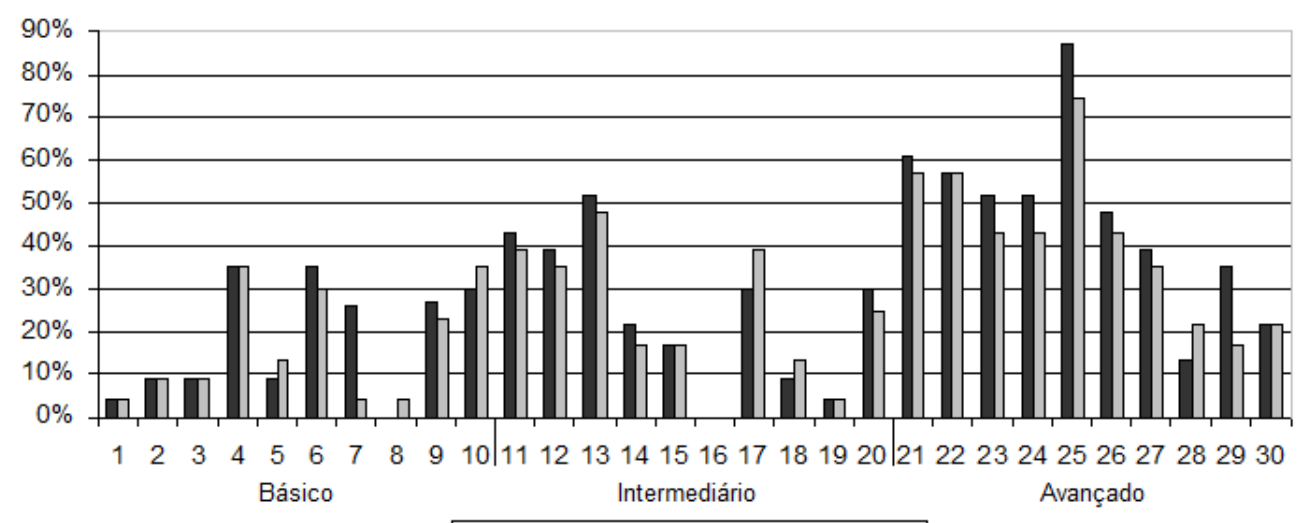

Com Choque $\square$ Sem Choque

Gráfico 20: Retração de acento por informante e por contexto - Inglês como L2

Vejamos, por fim, os resultados referentes à variável Idade de Início da Aquisição, que também foi estatisticamente relevante nos dados referentes à regra de retração de acento. A Tabela 33 a seguir mostra que a aplicação da regra foi favorecida pelos informantes que iniciaram a aquisição da língua inglesa antes dos 12 anos, com peso relativo de 0,56 e proporção de aplicação de 33,3\%. Os falantes que iniciaram a aquisição depois dos 12 anos, por outro lado, não favoreceram a aplicação da retração acentual, com peso relativo de 0,43 e taxa de $24,2 \%$.

Tabela 33: Retração de Acento por Idade de Início da Aquisição

\begin{tabular}{cccccc}
\hline Idade de Início & \multicolumn{2}{c}{ Retração } & \multicolumn{2}{c}{ Sem retração } & PESO \\
\cline { 2 - 5 } da Aquisição & $\mathbf{n}$ & $\mathbf{\%}$ & $\mathbf{n}$ & $\mathbf{\%}$ & REL. \\
\hline Antes dos 12 anos & 229 & $33,3 \%$ & 459 & $66,7 \%$ & 0,56 \\
Depois dos 12 anos & 167 & $24,2 \%$ & 523 & $75,8 \%$ & 0,43
\end{tabular}

De modo a facilitar a observação da taxa de aplicação por Idade de Início da Aquisição, o Gráfico 21 a seguir apresenta a taxa de aplicação da retração entre os dois grupos de idade em comparação com a taxa de retração dos falantes nativos. Percebe-se que a média de aplicação da regra é mais alta no grupo que iniciou a aquisição antes dos 12 anos e que os dois grupos são bastante heterogêneos, o que se justifica pela variação na aplicação da regra pelos informantes apresentada no Gráfico $20 .^{32}$

\footnotetext{
${ }^{32} 0$ gráfico também mostra a produção dos outliers, isto é, dos informantes que apresentaram taxas muito acima ou muito abaixo das médias de seus grupos, representados por uma bolinha branca.
} 


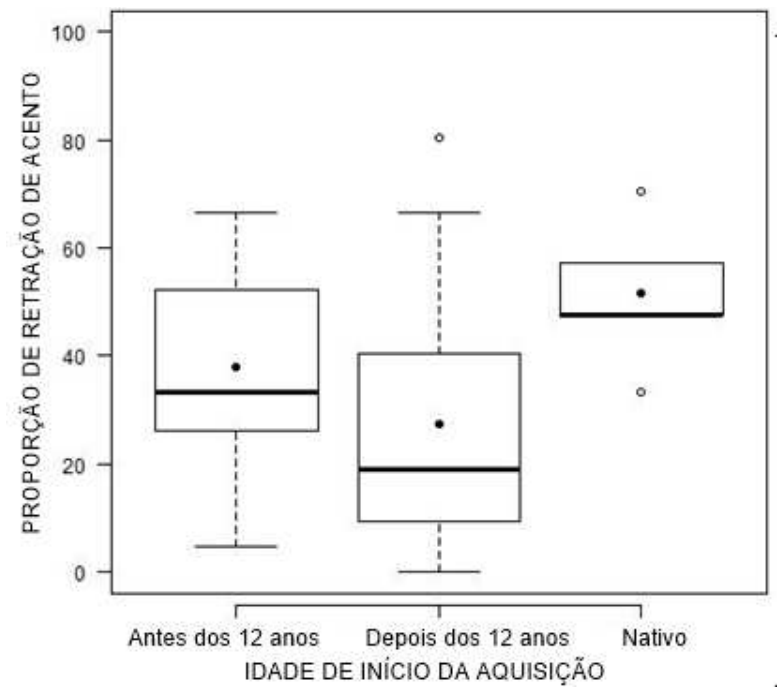

\section{Gráfico 21: Retração de acento por Idade de início da aquisição}

Por fim, o Gráfico 22 a seguir compara a taxa de aplicação da retração por nível de proficiência e por idade de início da aquisição. Pode-se observar que, nos três níveis de proficiência, os falantes que iniciaram a aquisição antes dos 12 anos de idade apresentaram uma taxa de aplicação da regra mais alta do que os que iniciaram a aquisição após os 12 anos. Percebe-se, também, que o grupo que iniciou a aquisição após os 12 anos no nível avançado é o mais heterogêneo de todos, o que se justifica pela taxa de aplicação do informante 25 , que ficou muito acima da média do grupo $(80,4 \%)$, e pela baixa taxa de aplicação do informante 28, que foi bastante baixa para o nível avançado $(17,4 \%)$.

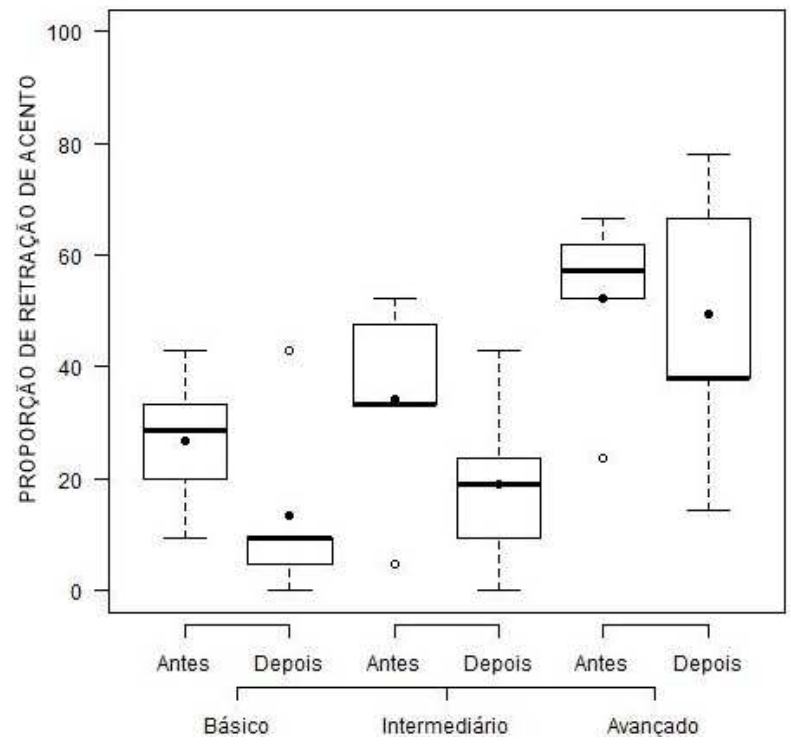

Gráfico 22: Retração por Idade de início da aquisição e nível de proficiência 
A Tabela 34 a seguir apresenta a proporção de retração por idade de início da aquisição e por contexto. Pode-se observar que a taxa de retração nas frases com choque e sem choque é bastante semelhante tanto entre os informantes que iniciaram a aquisição antes dos 12 anos quando entre aqueles que iniciaram após essa idade.

Tabela 34: Cruzamento entre idade de início da aquisição e contexto

\begin{tabular}{ccccc}
\hline \multirow{2}{*}{$\begin{array}{c}\text { Idade de Início } \\
\text { da Aquisição }\end{array}$} & \multicolumn{4}{c}{ Contexto } \\
\cline { 2 - 5 } & Com Choque & \multicolumn{2}{c}{ Sem Choque } \\
\cline { 2 - 5 } & $\mathrm{N}$ & $\%$ & $\mathrm{n}$ & $\%$ \\
\hline Antes dos 12 anos & 119 & $35 \%$ & 110 & $32 \%$ \\
Depois dos 12 anos & 87 & $25 \%$ & 80 & $23 \%$
\end{tabular}

Em suma, os resultados referentes aos dados dos 30 falantes de inglês como L2 julgados perceptualmente indicaram que o fato de a palavra estar inserida em frases com ou sem sequência de choque acentual não foi estatisticamente significativo, ainda que a proporção de retração tenha sido um pouco mais alta nas sequências com choque $(29,9 \%)$ do que nas sequências sem choque $(27,6 \%)$. Além disso, observou-se que a única variável linguística estatisticamente significativa para a retração de acento foi Palavra Alvo e que a regra foi favorecida por palavras terminadas em vogal longa (ex: U2) e consoante nasal (ex: fifteen). Observou-se, também, que a variável Pausa, apesar de não ter sido estatisticamente significativa, mostrou que a retração foi desfavorecida nos poucos casos em que os informantes fizeram alguma interrupção entre a primeira e a segunda palavra do choque. Por fim, no que diz respeito às variáveis sociais, os resultados indicaram que a retração passa a ser mais frequente conforme o aumento do nível de proficiência e que os informantes que iniciaram a aquisição antes dos 12 anos apresentam mais casos de retração do que os informantes que iniciaram a aquisição após essa faixa de idade.

\subsubsection{Correlatos Acústicos}

Esta seção apresenta os resultados referentes às medidas de duração e de F0 empregadas pelos falantes nativos e pelos falantes de inglês como L2 nas 21 palavras oxítonas em contexto de sequência com choque, sequência sem choque e isoladas. 


\subsubsection{Falantes Nativos}

Esta seção apresenta os resultados referentes aos correlatos acústicos empregados pelos 7 falantes nativos que fazem parte do grupo de controle desta pesquisa. As tabelas a seguir mostram as médias e o desvio padrão (DP) da duração e do pico de F0 (pitch) nas sílabas das mesmas palavras produzidas nos contextos de sequência com choque acentual (ex: bamBOO BRAcelets), de sequência sem choque acentual (ex: bamBOO maTErials) e a palavra isolada (ex: bamBOO). 0 p-valor, obtido através do teste Kruskal-Wallis (cf. Seção 5.2.3.2), indica se a diferença nas médias de duração ou de F0 nas sílabas de cada palavra nos três contextos foi estatisticamente significativa. Os asteriscos na coluna à direita indicam os casos em que o p-valor mostrou-se significativo, lembrando que foi fixado o valor de significância de $<0,05 \mathrm{em}$ todas as análises dos correlatos acústicos.

A Tabela 35 a seguir mostra que a diferença de duração na última sílaba de todas as palavras nos três contextos foi estatisticamente significativa, exceto na palavra seventeen.

Tabela 35: Médias de duração nos três contextos analisados - Nativos

\begin{tabular}{|c|c|c|c|c|c|c|c|c|c|}
\hline \multicolumn{10}{|c|}{ Duração (em milissegundos) - Falantes Nativos } \\
\hline \multirow[t]{2}{*}{ Palavra } & \multirow[t]{2}{*}{ Sílaba } & \multicolumn{2}{|c|}{$\begin{array}{c}\text { Frase com } \\
\text { Choque }\end{array}$} & \multicolumn{2}{|c|}{$\begin{array}{c}\text { Frase sem } \\
\text { Choque }\end{array}$} & \multicolumn{2}{|c|}{$\begin{array}{l}\text { Palavra } \\
\text { Isolada } \\
\end{array}$} & \multirow[t]{2}{*}{ p-valor } & \\
\hline & & Média & DP & Média & DP & Média & DP & & \\
\hline \multirow{2}{*}{ bamboo } & bam & 212,29 & 67,16 & 189,00 & 38,75 & 226,71 & 40,50 & 0,0857 & \\
\hline & boo & 185,57 & 33,70 & 179,86 & 70,54 & 311,14 & 54,95 & 0,0037 & * \\
\hline \multirow{2}{*}{ Bel-Air } & bel & 173,71 & 28,94 & 162,29 & 36,04 & 228,86 & 42,71 & 0,0101 & $*$ \\
\hline & air & 194,43 & 37,58 & 196,00 & 60,48 & 298,71 & 31,34 & 0,0035 & $*$ \\
\hline \multirow{2}{*}{ complete } & com & 163,43 & 36,71 & 143,43 & 20,61 & 162,71 & 26,25 & 0,3876 & \\
\hline & plete & 242,29 & 26,85 & & 39,25 & 454,14 & 80,28 & 0,0008 & $*$ \\
\hline \multirow{2}{*}{ discrete } & dis & 189,29 & 35,26 & 187,86 & 28,61 & 208,00 & 34,42 & 0,5735 & \\
\hline & crete & 263,71 & 54,17 & 261,71 & 46,52 & 434,86 & 60,63 & 0,0016 & $*$ \\
\hline \multirow{2}{*}{ dislike } & dis & 200,14 & 27,91 & 200,62 & 23,32 & 250,00 & 45,88 & 0,0240 & $*$ \\
\hline & like & 228,00 & 30,06 & 243,05 & 35,69 & 375,86 & 70,32 & 0,0002 & * \\
\hline \multirow[t]{2}{*}{ eighteen } & eigh & 143,86 & 35,27 & 132,57 & 23,86 & 169,86 & 22,27 & 0,0413 & $*$ \\
\hline & teen & 255,71 & 33,79 & 214,29 & 39,35 & 394,43 & 44,73 & 0,0005 & $*$ \\
\hline \multirow{2}{*}{ express } & ex & 167,00 & 52,81 & 176,43 & 28,26 & 188,29 & 46,51 & 0,7322 & \\
\hline & press & 321,00 & 57,49 & 326,14 & 66,46 & 521,29 & 53,91 & 0,0012 & $*$ \\
\hline fifteen & fif & 203,86 & 53,65 & 208,57 & 50,18 & 227,00 & 59,02 & 0,7341 & \\
\hline
\end{tabular}




\begin{tabular}{|c|c|c|c|c|c|c|c|c|}
\hline & teen & 272,14 & 37,86 & 252,14 & 67,99 & 397,00 & 84,71 & 0,0030 \\
\hline \multirow{2}{*}{ fourteen } & four & 213,71 & 50,93 & 256,43 & 40,36 & 232,00 & 44,43 & 0,3526 \\
\hline & teen & 261,29 & 45,54 & 258,86 & 49,54 & 414,71 & 44,01 & 0,0012 \\
\hline \multirow{2}{*}{ grotesque } & & 132,43 & 24,00 & 54,71 & 42,50 & 39,57 & 25,95 & 0,5372 \\
\hline & tesque & 356,00 & 73,89 & 413,29 & 60,50 & 503,71 & 34,10 & 0,0021 \\
\hline \multirow{3}{*}{ kangaroo } & kan & 215,86 & 28,40 & 208,29 & 30,77 & 203,43 & 39,84 & 0,7627 \\
\hline & ga & 106,00 & 20,72 & 108,29 & 21,91 & 122,43 & 27,77 & 0,4037 \\
\hline & roo & 149,43 & 29,02 & 134,00 & 26,87 & 275,14 & 53,06 & 011 \\
\hline \multirow{4}{*}{$\begin{array}{c}\text { nineteen } \\
\text { police }\end{array}$} & nine & 230,57 & 37,81 & 215,71 & 50,18 & 244,00 & 47,37 & 571 \\
\hline & teen & 306,71 & 47,64 & 07,86 & 42,24 & 43 & 55,47 & 008 \\
\hline & po & & & & & & & \\
\hline & lice & 208,00 & 51,60 & 241,00 & 49,35 & 00 & 76,87 & 07 \\
\hline \multirow{2}{*}{ retake } & $\mathrm{re}$ & 144,14 & 16,06 & 132,86 & 19,82 & & 40,86 & 67 \\
\hline & take & & 34,55 & & & & & \\
\hline \multirow{2}{*}{ robust } & ro & 130,71 & 22,46 & 41,71 & 26,18 & 132,71 & 29,81 & 743 \\
\hline & bust & 332,14 & 63,16 & 397,86 & 108,22 & 499,29 & 47,30 & 47 \\
\hline \multirow{3}{*}{ seventeen } & & & & & & & & \\
\hline & ven & 142,86 & 18,99 & 138,86 & 19,65 & & 27,17 & 33 \\
\hline & teen & 253,14 & 51,64 & 289,29 & 86,75 & 347,29 & 61,71 & 539 \\
\hline \multirow{2}{*}{ sixteen } & $\operatorname{six}$ & 302,71 & 64,73 & 305,14 & 58,76 & 303,43 & 32,05 & 564 \\
\hline & teen & 249,71 & 51,71 & 225,43 & 73,00 & & 23,99 & 50 \\
\hline \multirow{3}{*}{ Tennessee } & te & 125,43 & 28,24 & 130,71 & 19,31 & $; 00$ & 23,61 & 175 \\
\hline & nne & 103,00 & 14,36 & 106,14 & 13,72 & 115,00 & 10,30 & 0,2849 \\
\hline & ssee & 241,57 & 64,89 & 239,00 & 31,03 & 369,29 & 39,71 & 0,0027 \\
\hline \multirow{2}{*}{ thirteen } & thir & 207,71 & 57,64 & 212,00 & 77,54 & 178,29 & 20,85 & 0,6223 \\
\hline & teen & 257,14 & 49,79 & 250,29 & 50,98 & 441,29 & 80,31 & 0,0021 \\
\hline \multirow{2}{*}{$U 2$} & $\mathrm{u}$ & 137,57 & 17,39 & 129,14 & 29,99 & 155,71 & 33,67 & 0,5274 \\
\hline & 2 & 223,71 & 31,34 & 251,43 & 37,58 & 387,29 & 50,03 & 0,0007 \\
\hline \multirow{2}{*}{ unkind } & un & 178,71 & 35,65 & 187,00 & 50,71 & 167,86 & 39,65 & 0,6196 \\
\hline & kind & 353,00 & 78,43 & 372,86 & 103,62 & 494,43 & 58,51 & 0,0180 \\
\hline
\end{tabular}

Nas 20 palavras em que a média de duração da última sílaba foi significativa (destacadas em cinza escuro), pode-se observar que a duração foi bem mais alta nos contextos de palavra isolada (ex: $\operatorname{bam} \underline{B O O}$, dis $\underline{L I K E}$ ). No caso da palavra kangaroo, por exemplo, a média de duração na sílaba -roo em contexto de palavra isolada é de $275,14 m s$, mais que o dobro da média na mesma sílaba em contexto de frase sem choque acentual, de $134 \mathrm{~ms}$, e bastante superior à média em contexto de choque acentual, de 149,43ms. Na palavra thirteen, a média de duração na sílaba -teen em contexto de palavra isolada é de 441,29ms, quase o dobro da média na mesma sílaba em contexto de frase sem choque acentual, de 250,29ms e em contexto de choque acentual, 
de 257,14ms. Esse padrão de duração mais longa na sílaba final no contexto de palavra isolada se repete em todas as 21 palavras, inclusive nineteen, a única que não apresentou diferença de duração significativa em nenhuma das sílabas.

Vejamos, então, a diferença de duração na última sílaba em contextos de frase com choque e sem choque acentual. Das 21 palavras, 11 apresentaram duração maior na última sílaba em contexto de choque: bamboo, discrete, eighteen, fifteen, fourteen, kangaroo, nineteen, retake, sixteen, Tennessee, e thirteen. Observa-se que, neste grupo, a grande maioria das palavras é terminada em vogal longa ou consoante nasal, exceto retake, que termina em consoante obstruinte. As outras 10 palavras apresentaram uma duração um pouco maior na última sílaba em contexto sem choque. Este é o caso das palavras Bel-Air, complete, dislike, express, grotesque, police, robust, seventeen, U2 e unkind, todas terminadas em obstruintes, exceto seventeen, U2 e Bel-Air. Observa-se, portanto, uma tendência de a duração em sílabas contendo uma vogal longa ou nasal ser maior em casos de choque e de a duração em sílabas terminadas em consoante obstuinte ser mais longa em casos sem choque.

As palavras Bel-Air, dislike, eighteen e police foram as únicas que apresentaram diferença significativa tanto na última sílaba quanto na penúltima. Se compararmos somente a duração das penúltimas sílabas dessas palavras (Bel-, dis-, eight- e po-, destacadas em cinza claro) em contextos com choque e sem choque, percebemos que as médias são mais altas em contexto de choque nas palavras Bel-Air e eighteen $(173,71 \mathrm{~ms}$ e $143,86 \mathrm{~ms}$, respectivamente), praticamente iguais nos dois contextos na palavra dislike (200ms em ambos os contextos) e mais alta no contexto sem choque na palavra police (70,14 em contexto sem choque e 110,86 em contexto sem choque.

Consideremos agora a duração das sílabas que, no caso de retração acentual, receberiam o acento, isto é, a sílaba paroxítona de palavras como nineteen e $\underline{\text { Bel-Air e a }}$ paroxítona em palavras como kangaroo e Tennessee. Se observarmos todas as palavras que não apresentaram diferença significativa neste contexto (todas exceto Bel-Air, dislike, eighteen e police, já descritas acima), percebe-se que a duração em bamboo, complete, discrete, kangaroo, nineteen, retake e $\underline{U} 2$ foi maior em casos de choque

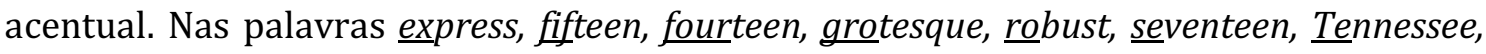
thirteen e unkind, por outro lado, a duração nessas sílabas foi mais alta em frases sem sequência de choque acentual. 
A Tabela 36 a seguir apresenta as médias do pico de F0 nas sílabas de todas as 21 palavras oxítonas investigadas nos três contextos em análise: isolada, frase com choque e frase sem choque. Observa-se que não houve diferença significativa no valor do F0 em nenhuma palavra produzida pelos falantes nativos.

Tabela 36: Médias do Pico de F0 nos três contextos analisados - Nativos

\begin{tabular}{|c|c|c|c|c|c|c|c|c|}
\hline \multicolumn{9}{|c|}{ Pico de F0 (em Hertz) - Falantes Nativos } \\
\hline \multirow[t]{2}{*}{ Palavra } & \multirow[t]{2}{*}{ Sílaba } & \multicolumn{2}{|c|}{$\begin{array}{c}\text { Frase com } \\
\text { Choque }\end{array}$} & \multicolumn{2}{|c|}{$\begin{array}{c}\text { Frase sem } \\
\text { Choque }\end{array}$} & \multicolumn{2}{|c|}{$\begin{array}{c}\text { Palavra } \\
\text { Isolada }\end{array}$} & \multirow[t]{2}{*}{ p-valor } \\
\hline & & Média & DP & Média & DP & Média & DP & \\
\hline \multirow{2}{*}{ bamboo } & bam & 150,71 & 34,50 & 5,43 & 39,14 & & 38,03 & \\
\hline & boo & 149,57 & 37,98 & 152,29 & 39,77 & 144,43 & 46,78 & \\
\hline \multirow{2}{*}{ Bel-Air } & bel & 150,57 & 40,36 & 145,71 & 38,51 & 142,14 & 40,56 & 0,7075 \\
\hline & air & 150,29 & 33,60 & 143,14 & 36,25 & 5,86 & 41,99 & 0,6903 \\
\hline \multirow{2}{*}{ complete } & com & & & 170,57 & & & & \\
\hline & plete & 174,57 & 56 & 168,57 & 41 & & & 716 \\
\hline \multirow{2}{*}{ discrete } & dis & 171,00 & 49,17 & 55,50 & 43,40 & 200,80 & 52,62 & 421 \\
\hline & crete & 167,71 & 39,35 & 151,00 & 49,67 & & 39,69 & \\
\hline \multirow{2}{*}{ dislike } & & & & & & & & \\
\hline & like & 156,14 & 40,76 & 158,29 & 34 & & 33 & \\
\hline \multirow{2}{*}{ eighteen } & eigh & 162,57 & 36,8 & 52,14 & & & 20 & \\
\hline & teen & 176,43 & & & & & & \\
\hline \multirow[b]{2}{*}{ express } & & 150 & & 44,29 & 40,6 & & 63 & \\
\hline & press & 161,57 & 34,2 & 157,57 & 31 , & 00 & 35 & 344 \\
\hline \multirow{2}{*}{ fifteen } & & 163, & 33, & ,86 & & & 43, & \\
\hline & & 167,29 & 42,7 & 177,14 & 50 , & & & \\
\hline \multirow{2}{*}{ fourteen } & four & 189,00 & 59,69 & 167,43 & 39,89 & 14 & 52,40 & 0,3605 \\
\hline & teen & 178,71 & 47,37 & 176,57 & 54,10 & 86 & 44,49 & 656 \\
\hline \multirow{3}{*}{ grotesque } & gro & & & & & & & \\
\hline & tesque & 159,29 & 36,34 & 164,86 & 37,41 & & 40,42 & 0,6619 \\
\hline & kan & 161,14 & 40,12 & 157,29 & 41,18 & 158,43 & 52,95 & 0,9432 \\
\hline \multirow[t]{2}{*}{ kangaroo } & ga & & & & & & & \\
\hline & roo & & 37,16 & & 38,6 & & & 0,9752 \\
\hline \multirow{2}{*}{ nineteen } & nine & 153,43 & 33,73 & 151,57 & 36,8 & & 42,83 & 0,6143 \\
\hline & teen & 169,43 & 45,43 & 166,00 & 43,51 & 149,00 & 36,38 & 0,3392 \\
\hline \multirow{2}{*}{ police } & po & 159,14 & 41,33 & 158,00 & 37,52 & 149,86 & 47,10 & 0,7353 \\
\hline & lice & & 32,98 & 152,43 & 37,07 & 144,00 & 38,53 & 0,4463 \\
\hline \multirow{2}{*}{ retake } & re & 150,43 & 39,14 & 153,71 & 38,31 & 146,86 & 42,50 & 0,6621 \\
\hline & take & & 37,99 & 163,43 & 37,82 & 161,71 & 40,24 & 0,6817 \\
\hline \multirow{2}{*}{ robust } & ro & 142,00 & 35,71 & 144,57 & 44,30 & 139,71 & 34,34 & 0,9991 \\
\hline & bust & 149,86 & 35,02 & 161,86 & 35,78 & 139,57 & 36,38 & 0,3207 \\
\hline seventeen & se & 169,71 & 52,99 & 167,86 & 36,05 & 163,57 & 37,97 & 0,9319 \\
\hline
\end{tabular}




\begin{tabular}{|c|c|c|c|c|c|c|c|c|}
\hline & ven & 162,00 & 44,36 & 167,00 & 39,52 & 150,14 & 39,76 & 0,4526 \\
\hline & teen & 172,14 & 49,42 & 176,29 & 45,26 & 150,43 & 36,73 & 0,3448 \\
\hline \multirow{3}{*}{ sixteen } & six & 168,86 & 34,77 & 169,00 & 29,72 & 160,29 & 39,94 & 0,4852 \\
\hline & teen & 172,86 & 46,92 & 173,57 & 46,34 & 152,71 & 45,91 & 0,4146 \\
\hline & te & 165,00 & 35,30 & 158,86 & 39,33 & 177,71 & 65,86 & 0,9088 \\
\hline \multirow[t]{2}{*}{ Tennessee } & nne & 156,00 & 35,27 & 151,14 & 38,93 & 162,57 & 56,49 & 0,9173 \\
\hline & ssee & 162,43 & 32,18 & 161,14 & 36,92 & 185,00 & 103,43 & 0,9013 \\
\hline \multirow{2}{*}{ thirteen } & thir & 162,71 & 38,33 & 172,86 & 45,34 & 166,71 & 49,86 & 0,7728 \\
\hline & teen & 178,57 & 49,76 & 158,71 & 66,51 & 157,71 & 39,98 & 0,4212 \\
\hline \multirow{2}{*}{$U 2$} & $\mathrm{U}$ & 151,57 & 37,62 & 157,00 & 38,83 & 148,43 & 47,69 & 0,7319 \\
\hline & 2 & 167,14 & 37,85 & 168,43 & 36,62 & 156,14 & 39,15 & 0,6087 \\
\hline \multirow{2}{*}{ unkind } & un & 162,71 & 36,20 & 161,71 & 36,50 & 151,57 & 37,64 & 0,7543 \\
\hline & kind & 159,14 & 45,26 & 155,43 & 36,79 & 155,14 & 36,81 & 0,9807 \\
\hline
\end{tabular}

Observemos especificamente os valores de F0 na última sílaba de cada palavra nos três contextos. A única palavra que apresentou F0 mais alto no contexto de palavra isolada na última sílaba foi Tennessee, que apresentou média de $185 \mathrm{~Hz}$ na sílaba -see no contexto de palavra isolada, de $162,43 \mathrm{~Hz}$ em frases com choque acentual e de $161,14 \mathrm{~Hz}$ em frases sem choque acentual (destacada em cinza escuro). As palavras que apresentaram F0 mais alto na última sílaba em contexto com choque foram Bel-Air, complete, discrete, eighteen, express, fourteen, nineteen, police, retake, thirteen e unkind e, em contexto sem choque, bamboo, dislike, fifteen, grotesque, robust, seventeen, sixteen e $U 2$.

Vejamos as médias de F0 nas sílabas que, no caso de retração acentual,

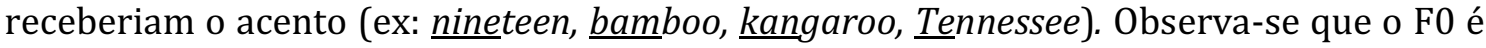

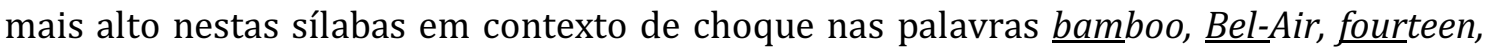
grotesque, kangaroo, nineteen, police, seventeen e unkind (destacadas em cinza claro).

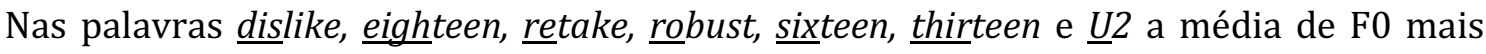
alto nessas sílabas ocorre nas palavras inseridas em frase sem choque acentua. Por fim,

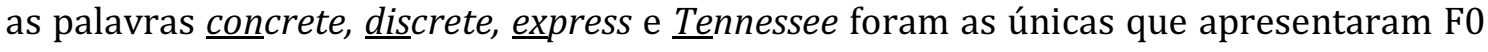
mas alto nessas sílabas no contexto de palavra isolada do que nos dois contextos de frase. Observa-se que as palavras concrete, discrete e express, que apresentaram o valor de F0 mais baixo nas sílabas que receberiam o acento em caso de retração, não tiveram nenhuma ocorrência de retração registrada na verificação perceptual dos dados dos falantes nativos (cf. Seção 5.3.2.1).

A Seção 5.3.2.2 a seguir apresenta os resultados referentes aos correlatos acústicos dos falantes de inglês como L2. 


\subsubsection{Falantes de inglês como L2}

Esta seção apresenta os resultados referentes às médias de duração e de F0 empregadas pelos 30 falantes de inglês como L2. A Tabela 37 a seguir apresenta os resultados de duração referentes a todos os falantes não nativos nos três contextos em análise: palavra isolada, frase com choque acentual e frase sem choque acentual. Os asteriscos indicam os casos em que a diferença de duração nos três contextos foi estatisticamente significativa.

Tabela 37: Médias de duração nos três contextos analisados - Inglês como L2

\begin{tabular}{|c|c|c|c|c|c|c|c|c|c|}
\hline \multicolumn{10}{|c|}{ Duração (em Milissegundos) - Falantes de inglês como L2 } \\
\hline \multirow[t]{2}{*}{ Palavra } & \multirow{2}{*}{$\begin{array}{c}\text { Sílab } \\
\text { a }\end{array}$} & \multicolumn{2}{|c|}{$\begin{array}{c}\text { Frase com } \\
\text { Choque }\end{array}$} & \multicolumn{2}{|c|}{$\begin{array}{c}\text { Frase sem } \\
\text { Choque }\end{array}$} & \multicolumn{2}{|c|}{$\begin{array}{l}\text { Palavra } \\
\text { Isolada }\end{array}$} & \multirow{2}{*}{$\begin{array}{c}\text { p- } \\
\text { valor }\end{array}$} & \\
\hline & & Média & DP & Média & DP & Média & DP & & \\
\hline \multirow{2}{*}{ bamboo } & bam & 229,93 & 39,14 & 225,47 & 56,88 & 268,37 & 49,68 & 0,0021 & * \\
\hline & boo & 222,63 & 77,38 & 175,10 & 70,75 & 251,20 & 64,00 & 0,0001 & * \\
\hline \multirow{2}{*}{ Bel-Air } & bel & 250,07 & 61,47 & 226,13 & 44,10 & 267,27 & 40,12 & 0,0035 & * \\
\hline & air & 284,60 & 110,72 & 269,47 & 86,65 & & 73,05 & 0,0125 & * \\
\hline \multirow{2}{*}{ complete } & com & 164,00 & 25,24 & 154,50 & 27,80 & & 25,19 & 0,0010 & * \\
\hline & plete & 275,47 & 68,94 & 303,17 & 67,43 & 447,30 & 90,62 & 0,0000 & \\
\hline \multirow{2}{*}{ discrete } & dis & 191,93 & 37,28 & 188,73 & 61,06 & & 36,70 & & * \\
\hline & crete & & & & & & & & * \\
\hline \multirow{2}{*}{ dislike } & dis & 183,27 & 48,86 & 186,81 & 43,05 & 220,60 & 50,27 & 0,0009 & * \\
\hline & like & 312,24 & 88,67 & 329,19 & 92,96 & & 61,49 & & 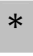 \\
\hline \multirow{2}{*}{ eighteen } & eigh & & & & & & & & \\
\hline & teen & 325,93 & 85,23 & 293,63 & 60,37 & 393,03 & 81,06 & 0,0000 & * \\
\hline \multirow{2}{*}{ express } & ex & 225,97 & 43,63 & 231,60 & 46,65 & 224,53 & 64,34 & 0,4389 & \\
\hline & press & 383,80 & 64,58 & & 75,45 & 562,07 & 92,40 & 00 & * \\
\hline \multirow{2}{*}{ fifteen } & fif & 239,83 & 50,54 & 246,16 & 49,22 & 262,87 & 54,84 & & \\
\hline & teen & 304,07 & 78,70 & 253,94 & 47,20 & 366,73 & 86,78 & 0,0000 & * \\
\hline \multirow{2}{*}{ fourteen } & four & 245,16 & 44,48 & 282,42 & 62,97 & 246,90 & 43,82 & 0,0437 & * \\
\hline & teen & 334,03 & 81,42 & & & & 72,65 & 0,0285 & * \\
\hline \multirow[b]{2}{*}{ grotesque } & gro & 179,52 & 44,18 & 226,76 & 71,58 & 183,00 & 49,73 & 0,0157 & * \\
\hline & $\begin{array}{l}\text { tesqu } \\
\mathrm{e}\end{array}$ & 466,38 & 108,07 & & 129,74 & 557,03 & 78,69 & 0,0018 & * \\
\hline \multirow{3}{*}{ kangaroo } & kan & 217,83 & 39,47 & & 30,62 & & 24,45 & 0,1235 & \\
\hline & ga & 129,31 & 47,64 & 112,20 & 29,79 & 135,10 & 39,69 & 0,0391 & * \\
\hline & roo & 207,14 & 76,99 & 139,37 & 39,49 & 254,80 & 66,43 & 0,0000 & * \\
\hline \multirow{2}{*}{ nineteen } & nine & 322,55 & 80,77 & 326,52 & 64,65 & 321,20 & 59,78 & 0,9154 & \\
\hline & teen & 311,39 & 77,95 & 285,66 & 67,19 & 356,07 & 71,56 & 0,0005 & * \\
\hline \multirow{2}{*}{ police } & po & 118,93 & 35,65 & 137,00 & 47,02 & 141,70 & 32,25 & 0,0673 & \\
\hline & lice & 275,73 & 49,32 & 294,17 & 70,67 & 433,60 & 105,4 & 0,0000 & \\
\hline
\end{tabular}




\begin{tabular}{|c|c|c|c|c|c|c|c|c|c|}
\hline & & & & & & & 0 & & \\
\hline \multirow{2}{*}{ retake } & $\mathrm{re}$ & 145,30 & 44,73 & 145,63 & 32,49 & 151,30 & 47,30 & 0,7696 & \\
\hline & take & 402,40 & 82,49 & 369,33 & 73,08 & 518,97 & 78,05 & 0,0000 & $*$ \\
\hline \multirow{2}{*}{ robust } & ro & 164,90 & 42,49 & 202,77 & 58,48 & 173,27 & 43,74 & 0,0253 & * \\
\hline & bust & 347,90 & 75,34 & 372,40 & 80,79 & 494,13 & 72,71 & 0,0000 & * \\
\hline \multirow{3}{*}{ seventeen } & se & 214,70 & 42,59 & 235,27 & 47,54 & 225,93 & 42,28 & 0,2674 & \\
\hline & ven & 170,63 & 23,95 & 168,90 & 32,20 & 190,47 & 24,40 & 0,0056 & $*$ \\
\hline & teen & 256,07 & 66,09 & 279,73 & 65,31 & 326,27 & 74,17 & 0,0022 & * \\
\hline \multirow{2}{*}{ sixteen } & $\operatorname{six}$ & 344,38 & 64,26 & 343,00 & 64,25 & 345,37 & 49,10 & 0,7836 & \\
\hline & teen & 248,78 & 53,87 & 255,79 & 49,22 & 322,33 & 72,20 & 0,0000 & * \\
\hline \multirow{3}{*}{ Tennessee } & te & 110,53 & 30,20 & 112,70 & 28,35 & 123,27 & 37,78 & 0,5672 & \\
\hline & nne & 153,30 & 55,18 & 140,37 & 49,32 & 155,80 & 61,31 & 0,2092 & \\
\hline & ssee & 249,23 & 94,37 & 241,87 & 73,75 & 356,60 & 79,00 & 0,0000 & * \\
\hline \multirow{2}{*}{ thirteen } & thir & 192,07 & 38,28 & 190,82 & 46,53 & 202,10 & 45,73 & 0,5346 & \\
\hline & teen & 290,53 & 78,32 & 274,07 & 56,42 & 365,20 & 75,67 & 0,0000 & * \\
\hline \multirow{2}{*}{$U 2$} & $\mathrm{u}$ & 186,45 & 41,80 & 166,28 & 33,86 & 182,90 & 42,25 & 0,1158 & \\
\hline & 2 & 249,84 & 64,06 & 279,48 & 73,27 & 356,10 & 64,50 & 0,0000 & $*$ \\
\hline \multirow{2}{*}{ unkind } & un & 182,81 & 36,50 & 172,43 & 35,96 & 180,47 & 36,71 & 0,4351 & \\
\hline & kind & 388,94 & 119,30 & 397,96 & 93,65 & 493,13 & 87,93 & 0,0001 & * \\
\hline
\end{tabular}

Observa-se que houve diferença significativa na duração da última sílaba em todas as palavras do experimento (destacadas em cinza escuro) e da penúltima sílaba em 10 palavras (destacadas em cinza claro). No que diz respeito à duração da última sílaba, observa-se que, assim como no caso dos falantes nativos, a duração é significativamente mais alta nos casos de palavra isolada. Na palavra complete $^{33}$, por exemplo, a sílaba -plete apresenta média de duração de 447,3ms na palavra isolada, $222,53 \mathrm{~ms}$ em frase com choque acentual e $175,1 \mathrm{~ms}$ em frase sem choque acentual. 0 mesmo se observa nos casos de diferença significativa na penúltima sílaba (células em cinza claro): dentre os três contextos, a média de duração mais alta ocorre no contexto de palavra isolada. Na palavra bamboo, por exemplo, a média de duração na sílaba bamfoi de $268,37 \mathrm{~ms}$ na palavra isolada, de $229,93 \mathrm{~ms}$ na palavra inserida em contexto de choque e de $225,47 \mathrm{~ms}$ na palavra em contexto sem choque. Observa-se, portanto, que as palavras produzidas isoladamente apresentam, de modo geral, médias de duração mais altas em todas as sílabas se comparadas às palavras inseridas em frases com ou sem choque.

\footnotetext{
${ }^{33}$ As palavras que foram produzidas com inserção de epêntese (ex: [kõ.'pli.tfi]) não foram incluídas nas análises dos correlatos acústicos de retração de acento, pois as médias tiveram de ser calculadas com base em sílabas iguais para a comparação dos correlatos acústicos nos três contextos.
} 
Percebe-se, também, que, das 21 palavras testadas, 13 apresentam uma duração mais alta na última sílaba em contexto com choque (bamboo, Bel-Air. complete, discrete, eighteen, fifteen, fourteen, kangaroo, nineteen, retake, sixteen, Tennessee, thirteen) e 8 apresentam duração mais alta nos contextos sem choque.

As Tabelas 38, 39 e 40 a seguir apresentam as médias de duração separadas por nível de proficiência (básico, intermediário e avançado, respectivamente). Observa-se que, no nível básico, as ocorrências de diferença estatisticamente significativa nos três contextos analisados são poucas: apenas nas palavras fifteen, grotesque, kangaroo, police e robust. No caso da palavra fifteen, houve diferença significativa na penúltima sílaba (fif), que foi mais longa no contexto de palavra isolada (292ms), mais breve no contexto de choque $(265,8 \mathrm{~ms})$ e ainda mais breve no contexto de frase sem choque $(263,0 \mathrm{~ms})$. No caso da palavra gotesque, que também apresentou diferença significativa na penúltima sílaba (gro-), a duração foi mais curta na palavra isolada $(161,89 \mathrm{~ms})$, um pouco mais longa no contexto de choque $(178,33 \mathrm{~ms})$ e bem mais longa no contexto sem choque $(221,78 \mathrm{~ms})$. Resultados semelhantes foram encontrados para a palavra robust, em que a penúltima sílaba (ro-) foi mais longa no contexto de frase sem choque $(233,9 \mathrm{~ms})$. As palavras robust, kangaroo e police foram as únicas que apresentaram diferença significativa na última sílaba. Nos três casos, observa-se que a duração mais longa dentre os três contextos correu no contexto de palavra isolada. Observa-se, também que nas palavras robust e kangaroo a última sílaba foi mais longa em frase com choque do que em frase sem choque e na palavra police foi mais longa no contexto sem choque do que no contexto com choque. 
Tabela 38: Médias de duração no nível Básico - Inglês como L2

\begin{tabular}{|c|c|c|c|c|c|c|c|c|c|}
\hline \multicolumn{10}{|c|}{ Duração (em Milissegundos) - Falantes de Nível Básico } \\
\hline \multirow[t]{2}{*}{ Palavra } & \multirow[t]{2}{*}{ Sílaba } & \multicolumn{2}{|c|}{$\begin{array}{c}\text { Frase com } \\
\text { Choque }\end{array}$} & \multicolumn{2}{|c|}{$\begin{array}{c}\text { Frase sem } \\
\text { Choque }\end{array}$} & \multicolumn{2}{|c|}{ Isolada } & \multirow[t]{2}{*}{ p-valor } & \\
\hline & & Média & DP & Média & DP & Média & DP & & \\
\hline \multirow{2}{*}{ bamboo } & bam & 240,20 & 45,86 & 237,30 & 57,76 & 246,70 & 24,49 & 0,9399 & \\
\hline & boo & 253,00 & 78,43 & 211,80 & 85,19 & 220,70 & 62,21 & 0,3764 & \\
\hline \multirow{2}{*}{ Bel-Air } & bel & 278,60 & 74,76 & 247,70 & 47,56 & 254,40 & 36,99 & 0,7158 & \\
\hline & air & 369,80 & 112,72 & 321,30 & 63,51 & 347,80 & 74,01 & 0,4535 & \\
\hline \multirow{2}{*}{ complete } & com & 170,30 & 18,67 & 157,10 & 14,82 & 175,00 & 27,29 & 0,3235 & \\
\hline & plete & 311,40 & 86,63 & 340,60 & 38,44 & 414,90 & 96,00 & 0,0524 & \\
\hline \multirow{2}{*}{ discrete } & dis & 183,00 & 36,68 & 171,60 & 24,79 & 194,80 & 43,27 & 0,3946 & \\
\hline & crete & 408,40 & 67,97 & 389,10 & 71,20 & 453,30 & 53,73 & 0,0652 & \\
\hline \multirow{2}{*}{ dislike } & dis & 192,52 & 59,17 & 207,72 & 42,61 & 217,40 & 59,44 & 0,2310 & \\
\hline & like & 385,77 & 88,81 & 409,28 & 80,29 & 441,20 & 62,69 & 0,0924 & \\
\hline \multirow{2}{*}{ eighteen } & eigh & 189,33 & 38,35 & 205,70 & 42,14 & 205,90 & 48,73 & 0,7216 & \\
\hline & teen & 357,56 & 78,84 & 330,20 & 59,40 & 371,50 & 95,60 & 0,4924 & \\
\hline \multirow{2}{*}{ express } & ex & 224,00 & 62,28 & 210,40 & 66,40 & 186,70 & 62,87 & 0,5318 & \\
\hline & press & 420,20 & 81,80 & 429,70 & 65,48 & 554,90 & 94,42 & 0,0052 & \\
\hline \multirow{2}{*}{ fifteen } & fif & 265,80 & 59,51 & 263,90 & 52,95 & 292,00 & 58,10 & 0,4534 & * \\
\hline & teen & 297,10 & 96,77 & 260,90 & 41,79 & 315,60 & 76,45 & 0,2867 & \\
\hline \multirow{2}{*}{ fourteen } & four & 281,40 & 40,36 & 318,10 & 47,19 & 264,90 & 50,27 & 0,0708 & \\
\hline & teen & 380,10 & 66,71 & 385,60 & 65,75 & 331,70 & 61,23 & 0,1875 & \\
\hline \multirow{3}{*}{ grotesque } & gro & 178,33 & 35,64 & 221,78 & 54,87 & 161,89 & 34,21 & 0,0417 & $*$ \\
\hline & tesque & 565,44 & 123,01 & 600,11 & 109,36 & 551,67 & 74,34 & 0,5975 & \\
\hline & kan & 234,50 & 44,26 & 203,50 & 26,97 & 211,50 & 16,36 & 0,1750 & \\
\hline \multirow[t]{2}{*}{ kangaroo } & ga & 152,60 & 65,66 & 121,70 & 38,02 & 146,80 & 54,40 & 0,4935 & \\
\hline & roo & 209,80 & 61,44 & 122,70 & 36,16 & 213,90 & 43,65 & 0,0007 & * \\
\hline \multirow{2}{*}{ nineteen } & nine & 367,45 & 108,58 & 380,90 & 73,08 & 330,80 & 57,75 & 0,2586 & \\
\hline & teen & 333,27 & 107,36 & 303,60 & 69,44 & 355,50 & 92,55 & 0,4124 & \\
\hline \multirow{2}{*}{ police } & po & 146,40 & 26,75 & 175,00 & 31,31 & 155,70 & 26,01 & 0,1398 & \\
\hline & lice & 282,40 & 50,91 & 332,70 & 62,63 & 367,10 & 42,88 & 0,0082 & * \\
\hline \multirow{2}{*}{ retake } & re & 148,30 & 35,54 & 142,40 & 28,07 & 142,10 & 45,65 & 0,9900 & \\
\hline & take & 470,00 & 80,13 & 425,70 & 76,12 & 513,20 & 102,49 & 0,1357 & \\
\hline \multirow{2}{*}{ robust } & ro & 163,20 & 43,89 & 233,90 & 62,59 & 162,40 & 45,06 & 0,0269 & * \\
\hline & bust & 405,20 & 75,58 & 390,60 & 80,61 & 472,00 & 56,26 & 0,0405 & * \\
\hline \multirow{3}{*}{ seventeen } & se & 228,00 & 43,81 & 257,50 & 55,63 & 234,90 & 42,00 & 0,4061 & \\
\hline & ven & 173,90 & 21,14 & 181,00 & 31,08 & 178,10 & 19,36 & 0,5649 & \\
\hline & teen & 265,90 & 72,54 & 302,60 & 59,93 & 305,50 & 89,08 & 0,5820 & \\
\hline civteon & $\operatorname{six}$ & 358,00 & 70,85 & 389,50 & 44,37 & 359,20 & 53,39 & 0,3556 & \\
\hline sixceen & teen & 257,00 & 56,37 & 316,50 & 34,73 & 282,10 & 65,32 & 0,1329 & \\
\hline & te & 106,00 & 24,53 & 108,10 & 22,66 & 106,20 & 20,85 & 0,9598 & \\
\hline Tennessee & nne & 175,80 & 76,66 & 167,20 & 60,71 & 168,60 & 67,03 & 0,9900 & \\
\hline & ssee & 272,90 & 92,06 & 265,30 & 79,06 & 329,60 & 58,36 & 0,1332 & \\
\hline
\end{tabular}




\begin{tabular}{ccccccccc}
\multirow{2}{*}{ thirteen } & thir & 198,09 & 22,06 & 211,00 & 37,96 & 189,60 & 28,96 & 0,3286 \\
& teen & 321,64 & 103,48 & 288,33 & 68,16 & 319,70 & 68,75 & 0,5448 \\
\multirow{2}{*}{$U 2$} & $\mathrm{u}$ & 193,00 & 36,74 & 172,33 & 41,30 & 163,50 & 33,78 & 0,3002 \\
& 2 & 294,09 & 63,27 & 344,22 & 75,65 & 334,20 & 54,66 & 0,1937 \\
\multirow{2}{*}{ unkind } & un & 188,70 & 47,59 & 181,10 & 47,71 & 189,10 & 41,66 & 0,7174 \\
& kind & 416,10 & 144,24 & 441,60 & 127,42 & 444,60 & 102,53 & 0,8269
\end{tabular}

A Tabela 39 a seguir apresenta as médias de duração dos falantes de nível intermediário. Percebe-se que há diferença significativa em 18 palavras do experimento, bem mais que no nível básico, e essa diferença significativa ocorreu na última sílaba em 16 palavras (destacadas em cinza escuro). Percebe-se que em todas essas palavras a última sílaba é mais longa no contexto de palavra isolada e que, na maioria dos casos, é mais longa no contexto de frase com choque do que no contexto sem choque (bamboo, dislike eighteen express, fifteen kangaroo retake sixteen Tennessee unkind). Nas palavras em que a penúltima sílaba apresentou diferença de duração significativa (destacadas em cinza claro), a média mais alta ocorreu no contexto de palavra isolada (exceto na palavra unkind) e, dentre os dois contextos de frase, foi mais alta no contexto de choque (exceto fourteen).

Tabela 39: Médias de duração no nível Intermediário - Inglês como L2

\begin{tabular}{|c|c|c|c|c|c|c|c|c|c|}
\hline \multicolumn{10}{|c|}{ Duração (em Milissegundos) - Falantes de Nível Intermediário } \\
\hline \multirow{2}{*}{ Palavra } & \multirow{2}{*}{ Sílaba } & \multicolumn{2}{|c|}{$\begin{array}{c}\text { Frase com } \\
\text { Choque }\end{array}$} & \multicolumn{2}{|c|}{$\begin{array}{c}\text { Frase sem } \\
\text { Choque }\end{array}$} & \multicolumn{2}{|c|}{$\begin{array}{l}\text { Palavra } \\
\text { Isolada }\end{array}$} & \multirow{2}{*}{ p-valor } & \\
\hline & & Média & DP & Média & DP & Média & DP & & \\
\hline \multirow{2}{*}{ bamboo } & bam & 206,30 & 26,07 & 198,00 & 29,77 & 261,00 & 51,71 & 0,0023 & $*$ \\
\hline & boo & & 82 & & 47, & & & & * \\
\hline \multirow{2}{*}{ Bel-Air } & bel & & & & & & & & $*$ \\
\hline & air & 268,00 & 89,32 & 266,30 & 96,08 & 336,50 & 75,20 & 0,0 & \\
\hline \multirow{2}{*}{ complete } & com & & 25,0 & 45,70 & & & 17 & 0,0152 & * \\
\hline & plete & & & & & & & 0,0 & * \\
\hline \multirow{2}{*}{ discrete } & dis & 189,80 & 39,50 & & & & & & * \\
\hline & crete & 315,20 & 36,87 & 316,20 & 115,34 & & 72 , & $0,0 \mathrm{C}$ & * \\
\hline \multirow{2}{*}{ dislike } & dis & 169,35 & 41,69 & 165,24 & 39,53 & 216,30 & 55,82 & 0,0228 & * \\
\hline & like & 280,77 & 62,88 & & & & & & * \\
\hline \multirow{2}{*}{ eighteen } & eigh & 152,30 & 37,63 & 160,40 & 27,31 & 185,10 & 26,39 & 0,0615 & \\
\hline & teen & 335,20 & 104,95 & 269,80 & 47,69 & 362,70 & 57,50 & 0,0120 & * \\
\hline \multirow{2}{*}{ express } & ex & 212,70 & 30,53 & 245,20 & 35,16 & 253,80 & 61,51 & 0,1023 & \\
\hline & press & 361,40 & 43,42 & 360,80 & 74,47 & 534,50 & 96,77 & 0,0002 & \\
\hline fifteen & fif & 229,30 & 25,85 & 250,09 & 43,68 & 243,90 & 42,08 & 0,5211 & \\
\hline
\end{tabular}




\begin{tabular}{|c|c|c|c|c|c|c|c|c|c|}
\hline \multirow{4}{*}{ fourteen } & teen & 303,50 & 51,96 & 257,09 & 58,90 & 367,40 & 75,39 & 0,0025 & 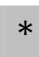 \\
\hline & four & 220,45 & 22,16 & 279,55 & 56,97 & 235,90 & 40,00 & 0,0153 & * \\
\hline & teen & 317,91 & 100,50 & 298,91 & 71,48 & 360,60 & 40,82 & 0,0682 & \\
\hline & gro & 197,30 & 54,14 & 265,80 & 90,74 & 197,10 & 65,27 & 0,1591 & \\
\hline \multirow[t]{2}{*}{ grotesque } & tesque & 416,50 & 72,55 & 498,00 & 163,99 & 529,00 & 85,80 & 0,0500 & \\
\hline & kan & 195,10 & 26,95 & 191,90 & 26,41 & 210,10 & 22,59 & 0,0966 & \\
\hline \multirow[t]{2}{*}{ kangaroo } & ga & 116,60 & 38,53 & 113,50 & 26,96 & 136,10 & 26,83 & 0,1220 & \\
\hline & roo & 244,00 & 90,92 & 151,30 & 42,83 & 267,50 & 42,59 & 0,0005 & $*$ \\
\hline \multirow{2}{*}{ nineteen } & nine & 296,40 & 58,48 & 291,70 & 31,96 & 310,70 & 73,62 & 0,9252 & \\
\hline & teen & 291,20 & 44,68 & 279,70 & 76,89 & 326,40 & 55,02 & 0,0876 & \\
\hline \multirow{2}{*}{ police } & po & 122,30 & 30,18 & 134,80 & 47,38 & 146,90 & 35,87 & 0,3020 & \\
\hline & lice & 260,10 & 43,62 & 267,70 & 69,72 & 403,20 & 68,56 & 0,0003 & * \\
\hline \multirow{2}{*}{ retake } & re & 150,20 & 46,02 & 154,90 & 42,35 & 173,10 & 55,82 & 0,5916 & \\
\hline & take & 340,10 & 66,61 & 325,50 & 39,74 & 506,10 & 70,88 & 0,0001 & * \\
\hline \multirow{2}{*}{ robust } & ro & 145,00 & 36,94 & 165,80 & 43,69 & 180,10 & 38,58 & 0,0569 & \\
\hline & bust & 353,70 & 55,78 & 375,00 & 93,59 & 495,70 & 81,67 & 0,0030 & $*$ \\
\hline \multirow{3}{*}{ seventeen } & & & & & & & 47,00 & & \\
\hline & ven & 156,20 & 25,45 & 155,90 & 36,42 & 190,10 & 30,19 & 0,0541 & \\
\hline & teen & 247,60 & 55,56 & 253,10 & 58,99 & 300,90 & 45,85 & 0,0894 & \\
\hline \multirow{2}{*}{ sixteen } & ix & 332,17 & 49,91 &, 57 & 24,62 &, 50 & 43,11 & 0,2003 & \\
\hline & teen & 249,50 & 62,20 & 229,43 & 28,77 & 315,90 & 54,45 & 091 & * \\
\hline \multirow{3}{*}{ Tennessee } & te & 99,90 & 26,29 & 107,70 & 30,96 & 119,80 & 42,90 & 0,7013 & \\
\hline & nne & 153,60 & 46,91 & 128,10 & 49,62 & 162,60 & 81,14 & 0,0504 & \\
\hline & ssee & 222,90 & 115,72 & 213,40 & 61,90 & 347,50 & 80,14 & 0,0042 & * \\
\hline \multirow{2}{*}{ thirteen } & thir & 176,56 & 25,73 & 174,56 & 52,08 & 194,80 & 33,70 & 0,1349 & \\
\hline & teen & 269,67 & 47,22 & 271,00 & 48,48 & 356,90 & 52,51 & 0,0011 & $*$ \\
\hline \multirow{2}{*}{$U 2$} & $\mathrm{u}$ & 174,30 & 28,80 & 158,60 & 29,54 & 201,00 & 33,48 & 0,0130 & * \\
\hline & 2 & 216,50 & 34,43 & 229,10 & 43,39 & 337,30 & 66,23 & 0,0004 & * \\
\hline \multirow{2}{*}{ unkind } & un & 193,10 & 29,53 & 156,40 & 28,73 & 178,20 & 38,75 & 0,0477 & * \\
\hline & kind & 440,10 & 127,70 & 368,10 & 57,49 & 499,80 & 70,35 & 0,0108 & * \\
\hline
\end{tabular}

A Tabela 40 a seguir apresenta as médias de duração pelos informantes do nível avançado, que apresentaram diferença significativa em todas as 21 palavras do experimento, sobretudo na última sílaba. Nas palavras que apresentaram diferença estatisticamente significativa na última sílaba, observa-se que, assim como no nível intermediário, as durações são mais altas no contexto de palavra isolada. No caso da palavra complete, por exemplo, a duração na sílaba -plete produzida isoladamente é quase o dobro da palavra em contexto de choque (503,5ms e $245 \mathrm{~ms}$, respectivamente). Além disso, observa-se que, em 11 palavras, a última sílaba é mais longa no contexto de 
frase com choque do que de frase sem choque (bamboo discrete, eighteen, fifteen, fourteen, kangaroo, nineteen, police, retake, Tennessee, thirteen) e em 10 palavras é mais longa em contexto sem choque do que em contexto com choque (Bel-Air, complete, dislike, express, grotesque, robust, seventeen, sixteen, U2, unkind).

Tabela 40: Médias de duração no nível Avançado - Inglês como L2

\begin{tabular}{|c|c|c|c|c|c|c|c|c|c|}
\hline \multicolumn{10}{|c|}{ Duração (em Milissegundos) - Falantes de Nível Avançado } \\
\hline \multirow{2}{*}{ Palavra } & \multirow{2}{*}{ Sílaba } & \multicolumn{2}{|c|}{$\begin{array}{l}\text { Frase com } \\
\text { Choque }\end{array}$} & \multicolumn{2}{|c|}{$\begin{array}{c}\text { Frase sem } \\
\text { Choque }\end{array}$} & \multicolumn{2}{|c|}{ Isolada } & \multirow{2}{*}{$\begin{array}{c}\text { p- } \\
\text { valor }\end{array}$} & \\
\hline & & Média & DP & Média & DP & Média & DP & & \\
\hline \multirow{2}{*}{ bamboo } & bam & 243,30 & 34,87 & 241,10 & 70,28 & 297,40 & 56,23 & 0,1066 & \\
\hline & boo & 197,80 & 68,12 & 172,40 & 61,99 & 286,30 & 62,01 & 0,0031 & * \\
\hline \multirow{2}{*}{ Bel-Air } & bel & 231,60 & 43,62 & 210,00 & 47,06 & 267,10 & 30,66 & 0,0162 & * \\
\hline & air & 216,00 & 72,23 & 220,80 & 72,81 & 307,80 & 71,53 & 0,0212 & * \\
\hline \multirow{2}{*}{ complete } & com & 162,20 & 31,72 & 160,70 & 39,77 & 184,10 & 30,49 & 0,1624 & \\
\hline & plete & 245,40 & 55,51 & 272,20 & 68,41 & & 76,72 & 0,0001 & * \\
\hline \multirow{2}{*}{ discrete } & dis & 203,00 & 36,66 & & & & 41,36 & & \\
\hline & crete & 328,60 & 79,20 & 310,20 & 90,45 & 497,80 & 63,71 & 0,0003 & * \\
\hline \multirow{2}{*}{ dislike } & dis & 188,10 & 41,80 & & 37,36 & 8,10 & 37,42 & 0,0218 & \\
\hline & like & & 60,2 & & & & & & \\
\hline \multirow{2}{*}{ eighteen } & eigh & 172,40 & 40,27 & 164,90 & 31,94 & 175,10 & 34,47 & 0,7067 & \\
\hline & teen & 288,20 & 58,16 & 280,90 & 60,35 & 444,90 & 64,82 & 0,0001 & T \\
\hline \multirow{2}{*}{ express } & ex & 241,20 & 29,45 & & 24,4 & 10 & 54,58 & 0,4790 & \\
\hline & press & 369,80 & 51,13 & 386,50 & 76,24 & & & & * \\
\hline \multirow{2}{*}{ fifteen } & fif & 224,40 & 53,69 & 224,10 & 47,36 & 252,70 & 55,56 & 0,3911 & \\
\hline & teen & 311,60 & 88,18 & 243,50 & 40,48 & 7,20 & 83,68 & 0,0001 & 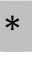 \\
\hline \multirow{2}{*}{ fourteen } & four & & & & & & & & \\
\hline & teen & 305,70 & 53,46 & 303,90 & 78,45 & 431,70 & 75,53 & 0,0016 & * \\
\hline \multirow{2}{*}{ grotesque } & gro & 162,80 & 36,74 & 192,20 & 44,57 & 187,90 & 41,25 & 0,2177 & \\
\hline & tesque & 427,10 & & & & & & 0,0002 & * \\
\hline \multirow{3}{*}{ kangaroo } & kan & 224,56 & 37,26 & 216,10 & 35,6 & 227,00 & 30,88 & 0,6413 & \\
\hline & ga & 117,56 & 19,68 & 101,40 & 21,34 & 122,40 & 32,64 & 0,1581 & \\
\hline & roo & 163,22 & 57,66 & 144,10 & 37,32 & 283,00 & 87,06 & 0,0007 & * \\
\hline \multirow{2}{*}{ nineteen } & nine & 299,30 & 37,42 & 304,78 & 41,55 & 322,10 & 50,35 & 0,5078 & \\
\hline & teen & 307,50 & 66,30 & 272,33 & 55,47 & 386,30 & 53,99 & 0,0024 & * \\
\hline \multirow{2}{*}{ police } & po & 88,10 & 23,71 & 101,20 & 29,42 & 122,50 & 27,05 & 0,0330 & * \\
\hline & lice & 284,70 & 54,17 & 282,10 & 68,70 & 530,50 & 113,52 & 0,0001 & * \\
\hline \multirow{2}{*}{ retake } & re & 137,40 & 54,40 & 139,60 & 25,92 & 138,70 & 34,79 & 0,7404 & \\
\hline & take & 397,10 & 40,60 & 356,80 & 63,23 & 537,60 & 59,09 & 0,0001 & * \\
\hline \multirow{2}{*}{ robust } & ro & 186,50 & 39,56 & 208,60 & 50,59 & 177,30 & 49,45 & 0,3988 & \\
\hline & bust & 284,80 & 36,85 & 351,60 & 70,11 & 514,70 & 78,63 & 0,0000 & \\
\hline seventeen & se & 213,70 & 50,64 & 231,90 & 43,35 & 217,90 & 40,31 & 0,5854 & \\
\hline
\end{tabular}




\begin{tabular}{|c|c|c|c|c|c|c|c|c|c|}
\hline & ven & 181,80 & 19,29 & 169,80 & 26,40 & 203,20 & 16,80 & 0,0050 & $*$ \\
\hline & teen & 254,70 & 74,40 & 283,50 & 72,71 & 372,40 & 64,25 & 0,0060 & $*$ \\
\hline \multirow{3}{*}{ sixteen } & $\operatorname{six}$ & 337,91 & 70,00 & 354,56 & 76,67 & 349,40 & 49,75 & 0,6363 & \\
\hline & teen & 237,08 & 42,86 & 248,50 & 46,28 & 369,00 & 72,80 & 0,0003 & $*$ \\
\hline & te & 125,70 & 35,24 & 122,30 & 31,05 & 143,80 & 38,96 & 0,5226 & \\
\hline \multirow[t]{2}{*}{ Tennessee } & nne & 130,50 & 24,38 & 125,80 & & 136,20 & 19,39 & 0,7534 & \\
\hline & ssee & 251,90 & 73,68 & 246,90 & 76,85 & 392,70 & 89,07 & 0,0027 & $*$ \\
\hline \multirow{2}{*}{ thirteen } & thir & 199,40 & 56,99 & 187,30 & 46,01 & 221,90 & 64,01 & 0,4253 & \\
\hline & teen & 275,10 & 63,26 & 264,00 & 54,81 & 419 & 73,32 & 0,0004 & $*$ \\
\hline \multirow{2}{*}{$U 2$} & $\mathrm{u}$ & 191,40 & 57,01 & 168,50 & 32,72 & 184,20 & 52,01 & 0,6827 & \\
\hline & 2 & 234,50 & 64,45 & 271,60 & 51,50 & 396,80 & 57,13 & 0,0001 & $*$ \\
\hline \multirow{2}{*}{ unkind } & un & 169,33 & 29,38 & 181,63 & 20,74 & 174,10 & 31,17 & 0,6416 & \\
\hline & kind & 323,67 & 45,19 & 380,75 & 66,09 & 535,00 & 69,55 & 0,0000 & $*$ \\
\hline
\end{tabular}

A Tabela 41, por fim, apresenta as médias do pico de F0 nas sílabas das 21 palavras oxítonas nos três contextos investigados. Percebe-se que, assim como nos resultados referentes aos falantes nativos, não houve diferença significativa no valor do F0 em nenhuma palavra produzida pelos falantes brasileiros.

Assim como nos dados dos falantes nativos, vejamos os valores de F0 na última sílaba das palavras em cada contexto. As únicas palavras que apresentaram pico de F0 mais alto no contexto de palavra isolada na última sílaba foram bamboo Bel-Air e kangaroo (destacadas em cinza escuro). As palavras que apresentaram F0 mais alto na última sílaba em contexto com choque foram discrete, express, fifteen, kangaroo, police, seventeen, sixteen, Tennessee, thirteen, unkind e em contexto sem choque foram complete, dislike, eighteen, fourteen, grotesque, nineteen, retake, robust e $U 2$.

Observemos as médias de F0 nas sílabas que, no caso de retração acentual,

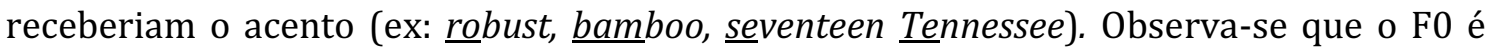
mais alto nestas sílabas em contexto de choque nas palavras bamboo, complete, fifteen, fourteen, police, seventeen, sixteen, Tennessee, U2 e unkind (destacadas em cinza claro). Nas palavras discrete, eighteen, express, grotesque, retake, robust, e thirteen o F0 é mais alto nessas sílabas no contexto de frase sem choque acentual. ${ }^{34}$

\footnotetext{
${ }^{34}$ Assim como no caso da duração, também obtivemos os valores de F0 separados por nível de proficiência, mas não houve diferença estatisticamente significativa em nenhuma palavra, em nenhum dos três níveis.
} 
Tabela 41: Médias do pico de F0 pelos falantes de inglês como L2

\begin{tabular}{|c|c|c|c|c|c|c|c|c|}
\hline \multicolumn{9}{|c|}{ Pico de F0 (em Hertz) - Falantes de Inglês como L2 } \\
\hline \multirow[t]{2}{*}{ Palavra } & \multirow[t]{2}{*}{ Sílaba } & \multicolumn{2}{|c|}{$\begin{array}{c}\text { Frase com } \\
\text { Choque }\end{array}$} & \multicolumn{2}{|c|}{$\begin{array}{c}\text { Frase sem } \\
\text { Choque }\end{array}$} & \multicolumn{2}{|c|}{ Isolada } & \multirow{2}{*}{$\begin{array}{l}\text { p- } \\
\text { valor }\end{array}$} \\
\hline & & Média & DP & Média & DP & Média & DP & \\
\hline \multirow{2}{*}{ bamboo } & & 208,50 & & 206,00 & & & 54,23 & 0,5819 \\
\hline & boo & 226,53 & 63,33 & 216,30 & 52,00 & & 74,46 & 0,9240 \\
\hline \multirow{2}{*}{ Bel-Air } & bel & & 54,04 & & & & 45,91 & \\
\hline & air & 200,77 & 50,89 & & & & 70,20 & \\
\hline \multirow{2}{*}{ complete } & com & 225,67 & 56,55 & 224,27 & 76,27 & 204,47 & 57,49 & 0,3908 \\
\hline & plete & & 57,72 & 233,40 & 65,61 & 223,67 & 66,08 & 0,8948 \\
\hline \multirow{2}{*}{ discrete } & dis & & & & & & & 065 \\
\hline & crete & 246,87 & 69,98 & 230,43 & 71,37 & & 59, & \\
\hline \multirow{2}{*}{ dislike } & dis & 214,69 & 53,07 & 211,98 & 56,06 & 202,33 & 53,78 & 0,6760 \\
\hline & like & & & & & & & \\
\hline \multirow{2}{*}{ eighteen } & eigh & & & & & & & \\
\hline & teen & 236,52 & 59,13 & 57 & 61,7 & 67 & & 0,4775 \\
\hline \multirow{2}{*}{ express } & & & & & & & & \\
\hline & press & & & & & & & \\
\hline \multirow{2}{*}{ fifteen } & fif & & 63,96 & 236,10 & 59,17 & 215,83 & 69,58 & 0,1843 \\
\hline & teen & & 61,38 & & & & 74,02 & \\
\hline \multirow{2}{*}{ fourteen } & & & & & & & & \\
\hline & teen & 236 & 82,2 & & & & & \\
\hline \multirow{2}{*}{ grotesque } & & & & 207,97 & & 41 & & 699 \\
\hline & tesque & 221,62 & 65,7 & 227,3 & 70,8 & & & 577 \\
\hline \multirow{3}{*}{ kangaroo } & & & & & & & & \\
\hline & ga & 209,72 & 54,80 & & 57,1 & & 52 & 119 \\
\hline & roo & 211,93 & 64,57 & & 56,6 & 87 & 96,26 & 456 \\
\hline \multirow{2}{*}{ nineteen } & & & & & & & & \\
\hline & & & 64,77 & 244,31 & 68,66 & & 79 & 0,7511 \\
\hline \multirow{2}{*}{ police } & po & & 48,98 & 204,43 & 57,4 & 199,40 & 52,24 & 0,7790 \\
\hline & lice & & & & & & & 0,7760 \\
\hline \multirow{2}{*}{ retake } & & & 60,22 & 222,43 & 54,26 & & & 0,6027 \\
\hline & take & 220,83 & 51,48 & 222,93 & 54,26 & 217,20 & 59,41 & 0,8928 \\
\hline \multirow{3}{*}{ robust } & & 204,97 & & & & & & 0,9473 \\
\hline & bust & 227,40 & 63,62 & 231,03 & 64,39 & 206,97 & 60,69 & 0,3279 \\
\hline & se & 234,77 & 62,22 & 229,40 & 62,92 & 204,40 & 59,40 & 0,1275 \\
\hline \multirow[t]{2}{*}{ seventeen } & & 231,97 & 61,50 & 235,23 & 61,54 & 201,40 & 57,47 & 0,0617 \\
\hline & teen & 238,40 & 57,05 & & 63,11 & 233,73 & 83,84 & 0,8701 \\
\hline \multirow{3}{*}{ sixteen } & & 234,21 & 60,61 & 215,40 & 67,24 & 208,90 & 80,34 & 0,1442 \\
\hline & teen & 235,65 & 56,69 & 207,58 & 64,30 & 216,67 & 65,92 & 0,1439 \\
\hline & te & 226,73 & 55,19 & 224,57 & 55,67 & 208,53 & 65,67 & 0,3263 \\
\hline & & 226,63 & 58,66 & 222,10 & 59,15 & 198,70 & 64,54 & 0,1488 \\
\hline & ssee & 229,29 & 65,96 & 222,97 & 60,93 & 224,59 & 79,35 & 0,9193 \\
\hline
\end{tabular}




\begin{tabular}{ccccccccc}
\multirow{2}{*}{ thirteen } & thir & 229,83 & 57,54 & 228,07 & 59,37 & 215,33 & 65,14 & 0,6043 \\
& teen & 244,83 & 60,04 & 241,54 & 63,14 & 229,27 & 71,01 & 0,5676 \\
\multirow{2}{*}{$U 2$} & $\mathrm{u}$ & 226,81 & 63,48 & 216,03 & 49,96 & 201,90 & 54,32 & 0,2865 \\
& 2 & 225,35 & 59,01 & 228,38 & 52,46 & 225,13 & 77,57 & 0,9538 \\
\multirow{3}{*}{ unkind } & un & 230,34 & 58,69 & 221,18 & 65,36 & 198,73 & 58,29 & 0,1025 \\
& kind & 226,25 & 53,72 & 224,93 & 52,36 & 218,43 & 77,32 & 0,8328
\end{tabular}

A Seção 5.4 a seguir discute os resultados apresentados na presente seção.

\subsection{Discussão}

Esta seção apresenta uma discussão dos resultados apresentados na Seção 5.3. Em 5.4.1 são discutidos os resultados referentes à verificação perceptual e acústica dos falantes nativos (grupo de controle) e, em 5.2.2 são discutidos os resultados referentes aos falantes não nativos.

\subsubsection{Falantes nativos}

Os resultados referentes à verificação perceptual das frases produzidas pelos 7 falantes nativos mostraram que a retração de acento ocorreu em 50,06\% dos casos, inclusive em sequências em que não havia choque entre dois acentos adjacentes.

Ainda que, se lidos de forma natural, todos os contextos inseridos no experimento fossem propícios para a retração de acento, ${ }^{35}$ a aplicação da regra em apenas $50 \%$ dos casos não é um resultado surpreendente, já que se trata de uma estratégia variável para a resolução de choques acentuais. No estudo de Levey (1999), que também investigou perceptualmente a ocorrência de retração de acento por falantes nativos de inglês (cf. Seção 5.1.2), a taxa de aplicação da regra foi de $27 \%$, ainda mais baixa do que a encontrada neste trabalho. Segundo a autora, esse resultado sugere que a resolução do choque acentual é inconsistente e pode depender de outros fatores além da ocorrência de choque acentual.

Como vimos em 5.1.2, segundo Hayes (1989), acentos adjacentes são rigorosamente evitados no inglês e acentos próximos, mas não-adjacentes, tendem a ocorrer com menos rigor. Sendo assim, esperava-se que a retração fosse mais frequente

${ }^{35}$ Exceto as palavras police e complete porque, como vimos na seção 5.1.2, elas contêm um schwa na sílaba que receberia o acento em caso de retração. 
nas frases com sequência de choque acentual, isto é, com dois acentos primários adjacentes (ex: thirTEEN $M E N$ ), do que nas frases sem choque acentual, quando não havia encontro de dois acentos primários (ex: thirTEEN poTAtoes). Os resultados indicaram que a variável Contexto, cujo objetivo era verificar a ocorrência de retração em frases com choque e sem choque acentual, não foi estatisticamente significativa para a aplicação da regra pelos falantes nativos, e que a proporção de retração de acento em frases nesses dois contextos foi praticamente a mesma, de 49,7\% em frases com choque e 51,6\% em frases sem choque. A irrelevância do contexto para a retração de acento fica bastante evidente quando observamos os resultados por informante e por contexto, no Gráfico 14 apresentado na Seção 5.3.1.1. Dos 7 falantes nativos, 4 apresentaram exatamente a mesma taxa de retração em frases com choque e sem choque, 2 apresentaram taxas aproximadas e apenas o Nativo 7 apresentou mais casos de retração em contexto sem choque do que em contexto com choque, contrariando o que esperávamos a respeito do resultado da variável Contexto.

O trabalho de Levey (1999), que também investigou a influência do contexto sobre a regra, registrou mais casos de retração em sequência com choque (27\%) do que em sequências sem choque (12\%). Segundo a autora, o efeito do acento de pitch (pitch accent), que foi controlado em seu trabalho através da inserção de sequências com choque acentual em início de frase e em final de frase, pode ter influenciado o julgamento perceptual nesses dois contextos. Como na presente pesquisa todas as sequências (com choque acentual e sem choque acentual) foram inseridas na mesma posição prosódica e sintática nas frases, acreditamos que o acento de pitch não esteja influenciando nossos resultados.

Os resultados obtidos através de verificação perceptual também indicaram que a única variável estatisticamente significativa para a aplicação da regra de retração de acento pelos falantes nativos foi Segmento Final. Observou-se que palavras terminadas em vogal longa (ex: bamboo) e em nasal (ex: thirteen) foram favorecedoras à aplicação da regra, enquanto as terminadas em obstruinte (ex: retake) não foram. Quando observamos a aplicação da retração por palavra (Tabela 20) fica evidente que o fato de palavras terminadas em obstruinte terem desfavorecido a aplicação da regra está relacionado ao fato de as palavras grotesque, complete, discrete, police e express não terem apresentado nenhuma ocorrência de retração. Além da estrutura da sílaba final, percebe-se que essas palavras têm em comum o fato de a penúltima sílaba conter um 
schwa (no caso de $p[\partial] l i c e$ e $c[\partial] m p l e t e)$, um ditongo com schwa (gr[əu]tesque) ou a vogal curta e frouxa [I] (d[I]screte, [I]xpress). Apesar de não termos controlado estatisticamente o tipo de vogal na sílaba que receberia o acento no caso de retração, acreditamos que esse aspecto também pode ter influenciado os resultados encontrados nesta pesquisa, já que resultados semelhantes foram encontrados no estudo de Levey (1999), que não registrou nenhum caso de retração em palavras com o ditongo [əひ] na sílaba que receberia o acento (ex: obese).

Consideremos agora os resultados referentes à duração e ao pico de F0 nas palavras produzidas pelos falantes nativos. Os correlatos acústicos referentes aos três contextos (palavra isolada, frase com choque e frase sem choque) indicaram que a duração foi estatisticamente significativa, mas não o F0. Observou-se que, em todas as palavras, a duração da última sílaba (ex: nineteen) foi significativamente mais alta nos contextos de palavra isolada do que em frases com e sem choque acentual. De acordo com Reetz e Jongman (2009, p. 216), esse aumento na duração da última sílaba de palavras em final de frase ou antes de uma pausa não é uma característica específica da língua inglesa, mas um fenômeno comum em muitas línguas.

No que diz respeito à duração da última sílaba em contexto de frase com choque e sem choque, os resultados apontaram que 11 palavras apresentaram duração mais alta em contexto de choque e 10 palavras a apresentaram duração um pouco maior em contexto sem choque. Os resultados referentes à duração das sílabas que, no caso de retração acentual, receberiam o acento, indicaram que a duração nas palavras bamboo,

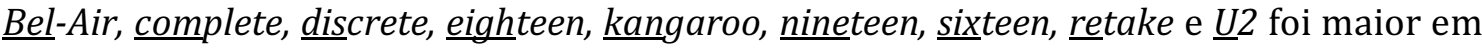
casos de choque acentual, enquanto nas palavras dislike, express, fifteen, fourteen,

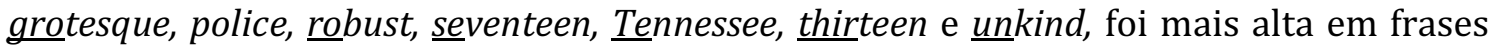
sem sequência de choque acentual.

Se compararmos os resultados referentes à duração nas palavras mencionadas acima com a taxa de aplicação da retração por palavra obtida através de verificação perceptual (cf. Tabela 20, Seção 5.3.1.1), é difícil fazer alguma generalização a respeito da duração nestas sílabas e o resultado obtido perceptualmente. As palavras eighteen, seventeen, sixteen, Tennessee, bamboo, kangaroo, fourteen, retake, thirteen e fifteen, por exemplo, foram as que apresentaram as maiores taxas de retração de acento nos resultados obtidos perceptualmente (todas entre 50\% e 100\% de aplicação). Dentre essas palavras, bamboo, eighteen, kangaroo, sixteen, fifteen e retake apresentaram 
duração mais alta na sílaba que receberia o acento no contexto de choque, e seventeen, Tennessee e thirteen apresentaram duração mais alta em contexto sem choque. Com relação à duração da última sílaba, percebemos que, dentre essas 10 palavras que apresentaram as maiores taxas de retração nos resultados verificados perceptualmente, a duração foi mais alta no contexto de choque em 8 (bamboo, fourteen, eighteen, Tennessee, kangaroo, retake, thirteen, fifteen) e mais alta em contexto sem choque em duas (sixteen e seventeen). Já nos casos de palavras que apresentaram taxa de retração muito baixa na verificação perceptual, 7 apresentam duração mais baixa na última sílaba nos contextos de choque (grotesque, complete, express, police, robust, dislike, U2) e apenas duas apresentam duração mais alta em contexto sem choque acentual (discrete, Bel-Air).

Não se consegue perceber, desse modo, nenhuma tendência regular no que diz respeito à duração das sílabas nos dois contextos de palavra inserida em frases e nem fazer algum tipo de generalização ou associação com os casos de retração julgados perceptualmente. Percebe-se que duração só apresentou diferença estatisticamente significativa porque as palavras produzidas isoladamente foram significativamente mais longas do que as palavras inseridas em frases, e não porque houve diferença relevante entre frases com choque e sem choque acentual. 0 alongamento de sílabas tônicas e sílabas finais de palavras em fronteira de domínios prosódicos já foi apontado como um processo comum em diversas línguas por Fougeron e Keating (1997) e por Santos e Leal (2008) no PB. O fato de as palavras produzidas isoladamente terem sido mais longas do que as que foram inseridas em frases apenas confirma, portanto, essa tendência de alongamento em posição de fonteira prosódica.

Com relação ao F0, por fim, observou-se que não houve diferença estatisticamente significativa em nenhuma palavra nos três contextos em análise nos dados dos falantes nativos e não foi possível encontrar nenhuma regularidade nos padrões encontrados em cada contexto.

Portanto, assim como os trabalhos de Cooper e Eady (1986) e Levey (1999), que não observaram nenhuma indicação de padrão regular referente à duração e ao F0 de sílabas em sequência com choque e sem choque, não encontramos nenhuma regularidade que pudesse indicar a ocorrência ou a não ocorrência da retração de acento nos dados verificados acusticamente na presente pesquisa, a não ser o fato de que 
palavras produzidas isoladamente apresentam duração mais longa do que palavras inseridas em frases.

Sendo assim, os resultados referentes aos falantes nativos de inglês apresentados nesta seção parecem mais uma evidência de que a retração de acento é um fenômeno de natureza perceptual, já que foi percebida em $50 \%$ dos casos, mas não acústica, já que não foi encontrada nenhuma regularidade na duração ou no F0 que pudesse indicar a ocorrência de retração, o que vai ao encontro dos resultados de Grabe e Warren (1995) e Kimball e Cole (2014), já mencionados na Seção 5.1.2.

\subsubsection{Falantes de inglês como L2}

Os resultados referentes aos 30 falantes de inglês como L2 indicaram que a retração foi aplicada em $21,7 \%$ dos casos. 0 Gráfico 23 a seguir compara a taxa de aplicação pelos falantes brasileiros de inglês como L2 e pelos falantes nativos, que, como vimos em 5.4.1, apresentaram 50\% de aplicação da regra.

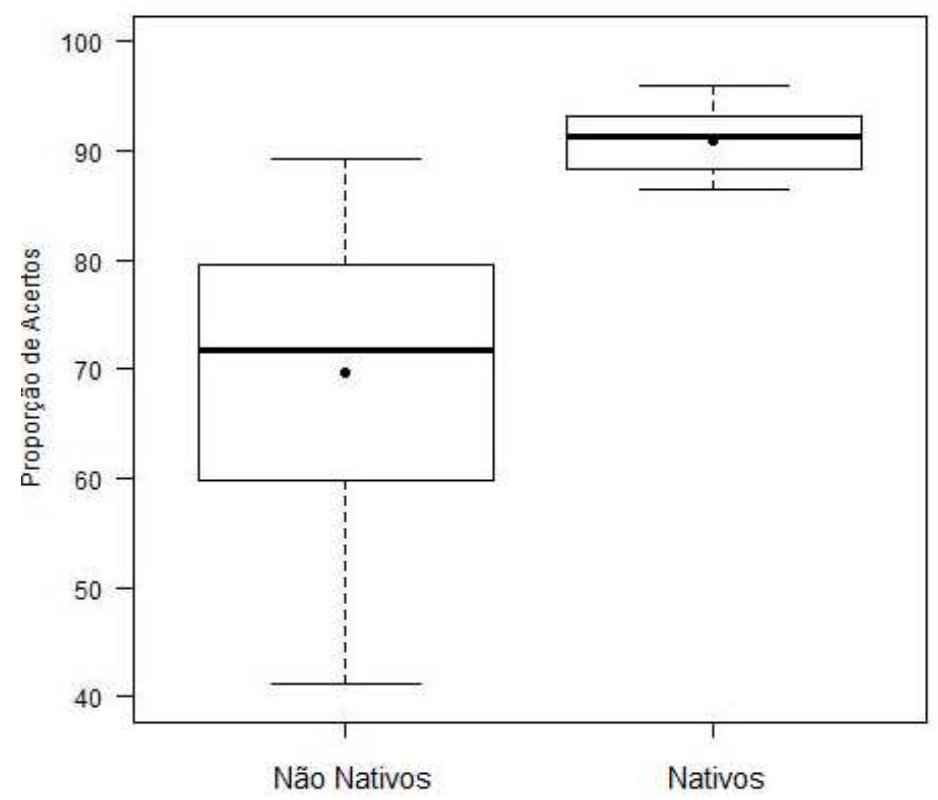

Gráfico 23: Aplicação da Retração de Acento por Nativos e Não Nativos

Os resultados também mostraram que a retração passa a ser mais frequente conforme o avanço do nível de proficiência, ou seja, os falantes de nível avançado aplicaram mais retração de acento do que os falantes de nível básico e intermediário. Observa-se que, no nível avançado, os falantes brasileiros apresentam uma taxa de retração muito aproximada à dos falantes nativos, conforme ilustra o Gráfico 24 a seguir. 


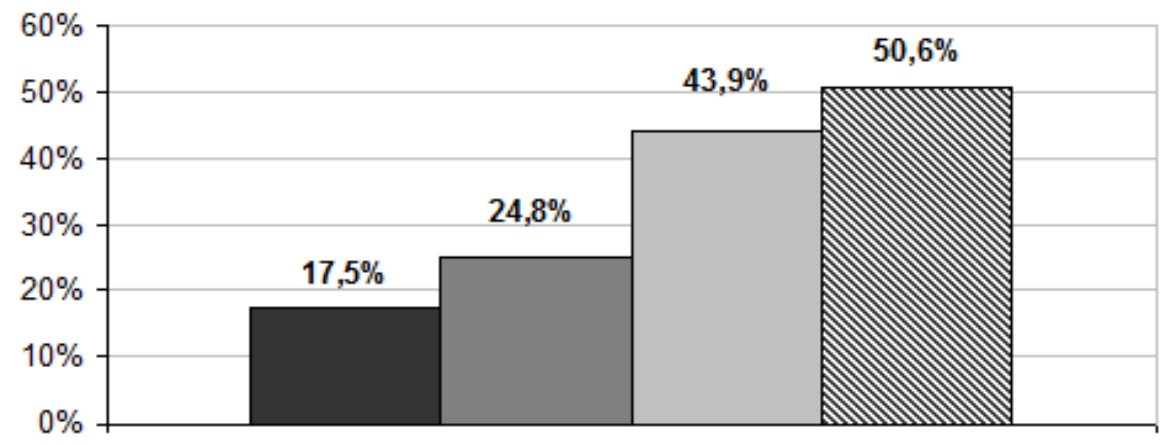

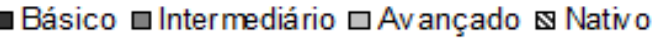

Gráfico 24: Retração de acento por nível de proficiência

Sendo a retração uma regra que ocorre tanto no PB quanto no inglês de maneira semelhante (do ponto de vista perceptual), o que justificaria o fato de os falantes de nível básico terem apresentado uma taxa de aplicação tão mais baixa que os falantes de nível avançado, se a aplicação da regra na L2 seria apenas uma questão de transferência da L1? Como a retração de acento é uma regra que ocorre na fala natural, acreditamos que a regra tenha sido pouco aplicada nos níveis iniciais porque esses informantes nem sempre são capazes de realizar a leitura das frases de modo natural, sem pausas, o que acaba bloqueando a aplicação da regra. Mas para além de aplicar na mesma quantidade, interessa-nos saber se os informantes estão aplicando da mesma forma que os nativos.

Assim como nos resultados dos falantes nativos, a variável Contexto, que tem como objetivo verificar a ocorrência de retração em frases com choque e sem choque acentual, não foi estatisticamente significativa nos dados dos falantes de inglês como L2. Os resultados indicaram que a retração ocorreu em 29,9\% dos casos de choque acentual (ex: SixTEEN CHAIRS) e em 27,6\% dos casos sem choque de acentos adjacentes (ex: sixTEEN imiTAtions). Vimos na Seção 5.2.1 que, no PB, a retração de acento ocorre apenas nos casos de choque entre dois acentos primários adjacentes (ex: JEsus CRISto) mas, no caso de alguma sílaba átona entre os acentos, a retração causa estranhamento (ex: *JEsus bonDOso). No inglês, por outro lado, a retração ocorre mesmo no caso de uma sílaba fraca entre duas sílabas acentuadas, como nos casos de sequência sem choque que foram inseridas no experimento de coleta (ex: THIRteen poTAtoes). Sendo assim, aplicação da retração nos contextos sem choque pelos falantes brasileiros poderia ser um indício de aquisição da regra do inglês, que é igual à do PB a não ser por esse fator da distância entre os acentos. 
Para verificar se a aplicação da retração nos contextos de frase sem choque acentual passa a ser mais frequente no decorrer do aprendizado, realizamos um cruzamento entre as variáveis Nível de Proficiência e Contexto. Caso a retração nos contextos sem choque fosse mais frequente no nível avançado do que nos outros dois níveis, poderíamos supor que a aplicação nesse contexto é adquirida durante o processo. Entretanto, podemos observar na Tabela 42 a seguir que a aplicação da retração em contextos sem choque ocorre desde o nível básico.

Tabela 42: Retração de Acento por Contexto e Nível de Proficiência

\begin{tabular}{ccccc}
\hline \multirow{2}{*}{ Nível de Proficiência } & \multicolumn{4}{c}{ Contexto por Nível de Proficiência } \\
\cline { 2 - 5 } & \multicolumn{2}{c}{ Com Choque } & \multicolumn{2}{c}{ Sem Choque } \\
\cline { 2 - 5 } & $\mathrm{n}$ & $\%$ & $\mathrm{n}$ & $\%$ \\
\hline Básico & 42 & $18 \%$ & 38 & $17 \%$ \\
Intermediário & 57 & $25 \%$ & 57 & $25 \%$ \\
Avançado & 107 & $47 \%$ & 95 & $41 \%$
\end{tabular}

A proporção da retração por contexto e por nível de proficiência também pode ser visualizada no Gráfico 25 a seguir, que mostra que a proporção de retração nos dois contextos é muito semelhante nos três níveis de proficiência.

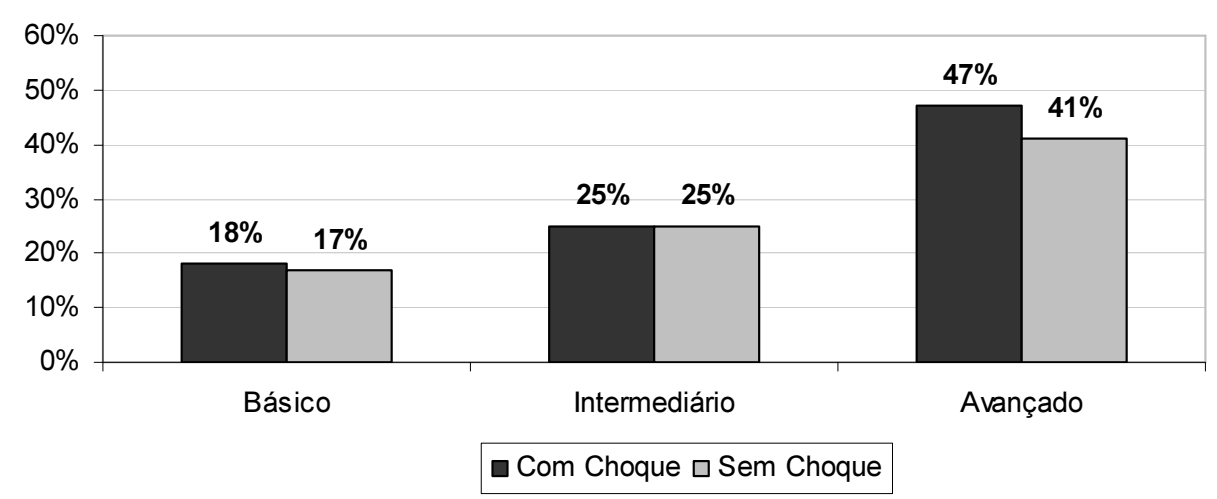

Gráfico 25: Retração de acento por contexto e nível de proficiência

Parece, portanto, que a aplicação da retração de acento em ambos os contextos testados nesta pesquisa é um processo natural para os falantes brasileiros desde o nível básico, e que a aplicação da regra passa a ser mais frequente assim que os falantes se tornam capazes de produzir sentenças com naturalidade (i.e. nível avançado), ainda que de forma variável, assim como os falantes nativos. 
Os resultados referentes aos falantes de inglês como L2 também mostraram que a única variável linguística estatisticamente relevante para a aplicação da regra foi palavra alvo. Observou-se que, dentre todas as palavras testadas, $U 2$ foi a maior favorecedora da retração, seguida de seventeen, sixteen, nineteen, fourteen, unkind, Tennessee, thirteen, fifteen, kangaroo, eighteen, robust e bamboo. Assim como nos dados referentes aos falantes nativos, as palavras que contêm um schwa (p[a]lice), um ditongo com schwa (gr[av]tesque) ou a vogal [I] (d[I]screte, [I]xpress) não favoreceram a retração.

Através do cruzamento entre Palavra Alvo e Segmento Final, percebemos que há uma tendência de palavras terminadas em vogal longa (ex: bamboo) ou nasal (ex: nineteen) serem mais favorecedoras para a retração do que as terminadas em obstruintes (ex: retake).

Diferentemente dos que se observou no caso dos falantes nativos, as taxas de aplicação da regra foram muito heterogêneas entre os informantes brasileiros, inclusive no mesmo nível de proficiência (cf. Gráfico 19 na Seção 5.3.1.2). Dentre os informantes de nível avançado, por exemplo, houve informantes que apresentaram taxas mais baixas que os informantes de nível básico e também um informante que apresentou mais aplicação da regra que os próprios falantes nativos. Em se tratando da regra de retração de acento essa variação é esperada, pois não se trata de uma regra categórica, mas uma regra que pode depender de outros fatores que não foram controlados nesta pesquisa, como velocidade e registro de fala. É possível, por exemplo, que alguns falantes não nativos tenham lido as frases de maneira exageradamente cautelosa para privilegiar uma pronúncia clara e "correta", o que acabou bloqueando a aplicação da regra, enquanto outros falantes realizaram uma leitura de forma mais natural.

No que diz respeito aos resultados referentes aos correlatos acústicos, apresentados na Seção 5.3.2.2, observou-se que somente a duração se mostrou estatisticamente significativa. Percebe-se que, assim como foi observado nos resultados dos falantes nativos, essa diferença estatisticamente significativa se deu principalmente pelo fato de as palavras produzidas isoladamente terem apresentado durações mais altas, o que é comum neste contexto (cf. Reetz e Jongman, 2009, p. 216).

Quando observamos os resultados de duração divididos por nível de proficiência, percebe-se que no nível básico há poucas ocorrências de diferença estatisticamente significativa, ao contrário dos níveis intermediário e avançado. Isso pode ser explicado porque, neste nível, os informantes ainda não são capazes de fazer uma leitura mais 
rápida e natural das sentenças, o que diminui a diferença de duração entre palavras lidas isoladamente e em contexto de frase.

Vimos na Seção 5.1.1 que, de acordo com Barbosa (2002), há um aumento na duração da última sílaba da primeira palavra do choque nos casos de choque acentual no PB. No presente trabalho observamos que, no que diz respeito aos resultados dos falantes de inglês como L2 (cf. Tabela 37), das 21 palavras testadas 13 apresentaram uma duração mais longa na última sílaba em contexto com choque se comparadas às palavras em contexto sem choque. Apesar de essa duração mais longa em contexto de choque não ter sido encontrada em todas as palavras analisadas, isso pode ser um indício de que os brasileiros também transferiram a regra do ponto de vista acústico.

Com relação às médias do pico de F0, assim como no caso dos falantes nativos, não foi identificado nenhum padrão de aplicação desse correlato nos contextos de choque, sem choque e de palavra isolada.

Em suma, observam-se muitas semelhanças entre os resultados dos falantes nativos e os falantes não nativos: 1) Do ponto de vista perceptual, a retração ocorre tanto em contexto com choque ou sem choque em proporções muito aproximadas; 2) A taxa de aplicação da retração pelos falantes de nível avançado $(43,9 \%)$ foi bastante aproximada à taxa de aplicação dos falantes nativos (50\%); 3) Palavras terminadas em obstruinte não favorecem a aplicação da regra, enquanto palavras terminadas em vogal longa ou nasal favorecem; 4) Palavras lidas isoladamente apresentam durações mais longas do que palavras lidas em contexto de frase com choque ou sem choque; 5) Não há evidências suficientes que indiquem que o pico de F0 ou a duração sejam fatores decisivos para a produção das palavras nos três contextos.

Os resultados referentes à regra de retração de acento indicaram, portanto, diversas semelhanças entre os resultados dos falantes nativos e os falantes não nativos tanto do ponto de vista da percepção quanto no ponto de vista acústico. Desse modo, consideramos que, sobretudo no nível avançado, a regra de retração de acento do inglês e todas as suas particularidades foi transferida do PB para o inglês. 


\section{Capítulo 6}

\section{SÍLABA E ACENTO}

Este capítulo apresenta o estudo referente à relação entre sílaba e acento, que ocorre de maneira diferente no inglês e no português. A Seção 6.1 caracteriza a relação entre sílaba e acento nas duas línguas e apresenta um trabalho desenvolvido sobre o tema. A Seção 6.2 apresenta a metodologia empregada no desenvolvimento desta pesquisa. Os resultados são apresentados em 6.3 e, por fim, a Seção 6.4 apresenta uma discussão a respeito dos resultados obtidos.

\subsection{A Relação entre Sílaba e Acento}

A sílaba é considerada por muitos teóricos (Nespor e Vogel, 1986; Selkirk, 1982), como o constituinte mais baixo na hierarquia prosódica. Uma sílaba consiste em um ataque (ou onset) e uma rima, que é constituída por um núcleo e uma coda. Qualquer categoria pode ser vazia, exceto o núcleo, que consiste em uma vogal, conforme a estrutura proposta por Selkirk (1982): ${ }^{36}$

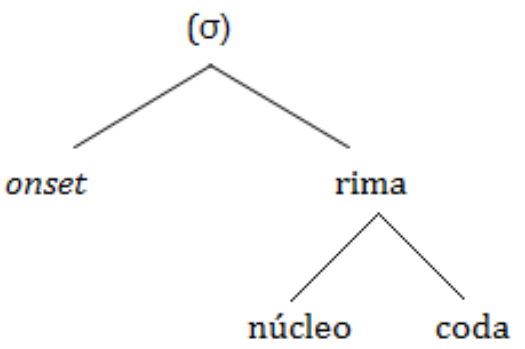

Em uma palavra como cat, por exemplo, a consoante [k] seria o onset, a vogal [æ] o núcleo e o [t] a coda. As línguas variam a respeito dos segmentos que podem compor

\footnotetext{
${ }^{36}$ Nesta pesquisa, adotamos a proposta de organização silábica estabelecida por Selkirk (1982), mas existem outras propostas que procuram explicar a organização desse constituinte. Propostas autossegmentais defendem que a sílaba não tem uma estrutura interna e que os segmentos encontram-se ligados diretamente ao nó silábico (cf. Itô (1986) e Nespor e Vogel (1986), por exemplo). Trabalhos desenvolvidos na abordagem métrica, como o próprio trabalho de Selkirk (1982), defendem que há outros constituintes entre os segmentos e o nó silábico, como ataque e rima. Apesar de concordarem com a existência de uma estrutura interna para a sílaba, esses trabalhos divergem a respeito da organização dos constituintes (cf. Fikkert, 1994; Bisol, 1989; Zec, 1995; Collishon, 2005).
} 
cada uma dessas posições, conforme será apresentado nas seções 6.1.1 e 6.1.2, sobre a sílaba no português e no inglês, respectivamente.

Atualmente, sabe-se que diversas propriedades universais da estrutura fonológica fazem referência à sílaba. Observa-se, por exemplo, que a estrutura silábica obedece a condição de sequência de sonoridade, segundo a qual o elemento mais sonoro sempre constituirá o núcleo da sílaba e será precedido/seguido por elementos com sonoridade crescente em direção ao núcleo e decrescente em direção à coda, conforme a seguinte escala:

(17) Escala de Sonoridade

$$
\begin{array}{cccc}
\text { Vogal } & >\text { Líquida } & > & \text { Nasal } \\
3 & 2 & 1 & \text { Obstruinte }
\end{array}
$$

Assim, a sequência $n t$, que apresenta sonoridade decrescente, não pode constituir o ataque de uma sílaba, mas pode constituir a coda. A sequência $p r$, por outro lado, pode constituir o ataque, mas não pode constituir a coda (Collischonn 2005, p. 111).

Goldstein, Chitoran e Selkirk (2007), ao discutirem essas propriedades universais, afirmam que (1) as sílabas CV são as únicas encontradas universalmente; (2) os ataques podem se combinar de modo relativamente livre com o núcleo, enquanto a combinação é mais restrita entre ataques, entre codas e entre núcleos e codas; (3) consoantes em coda são geralmente moraicas (pesadas) e podem influenciar o padrão métrico, enquanto consoantes no ataque raramente são consideradas para o peso silábico.

Em diversas línguas o peso silábico está diretamente relacionado às regras de atribuição de acento. As seções a seguir mostram essas regras no PB e no inglês.

\subsubsection{Sílaba e acento no Português Brasileiro}

Os padrões silábicos do português são os seguintes (Collischonn 2005, p.117):

$\begin{array}{ll}\text { V } & \underline{\text { é }} \\ \text { VC } & \underline{\text { ar }} \\ \text { VCC } & \underline{\underline{\text { instante }}} \\ \text { CV } & \underline{\text { cá }} \\ \text { CVC } & \underline{\text { lar }} \\ \text { CVCC } & \underline{\text { monstro }} \\ \text { CCV } & \underline{\text { tri }} \\ \text { CCVC } & \underline{\text { três }} \\ \text { CCVCC } & \underline{\text { transporte }}\end{array}$




$\begin{array}{ll}\text { VV } & \underline{\text { aula }} \\ \text { CVV } & \underline{\text { lei }} \\ \text { CCVV } & \text { grau } \\ \text { CCVVC } & \underline{\text { claustro }}\end{array}$

De acordo com (Collischonn, 2005), há duas propostas de representação da sílaba do PB para dar conta dos quinze padrões silábicos apresentados em (18): o molde CCVVCC, defendido por Câmara Jr. (1977), e o molde CCVCC, defendido por Bisol (1989).

Essas duas propostas têm em comum a ideia de que os verdadeiros ditongos no PB são os decrescentes, já que os crescentes apresentam variação com o hiato (ex: [su.'ar $\sim \operatorname{swar}]]^{37}$, mas diferem por permitirem ou não a ocorrência de núcleos ramificados VV no caso de ditongos decrescentes. Câmara Jr. (1977) defende que ditongos VV decrescentes constituem um núcleo ramificado, já que apresentam características diferentes das observadas em sílabas VC. Um dos argumentos apresentados pelo autor é que o ' $r$ ' apresenta-se como forte após uma sílaba travada VC (ex: Is[r]ael, hon[r]a), mas não após um ditongo (ex: au[r]ora, bei[r]a), o que seria uma evidência de que o ditongo não constitui uma sequência VC. Além disso, o autor aponta como evidências para a ramificação do núcleo a monotongação (ex: $c[a j] x a \rightarrow c a[x] a)$ e a possibilidade de ditongos átonos se transformarem em hiatos dependendo da velocidade de fala (ex: vai.da.de $\rightarrow$ va.i.da.de). Bisol (1989), por outro lado, argumenta que formas subjacentes VV se tornam codas VC durante a silabificação. Segundo a autora, há dois tipos de ditongo no português: ditongo pesado, caracterizado como um "ditongo verdadeiro", e ditongo leve, denominado "ditongo falso". Segundo a autora, o ditongo verdadeiro está associado a duas posições da rima e, portanto, tende a ser preservado. Esse tipo de ditongo tem caráter fonológico, pois é capaz de distinguir significado (ex: $r[e j]$ tor $\left.\rightarrow{ }^{*} r[e] t o r, p[a w] t a \rightarrow p[a] t a\right)$. 0 ditongo falso, por outro lado, está associado a apenas uma posição na rima, tem caráter fonético, pois não é capaz de distinguir significado, e tende a ser perdido (ex: b[aj]xa $\rightarrow$ [a]xa, banan[ej]ra $\rightarrow$ banan[e]ra).

Com relação à posição de coda, é consenso na literatura que o PB permite as consoantes líquidas /R/ e /l/, a nasal /N/, que se realiza através do traço de nasalidade na vogal precedente, e a fricativa coronal /S/. No caso de coda ramificada, as

\footnotetext{
${ }^{37}$ Exceto kw/gw seguidos de a/o (ex: qual ['kwaw] [*ku.'aw]). De acordo com Collishonn (2005, p. 122), nesses casos a sequência consoante velar + glide posterior estaria marcada no léxico como uma unidade monofonemática $/ \mathrm{k}^{\mathrm{w}} / \mathrm{e} / \mathrm{g}^{\mathrm{w}} /$.
} 
combinações possíveis são /IS/ (ex: sols.tí.cio), /RS/ (ex: pers.pi.caz) e /NS/ (ex: mons.tro, trans.ver.sal). ${ }^{38}$

No que diz respeito ao ataque, as propostas de Câmara Jr. (1977) e de Bisol (1989) concordam com a existência de três padrões no PB: ataque vazio (ØV), quando não há o preenchimento desta posição; ataque simples (CV), que contém apenas uma consoante; e ataque ramificado (CCV), composto por duas consoantes. Em ataques ramificados, a única combinação aceita no PB é a de uma consoante obstruinte uma consoante líquida (/r/, /l/), como nas palavras prato, treco, clama e flora.

Uma sílaba no português pode conter no máximo cinco segmentos, não havendo ao mesmo tempo um núcleo e uma coda ramificadas. No que se refere ao inventório de sílabas e a estrutura proposta por Selkirk (1982), percebe-se que esta estrutura claramente acomoda os tipos silábicos do português, como se observa em CCVVC:

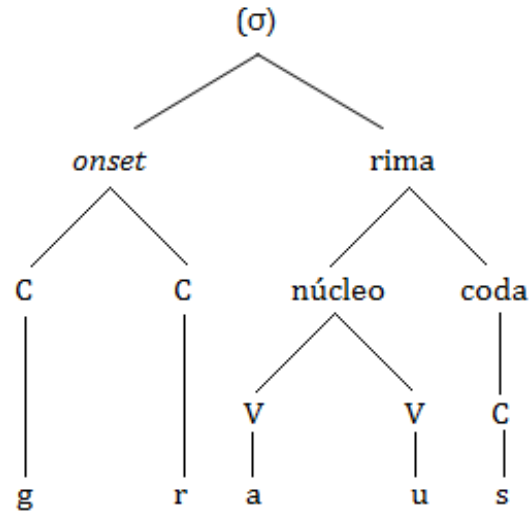

0 acento do PB é relativamente previsível. Conforme já mencionado na seção 5.1, o acento só pode recair em uma das três últimas sílabas, o que impede a existência de palavras como ÉScandalo e CÁtastrofe (Collischonn 2005, p. 143). A grande maioria dos não-verbos (substantivos, adjetivos) no português apresenta acento na penúltima sílaba (ex: CAsa, traBAlho, boNIto) ${ }^{39}$. 0 grupo das proparoxítonas é o mais reduzido na língua, sendo o acento na antepenúltima sílaba considerado menos usual (ex.: aBóbora, ÁRvore). No caso de palavras terminadas em consoante final, há uma preferência na língua em acentuar a última sílaba. De acordo com Bisol (1992), 78\% das palavras

\footnotetext{
${ }^{38}$ No caso de palavras como compacto, apto, psicólogo e advogado, que não se encaixam nos padrões descritos nesta seção, é comum a inserção de uma vogal epentética para desfazer essas sequências indesejáveis no português brasileiro (ex: /psi.'ko.lo.go/ $\rightarrow$ [pi.si.'ko.lo.go]; /kõ.'pak.to/ $\rightarrow$ [kõ.'pa.ki.to] (cf. Câmara Jr., 1972; Collishonn, 2003).

${ }^{39}$ Como esta pesquisa foca em nomes, somente este grupo será detalhado nesta seção.
} 
terminadas em consoante no Dicionário Delta Larousse são oxítonas (ex: palaDAR, ciVIL) e apenas $22 \%$ são paroxítonas (ex: aÇÚcar, MÓvel). No caso das oxítonas terminadas em vogais, a maioria das palavras são empréstimos ( $c a F E ́$, araÇÁ, xanGÔ) e um grupo muito menor é constituído de palavras do português (aVÓ, boCÓ).

À luz da fonologia métrica, Bisol (1992) propõe a seguinte regra para o acento primário do PB:

(20) Regra do acento primário segundo Bisol (1992, p.34)

Domínio: a palavra lexical

i. Atribua um asterisco $(*)$ à sílaba pesada final, i. e., de rima ramificada. ii. Nos demais casos, forme um constituinte binário (não-iterativamente) com proeminência à esquerda, do tipo (*.), junto à borda direita da palavra.

A regra prevê que o acento do português é, portanto, sensível à sílaba pesada final, ou seja, quando a última sílaba for pesada o acento cairá preferencialmente sobre ela. Nos casos em que última sílaba não é pesada, o acento recai sobre a penúltima sílaba (ex.: meNIno, CAsa). Estes são chamados de casos não-marcados, porque resultam da aplicação cega da regra.

No entanto, há em português casos que não seguem esta regra geral. Há proparoxítonas, oxítonas leves e paroxítonas com sílabas finais pesadas. Para dar conta dessas exceções à regra, Bisol (1992) propõe a extrametricidade.

No caso das proparoxítonas, a autora propõe que a sílaba final é extramétrica, o que permite a aplicação da regra geral apresentada em (20). Desse modo, uma palavra como lápide apresenta o seguinte padrão:

(21) Derivação de lápide

$\begin{array}{ll}\text { lá pi }<\text { de }> & \text { Forma Subjacente } \\ (* \text {. }) & \text { Regra apresentada em (20) (parte ii) } \\ \text { ['la.pi.dzi] } & \text { Forma de Superfície }\end{array}$

Pode-se observar que, devido ao fato de a última sílaba ser "invisível", aplica-se o mesmo padrão trocaico que encontramos em paroxítonas terminadas em sílaba leve, previsto em (20-ii). 
No caso de palavras terminadas em sílaba pesada com acento não-final como a palavra móvel, o elemento extramétrico é a coda da sílaba final. Desse modo, o acento ocorrerá na penúltima sílaba, já que a sílaba final não pode ser considerada pesada:

(22) Derivação de móvel

$\begin{array}{ll}\text { mó ve }<\mathrm{l}> & \text { Forma Subjacente } \\ \left(^{*} . \text {.) }\right. & \text { Regra apresentada em (20) (parte ii) } \\ {[\text { 'mo.vew] }} & \text { Forma de Superfície }\end{array}$

Por fim, no caso de oxítonas terminadas em sílaba leve como café e chá, Bisol (1992, p.291) propõe uma coda final abstrata, que torna a sílaba final pesada e atrai o acento através da regra em (20-i). A autora assume a existência dessa consoante abstrata com base em formas derivadas como cafeteira ( ${ }^{*}$ cafeeira), cafezinho ( ${ }^{*}$ cafeinho), chaleira ( ${ }^{*}$ chaeira) e chazinho $\left({ }^{*}\right.$ chainho), nas quais essa consoante emerge e, por ressilabificação, passa para a posição de ataque e se manifesta na superfície, conforme (23):

(23) Derivação de café e cafeteira (Collishonn 2005, p. 157)

\begin{tabular}{|c|c|c|}
\hline $\mathrm{kaf} \varepsilon \mathrm{C}$ & $\mathrm{kaf} \varepsilon \mathrm{C}$ & Forma Subjacente \\
\hline $\mathrm{ka} \cdot \mathrm{f} \varepsilon \mathrm{C}$ & $\mathrm{ka} \cdot \mathrm{f} \varepsilon \mathrm{C}$ & Silabação \\
\hline$(*)$ & $(*)$ & Acento \\
\hline & $\mathrm{ka} \cdot \mathrm{f} \varepsilon \mathrm{C}+\mathrm{e}$ ira & Derivação \\
\hline & $\mathrm{ka} . \mathrm{f} \varepsilon \cdot \mathrm{Ce} \mathrm{i} \cdot \mathrm{ra}$ & Ressilabação \\
\hline a.f $\varepsilon$ & & Apagamento de $\mathrm{C}$ \\
\hline [ka.'f $\varepsilon]$ & [ka.fe.'tej.ra] & Forma de Superf \\
\hline
\end{tabular}

Observe-se que os casos em que a última sílaba for leve e a penúltima sílaba for pesada, a regra prevê corretamente que o acento nunca cairá sobre a antepenúltima sílaba (ex.: caDAStro, paRENte), ou seja, não há proparoxítonas se a sílaba pós-tônica não final (penúltima) tiver rima ramificada (ex. camPEStre e não *CAMpestre).

Sendo assim, pode-se afirmar que, no português, o acento é não-marcado em paroxítonas terminadas em sílaba leve (ex.: boNIto) e oxítonas terminadas em sílaba pesada (ex.: viGOR), e é marcado em paroxítonas terminadas em sílaba pesada (ex.: FÁcil), nas oxítonas terminadas em sílaba leve (ex.: caFÉ) e nas proparoxítonas (ex.: 
ÁRvore). ${ }^{40} 0$ Quadro 12 a seguir apresenta um resumo da relação entre sílaba e acento no PB. São apresentados os casos não-marcados, que são resultado da regra geral proposta por Bisol (1992), e os casos marcados, que fogem à regra e são explicados através da extrametricidade.

Quadro 12: Sílaba e acento no PB

\begin{tabular}{|c|c|c|}
\hline \multicolumn{3}{|c|}{ ACENTO NO PORTUGUÊS BRASILEIRO (NOMES) } \\
\hline & PADRÃO ACENTUAL & EXEMPLOS \\
\hline \multirow{2}{*}{ NÃO MARCADO } & $\begin{array}{l}\text { Sílaba final leve: } \\
\text { paroxítono }\end{array}$ & $\begin{array}{l}\text { mesa, cadeira, batata, martelo, } \\
\text { forte, monte, bala, dedo, conhaque }\end{array}$ \\
\hline & $\begin{array}{l}\text { Sílaba final pesada: } \\
\text { oxítono }\end{array}$ & caracol, colher, civil, mulher, papel, \\
\hline \multirow{3}{*}{ MARCADO } & $\begin{array}{l}\text { Sílaba final leve: } \\
\text { proparoxítono }\end{array}$ & $\begin{array}{c}\text { catástrofe, médico, pálido, xícara, } \\
\text { abóbora }\end{array}$ \\
\hline & $\begin{array}{l}\text { Sílaba final leve: } \\
\text { oxítono }\end{array}$ & café, jacaré, aqui, urubu, abacaxi \\
\hline & $\begin{array}{l}\text { Sílaba final pesada: } \\
\text { paroxítono }\end{array}$ & fácil, álbum, revólver \\
\hline
\end{tabular}

\subsubsection{Sílaba e acento no inglês}

A fonotaxe do inglês permite os seguintes padrões silábicos, segundo Collischonn (2005, p. 108):
(i) $(. *)$ menin $+o$
(ii) $(. *)$ café
(iii) $(* \quad)$ móvel
(iv) $(* \quad$. princip $+\mathrm{e}$

${ }^{40}$ Lee (1995) propõe uma análise alternativa, segundo a qual o português brasileiro não é sensível ao peso silábico e o acento primário decorre de um constituinte binário com cabeça à direita (iambo) e da extrametricidade do marcador de palavra (cf. (i)-(ii)). Casos marcados seriam aqueles em que o constituinte binário teria cabeça à esquerda (troqueu) (cf. (iii)). Os proparoxítonos seriam gerados pela interação de um constituinte binário com cabeça à esquerda +extrametricidade (cf. (iv)):

No entanto, a proposta de Lee falha em explicar porque nunca encontramos em português brasileiro uma palavra proparoxítona em que a penúltima sílaba é pesada. 


$\begin{array}{lllll}\text { VC } & \text { id } & \text { VV } & \text { I } & \text { ([aj]) } \\ \text { CVC } & \text { bad } & \text { VVC } & \text { isle } & \text { ([ajl]) } \\ \text { CCVC } & \text { bread } & \text { CVV } & \text { bye } & \text { ([baj]) } \\ \text { CVCC } & \text { band } & \text { CVVC } & \text { bide } & \text { ([bajd]) } \\ \text { CCVCC } & \text { brand } & \text { CVVCC } & \text { bind } & \text { ([bajnd]) } \\ & & \text { CCVVC } & \text { bride } & \text { ([brajd]) } \\ & & \text { CCVVCC } & \text { grind } & \text { ([grajnd]) }\end{array}$

De acordo com a autora, a estrutura mínima é VC ou VV, e a estrutura máxima é CCVVCC, com seis segmentos. Yavas (2006, p.135), por sua vez, inclui os seguintes padrões:

$\begin{array}{lll}\text { CCCVV } & \text { spray } & \text { [spuej] } \\ \text { VCC } & \text { act } & {[æ k t]} \\ \text { VCCC } & \text { busts } & {[\mathrm{b} \Lambda \text { sts }]} \\ \text { CVCCC } & \text { text } & {[\text { tzkst] }} \\ \text { CCVCCC } & \text { sphinx } & {[\text { sfinks] }} \\ \text { CCCVCC } & \text { sprint } & {[\text { sp.ınt }]}\end{array}$

O autor demonstra, ainda, a possibilidade de mais estruturas silábicas possíveis se os sufixos forem considerados:

$$
\begin{array}{ll}
\text { CCCVCCC sprints } & \text { [spunts] } \\
\text { CVCCCC worlds } & {[\text { w3lldz] }} \\
\text { CCVCCCC twelfths } & \text { [twelf }]
\end{array}
$$

A estrutura silábica proposta em Selkirk (1982), apresentada em (27), permite no máximo duas consoantes no onset, duas vogais no núcleo e duas consoantes na coda (CCVVCC), conforme o molde a seguir:

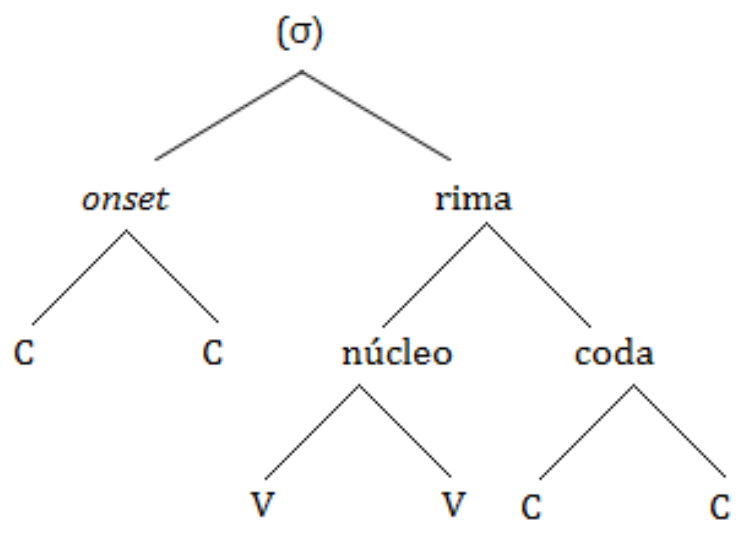


Entretanto, como vimos, autores como Yavas (2006) apresentam evidências para a ocorrência de até sete segmentos na sílaba do inglês: três consoantes no onset, uma vogal no núcleo e três consoantes na coda (CCCVCCC), como na palavra sprints; ou duas consoantes no onset, uma vogal no núcleo e quatro consoantes na coda (CCVCCCC), como na palavra twelfths.

Segundo Selkirk (1982), esses casos ocorrem apenas em posição inicial ou final de palavra e devem ser caracterizados como apêndices, ou violações da estrutura silábica proposta em (27). Os apêndices podem conter uma consoante ou sequência de consoantes que não é permitida em posição medial. Sendo assim, a sílaba de uma palavra como sprints (CCCVCCC), na proposta da autora, seria organizada da seguinte forma:

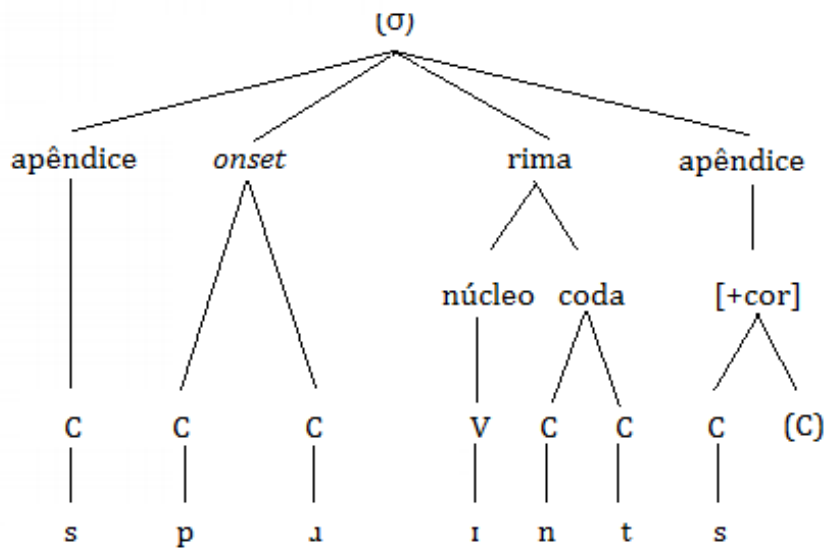

No inglês, a única consoante que não pode ocorrer em posição de ataque é /y/. 0 fonema /3/, por sua vez, ocorre em início de palavra apenas em estrangeirismos como genre, mas pode ocorrer em ataque medial em palavras como vi[3]ion. Yavas (2006, p. 136) ressalta que a ocorrência do fonema /ð/ em ataque em início de palavra é restrita a palavras funcionais como the, this, then, etc.

Com relação a ataques ramificados com duas consoantes, pode-se afirmar que as africadas são a única classe de consoantes que não aparece nessa posição. De maneira resumida, as possíveis combinações em ataque ramificado no inglês são (a) /s/ + C (sendo $C$ qualquer consoante que possa assumir a posição $C_{2}$, exceto / $/$ /; $/ \int /$ ocorre antes de /ג/), e (b) obstruinte + aproximante, com algumas restrições (Yavas 2006, p. 136). 
Por fim, em ataques ramificados com três consoantes, a única combinação possível é a seguinte: $C_{1}=/ s /, C_{2}=$ plosiva desvozeada, $C_{3}=$ aproximante. Apesar de essa combinação gerar 12 possibilidades, apenas 7 ocorrem na língua (ex.: spring, splash, spew, string, scrap, skate, squeeze).

A rima, assim como no português, pode ser constituída por uma vogal (ex.: card) ou um ditongo (ex.: spray), sendo o núcleo ramificado no segundo caso (cf. Hayes, 1980).

0 único som que não ocorre em posição de coda no inglês é /h/. Em codas ramificadas com duas consoantes, as combinações possíveis podem ser generalizadas da seguinte forma:

(1) $C_{1}$ é uma nasal e $C_{2}$ é uma das obstruintes /d, z, d3/.

(2) $\mathrm{C}_{1}$ é /s/ e $\mathrm{C}_{2}$ é uma plosiva não vozeada.

(3) $C_{1}$ é uma líquida $\left(/ \mathrm{l}, \mathrm{x} /\right.$ ) e $\mathrm{C}_{2}$ é uma consoante, exceto $/ \mathrm{z}, 3$, $\mathrm{d} /$, sendo que a sequência $/ \mathrm{lg} /$ também não existe.

(4) $C_{1}$ é uma plosiva não-alveolar não vozeada (/p, k/) e $C_{2}$ é uma obstruinte alveolar não vozeada $(/ \mathrm{t}, \mathrm{s} /)$, sendo que a sequência $/ \mathrm{ft} /$ também é permitida.

(Yavas 2006, p. 139)

Finalmente, em codas ramificadas com três consoantes, de maneira geral, todas as combinações consistem em uma líquida ou uma nasal seguida por duas obstruintes não vozeadas (ex.: sculpt, corpse), exceto quando $\mathrm{C}_{1}=$ plosiva, $\mathrm{C}_{2}=$ fricativa, $\mathrm{C}_{3}=$ plosiva (ex.: midst /dst/, next /kst/).

Segundo Yavas (2006, p. 153), mais de $80 \%$ dos substantivos e adjetivos dissilábicos no inglês apresentam acento na penúltima sílaba (ex.: Agent, BAlance, COmmon, FLUent). Assim como no português, sílabas pesadas, isto é, com rima ramificada (com uma vogal curta seguida de uma consoante em posição de coda ou com uma vogal longa, com ou sem coda) atraem o acento no inglês. Entretanto, especificamente em posição final, o peso silábico corresponde ao núcleo ramificado, isto é, uma vogal longa ou um ditongo na sílaba final (ex: bamBOO, baZAAR), ou coda complexa (ex: abSURD, coRRUPT). Sendo assim, sílabas finais com vogal curta seguida de apenas uma consoante não atraem o acento no inglês (ex: meCHAnic).

Hayes $(1980,1982)$, à luz da fonologia métrica, assume que o acento no inglês é listado no léxico e derivado através de regras. No que diz respeito aos substantivos, o autor prevê o seguinte: 
i) Se a penúltima sílaba for pesada (isto é, contém uma vogal longa ${ }^{41}$ ou uma consoante em posição de coda), o acento cairá sobre esta sílaba (ex: ariZOna, paPAYa, neBRASka, aGENda)

ii) Se a penúltima sílaba for leve, o acento recai sobre a antepenúltima sílaba (ex: aMErica, CAmera, CInema, CApital).

De acordo com o autor, o acento do inglês segue o padrão trocaico na borda direita da palavra e, nos substantivos que seguem o padrão regular apresentado em (29), o acento jamais cairá sobre a última sílaba porque ela é extramétrica. Assim, dependendo do padrão da penúltima sílaba, a palavra será paroxítona ou proparoxítona, conforme as previsões apontadas em (29). No caso dos dissílabos, o acento geralmente cairá sobre a penúltima sílaba, independentemente do peso da última (ex: CHAnnel, TEXtile). No caso de dissílabos como caNAL e giRAFFE, empréstimos do Francês que fogem à regra, o acento é marcado no léxico.

Com relação a verbos e adjetivos, o autor propõe o seguinte:

i) Palavras terminadas em vogal longa receberão o acento na última sílaba, como nos verbos mainTAIN, eRASE e deCIDE e nos adjetivos SUPREME, e reMOTE;

ii) Palavras terminadas em vogal curta seguida de coda complexa ((C)VCC), também receberão o acento na última sílaba, como no caso dos verbos coLLAPSE, eLECT e obSERVE e dos substantivos abSURD, CORRUPT e IMMENSE;

iii) Palavras terminadas em vogal curta seguida de apenas uma consoante receberão o acento na penúltima sílaba, como nos verbos Edit, iMAgine e reMEMber e nos adjetivos SOlid, HANDsome e meCHAnic.

Enquanto nos substantivos a última sílaba é extramétrica, no caso de verbos e adjetivos a última consoante é extramétrica, de modo que a tribuição da regra de acento ocorra do mesmo modo que nos nomes: construa um pé trocaico alinhado à borda direita da palavra. Dessa forma, o autor explica os padrões acentuais encontrados no inglês.

Vimos, portanto, na Seção 6.1.1 e na presente seção que, tanto no PB quanto no inglês, sílabas finais pesadas atraem o acento (cf. Bisol, 1992; Hayes 1980, 1982). Entretanto, enquanto no $\mathrm{PB}$ o peso equivale à rima ramificada (ex: poMAR), no inglês

${ }^{41}$ Para a atribuição do acento, vogais tensas contam como longas (cf. Angelou, 2013). 
sílabas finais com apenas uma consoante em coda não atraem o acento (ex: meCHAnic), já que o peso equivale a uma vogal longa (ex: fricaSSEE, bamBOO), o que constitui o núcleo ramificado, ou a duas consoantes em posição de coda (ex: abSURD, coRRUPT).

O Quadro 13 a seguir resume as semelhanças e diferenças entre o acento no inglês e no português que mais interessam nesta pesquisa:

Quadro 13: Diferenças e semelhanças no acento do PB e do inglês

\begin{tabular}{|c|c|}
\hline \multicolumn{2}{|c|}{ ACENTO NO PB X ACENTO NO INGLÊS } \\
\hline SEMELHANÇAS & DIFERENÇAS \\
\hline \multirow{3}{*}{$\begin{array}{c}\text { Paroxítonas } \\
\text { são desejáveis }\end{array}$} & $\begin{array}{c}\text { Português: penúltima pode ser leve, desde que a última } \\
\text { também seja leve (ex: baTAta) }\end{array}$ \\
\cline { 2 - 3 } & $\begin{array}{c}\text { Inglês: somente se a penúltima sílaba for pesada (ex: } \\
\text { phaRISma, aGENda). Em dissílabos, há uma preferência } \\
\text { pelo acento na penúltima sílaba independentemente do } \\
\text { peso da sílaba final (ex: CHAnnel) }\end{array}$ \\
\hline $\begin{array}{c}\text { Sílabas finais } \\
\text { pesadas atraem o } \\
\text { acento }\end{array}$ & $\begin{array}{c}\text { Português: peso equivale a um segmento na coda (ex: } \\
\text { caNAL, coLHER). Não há distinção entre vogal curta e } \\
\text { vogal longa. }\end{array}$ \\
\cline { 2 - 3 } & $\begin{array}{c}\text { Inglês: Especificamente em sílabas finais, peso equivale a } \\
\text { uma vogal longa ou a coda ramificada (ex: bamBOO, } \\
a b S U R D) \text { Sílabas finais com apenas uma consoante na } \\
\text { coda não atraem o acento (ex: FInal, meCHAnic) }\end{array}$ \\
\hline
\end{tabular}

\subsubsection{Sílaba e Acento do inglês por falantes brasileiros}

A partir da descrição da estrutura silábica das duas línguas nas seções 6.1.1 e 6.1.2, pôde-se observar que o inglês, que permite a ocorrência de até 7 segmentos em cerca de 18 combinações de vogais e consoantes em uma mesma sílaba, apresenta estruturas muito mais complexas do que as do português, que permite até 5 segmentos em 13 possíveis combinações. Essa diferença faz com que aprendizes brasileiros de inglês como língua estrangeira adaptem estruturas não existentes na língua materna, como na palavra breakfast. Como o PB não permite a sequência /s/ e /t/ em coda, o aprendiz tende a desfazer essa estrutura inexistente e aplicar um processo que repare a sequência para uma estrutura no português, neste caso, a epêntese, que leva à 
ressilabificação. A partir dessa ressilabificação, o acento tende a recair sobre a penúltima sílaba, pois é o acento não-marcado na língua, ou o mais usual, conforme (31):

(31) BREAK.fast $\rightarrow$ brea.ki.FAS.ti (café da manhã)

Além dos casos de epêntese, observam-se, também, casos de supergeneralização das regularidades que ocorrem no input da L2. Devido à supergeneralização da regra de acento na penúltima sílaba em substantivos no inglês, por exemplo, muitos aprendizes brasileiros acentuam a penúltima sílaba de palavras como hotel, ao invés da última, ainda que o padrão acentual para essa palavra em português seja exatamente o mesmo em inglês (Zimmer, Silveira e Alves, 2009).

Poucos são os estudos sobre a aquisição do acento primário do inglês por falantes brasileiros. Dentre eles, destacamos a pesquisa de Post (2010), que investigou a aquisição do acento tanto em palavras sufixadas quanto em palavras não-sufixadas do inglês, assim como a investigação proposta na presente pesquisa. ${ }^{42}$ À luz da Teoria da Otimidade, a autora investigou as estratégias de reparo aplicadas por falantes brasileiros ao padrão de acento primário do Inglês durante o processo de aquisição da L2. Foram utilizados os dados de 16 informantes, acadêmicos de Letras, que realizaram a leitura de 135 palavras (entre sufixadas e não sufixadas) e 135 frases-veículo. No grupo de palavras não-sufixadas foram incluídos substantivos (ex: Iron), advérbios (ex: beLOW) e verbos (ex: deTEST), totalizando 27 palavras, todas compostas de duas ou três sílabas e terminadas em sílaba fechada CVC ou CVCC. Os substantivos deste grupo apresentam padrão oxítono (ex: deSSERT), paroxítono (ex: NAture) ou proparoxítono (ex: LAbyrinth). Os verbos, por sua vez, apresentam acento na última (ex: proCLAIM) ou na penúltima sílaba (ex: NURture). 0 único advérbio incluído no experimento foi below, o qual apresenta o padrão oxítono. Dentre as palavras sufixadas, foram incluídas palavras terminadas em vogal longa com sufixos que atraem o acento para a última sílaba (palavras terminadas em -oon, -eer, -ee, -ette, -esque, -ese, -ique, -et, - aire, -euse e -eur). A pesquisa investigou, ainda, palavras em que o sufixo não atrai e nem modifica o acento da palavra primitiva (ex: CAREless), palavras em que o sufixo modifica o acento da palavra primitiva (ex: curiOsity) e verbos e substantivos diferenciados pelo acento (ex:

\footnotetext{
42 Trabalhos como Stander (2007) e Garcia (2012) também investigaram a aquisição do acento do inglês por falantes brasileiros à luz da Teoria da Otimidade, mas, diferentemente de Post (2010), se dedicaram exclusivamente à aquisição do acento em palavras sufixadas.
} 
REcord vs. reCORD). Os dados foram verificados perceptualmente pela própria pesquisadora e por mais dois avaliadores.

Seus resultados apontaram que o padrão paroxítono foi empregado em 48,2\% dos casos de erro no padrão acentual do Inglês, tanto em palavras sufixadas quanto não sufixadas, seguido do padrão proparoxítono, que foi empregado em 24,3\% dos casos e, por último, do padrão oxítono, que foi aplicado como estratégia de reparo em $21,4 \%$ dos casos. Sendo o padrão paroxítono o predominante na língua portuguesa (cf. Cintra, 1997), a preferência desse padrão como estratégia de reparo pode, segundo a autora, ser um indicativo da influência do padrão acentual da L1 sobre a L2. A autora constatou, também, que as palavras que apresentaram o menor percentual de acertos foram aquelas em que os sufixos atraem o acento primário para a última sílaba (ex: employEE, anTIQUE), com 50\% de acertos. Nessas palavras, predominou o padrão acentual paroxítono como estratégia de reparo tanto nos casos em que houve inserção de epêntese (ex: antique: /æn.'ti:k/ $\rightarrow$ [æn.'tı.kI]) quanto nos casos em que não houve (ex: /æn.'ti:k/ $\rightarrow$ ['æn.tık]).

Portanto, assim como o estudo de Post (2010), o objetivo do presente estudo é investigar a influência do padrão acentual do PB sobre a aquisição do acento do inglês como L2. Porém, não só investigarmos a aquisição do acento em palavras existentes na língua inglesa, mas também analisamos a atribuição do acento em logatomas, isto é, palavras inventadas que obedecem o padrão de palavras existentes no inglês. Além disso, nosso trabalho se propõe a investigar o percurso de aquisição do acento do inglês pelos falantes brasileiros através da análise dos dados de informantes nos níveis básico, intermediário e avançado e a analisar os dados tanto perceptualmente quanto acusticamente, o que não foi realizado nem no trabalho de Post (2010) e nem nos outros dois trabalhos mencionados em nota (Stander, 2007; Garcia, 2012).

\subsection{Metodologia}

Esta seção a apresenta os procedimentos metodológicos utilizados para investigar a relação entre sílaba e acento no inglês por falantes do PB. Os critérios para a seleção dos 37 informantes e os procedimentos de coleta são os mesmos descritos em 4.2.1 e 4.2.3, e o registro dos dados referentes aos três fenômenos investigados se deu através de uma única gravação com o mesmo grupo de informantes. A presente seção 
apresenta o desenho do experimento para a coleta dos dados referentes à sílaba e acento em 6.2.1, os procedimentos para as verificações perceptual e acústica em 6.2.2 e os critérios para a classificação dos dados e verificação estatística em 6.2.3.

\subsubsection{Desenho do Experimento}

Para verificar se os falantes se baseiam na noção de peso silábico do PB (rima ramificada) ou do inglês (núcleo ramificado), desenvolvemos um experimento contendo 124 palavras divididas em duas categorias: 60 palavras com posição de coda complexa preenchida pelas plosivas [p, t, $\mathrm{k}, \mathrm{d}$ ] na sílaba final e 64 palavras com núcleo ramificado (vogal longa ou ditongo) na sílaba final.

0 primeiro grupo de palavras foi incluído porque, principalmente nos níveis iniciais, poderia haver uma ressilabificação por meio de epêntese devido ao fato de as consoantes plosivas $[\mathrm{p}, \mathrm{t}, \mathrm{k}, \mathrm{d}]$ não ocorrerem em posição de coda silábica no PB. Consequentemente, o acento da palavra poderia ser alterado (ex: carrot - ['kæ.rət] $\rightarrow$ [kæ.'ro.t]i). Do total de 60 palavras neste grupo, 30 são palavras existentes na língua inglesa (ex: hornet, market, lizard) e 30 são logatomas terminados em rima complexa terminadas em $[\mathrm{p}, \mathrm{t}, \mathrm{k}]$ com características de palavras existentes na língua inglesa (ex: peTAnip, semelhante a meCHAnic). 0 objetivo com essas palavras era verificar se, ao deparar-se com uma palavra desconhecida e supostamente pertencente à língua inglesa, o aprendiz aplicaria a regra de acento do inglês ou do PB.

O mesmo critério foi utilizado para a seleção das 64 palavras com núcleo ramificado na sílaba final: 30 são palavras oxítonas existentes na língua inglesa (ex: thirTEEN) e 34 são logatomas com o mesmo padrão de escrita e, assim, com o mesmo padrão acentual esperado (ex: tanLEEN). Todas as palavras neste grupo possuem sílaba final com núcleo ramificado, isto é, vogal longa (ex: thirTEEN). Nesses casos, é possível que os participantes produzam uma vogal curta em vez de uma vogal longa na sílaba final e, consequentemente, alterem o acento da palavra (ex: thirTEEN $\rightarrow$ THIRteen).

A coleta para avaliar a relação entre sílaba e acento em inglês foi realizada a partir da leitura dessas palavras isoladamente, apresentadas de maneira aleatória no mesmo arquivo de PowerPoint que apresentava as palavras e frases apresentadas nos Capítulos 4 e 5, de modo que os informantes não percebessem quais fenômenos estavam 
sendo analisados. O Quadro 14 a seguir apresenta as palavras reais e inventadas utilizadas no experimento para verificar a relação entre sílaba e acento.

Quadro 14: Palavras para avaliação da relação entre sílaba e acento

\begin{tabular}{|c|c|c|c|}
\hline \multicolumn{2}{|c|}{$\begin{array}{l}\text { Sílaba final com rima ramificada } \\
\text { (Paroxítonas/Proparoxítonas) }\end{array}$} & \multicolumn{2}{|c|}{$\begin{array}{l}\text { Sílaba final com núcleo ramificado } \\
\text { (Oxítonas) }\end{array}$} \\
\hline REAIS & LOGATOMAS & REAIS & LOGATOMAS \\
\hline 1. standard & Terminadas em [p]: & 1. police & 1. poleen \\
\hline 2. ábsent & 1. sánkep & 2. thirteen & 2. tolee \\
\hline 3. húsband & 2. láttap & 3. fourteen & 3. tasparoo \\
\hline 4. bréakfast & 3. táplop & 4. fifteen & 4. tabaar \\
\hline 5. márket & 4. crástip & 5. regime & 5. tanleen \\
\hline 6. cárrot & 5. petánip & 6. kangaroo & 6. tascreet \\
\hline 7. frólic & 6. selántip & 7. Tennessee & 7. ponessee \\
\hline 8. túrnip & 7. lochánip & 8. bazaar & 8. dagree \\
\hline 9. rábbit & 8. tánlip & 9. bamboo & 9. tanloo \\
\hline 10. hórnet & & 10. degree & 10. ponteen \\
\hline 11. gárment & Terminadas em [t]: & 11. magazine & 11. caspelee \\
\hline 12. lócust & 9. blárket & 12. referee & 12. pantoo \\
\hline 13. mállard & 10. púllent & 13. employee & 13. landee \\
\hline 14. múskrat & $\begin{array}{l}\text { 11. appit } \\
\text { 12 lúrrent }\end{array}$ & 14. discrete & 14. porelee \\
\hline 15. wómbat & 12. lúrrent & 15. trainee & 15. pontalese \\
\hline 16. básement & 13. bornet & 16. career & 16. calonese \\
\hline 17. blánket & 14. carrit & 17. complete & 17. pebree \\
\hline 18. párrot & 15. ánicot & 18. concrete & 18. pentanese \\
\hline 19. áttic & Terminadas em [d] & 19. extreme & 19. colonee \\
\hline 20. cúrrant & 16. cústand & 20. engineer & 20. toneen \\
\hline 21. accóuntant & 17. tráppid & 21. saloon & 21. releen \\
\hline 22. lízard & 18. plíttod & 22. Japanese & 22. landoo \\
\hline 23. lóquat & 19. dráspid & 23. Portuguese & 23. porsee \\
\hline 24. áwkward & 20. plántid & 24. Chinese & 24. colenteen \\
\hline 25. bónnet & 21. dúllpod & 25. cocoon & 25. deleen \\
\hline 26. págeant & 22. lámard & 26. volunteer & 26. paneer \\
\hline 27. ápricot & 23. cállpid & 27. pioneer & 27. tenneree \\
\hline 28. lóllipop & & 28. baloon & 28. apriteen \\
\hline 29. póniard & Terminadas em [k]: & 29. lagoon & 29. galeen \\
\hline 30. coconut & 24. nárpek & 30. supreme & 30. sadoon \\
\hline & $\begin{array}{l}\text { 25. alosmic } \\
\text { 26. brántec }\end{array}$ & & 31. paneep \\
\hline & 20. Drantec & & 32. lanese \\
\hline & 2\%.pabloc & & 33. poloose \\
\hline & 28. pebbuck & & 34. soloop \\
\hline & $\begin{array}{l}\text { 29. triálic } \\
\text { 30. tárpec }\end{array}$ & & \\
\hline
\end{tabular}


Os procedimentos para a classificação dos dados referentes a sílaba e acento foram os mesmos aplicados nos dados de retração de acento (cf. Seção 5.2.2): primeiramente, o acento de cada palavra foi verificado perceptualmente pela pesquisadora e por outra avaliadora, também brasileira, e nos casos de discordância as palavras eram ouvidas novamente até que se chegasse a um consenso. Após essa etapa, as palavras e sílabas foram segmentadas seguindo os mesmos critérios descritos em 5.2.2 e a duração de cada sílaba foi obtida automaticamente através do script no Praat mencionado na mesma seção.

\subsubsection{Classificação dos dados e Metodologia Estatística}

A Seção 6.2.3.1 a seguir apresenta as variáveis estabelecidas para a investigação dos dados classificados através de julgamento perceptual e o tipo de verificação estatística empregada na análise desses dados. Na Seção 6.2.3.2, é apresentada a metodologia estatística empregada na análise dos correlatos acústicos.

\subsubsection{Verificação perceptual}

A variável dependente, neste caso, é o acerto, o qual está diretamente relacionado a duas variáveis independentes: Padrão Acentual Esperado e Padrão Acentual Empregado. No caso da palavra magazine, por exemplo, como o padrão esperado é o oxítono (magaZINE), considerou-se um "acerto" quando o informante aplicou o padrão oxítono e um "erro" quando o informante aplicou o padrão paroxítono (maGAzine) ou o padrão proparoxítono (MAgazine). A combinação dessas variáveis tem como objetivo proporcionar a proporção de acertos e de erros de acordo com cada grupo de informante.

O Quadro 15 a seguir apresenta os fatores da variável dependente e, também, das variáveis independentes linguísticas que foram estabelecidas para a análise da relação entre sílaba e acento. 


\section{Quadro 15: Variáveis Controladas - Sílaba e Acento}

\begin{tabular}{|c|c|c|}
\hline $\begin{array}{c}\text { VARIÁVEL } \\
\text { DEPENDENTE }\end{array}$ & Acerto & $\begin{array}{l}\text { Acerto } \\
\text { Erro }\end{array}$ \\
\hline \multirow{10}{*}{$\begin{array}{c}\text { VARIÁVEIS } \\
\text { INDEPENDENTES }\end{array}$} & $\begin{array}{l}\text { Padrão acentual } \\
\text { empregado }\end{array}$ & $\begin{array}{l}\text { Oxítono } \\
\text { Paroxítono } \\
\text { Proparoxítono }\end{array}$ \\
\hline & $\begin{array}{c}\text { Padrão acentual } \\
\text { esperado }\end{array}$ & $\begin{array}{l}\text { Oxítono } \\
\text { Paroxítono } \\
\text { Proparoxítono }\end{array}$ \\
\hline & Tipo de Palavra & $\begin{array}{l}\text { Real } \\
\text { Logatoma }\end{array}$ \\
\hline & Epêntese & $\begin{array}{l}\text { Com epêntese } \\
\text { Sem epêntese }\end{array}$ \\
\hline & $\begin{array}{l}\text { Segmento na } \\
\text { Sílaba Final }\end{array}$ & $\begin{array}{l}\text { Vogal Longa } \\
\text { Vogal Longa }+[\mathrm{n}] \\
\text { Vogal Longa }+[\mathrm{p}] \text { ou }[\mathrm{t}] \\
\text { Vogal Longa }+[\mathrm{r}] \\
\text { Vogal Longa }+[\mathrm{s}] \\
{[\mathrm{d}]^{43}} \\
{[\mathrm{k}]} \\
{[\mathrm{p}]} \\
{[\mathrm{t}]}\end{array}$ \\
\hline & \multirow{2}{*}{$\begin{array}{c}\text { Padrão da Sílaba } \\
\text { Final }\end{array}$} & Núcleo Ramificado \\
\hline & & Núcleo Simples \\
\hline & $\begin{array}{c}\text { Nível de } \\
\text { Proficiência }\end{array}$ & $\begin{array}{l}\text { Básico } \\
\text { Intermediário } \\
\text { Avançado } \\
\text { Falante Nativo } \\
\end{array}$ \\
\hline & $\begin{array}{c}\text { Início da } \\
\text { Aquisição da L2 }\end{array}$ & $\begin{array}{l}\text { Antes dos } 12 \text { anos } \\
\text { Depois dos } 12 \text { anos }\end{array}$ \\
\hline & Informante & $\begin{array}{l}1 \\
2 \\
\cdots \\
30\end{array}$ \\
\hline
\end{tabular}

Como vimos, a variável Padrão Acentual Esperado possibilita a comparação entre o padrão acentual empregado pelos informantes e o padrão acentual que seria esperado

\footnotetext{
${ }^{43}$ Com vogais curtas.
} 
para cada palavra, caracterizando um "acerto" ou um "erro". Os fatores para esta variável são Oxítono, Paroxítono e Proparoxítono. No grupo de oxítonas foram incluídas palavras com núcleo ramificado na sílaba final (ex: thirTEEN, magaZINE, bamBOO). Como vimos em 6.2.1, é possível que os participantes produzam vogais curtas em vez de longas na sílaba final e, consequentemente, alterem o acento da palavra (ex: employEE $\rightarrow$ emPLOYee). No grupo de palavras com padrão paroxítono (ex: MARket, CArrot) e proparoxítono (ex: COconut, LOllipop), por sua vez, foram incluídas palavras terminadas em núcleo simples com as plosivas $[\mathrm{p}, \mathrm{t}, \mathrm{k}]$ em posição de coda. Nesses casos, os informantes poderiam aplicar a epêntese na última sílaba, o que leva à ressilabificação à modificação da posição do acento da palavra (ex: LO.lli.pop $\rightarrow$ lo.lli.PO.pi), sobretudo nos níveis básico e intermediário.

A variável Tipo de Palavra tem como objetivo verificar a atribuição do acento em palavras reais (ex: fourTEEN, LOllipop) e em logatomas (ex: tanLEEN, CRAStip), de modo a verificar se os informantes aplicariam a mesma regra de acento ao se depararem com palavras conhecidas e com palavras desconhecidas, mas supostamente pertencentes à língua inglesa. Essa variável permite que se minimize o fato de a acentuação decorrer de palavras muito utilizadas em português (ex: trainee) ou palavras muito parecidas (ex: bamboo).

Com a variável Epêntese espera-se observar se a proporção de acertos seria influenciada pelos nos casos de inserção de vogal epentética (ex: aw.kward $\rightarrow$ aw.kwar.[d]]i].

A variável Segmento na Sílaba Final foi incluída para verificar a influência do padrão da sílaba final sobre a atribuição do acento. Nos casos de palavra cujo padrão acentuado esperado era oxítono, os fatores foram: vogal longa (ex: bamBOO), vogal longa seguida de [n] (ex: thirTEEN), vogal longa seguida de [p] (ex: soloop), vogal longa seguida de [r] (ex: engiNEER), vogal longa seguida de [s] (ex: japaNESE) e vogal longa seguida de [t] (ex: conCRETE). Já nos casos de palavra cujo padrão acentual esperado era paroxítono ou proparoxítono, os fatores foram: [d] (ex: LIzard), [k] (ex: Attic), [p] (ex: LOllipop) e [t] (ex: BREAKfast) - que ocorrem com vogais curtas.

Por fim, a variável Padrão da Sílaba Final foi incluída com o objetivo de verificar a proporção de acertos de acordo com o padrão silábico da última sílaba. Os fatores desta variável são Núcleo Ramificado, cujo padrão acentual esperado é o oxítono (ex: 
thirTEEN) e Núcleo Simples, cujo padrão acentual esperado é o paroxítono (ex: RAbbit) ou o proparoxítono (ex: LOllipop).

Além dessas variáveis linguísticas, foram controladas as variáveis sociais Nível de Proficiência, Idade e Informante.

Assim como na análise da assimilação de vozeamento (Cap. 4) e da retração de acento (Cap. 5), a verificação estatística dos dados de sílaba e acento classificados através de julgamento perceptual foi realizada através do programa GoldVarb-X, descrito na Seção 4.2.5. A variável dependente na análise da relação entre sílaba e acento tem caráter binário (acerto/erro) e, portanto, também é condizente com o tipo de teste estatístico oferecido pelo programa.

\subsubsection{Correlatos acústicos}

Para a análise dos correlatos acústicos nas palavras cujo objetivo era verificar a atribuição do acento no inglês foi utilizado o teste não paramétrico de Wilcoxon, utilizado na estatística para a comparação entre dois grupos - neste caso, as médias dos grupos de nativos e de não nativos. 0 teste Kruskal-Wallis, utilizado na estatística para a comparação entre três ou mais grupos, foi utilizado para a comparação das médias de duração nos três níveis de proficiência analisados (básico, intermediário e avançado). Ambos os testes foram realizados através da PROC WILCOXON do software SAS. As análises foram realizadas no software estatístico SAS 9.4 e foi fixado o nível de significância $\alpha=0,05$ para todas as análises.

\subsection{Resultados}

Nesta seção serão apresentados os resultados referentes à relação entre sílaba $e$ acento. Foram obtidos 4.551 dados $^{44}$ referentes a esse estudo, incluindo o grupo de controle. Os resultados referentes à verificação perceptual são apresentados na Seção 6.3.1 a seguir e, na Seção 6.3.2, são apresentados os resultados referentes aos correlatos acústicos empregados pelos informantes.

\subsubsection{Verificação Perceptual}

44 Este valor total já exclui 37 casos em que os informantes não conseguiram produzir as palavras do experimento, sobretudo no nível básico (ex: awkward). 
Esta seção apresenta os resultados obtidos através de julgamento perceptual, seguindo os critérios metodológicos descritos em 6.2. Na Seção 6.3.1.1 são apresentados os resultados referentes aos falantes nativos e, em 6.3.1.2 os resultados referentes aos falantes de inglês como L2.

\subsubsection{Falantes Nativos}

A proporção de acertos pelos sete falantes nativos que constituem a amostra de controle nesta pesquisa pode ser observada no Gráfico 26 a seguir, que inclui os casos de palavras reais e de logatomas nos três padrões acentuais esperados (oxítono, paroxítono e proparoxítono).

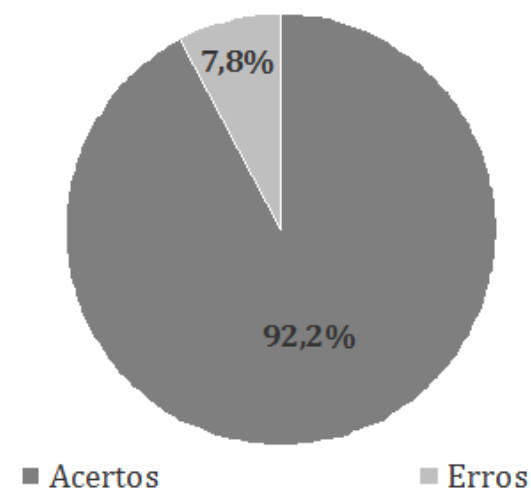

Gráfico 26: Proporção de acertos do acento por falante nativos

Pode-se observar que os falantes nativos aplicaram o padrão acentual esperado (acerto) em 92,2\% dos casos (800/868) e um padrão acentual diferente do esperado (erro) em apenas 7,8\% dos casos (68/868). A análise estatística apontou que a única variável significativa para a atribuição do acento foi Padrão Acentual Esperado. As variáveis Padrão da Sílaba Final, Tipo de Palavra e Segmento na Sílaba Final não foram, portanto, consideradas estatisticamente relevantes para a aplicação do acento pelos falantes nativos. ${ }^{45}$

A Tabela 43 a seguir apresenta os resultados referentes à variável Padrão Acentual Esperado, a única considerada relevante pelo programa estatístico. A porcentagem de acertos foi alta nos três padrões analisados: houve 94,5\% de acertos

45 A variável Epêntese não foi incluída nesta rodada estatística porque, conforme o esperado, não foi registrado nenhum caso de epêntese nos dados dos nativos. 
quando o padrão esperado era o proparoxítono (ex: LOllipop), 91,4\% de acertos quando o padrão esperado era o paroxítono (ex: CArrot) e 92,6\% de acertos quando o padrão esperado era o oxítono (ex: $b a Z A A R$ ). Os pesos relativos indicam que os padrões proparoxítono e paroxítono favoreceram o acerto, enquanto o padrão oxítono desfavoreceu.

Tabela 43: Acertos por Padrão Acentual Esperado - Nativos

\begin{tabular}{cccccc}
\hline \multirow{2}{*}{$\begin{array}{c}\text { Padrão Acentual } \\
\text { Esperado }\end{array}$} & \multicolumn{4}{c}{ Sim } & \multicolumn{2}{c}{ Não } & PESO \\
\cline { 2 - 5 } & $\mathbf{N}$ & $\mathbf{\%}$ & $\mathbf{n}$ & $\mathbf{\%}$ & REL. \\
\hline Proparoxítona & $33 / 35$ & $94,3 \%$ & $2 / 35$ & $5,7 \%$ & 0,99 \\
Paroxítona & $352 / 385$ & $91,4 \%$ & $33 / 385$ & $8,6 \%$ & 0,68 \\
Oxítona & $415 / 448$ & $92,6 \%$ & $33 / 448$ & $7,4 \%$ & 0,26
\end{tabular}

A variável Tipo de Palavra, que observa a proporção de acertos em palavras existentes na língua inglesa (ex: market, fourteen, engineer) e em palavras inventadas (ex: soloop, calonese, apriteen) indicou que houve mais acertos nos casos de palavras reais. Os falantes nativos aplicaram o padrão acentual esperado em 94,4\% dos casos de palavras reais e em $90,1 \%$ dos casos de logatomas, conforme a Tabela 44 a seguir.

Tabela 44: Acertos por Tipo de Palavra - Nativos

\begin{tabular}{|c|c|c|c|c|}
\hline \multirow{3}{*}{ Tipo de Palavra } & \multicolumn{4}{|c|}{ Acerto } \\
\hline & \multicolumn{2}{|c|}{ Sim } & \multicolumn{2}{|c|}{ Não } \\
\hline & $\mathbf{N}$ & $\%$ & $\mathbf{n}$ & $\%$ \\
\hline Real & $390 / 413$ & $94,4 \%$ & $23 / 413$ & $5,6 \%$ \\
\hline Logatoma & $410 / 455$ & $90,1 \%$ & $45 / 455$ & $9,9 \%$ \\
\hline
\end{tabular}

A Tabela 45 mostra a proporção de acertos por padrão acentual esperado em logatomas e palavras reais. Percebe-se que, nos três padrões acentuais, a taxa de acertos foi maior em palavras reais do que em logatomas. Pode-se observar que a maior taxa de acertos foi em palavras reais proparoxítonas (ex: Apricot) e a menor em logatomas cujo padrão acentual esperado também era o proparoxítono (ex: Anicot). No caso de palavras cujo padrão acentual esperado era o oxítono, a taxa de acertos em palavras reais (ex: thirTEEN) foi de 95\% e em logatomas (ex: tanLEEN) de 91\%. Em paroxítonas, a taxa de acertos em palavras reais (ex: MARket) foi de 94\% e em logatomas (ex: TURnip) de 90\%. 
Tabela 45: Acertos por Padrão Acentual Esperado e Tipo de Palavra - Nativos

\begin{tabular}{ccccc}
\cline { 2 - 5 } Padrão & \multicolumn{3}{c}{ Tipo de Palavra } \\
\cline { 2 - 5 } Acentual & \multicolumn{2}{c}{ Real } & \multicolumn{3}{c}{ Logatoma } \\
\cline { 2 - 5 } Esperado & n/Total & $\%$ & n/Total & $\%$ \\
\hline Oxítono & $199 / 210$ & $95 \%$ & $216 / 238$ & $91 \%$ \\
Paroxítono & $164 / 175$ & $94 \%$ & $188 / 210$ & $90 \%$ \\
Proparoxítono & $27 / 28$ & $96 \%$ & $6 / 7$ & $86 \%$
\end{tabular}

A taxa de acertos pelo padrão da sílaba final é apresentada na Tabela 44 a seguir. Percebe-se que a taxa de acertos foi um pouco mais alta em palavras terminadas em sílaba com núcleo ramificado, cujo padrão acentual esperado era o oxítono (ex: bamBOO), do que em palavras terminadas em sílaba com núcleo simples, cujo padrão acentual esperado era o paroxítono (ex: MARket) ou o proparoxítono (ex: LOllipop), conforme a Tabela 46 a seguir.

Tabela 46: Acertos por Padrão da Sílaba Final - Nativos

\begin{tabular}{ccccc}
\hline \multirow{2}{*}{$\begin{array}{c}\text { Padrão da Sílaba } \\
\text { Final }\end{array}$} & \multicolumn{3}{c}{ Sim } & \multicolumn{2}{c}{ Não } \\
\cline { 2 - 5 } & n/total & $\%$ & n/total & $\%$ \\
\hline Núcleo Ramificado & $415 / 448$ & $92,6 \%$ & $33 / 448$ & $7,4 \%$ \\
Núcleo Simples & $385 / 420$ & $91,7 \%$ & $35 / 420$ & $8,3 \%$
\end{tabular}

A taxa de acertos por padrão da sílaba final e tipo de palavra é apresentada na Tabela 47 a seguir. Observa-se que palavras reais terminadas em sílaba com núcleo simples (ex: MARket, CArrot) apresentaram a taxa de acertos mais alta e logatomas terminados em núcleo ramificado (ex: $\operatorname{ta} B A A R$, lanDOO) apresentaram a taxa de acertos mais baixa.

Tabela 47: Acertos por Padrão da Sílaba Final e Tipo de Palavra - Nativos

\begin{tabular}{ccccc}
\cline { 2 - 5 } Padrão da Sílaba & \multicolumn{3}{c}{ Tipo de Palavra } \\
\cline { 2 - 5 } Final & \multicolumn{2}{c}{ Real } & Logatoma \\
\cline { 2 - 5 } & n/Total & $\%$ & n/Total & $\%$ \\
\hline Núcleo Ramificado & $191 / 203$ & $94 \%$ & $194 / 217$ & $89 \%$ \\
Núcleo Simples & $199 / 210$ & $95 \%$ & $216 / 238$ & $91 \%$
\end{tabular}


A Tabela 48 a seguir mostra os resultados referentes à variável Segmento da Sílaba Final. Observa-se que houve 99\% de acertos nas palavras terminadas em [d], como as palavras reais standard e lizard e os logatomas plittod e draspid, cujo padrão esperado era o paroxítono. Palavras terminadas em vogal longa seguida de [p] ou [t], como os logatomas paneep e tascreet, e vogal longa seguida de [s] (ex: japanese, chinese) também apresentaram uma alta taxa de acertos, de 95,2\%. Palavras terminadas em vogal longa seguida de nasal (ex: thirteen) e em [k] (ex: frolic) apresentaram a terceira maior taxa de acertos, de 93,9\%. As palavras terminadas em vogal longa seguida de [r] (ex: paneer), cujo padrão acentual esperado era o oxítono, e em [t] (ex: market), cujo padrão esperado era o paroxítono, apresentaram taxas aproximadas, de 91,8\% 390,5\%, respectivamente. As menores taxas de acertos ocorreram em palavras terminadas em vogal longa (ex: trainee) e palavras terminadas em [p] (ex: lollipop), com 89,8\% e 83,1\%, respectivamente.

Tabela 48: Acertos por Segmento na Sílaba Final - Nativos

\begin{tabular}{ccccc}
\hline \multirow{2}{*}{$\begin{array}{c}\text { Segmento da Sílaba } \\
\text { Final }\end{array}$} & \multicolumn{3}{c}{ Sim } & \multicolumn{3}{c}{ Não } \\
\cline { 2 - 5 } & $\mathrm{n} /$ total & $\%$ & $\mathrm{n} /$ total & $\%$ \\
\hline$[\mathrm{d}]$ & 104 & $99 \%$ & 1 & $1 \%$ \\
Vogal Longa $+[\mathrm{p}]$ ou $[\mathrm{t}]$ & 40 & $95,2 \%$ & 2 & $4,8 \%$ \\
Vogal Longa $+[\mathrm{s}]$ & 60 & $95,2 \%$ & 3 & $4,8 \%$ \\
Vogal Longa $+[\mathrm{n}]$ & 138 & $93,9 \%$ & 9 & $6,1 \%$ \\
{$[\mathrm{k}]$} & 46 & $93,9 \%$ & 3 & $6,1 \%$ \\
Vogal Longa $+[\mathrm{r}]$ & 45 & $91,8 \%$ & 4 & $8,2 \%$ \\
{$[\mathrm{t}]$} & 171 & $90,5 \%$ & 18 & $18 \%$ \\
Vogal Longa & 132 & $89,8 \%$ & 15 & $10,2 \%$ \\
{$[\mathrm{p}]$} & 64 & $83,1 \%$ & 13 & $16,9 \%$
\end{tabular}

Para verificar a proporção de acertos por segmento final em logatomas e em palavras reais realizou-se o cruzamento entre as variáveis Segmento da Sílaba Final e Tipo de Palavra. Pode-se observar que palavras reais terminadas em [d], [k], vogal longa seguida de [r] e vogal longa seguida de [s] (ex: husband, frolic, career, police) apresentaram 100\% de acertos, enquanto logatomas terminados nesses mesmos segmentos apresentaram taxas de 98\%, 91\%, 71\% e 91\%, respectivamente (ex: draspid, narpek, paneer, poloose). Nos demais casos, observa-se que a proporção de acertos foi mais alta em palavras reais do que em logatomas, exceto em palavras terminadas em 
vogal longa seguida de [n], que apresentram mais acertos em logatomas (ex: tanleen), conforme a Tabela 49 a seguir.

Tabela 49: Acertos por Segmento na Sílaba Final e Tipo de Palavra - Nativos

\begin{tabular}{ccccc}
\hline \multirow{2}{*}{$\begin{array}{c}\text { Segmento na Sílaba } \\
\text { Final }\end{array}$} & \multicolumn{4}{c}{ Tipo de Palavra } \\
\cline { 2 - 5 } & $\mathbf{n}$ & $\mathbf{\%}$ & $\mathbf{N}$ & $\mathbf{\%}$ \\
\cline { 2 - 5 }$[\mathrm{d}]$ & $35 / 35$ & $100 \%$ & $69 / 70$ & $98 \%$ \\
{$[\mathrm{k}]$} & $14 / 14$ & $100 \%$ & $32 / 35$ & $91 \%$ \\
Vogal Longa $+[\mathrm{r}]$ & $35 / 35$ & $100 \%$ & $10 / 14$ & $71 \%$ \\
Vogal Longa $+[\mathrm{s}]$ & $28 / 28$ & $100 \%$ & $32 / 35$ & $91 \%$ \\
Vogal Longa & $47 / 49$ & $96 \%$ & $85 / 98$ & $87 \%$ \\
Vogal Longa $+[p]$ ou $[t]$ & $20 / 21$ & $95 \%$ & $20 / 21$ & $95 \%$ \\
{$[t]$} & $130 / 140$ & $93 \%$ & $41 / 49$ & $84 \%$ \\
{$[p]$} & $13 / 14$ & $93 \%$ & $51 / 63$ & $81 \%$ \\
Vogal Longa $+[\mathrm{n}]$ & $69 / 77$ & $90 \%$ & $69 / 70$ & $99 \%$
\end{tabular}

Vejamos a proporção de acertos por informante. Pode-se observar na Tabela 50 a seguir que o Falante Nativo 6 foi o que apresentou a maior proporção de acertos, de 97,6\%, seguido pelo Nativo 4, de 96\%. Os Nativos 1, 5 e 7 por sua vez, apresentaram taxas acima de 90\%, enquanto os Nativos 2 e 3 apresentaram taxas de $88,7 \%$ e $83,7 \%$, respectivamente.

Tabela 50: Acertos por informante - Nativos

\begin{tabular}{ccc}
\hline \multirow{2}{*}{ Informantes } & \multicolumn{2}{c}{ Acertos } \\
\cline { 2 - 3 } & $\mathbf{n}$ & $\mathbf{\%}$ \\
\hline Nativo 1 & $114 / 124$ & $91,4 \%$ \\
Nativo 2 & $110 / 124$ & $88,7 \%$ \\
Nativo 3 & $104 / 124$ & $83,9 \%$ \\
Nativo 4 & $119 / 124$ & $96 \%$ \\
Nativo 5 & $118 / 124$ & $95,2 \%$ \\
Nativo 6 & $121 / 124$ & $97,6 \%$ \\
Nativo 7 & $114 / 124$ & $91,4 \%$
\end{tabular}

A taxa de acertos por informante também pode ser visualizada no Gráfico 27 a seguir. Percebe-se que não houve uma variação expressiva na taxa de acertos pelos falantes nativos, já que todos apresentaram porcentagens entre 83\% e 97\%. 


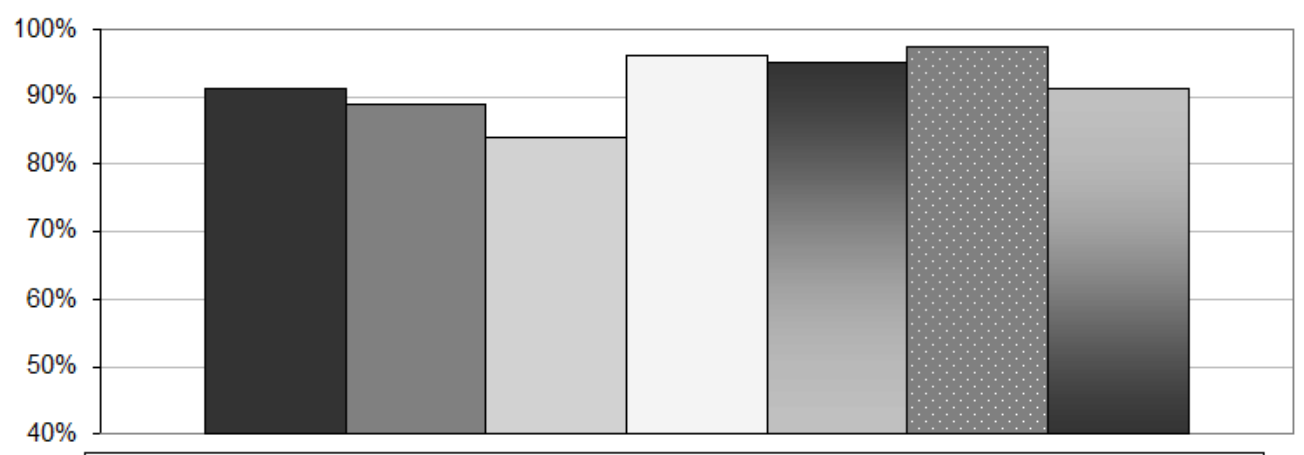

$\square$ Nativo $1 \square$ Nativo $2 \square$ Nativo $3 \square$ Nativo $4 \square$ Nativo $5 \square$ Nativo $6 \square$ Nativo 7

Gráfico 27: Acertos por informante - Nativos

0 Gráfico 28, por fim, mostra a proporção de acertos por informante e por padrão da sílaba final. Percebe-se que a maioria dos falantes nativos apresentou uma taxa de acertos maior nos casos de palavras terminadas em sílaba com núcleo ramificado (ex: bazaar, bamboo), nas quais o padrão esperado era o oxítono. Dentre todos os informantes, o Falante Nativo 6 foi o que apresentou a maior taxa de acertos, de 98\% em palavras terminadas em núcleo ramificado. Nos casos de palavras terminadas em núcleo simples, nas quais o padrão acentual esperado era o paroxítono ou proparoxítono (ex: carrot, lollipop), apenas os Nativos 3 e 4 apresentaram uma taxa de acertos um pouco maior do que em palavras oxítonas.

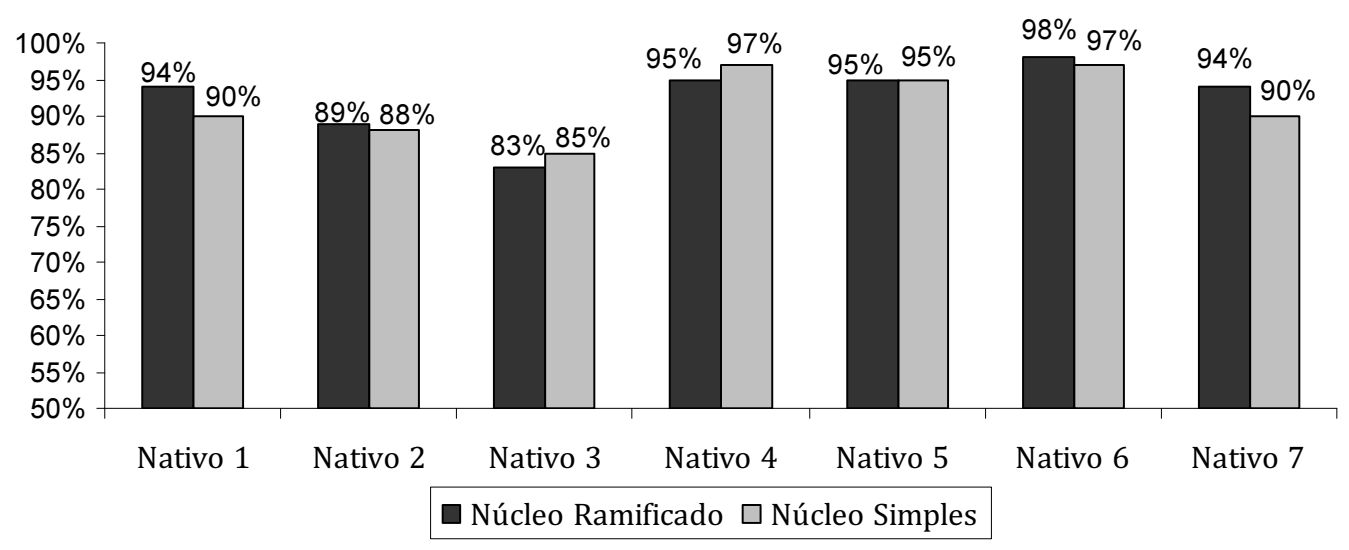

Gráfico 28: Acertos por informante e por Padrão da Sílaba Final: Falantes Nativos

Em suma, observa-se que, no que diz respeito à relação entre sílaba e acento, todos os falantes nativos apresentaram altas taxas de acerto, sobretudo em palavras reais. Percebe-se, também, que não houve uma variação significativa nas taxas por informante e que a proporção de acerto foi um pouco mais alta em palavras terminadas 
em núcleo ramificado, nas quais o padrão acentual esperado era o oxítono, do que em palavras terminadas em núcleo simples, nas quais o padrão esperado era o paroxítono ou o proparoxítono.

Devido a uma limitação do programa estatístico utilizado nesta pesquisa (cf. 6.2.3.1), no qual a codificação dos fatores é realizada através de caracteres únicos, não foi possível relizarmos uma análise por palavra, já que nosso instrumento contém 124 palavras e não há esse número de caracteres únicos no teclado do computador. Apesar de não conseguirmos obter a proporção acertos por palavra, apresentamos no Quadro 16 a seguir todas as palavras que foram produzidas com um padrão acentual diferente do esperado pelos falantes nativos. Observa-se que a grande maioria dos "erros" ocorreu em logatomas oxítonos que foram produzidos como paroxítonos. No caso de palavras reais, apenas três oxítonos foram produzidos como paroxítonos: concrete, fifteen e fourteen. Com relação a paroxítonos que foram produzidos como oxítonos, as cinco palavras reais que apresentaram erros são as menos comuns no inglês dentre todas as palavras do experimento.

Quadro 16: Palavras Produzidas com Acento Diferente do Esperado - Nativos

\begin{tabular}{|c|c|c|}
\hline \multirow{2}{*}{$\begin{array}{c}\text { Padrão Esperado } \rightarrow \\
\text { Padrão Produzido }\end{array}$} & \multicolumn{2}{|c|}{ TIPO DE PALAVRA } \\
\cline { 2 - 3 } Oxítono $\rightarrow$ Paroxítono & $\begin{array}{c}\text { Laspelee, colonee, ponessee, } \\
\text { tabaar, tanloo, tascreet, } \\
\text { tasparoo, tolee, toneen }\end{array}$ & Palavras Reais \\
\hline Oxítono $\rightarrow$ Proparoxítono fifteen, fourteen & $\begin{array}{c}\text { caspelee, colonee, pontalese, } \\
\text { porelee }\end{array}$ & \\
\hline Paroxítono $\rightarrow$ 0xítono & $\begin{array}{c}\text { bornet, carrit, lattap, } \\
\text { petanip, selantip }\end{array}$ & $\begin{array}{c}\text { loquat, mallard, muskrat, } \\
\text { wombat }\end{array}$ \\
\hline Paroxítono $\rightarrow$ Proparox. & $\begin{array}{c}\text { alosmic, lochanip, petanip, } \\
\text { selantip }\end{array}$ & \\
\hline Proparoxítono $\rightarrow$ 0xítono & anicot & \\
\hline
\end{tabular}

\subsubsection{Falantes de inglês como L2}

A proporção de acertos pelos 30 falantes de inglês como L2 pode ser observada no Gráfico 29 a seguir, que inclui os casos de palavras reais e de logatomas nos três padrões acentuais esperados (oxítono, paroxítono e proparoxítono). 


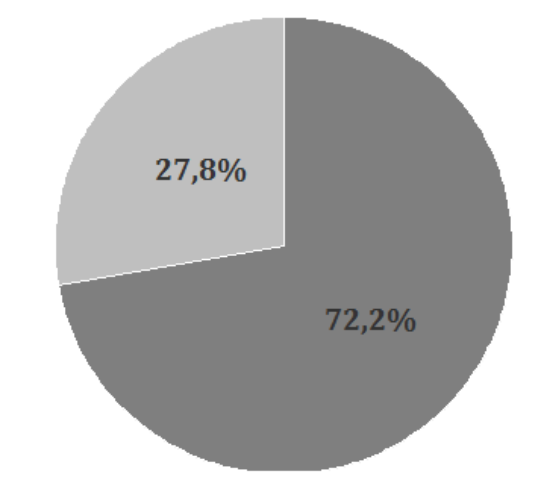

Acertos

Erros

\section{Gráfico 29: Proporção de acertos do acento por falantes de inglês como L2}

Pode-se observar que os falantes brasileiros aplicaram o padrão acentual esperado (acerto) em 72,2\% dos casos (2658/3683) e um padrão acentual diferente do esperado (erro) em 27,8\% dos casos (1025/3683). O programa estatístico selecionou cinco das sete variáveis testadas como estatisticamente significativas, nesta ordem: Segmento na Sílaba Final, Epêntese, Nível de Proficiência, Tipo de Palavra e Padrão Acentual Esperado. Dentre as variáveis testadas, Padrão da Sílaba Final e Idade não se mostraram estatisticamente significativas. Os resultados a seguir não serão necessariamente apresentados na ordem de seleção do programa.

A Tabela 51 mostra a taxa de acertos por padrão acentual esperado. Percebe-se que o acerto foi favorecido em palavras cujo acento esperado era o paroxítono, com peso relativo de 0,63 . Os informantes acertaram o acento nessas palavras em $82,9 \%$ dos casos (ex: CArrot, BREAKfast) e erraram em 17,1\% dos casos (ex: caRROT, breakFAST). Nas palavras cujo padrão acentual esperado era o oxítono, o peso relativo foi de 0,51, próximo ao ponto neutro, o que indica que o fator não teve efeito significativo sobre o acerto. Os informantes acertaram o acento nessas palavras em 62,8\% dos casos (ex: bamBOO, fourTEEN) e erraram em 37,2\% dos casos (ex: BAMboo, FOURteen). Por fim, os casos em que o padrão proparoxítono era o esperado ficaram próximos do ponto neutro, com peso relativo de 0,47. Em palavras proparoxítonas, os informantes acertaram o acento em 72,6\% dos casos (ex: LOllipop, Apricot) e erraram em 27,4\% (ex: PORtuguese, JApanese). 
Tabela51: Acertos por Padrão Acentual Esperado - Inglês como L2

\begin{tabular}{cccccc}
\hline \multirow{2}{*}{$\begin{array}{c}\text { Padrão Acentual } \\
\text { Esperado }\end{array}$} & \multicolumn{2}{c}{ Acerto } & \multicolumn{2}{c}{ Erro } & PESO \\
\cline { 2 - 5 } & n & \% & n & \% & REL. \\
\hline Paroxítono & $1364 / 1646$ & $82,9 \%$ & $282 / 1646$ & $17,1 \%$ & 0,63 \\
Oxítono & $1188 / 1891$ & $62,8 \%$ & $703 / 1891$ & $37,2 \%$ & 0,51 \\
Proparoxítono & $106 / 146$ & $72,6 \%$ & $40 / 146$ & $27,4 \%$ & 0,47
\end{tabular}

Os resultados referentes à variável Tipo de Palavra, que observa a proporção de acertos em palavras que existem em inglês (ex: market, fourteen, engineer) e em palavras inventadas (ex: soloop, calonese, apriteen), indicou que, assim como nos dados dos falantes nativos, houve mais acertos em palavras reais. Os aprendizes aplicaram o padrão acentual esperado em 77,9\% dos casos de palavras reais e em $67 \%$ dos casos de logatomas, conforme a Tabela 52 a seguir.

Tabela 52: Acertos por Tipo de Palavra: Inglês como L2

\begin{tabular}{cccccc}
\hline \multirow{2}{*}{ Tipo de Palavra } & \multicolumn{2}{c}{ Acerto } & \multicolumn{2}{c}{ Erro } & PESO \\
\cline { 2 - 5 } & $\mathbf{n}$ & $\mathbf{\%}$ & $\mathbf{n}$ & $\mathbf{\%}$ & REL. \\
\hline Real & 1369 & $77,9 \%$ & 389 & $22,1 \%$ & 0,55 \\
Logatoma & 1289 & $67 \%$ & 636 & $33 \%$ & 0,45
\end{tabular}

A Tabela 53 a seguir apresenta o cruzamento entre as variáveis Padrão Acentual Esperado e Tipo de Palavra. Percebe-se que a taxa de acertos mais alta ocorreu em palavras reais cujo padrão esperado era o paroxítono (ex: BLANket, RAbbit), de 89\%, e a mais baixa em logatomas cujo padrão acentual esperado era o oxítono (ex: caloNESE, tanLOO), de 57\%. Curiosamente, no caso de palavras cujo padrão esperado era o proparoxítono, constatou-se mais acertos em logatomas (ex: Anicot, POniard) do que em palavras reais (ex: Anicot, COconut).

Tabela 53: Proporção de Acertos por Tipo de Palavra: Inglês como L2

\begin{tabular}{ccccc}
\hline Padrão & \multicolumn{3}{c}{ Tipo de Palavra } \\
\cline { 2 - 5 } Acentual & \multicolumn{2}{c}{ Real } & \multicolumn{2}{c}{ Logatoma } \\
\cline { 2 - 5 } Esperado & n/Total & $\%$ & n/Total & $\%$ \\
\hline Oxítono & $620 / 893$ & $69 \%$ & $568 / 998$ & $57 \%$ \\
Paroxítono & $668 / 750$ & $89 \%$ & $696 / 896$ & $83 \%$ \\
Proparoxítono & $81 / 115$ & $70 \%$ & $25 / 31$ & $81 \%$
\end{tabular}


A Tabela 54 a seguir apresenta os resultados referentes à variável Segmento Final, cujo objetivo é verificar a influência do padrão silábico da última sílaba das palavras em análise sobre o emprego do acento. Os resultados mostraram que os acertos foram favorecidos em palavras terminadas nas plosivas [t] e [d], que apresentaram taxas de acertos de 87,2\% e 84,9\% e pesos relativos de 0,63 e 0,56, respectivamente, ambos casos em que o padrão esperado era o paroxítono (ex: carrot, plantid). Palavras terminadas na plosiva [k] (ex: frolic) apresentaram uma taxa de acerto aproximada aos valores para [t] e [d], de 83,8\%, mas o peso relativo de 0,54 ficou mais próximo ao ponto neutro. Palavras terminadas em vogal longa seguida de [s] (ex: police, portuguese) apresentaram taxa de acerto de $55,4 \%$ e peso relativo de 0,52 . Palavras terminadas em vogal longa seguida das obstruintes [p] ou [t] (ex: complete, soloop, tascreet), cujo padrão esperado era o oxítono, apresentaram uma alta taxa de acertos, de 74,6\%, mas o peso relativo ficou próximo do ponto neutro $(0,51)$. Palavras terminadas em vogal longa seguida de [r] apresentaram taxa de acerto de 71\% e peso relativo próximo ao ponto neutro (0,51). Esses são os casos de palavras reais como bazaar e logatomas como tabaar, cujo padrão esperado era o oxítono. Palavras terminadas em vogal longa seguida de [n] e vogal longa apresentaram taxas de acerto mais baixas, de $66 \%$ e 56,6\%, respectivamente, com padrão esperado oxítono. Esses fatores incluem palavras reais como thirteen, e employee e logatomas como releen e tolee. Palavras terminadas em [p], por fim, foram as que apresentaram o peso relativo mais baixo, de 0,30. A única palavra real terminada em [p] era lollipop, cujo padrão esperado era o proparoxítono. As outras palavras eram logatomas como crastip, turnip e sankep, cujo padrão acentual esperado era o paroxítono.

Tabela 54: Acertos por Segmento na Sílaba Final: Não Nativos

\begin{tabular}{cccccc}
\hline \multirow{2}{*}{$\begin{array}{c}\text { Segmento na Sílaba } \\
\text { Final }\end{array}$} & \multicolumn{4}{c}{ Sim } & \multicolumn{2}{c}{ Não } & PESO \\
\cline { 2 - 5 } & $\mathbf{n}$ & $\mathbf{\%}$ & $\mathbf{n}$ & $\mathbf{\%}$ & \\
\cline { 2 - 5 } & 703 & $87,2 \%$ & 103 & $12,8 \%$ & 0,63 \\
{$[t]$} & 389 & $84,9 \%$ & 69 & $15,1 \%$ & 0,56 \\
{$[d]$} & 176 & $83,8 \%$ & 34 & $16,2 \%$ & 0,54 \\
{$[k]$} & 144 & $55,4 \%$ & 116 & $44,6 \%$ & 0,52 \\
Vogal Longa $+[\mathrm{s}]$ & 127 & $74,7 \%$ & 43 & $25,3 \%$ & 0,51 \\
Vogal Longa $+[p]$ ou $[t]$ & 150 & $71,8 \%$ & 59 & $28,2 \%$ & 0,51 \\
Vogal Longa $+[r]$ & 411 & $66 \%$ & 212 & $34 \%$ & 0,43 \\
Vogal Longa $+[n]$ & 356 & $56,6 \%$ & 273 & $43,4 \%$ & 0,41 \\
Vogal Longa & 202 & $63,5 \%$ & 116 & $36,5 \%$ & 0,30 \\
{$[p]$} & & & & &
\end{tabular}


A Tabela 55 a seguir apresenta o cruzamento entre as variáveis Segmento Final e Tipo de Palavra. Pode-se observar que, em todos os casos, a proporção de acertos é maior nas palavras reais, exceto em palavras terminadas em [d], que apresentaram uma proporção de acertos um pouco maior em logatomas (ex: PLANtid) do que em palavras reais (ex: STANdard) e em palavras terminadas em vogal longa seguida de [s], que tiveram 61\% de acertos em logatomas (ex: poLOOSE) e 49\% em palavras reais (ex: poLICE, portuGUESE). Dentre todos os tipos de palavras, observa-se que palavras reais terminadas em $[\mathrm{k}]$ foram as que apresentaram a taxa de acertos mais alta. Este é o caso das palavras frolic e attic, as quais foram produzidas corretamente com o acento paroxítono em $98 \%$ dos casos.

\section{Tabela 55: Acertos por Segmento Final e Tipo de Palavra - Inglês como L2}

\begin{tabular}{ccccc}
\hline \multirow{2}{*}{$\begin{array}{c}\text { Segmento na Sílaba } \\
\text { Final }\end{array}$} & \multicolumn{3}{c}{ Tipo de Palavra } \\
\cline { 2 - 5 } & n/Total & $\%$ & n/Total & $\%$ \\
\cline { 2 - 5 }$[\mathrm{k}]$ & $59 / 60$ & $98 \%$ & $117 / 150$ & $78 \%$ \\
{$[t]$} & $522 / 596$ & $88 \%$ & $181 / 210$ & $86 \%$ \\
Vogal Longa $+[\mathrm{p}]$ ou $[t]$ & $79 / 90$ & $88 \%$ & $48 / 80$ & $60 \%$ \\
Vogal Longa $+[\mathrm{r}]$ & $133 / 159$ & $84 \%$ & $256 / 299$ & $86 \%$ \\
Vogal Longa $+[\mathrm{n}]$ & $234 / 324$ & $72 \%$ & $177 / 299$ & $59 \%$ \\
{$[p]$} & $35 / 50$ & $70 \%$ & $167 / 268$ & $62 \%$ \\
Vogal Longa & $137 / 210$ & $65 \%$ & $219 / 419$ & $52 \%$ \\
Vogal Longa $+[\mathrm{s}]$ & $59 / 120$ & $49 \%$ & $85 / 140$ & $61 \%$
\end{tabular}

Vejamos os resultados nos casos de inserção de epêntese (ex: ca.rrot $\rightarrow$ ca.rro.[tfi]]. No total, foram registrados apenas 79 casos de epêntese: 66 no nível básico, em palavras reais como accountant e complete e em logatomas como anicot e garment; 12 no nível intermediário, somente nos logatomas calonese, lanese, poloose e paneep; e apenas um caso no nível avançado, no logatoma poloose, cuja produção esperada era po['lu:s] e a produção foi po['lu.sı]. Observou-se, também, que dos 79 casos de aplicação de epêntese, 29 ocorreram em palavras reais (ex: RA.bbit $\rightarrow$ RA.bbi.[tfi]) e 50 em logatomas (ex: A.ni.cot $\rightarrow$ a.ni.CO.[tfi]).

A Tabela 56 a seguir apresenta a proporção de acertos nos casos de inserção de vogal epentética. Conforme o esperado, a taxa de acertos foi mais baixa em casos de epêntese. Enquanto a proporção de acertos foi de 73,6\% nos casos em que não houve 
aplicação de epêntese, foi de apenas 5,1\%, quando houve. Os 4 acertos registrados ocorreram especificamente nas palavras aCCOUNtant e RAbbit, que mantiveram o acento nas sílabas -ccoun- e ra- mesmo após a inserção da vogal. Nos outros 75 casos a ressilabificação ocasionou o erro.

Tabela 56: Acertos em casos de Epêntese: Inglês como L2

\begin{tabular}{cccccc}
\hline \multirow{2}{*}{ Epêntese } & \multicolumn{4}{c}{ Acerto } & \multirow{2}{*}{ PESO } \\
\cline { 2 - 5 } & \multicolumn{2}{c}{ Sim } & \multicolumn{2}{c}{ Não } & REL. \\
\cline { 2 - 5 } & $\mathbf{n}$ & $\mathbf{\%}$ & $\mathbf{n}$ & $\mathbf{\%}$ & \\
\hline Sem epêntese & 2564 & $73,6 \%$ & 950 & $26,4 \%$ & 0,52 \\
Com epêntese & 4 & $5,1 \%$ & 75 & $94,9 \%$ & 0,02
\end{tabular}

A Tabela 57 a seguir apresenta o cruzamento entre Epêntese e Segmento na Sílaba Final, que possibilita observar em que tipo de palavra a epêntese foi aplicada. Observase que a epêntese foi aplicada 24 vezes em palavras terminadas em [t] e, conforme já mencionado, em 4 casos essa inserção não resultou no erro. No caso de palavras terminadas em [k] houve 4 casos de epêntese, os quais ocorreram na produção de um mesmo informante do nível básico nos logatomas narpek, tarpec, brantec e pabloc. Nessas palavras, esperava-se que o acento fosse atribuído nas sílabas nar-, tar-, bran- e $p a$ - e o informante, apesar de manter o padrão paroxítono após a inserção de epêntese, atribuiu o acento em uma sílaba diferente (nar.PE.ki, tar.PE.ki, bran.TE.ki, pa.BLO.ki). A tabela mostra, também, que houve 10 ocorrências de epêntese em palavras terminadas em [d] (ex: PLANtid $\rightarrow$ plan.TI.[dzi]) e 9 em palavras terminadas em [p] (ex: CRAStip $\rightarrow$ cras.TI.[pi]), nas quais o acento foi atribuído em uma sílaba diferente por causa da ressilabificação, ainda que tenha permanecido no padrão paroxítono. Por fim, observouse 6 casos de epêntese em três palavras terminadas em vogal longa seguidas de [p] ou [t] (paneep, complete, discrete), 3 casos de epêntese em palavras terminadas em vogal longa seguida de nasal (extreme, regime, supreme) e 22 casos em palavras terminadas em vogal longa seguida de [s] (somente nas palavras reais chinese e police e nos logatomas lanese, calonese, poloose e pontalese), nas quais o padrão acentual esperado era o oxítono e o padrão empregado após a epêntese foi o paroxítono. 
Tabela 57: Acertos por segmento final em casos de Epêntese: Inglês como L2

\begin{tabular}{ccccc}
\hline \multirow{2}{*}{$\begin{array}{c}\text { Segmento na Sílaba } \\
\text { Final }\end{array}$} & \multicolumn{4}{c}{ Epêntese } \\
\cline { 2 - 5 } & \multicolumn{2}{c}{ Com Epêntese } & \multicolumn{2}{c}{ Sem Epêntese } \\
\cline { 2 - 5 } & n/Total & $\%$ & n/Total & $\%$ \\
\hline$[t]$ & $4 / 24$ & $16 \%$ & $700 / 782$ & $90 \%$ \\
{$[k]$} & $0 / 4$ & 0 & $176 / 206$ & $85 \%$ \\
{$[d]$} & $0 / 10$ & 0 & $389 / 448$ & $87 \%$ \\
{$[p]$} & $0 / 9$ & 0 & $202 / 309$ & $65 \%$ \\
Vogal Longa $+[p]$ ou $[t]$ & $0 / 6$ & 0 & $127 / 164$ & $77 \%$ \\
Vogal Longa $+[n]$ & $0 / 3$ & 0 & $411 / 620$ & $66 \%$ \\
Vogal Longa $+[s]$ & $0 / 22$ & 0 & $144 / 238$ & $61 \%$ \\
Vogal Longa $+[r]$ & 0 & 0 & $149 / 208$ & $72 \%$ \\
Vogal Longa & 0 & 0 & $356 / 629$ & $57 \%$
\end{tabular}

A Tabela 58 apresenta a proporção de acertos de acordo com o padrão da sílaba final, a única variável linguística que não foi considerada estatisticamente significativa. Pode-se observar que a taxa de acertos foi mais alta em palavras terminadas em núcleo simples, cujo padrão acentual esperado era o paroxítono ou o proparoxítono (ex: CArrot, LOllipop) do que em palavras terminadas em núcleo ramificado, nas quais o padrão acentual esperado era o oxítono (ex: bamBOO, baZAAR).

Tabela 58: Acento e Padrão da Sílaba Final - Inglês como L2

\begin{tabular}{ccccc}
\hline \multirow{2}{*}{ Padrão da Sílaba Final } & \multicolumn{4}{c}{ Acerto } \\
\cline { 2 - 5 } & $\mathbf{n}$ & $\mathbf{~} \mathbf{0}$ & $\mathbf{n}$ & $\mathbf{0}$ \\
\hline Núcleo Simples & 1469 & $82 \%$ & 322 & $18 \%$ \\
Núcleo Ramificado & 1189 & $62,8 \%$ & 703 & $37,2 \%$
\end{tabular}

Consideremos, por fim, os resultados referentes às variáveis sociais Nível de Proficiência e Idade de Início da Aquisição. A variável Nível de Proficiência, a segunda selecionada como significativa na verificação estatística, apontou que os informantes de nível básico apresentaram a menor taxa de acertos, de 60,9\%, seguidos dos informantes de nível intermediário, que aplicaram o padrão acentual esperado em 72,4\% dos casos, e dos informantes de nível avançado, que apresentaram 83,3\% de acertos e foram os únicos que apresentaram um peso relativo favorecedor, de 0,67 , conforme a Tabela 59 a seguir. 
Tabela 59: Proporção de Acertos por Nível de Proficiência

\begin{tabular}{|c|c|c|c|c|c|}
\hline \multirow{3}{*}{$\begin{array}{c}\text { Nível de } \\
\text { Proficiência }\end{array}$} & \multicolumn{4}{|c|}{ Acerto } & \multirow{3}{*}{$\begin{array}{l}\text { PESO } \\
\text { REL. }\end{array}$} \\
\hline & \multicolumn{2}{|c|}{ Sim } & \multicolumn{2}{|c|}{ Não } & \\
\hline & $\mathbf{n}$ & $\%$ & $\mathbf{n}$ & $\%$ & \\
\hline Básico & 751 & $60,9 \%$ & 483 & $39,1 \%$ & 0,35 \\
\hline Intermediário & 885 & $72,4 \%$ & 337 & $27,6 \%$ & 0,47 \\
\hline Avançado & 1022 & $83,3 \%$ & 205 & $16,7 \%$ & 0,67 \\
\hline
\end{tabular}

Observa-se, portanto, um percurso de aquisição do padrão acentual do inglês no que diz respeito aos resultados obtidos através da verificação perceptual, pois a taxa de acertos é maior conforme o aumento do nível de proficiência. 0 avanço gradual na proporção de acertos por nível de proficiência também pode ser observado no Gráfico 30 a seguir, que apresenta os resultados dos falantes nativos para fins de comparação.

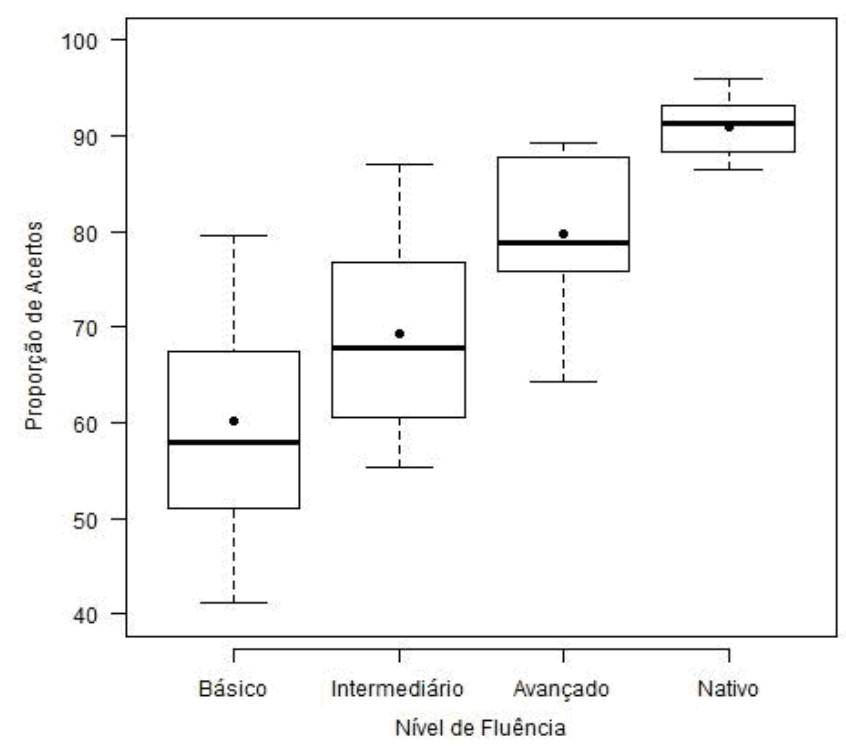

Gráfico 30: Acertos por Nível de Proficiência

Percebe-se que há um aumento na média de acertos em direção ao nível avançado e que os falantes nativos, conforme o esperado, apresentaram a taxa de acertos mais alta. Observa-se, também, uma variação maior nos resultados dos três grupos de falantes não-nativos do que no grupo de falantes nativos.

Essa variação fica bastante evidente quando observamos a taxa de acertos por informante, na Tabela 60 a seguir. Observa-se que as menores porcentagens foram as dos Informantes 1 e 8, do nível básico, que apresentaram 41\% e 45,5\% de acertos, respectivamente (destacados em cinza claro). As porcentagens mais altas foram as dos 
Informantes 23 e 25, do nível avançado, que apresentaram 92,7\% e 91,9\% de acertos, respectivamente (destacados em cinza escuro).

Tabela 60: Acertos por Informante - Inglês como L2

\begin{tabular}{|c|c|c|c|}
\hline NÍVEL & INFORMANTE & CASOS/TOTAL & PORCENTAGEM \\
\hline \multirow{10}{*}{ Básico } & Inf. 1 & $51 / 124$ & $41 \%$ \\
\hline & Inf. 2 & $78 / 124$ & $62,9 \%$ \\
\hline & Inf. 3 & $69 / 124$ & $55,6 \%$ \\
\hline & Inf. 4 & $98 / 124$ & $79 \%$ \\
\hline & Inf. 5 & $67 / 124$ & $54 \%$ \\
\hline & Inf. 6 & $86 / 124$ & $69,4 \%$ \\
\hline & Inf. 7 & $70 / 122$ & $57,4 \%$ \\
\hline & Inf. 8 & $55 / 121$ & $45,5 \%$ \\
\hline & Inf. 9 & $71 / 124$ & $57,3 \%$ \\
\hline & Inf. 10 & $106 / 123$ & $86,2 \%$ \\
\hline \multirow{10}{*}{ Interm. } & Inf. 11 & $81 / 121$ & $66,9 \%$ \\
\hline & Inf. 12 & $109 / 123$ & $88,6 \%$ \\
\hline & Inf. 13 & $103 / 124$ & $83,1 \%$ \\
\hline & Inf. 14 & $75 / 124$ & $60,5 \%$ \\
\hline & Inf. 15 & $90 / 124$ & $72,6 \%$ \\
\hline & Inf. 16 & $75 / 117$ & $64,1 \%$ \\
\hline & Inf. 17 & $75 / 117$ & $64,1 \%$ \\
\hline & Inf. 18 & $92 / 124$ & $74,2 \%$ \\
\hline & Inf. 19 & $85 / 124$ & $68,5 \%$ \\
\hline & Inf. 20 & $100 / 124$ & $80,6 \%$ \\
\hline \multirow{11}{*}{ Avançado } & Inf. 21 & $96 / 124$ & $77,4 \%$ \\
\hline & Inf. 22 & $111 / 124$ & $89,5 \%$ \\
\hline & Inf. 23 & $115 / 124$ & $92,7 \%$ \\
\hline & Inf. 24 & $83 / 120$ & $69,2 \%$ \\
\hline & Inf. 25 & $114 / 124$ & $91,9 \%$ \\
\hline & Inf. 26 & $106 / 124$ & $85,5 \%$ \\
\hline & Inf. 27 & $101 / 124$ & $81,5 \%$ \\
\hline & Inf. 28 & $104 / 124$ & $83,4 \%$ \\
\hline & Inf. 29 & $97 / 119$ & $81,5 \%$ \\
\hline & Inf. 30 & $95 / 120$ & $79,2 \%$ \\
\hline & TOTAL & $2658 / 3683$ & $72.2 \%$ \\
\hline
\end{tabular}

A proporção de acertos por informante também pode ser visualizada no Gráfico 31 a seguir. Percebe-se que, no nível básico, há tanto informantes que apresentaram taxas de acertos bastante baixas, como os informantes 1, 5 e 8, quanto informantes que apresentaram uma proporção de acertos acima da média, como o 4 e o 10. Observa-se que o Informante 10, do nível básico, apresentou uma taxa de acertos mais alta do que quase todos os informantes do nível intermediário e inclusive alguns informantes de 
nível avançado (86,2\%). 0 nível intermediário se comporta de maneira semelhante: alguns informantes apresentam taxas abaixo da média do grupo, como o 14, o 16 e o 17, enquanto o informante 12 apresentou uma taxa de acertos bastante alta, de 88,6\%. No nível avançado, por fim, as taxas de acerto ficaram todas acima de 69,2\% e os informantes 22, 23 e 25 apresentaram as maiores porcentagens do grupo.

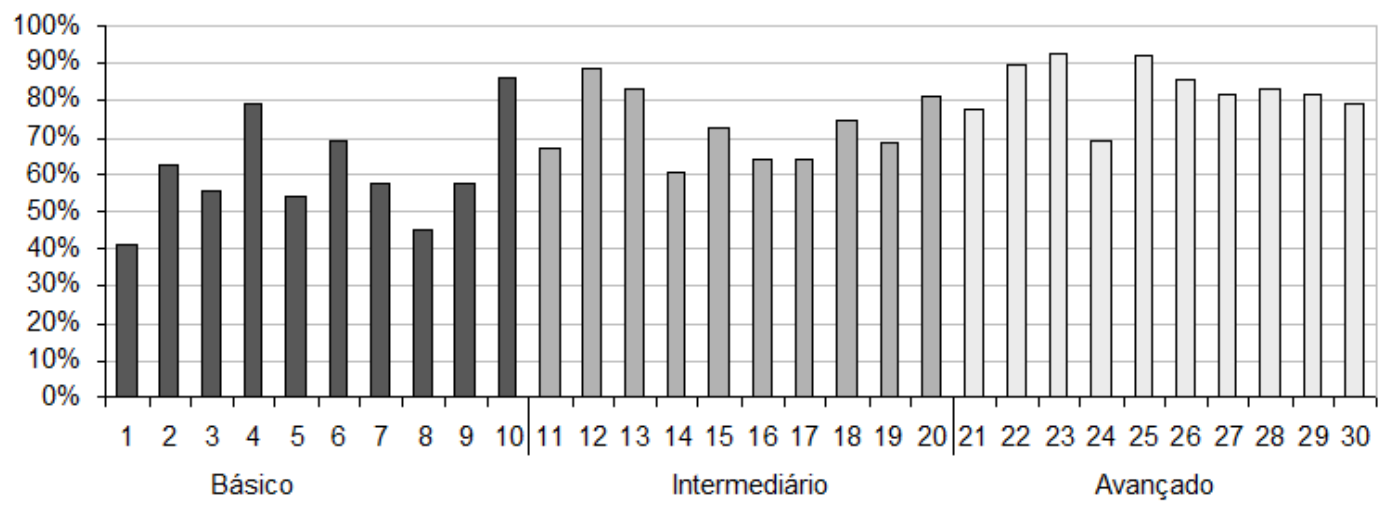

Gráfico 31: Acertos por informante: Inglês como L2

O Gráfico 32 a seguir apresenta a proporção de acertos por informante e por padrão da sílaba final. Pode-se observar que todos os informantes, exceto o 8, o 23 e o 26, apresentaram um percentual de acertos maior em palavras terminadas em núcleo simples, nas quais o padrão acentual esperado era o paroxítono ou o proparoxítono (ex: carrot, lollipop), do que em palavras terminadas em núcleo ramificado (ex: bazaar, bamboo), nas quais o padrão esperado era o oxítono. Percebe-se, também, que a diferença de acertos entre esses padrões acentuais é bem mais significativa do que pudemos observar nos resultados dos falantes nativos (Cf. Gráfico 22). 0 Informante 3, por exemplo, apresentou uma taxa de acertos significativamente mais baixa em palavras terminadas em núcleo ramificado (22\%) do que em palavras terminadas em núcleo simples (92\%), assim como os Informantes 5, 7 e 10, do nível básico, 16, 17 e 18, do nível intermediário e 21, 24, 29 e 30, do nível avançado. Observa-se, também, que o único informante que apresentou $100 \%$ de acertos foi o 10, do nível básico, em palavras terminadas em núcleo simples. 


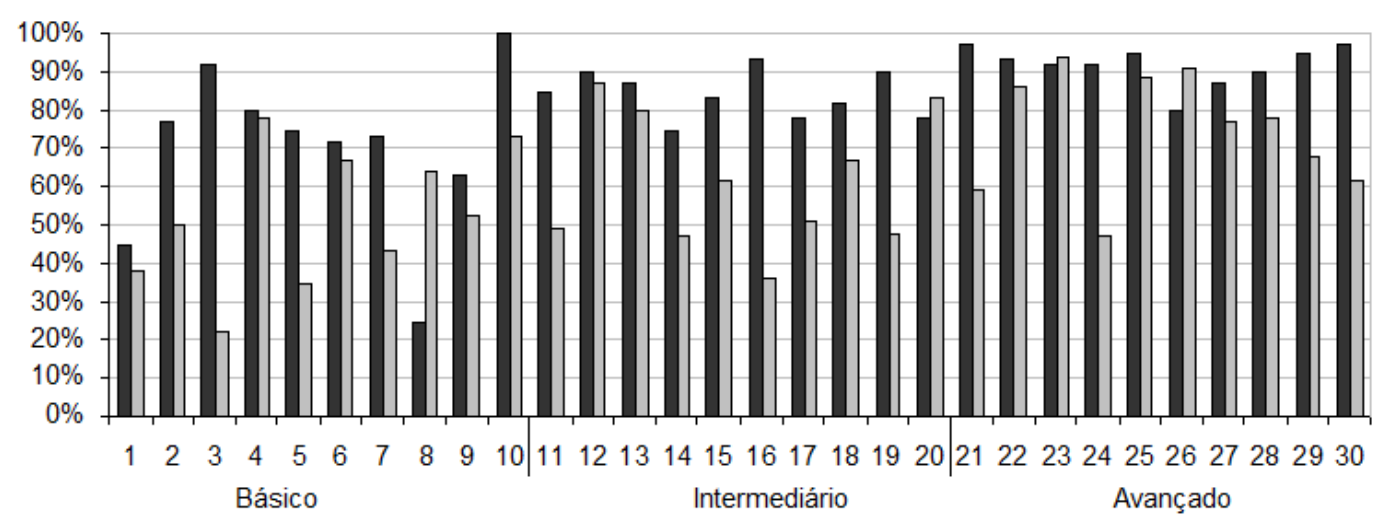

—Núcleo Simples (paroxitonas/proparoxitonas) \Núcleo Ramificado (oxitonas)

Gráfico 32: Acertos por Informante e Padrão da Sílaba Final: Inglês como L2

O Gráfico 33 a seguir apresenta a proporção de acertos por informante separada por tipo de palavra. Percebe-se que a porcentagem de acertos é mais alta em palavras reais na produção de quase todos os informantes, exceto o 6, do nível básico, e o 23 e o 27, do nível avançado, que apresentaram uma taxa de acertos um pouco maior em logatomas. Em alguns casos, a diferença na proporção de acertos entre palavras reais e logatomas é bastante significativa. 0 Informante 11, do nível intermediário, apresentou $83 \%$ de acertos em palavras reais e apenas 52\% em logatomas, assim como o Informante 21, do nível avançado, que apresentou 97\% de acertos em palavras reais e $60 \%$ em logatomas.

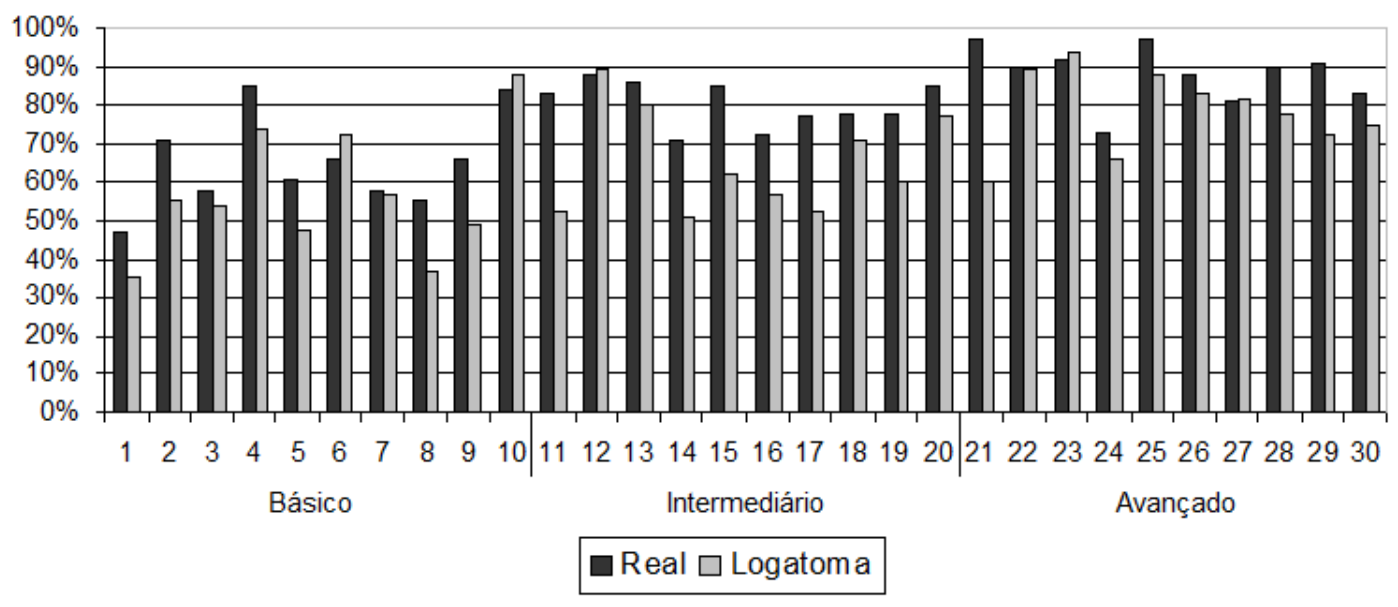

Gráfico 33: Acertos por Informante e Tipo de Palavra: Inglês como L2

A proporção de acertos por tipo de palavra em cada nível de proficiência pode ser visualizada no Gráfico 34 a seguir. Percebe-se que, nos três níveis de proficiência, a taxa de acertos em palavras reais é mais alta em palavras reais do que em logatomas. 


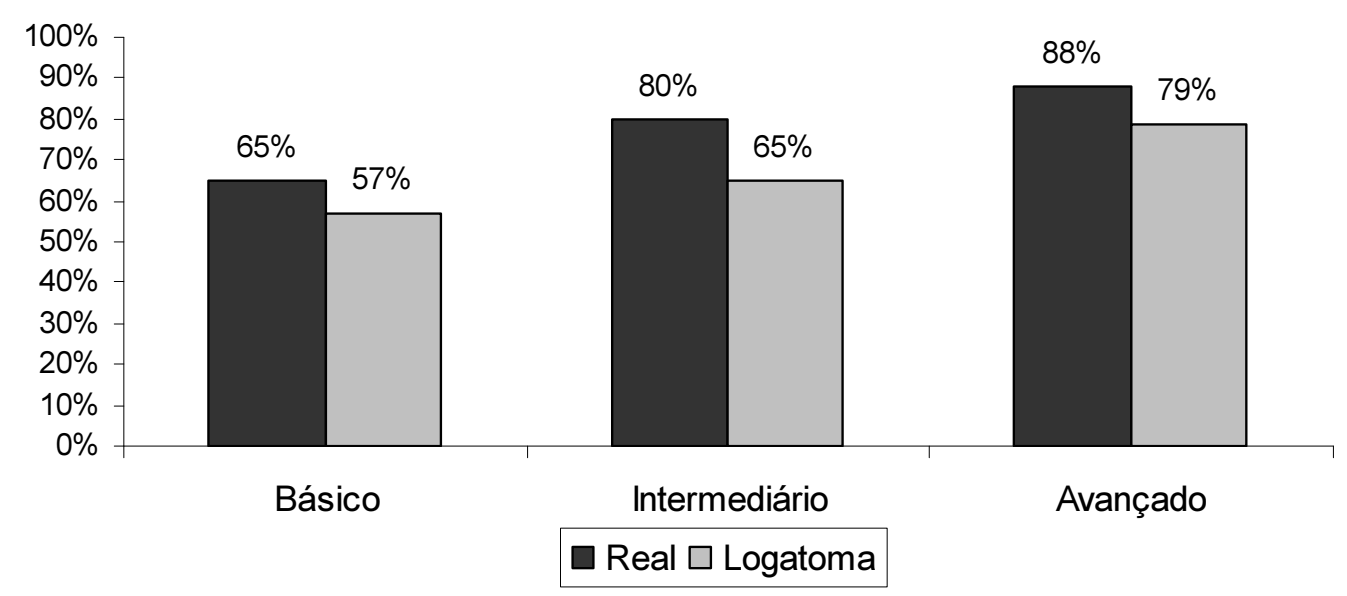

Gráfico 34: Acertos por nível de proficiência e tipo de palavra: Inglês como L2

A Tabela 61, por fim, apresenta os resultados referentes à variável Idade de Início da Aquisição, cujo objetivo é verificar se os informantes que iniciaram os estudos antes dos 12 anos de idade apresentariam uma taxa de acertos mais alta do que os que iniciaram o aprendizado após os 12 anos (cf. Hipótese do Período Crítico, apresentada na Seção 4.3.1). Os resultados referentes à esta variável, que não foi selecionada como estatisticamente significativa, mostraram que os informantes que iniciaram o aprendizado antes dos 12 anos tiveram uma taxa de acertos de $73,8 \%$, enquanto os informantes que iniciaram a aquisição depois dos 12 anos tiveram 70,4\% de acertos.

Tabela 61: Acertos por Idade de Início da Aquisição

\begin{tabular}{ccccc}
\hline \multirow{2}{*}{$\begin{array}{c}\text { Idade de Início } \\
\text { da Aquisição }\end{array}$} & \multicolumn{3}{c}{ Não } & \multicolumn{2}{c}{ Sim } \\
\cline { 2 - 5 } & $\mathbf{n}$ & $\mathbf{\%}$ & $\mathbf{n}$ & $\mathbf{\%}$ \\
\hline Antes dos 12 & 1443 & $73,8 \%$ & 513 & $26,2 \%$ \\
Depois dos 12 & 1215 & $70,4 \%$ & 512 & $29,6 \%$
\end{tabular}

A proporção de acertos pelos dois grupos de idade também pode ser visualizada no Gráfico 35 a seguir. Pode-se observar que a média na proporção de acertos do grupo que iniciou o aprendizado da língua inglesa antes dos 12 anos é mais alta que a dos que iniciaram depois dessa idade. Observa-se, também, que a variação na taxa de acertos é maior nos dois grupos de falantes de inglês como L2 do que no grupo de falantes nativos. 


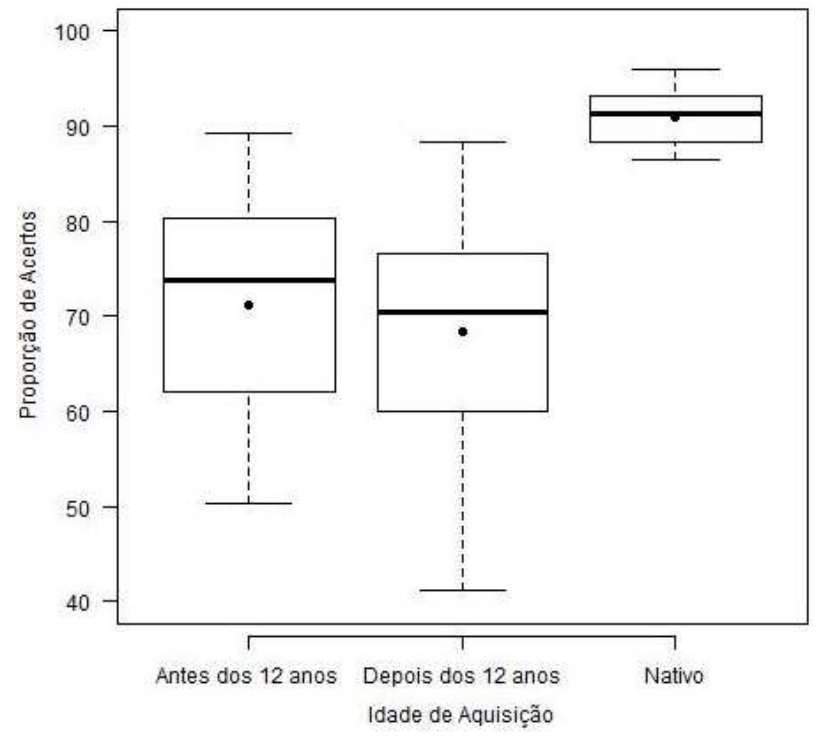

Gráfico 35: Proporção de acertos por Idade de Início da Aquisição

O Gráfico 36 compara a proporção de acertos por Idade de Início da Aquisição e por Nível de Proficiência. Pode-se observar que nos níveis básico e intermediário a média de acertos pelos informantes que iniciaram a aquisição antes dos 12 anos é mais baixa do que a média dos que iniciaram após os 12 anos, porém há bastante variação nesses grupos. De todos os grupos, o de nível básico com idade antes dos 12 anos é o que apresenta a maior variação, o que pode ser justificado pelo fato de os informantes 4 e 10, que iniciaram a aquisição antes dos 12 anos, terem apresentado uma proporção de acertos muito acima da média deste nível, como vimos no Gráfico 24. No nível avançado, a média de acertos pelos informantes que iniciaram a aquisição antes dos 12 anos foi mais alta do que a dos que iniciaram após os 12 anos. Observa-se, também, que o grupo de falantes que iniciaram a aquisição após os 12 anos no nível avançado é o mais homogêneo. 


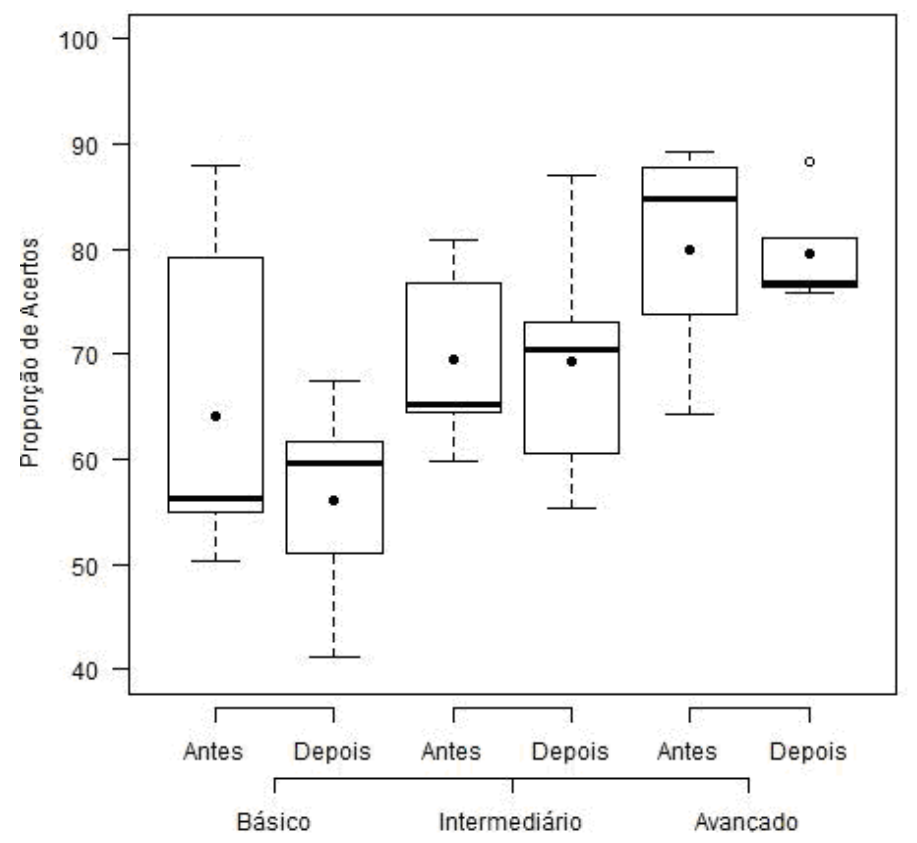

Gráfico 36: Acertos por nível de proficiência e idade de início da aquisição

Em suma, os resultados referentes à verificação perceptual da relação entre sílaba e acento pelos falantes de inglês como segunda língua indicaram que a taxa de acertos foi maior em palavras terminadas em sílaba com núcleo simples, nas quais o padrão acentual esperado era o paroxítono. Observou-se, também, que a proporção de acertos foi maior em palavras reais do que em logatomas e que, conforme o esperado, os casos de inserção de epêntese influenciaram na aplicação do acento correto. Além disso, os resultados mostraram que a taxa de acertos cresce à medida que o nível de proficiência aumenta e que os informantes que iniciaram os estudos antes dos 12 anos de idade apresentaram, no geral, uma proporção de acertos um pouco mais alta do que os que iniciaram após os 12 anos.

\subsubsection{Correlatos Acústicos}

Esta seção apresenta os resultados referentes às médias de duração empregadas pelos falantes de inglês como L2 em comparação com os falantes nativos. Como vimos na Seção 5.1, a duração é o correlato mais importante para o acento no Português, sendo as sílabas acentuadas mais longas do que sílabas átonas. A verificação dos correlatos acústicos se deu através de uma análise por palavra porque, no caso da duração, não é possível comparar sílabas de palavras diferentes, pois elas possuem 
segmentos diferentes e, portanto, naturalmente variam em duração. A palavra balloon, por exemplo, tem duas sílabas: ba-lloon. Independentemente do acento empregado, a sílaba "lloon" deverá ser a mais longa, pois há mais segmentos do que em "ba", e porque a duração intrínseca da consoante plosiva /b/ é menor do que a da consoante líquida /l/. Não se pode dizer, portanto, que, se os informantes apresentassem uma duração maior em "lloon" do que em "ba", estariam empregando o acento na sílaba esperada (lloon), pois as sílabas possuem características diferentes. Por isso, as tabelas mostram a comparação entre a média da sílaba "ba" produzida por todos os falantes não nativos e a média da sílaba "ba" pelos falantes nativos, o que possibilita verificar em quais palavras houve uma diferença significativa de duração entre os dois grupos.

As tabelas a seguir mostram a média e o desvio padrão da duração de cada sílaba produzida pelos falantes não nativos e compara com as mesmas sílabas produzidas pelos falantes nativos, de modo a verificar se houve alguma diferença significativa entre os dois grupos. ${ }^{46}$ Os asteriscos indicam os casos em que o p-valor foi significativo, lembrando que foi fixado o valor de significância de $<0,05$ em todas as análises dos correlatos acústicos (cf. Seção 6.2.3.2).

\subsubsection{Oxítonos}

A Tabela 61 a seguir apresenta os valores de duração nas 30 palavras reais em que o padrão acentual esperado era o oxítono porque a sílaba final possui núcleo ramificado, o que constitui uma sílaba pesada no inglês. Para verificar se, assim como foi apontado para os dados obtidos através de verificação perceptual (cf. Seção 6.3.2), há diferenças significativas no que diz respeito à duração nos três níveis de proficiência, apresentamos as médias de duração pelos falantes de nível básico, intermediário e avançado, além da média obtida pelos falantes nativos, para fins de comparação. Das 30 palavras neste grupo, a análise estatística apontou diferença significativa entre os três níveis de proficiência em 12 (todas destacadas em cinza e com um asterisco ao lado do p-valor). Observa-se que, em todos os casos em que houve diferença significativa na duração da última sílaba, há um aumento gradual em direção ao nível avançado (linhas em cinza escuro). Na palavra bamboo, por exemplo, a média de duração da sílaba -boo pelo nível básico foi de 226ms, do nível intermediário 271ms e do nível avançado

\footnotetext{
${ }^{46}$ Nesta análise, as 79 palavras em que houve inserção de epêntese foram desconsideradas.
} 
342ms, ou seja, quanto maior o nível de proficiência, maior a média de duração na última sílaba de palavras oxítonas. Observa-se , também, que o valor apresentado pelo nível avançado neste caso é o mais aproximado à média dos falantes nativos, de 330,43ms. Esse aumento gradual só não foi apontado na palavra concrete: a duração na última sílaba pelos informantes do nível básico teve média de $461 \mathrm{~ms}$, enquanto a do nível intermediário foi um pouco mais baixa, de 446ms. No nível avançado, como nos outros exemplos, a duração foi mais alta, de 529ms.

A diferença de duração na penúltima sílaba foi significativa apenas nas palavras employee, engineer e referee (destacadas em cinza claro). Nesses casos, observou-se o contrário: a duração diminui conforme o nível de proficiência aumenta. Na palavra employee, por exemplo, a sílaba -ploy apresenta a maior média de duração no nível básico, de 390ms. No nível intermediário, esse valor diminui para 334ms e, no nível avançado, diminui ainda mais, para $247 \mathrm{~ms}$.

Tabela 62: Duração em palavras reais com padrão oxítono por nível de proficiência

\begin{tabular}{|c|c|c|c|c|c|c|c|c|c|c|}
\hline \multicolumn{11}{|c|}{ Duração (em milissegundos) } \\
\hline \multirow{2}{*}{ Palavra } & \multirow{2}{*}{ Sílaba } & \multicolumn{2}{|c|}{ Básico } & \multicolumn{2}{|c|}{ Intermediário } & \multicolumn{2}{|c|}{ Avançado } & \multirow{2}{*}{ p-valor } & \multicolumn{2}{|c|}{ Nativos } \\
\hline & & Média & DP & Média & DP & Média & DP & & Média & DP \\
\hline \multirow{2}{*}{ baloon } & ba & 203,78 & 33,20 & 189,20 & 189,20 & 163,10 & 163,10 & 0,1494 & 121,57 & 44,58 \\
\hline & loon & 321,89 & 39,64 & 350,80 & 350,80 & 412,20 & 412,20 & 0,0994 & 380 & 50,81 \\
\hline \multirow{2}{*}{ bamboo } & bam & 268,40 & 39,66 & 278,80 & 278,80 & 261,50 & 261,50 & 0,7970 & 213,86 & 17,95 \\
\hline & boo & 226,20 & 51,54 & 271,70 & 271,70 & 342,40 & 342,40 & $0,0122 *$ & 330,43 & 25,81 \\
\hline \multirow{2}{*}{ bazaar } & ba & 173,10 & 43,83 & 185,90 & 185,90 & 148,80 & 148,80 & 0,5991 & 106,29 & 29,78 \\
\hline & zaar & 358,80 & 68,98 & 387,70 & 387,70 & 472,20 & 472,20 & 0,1058 & 425 & 39,77 \\
\hline \multirow{2}{*}{ career } & ca & 202,67 & 25,99 & 205,80 & 205,80 & 176,60 & 176,60 & 0,0952 & 176,43 & 24,34 \\
\hline & reer & 288,56 & 71,77 & 391,20 & 391,20 & 399,10 & 399,10 & $0,0090^{*}$ & 334,86 & 44,37 \\
\hline \multirow{2}{*}{ chinese } & chi & 222,10 & 61,32 & 231,60 & 231,60 & 217,50 & 217,50 & 0,7428 & 223,57 & 24,78 \\
\hline & nese & 379,22 & 78,79 & 427,60 & 427,60 & 493,60 & 493,60 & 0,1891 & 500 & 24,3 \\
\hline \multirow{2}{*}{ cocoon } & co & 141,89 & 40,71 & 127,44 & 127,44 & 104,44 & 104,44 & 0,1078 & 124,71 & 29,89 \\
\hline & coon & 364,00 & 71,30 & 394,44 & 394,44 & 439,22 & 439,22 & 0,1076 & 420 & 54,66 \\
\hline \multirow{2}{*}{ complete } & com & 160,80 & 19,69 & 182,80 & 182,80 & 169,90 & 169,90 & 0,4569 & 151,29 & 21,19 \\
\hline & plete & 416,44 & 87,08 & 410,90 & 410,90 & 499,60 & 499,60 & 0,0662 & 414,29 & 59,36 \\
\hline \multirow{2}{*}{ concrete } & con & 174,20 & 19,24 & 190,30 & 190,30 & 188,00 & 188,00 & 0,5364 & 218 & 46,88 \\
\hline & crete & 461,20 & 77,22 & 446,00 & 446,00 & 529,60 & 529,60 & $0,0486^{*}$ & 379,86 & 64,7 \\
\hline \multirow{2}{*}{ degree } & de & 162,50 & 52,18 & 145,10 & 145,10 & 132,60 & 132,60 & 0,4644 & 103 & 18,99 \\
\hline & gree & 353,70 & 54,00 & 377,80 & 377,80 & 426,10 & 426,10 & 0,1170 & 378,57 & 56,34 \\
\hline \multirow{2}{*}{ discrete } & dis & 205,40 & 67,47 & 220,20 & 220,20 & 200,80 & 200,80 & 0,4671 & 198,6 & 18,45 \\
\hline & crete & 445,89 & 78,51 & 466,60 & 466,60 & 538,10 & 538,10 & $0,0164^{*}$ & 410,2 & 70,3 \\
\hline employee & $\mathrm{em}$ & 139,78 & 33,82 & 152,30 & 152,30 & 134,10 & 134,10 & 0,4631 & 113 & 23,93 \\
\hline
\end{tabular}




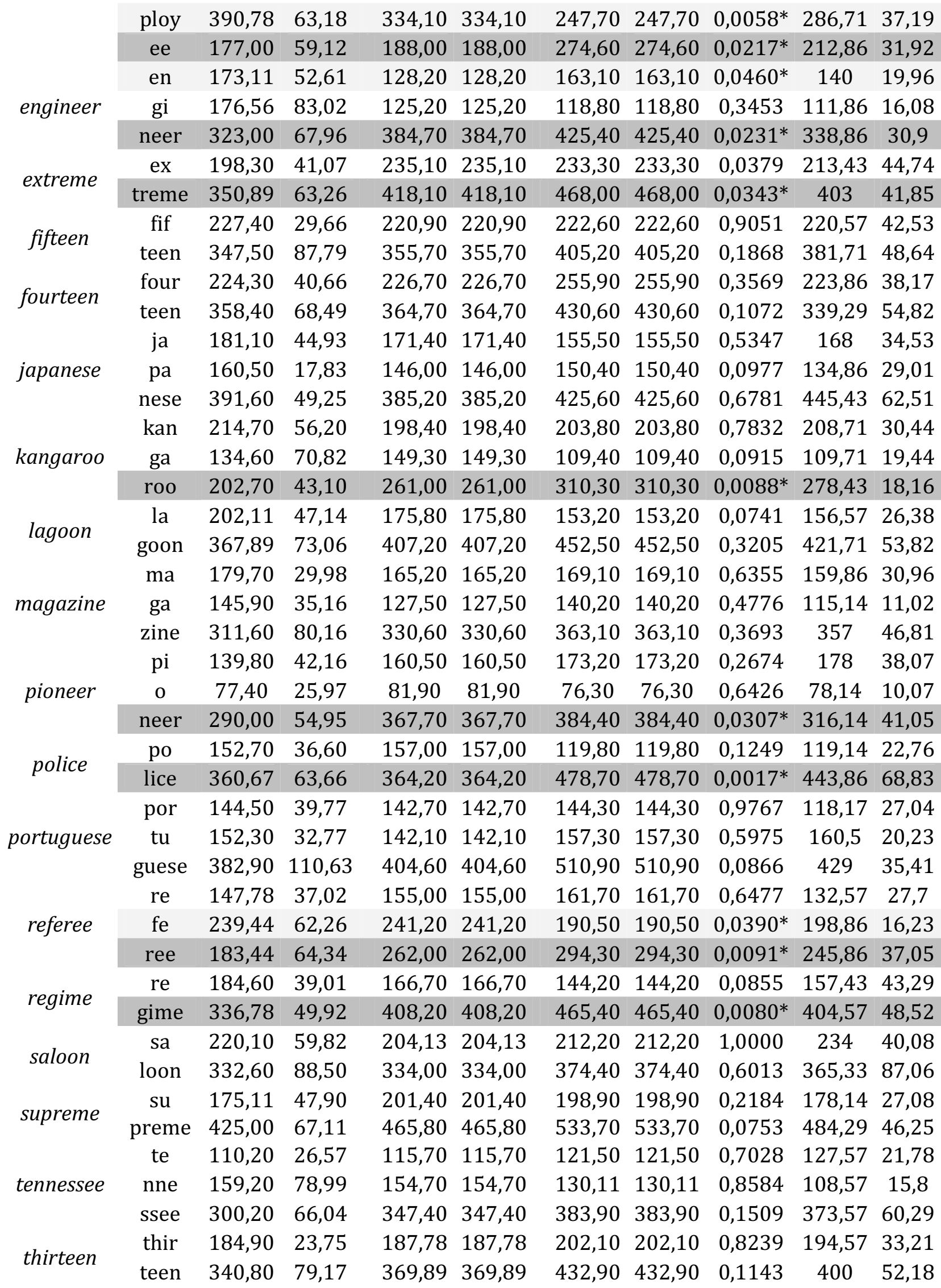




\begin{tabular}{ccccccccccc}
\multirow{2}{*}{ trainee } & trai & 233,60 & 50,32 & 209,70 & 209,70 & 216,70 & 216,70 & 0,4736 & 234,14 & 48,08 \\
& nee & 265,80 & 67,29 & 271,90 & 271,90 & 312,20 & 312,20 & 0,2849 & 307,29 & 42,23 \\
\multirow{2}{*}{ volunteer } & vo & 169,50 & 31,18 & 150,89 & 150,89 & 164,00 & 164,00 & 0,5557 & 142,14 & 28,35 \\
& lun & 204,30 & 56,29 & 185,22 & 185,22 & 179,89 & 179,89 & 0,4545 & 178,57 & 41,53 \\
& teer & 363,00 & 103,81 & 408,22 & 408,22 & 458,44 & 458,44 & 0,1071 & 386,71 & 29,99
\end{tabular}

Vejamos se os logatomas se comportam de maneira semelhante. A Tabela 63 a seguir mostra as médias de duração pelos falantes de nível básico, intermediário e avançado em logatomas cujo padrão acentual esperado era o oxítono, além das médias dos falantes nativos para comparação. Das 34 palavras neste grupo, a análise estatística apontou diferença significativa entre os níveis de proficiência em 23 (todas destacadas em cinza e com um asterisco ao lado do p-valor). Nos casos de diferença estatisticamente significativa na duração da última sílaba, observa-se que, assim como nas palavras reais, há um aumento na média conforme o avanço do nível de proficiência. Na palavra poloose, por exemplo, a média de duração da sílaba -loose no nível avançado (634ms) é quase o dobro da média do nível básico (365ms). Os únicos casos em que esse aumento gradual não foi constatado foram nas palavras paneep, em que a média do nível básico foi um pouco maior do que a do nível intermediário, e releen, em que a média do nível intermediário foi um pouco maior do que média do nível avançado.

A diferença de duração na penúltima sílaba foi significativa em cinco logatomas: colenteen, paneer, pantoo, soloop e tanloo. Diferentemente dos resultados de palavras existentes na língua inglesa, a média de duração nessas sílabas em logatomas aumentou conforme o avanço do nível de proficiência. A única palavra em que esse aumento não foi constatado foi paneer, pois a média de duração da sílaba - $p a$ diminuiu conforme o avanço do nível de proficiência. ${ }^{47}$

\footnotetext{
${ }^{47}$ Nesses casos, esperava-se que as durações mais longas fossem encontradas no nível básico, pelo fato de os falantes deste nível apresentarem produções mais cautelosas e, consequentemente, mais lentas. Além disso, o esperado era que, no nível avançado, os informantes produzissem a vogal neutra schwa nesta posição, assim como os nativos, que se caracteriza como uma vogal breve. Percebe-se, portanto, que este tema precisa de mais investigações.
} 
Tabela 63: Duração em logatomas com padrão oxítono por nível de proficiência

\begin{tabular}{|c|c|c|c|c|c|c|c|c|c|c|}
\hline \multicolumn{11}{|c|}{ Duração (em milissegundos) } \\
\hline \multirow{2}{*}{ Palavra } & \multirow{2}{*}{ Sílaba } & \multicolumn{2}{|c|}{ Básico } & \multicolumn{2}{|c|}{ Intermediário } & \multicolumn{2}{|c|}{ Avançado } & \multirow{2}{*}{ p-valor } & \multicolumn{2}{|c|}{ Nativos } \\
\hline & & Média & DP & Média & DP & Média & DP & & Média & DP \\
\hline \multirow{3}{*}{ apriteen } & $\mathrm{a}$ & 113,56 & & & & & 109,90 & & 123,71 & 33,24 \\
\hline & & & 59,45 & & & & & & 175,29 & \\
\hline & teen & 314,00 & 72,81 & 358,10 & 358,10 & 462,60 & 462,60 & $0,0009 *$ & 438,57 & 62,44 \\
\hline \multirow{3}{*}{ calonese } & & 138,33 & 27,96 & 161,50 & 161,50 & 148,67 & 148,67 & & 148,33 & 54,93 \\
\hline & & & 37,97 & 36,25 & 136,25 & 140,22 & 140,22 & & 137,43 & \\
\hline & nese & 409,88 & 84,35 & 410,44 & 410,44 & 561,33 & 561,33 & & 515,57 & \\
\hline \multirow{3}{*}{ caspelee } & & 246,67 & 34,01 & & 240,82 & 248,11 & 248,11 & 0,8085 & 281,86 & 57,54 \\
\hline & pe & 190,11 & 50,24 & 190,27 & 190,27 & 205,89 & 205,89 & & 196,43 & 63,38 \\
\hline & lee & 190,67 & 56,23 & & 254,64 & & 314,00 & & 7,86 & 42,22 \\
\hline \multirow{3}{*}{ colenteen } & & & & & & & & & & \\
\hline & len & 172,44 & 47,52 & 179,60 & 179,60 & 218,60 & 218,60 & 0,0 & 183,29 & 25,49 \\
\hline & & & & & & & & &, 71 & \\
\hline \multirow{3}{*}{ colonee } & & & & & & & & & & \\
\hline & lc & 170,33 & 59,17 & 70 & 149,70 & 78 & 13 & & 130,86 & 55,89 \\
\hline & & & & & & & & & 05 & \\
\hline \multirow{2}{*}{ dagree } & & & & & & & & & & \\
\hline & gree & 304,11 & 52,95 & 363,80 & 363,80 & 80 & 395,80 & 0,0 & 389,86 & 45,81 \\
\hline \multirow{2}{*}{ deleen } & & & 60,17 & & & & 00 & & 4,29 & \\
\hline & & & & & & & & & & \\
\hline \multirow{2}{*}{ galeen } & & 231,22 & 32,94 & & & & & & & 48,58 \\
\hline & leen & 273,67 & 43,61 & 40 & 327,40 & &, 50 & 0,0 &, 14 & 30,85 \\
\hline \multirow{2}{*}{ landee } & lan & & 29,08 & & & 89 &, 89 & & 3,86 & 58,48 \\
\hline & & & & & & & & & & \\
\hline \multirow{2}{*}{ landoo } & & & 37,90 & & & 60 & 4,60 & & 43 & \\
\hline & doo & 265,10 & 65,82 & 20 & 290,20 & ,30 & 329,30 & 37 & 304,57 & 57,12 \\
\hline \multirow{2}{*}{ lanese } & la & & & & & & & & & \\
\hline & & & 90,02 & & & & 527,43 & & 43 & \\
\hline \multirow{2}{*}{ paneep } & & 104,33 & 34,01 & 119,00 & 119,00 & 126,43 & 126,43 & 0,6084 & 109,29 & 40,03 \\
\hline & neep & 383,11 & 111,61 & & & & 501,43 & $0,0269 *$ & 357,57 & 65,7 \\
\hline \multirow{2}{*}{ paneer } & pa & & 27,36 & 126,20 & 126,20 & 108,00 & 108,00 & $0,0244^{*}$ & 113,57 & 20,12 \\
\hline & & 276,44 & 42,38 & 388,50 & 388,50 & 450,70 & 450,70 & $0,0003^{*}$ & 396 & 69,5 \\
\hline \multirow{2}{*}{ pantoo } & pan & 193,00 & 21,14 & 231,18 & 231,18 & 228,11 & 228,11 & $0,0137^{*}$ & 234,29 & 35,12 \\
\hline & too & 306,89 & 51,20 & 370,27 & 370,27 & 420,11 & 420,11 & $0,0046^{*}$ & 376,14 & 32,64 \\
\hline \multirow{2}{*}{ pebree } & pe & 130,44 & 36,13 & 114,00 & 114,00 & 115,44 & 115,44 & 0,4713 & 134,29 & 23,96 \\
\hline & bree & 310,89 & 64,29 & 381,82 & 381,82 & 434,22 & 434,22 & $0,0207^{*}$ & 399 & 44,44 \\
\hline & & & & 195,27 & 195,27 & & & 0,3382 & 184,14 & 42,29 \\
\hline & ta & 156,22 & 38,47 & 166,09 & 166,09 & 135,56 & 135,56 & 0,2498 & 155,71 & 47,35 \\
\hline & nese & 409,25 & 67,32 & 444,86 & 444,86 & 552,67 & 552,67 & $0,0096 *$ & 479 & 70,22 \\
\hline poleen & po & 181,56 & 28,26 & 200,22 & 200,22 & 172,10 & 172,10 & 0,3122 & 181,5 & 28,3 \\
\hline
\end{tabular}




\begin{tabular}{|c|c|c|c|c|c|c|c|c|c|c|}
\hline & leen & 254,67 & 39,58 & 301,78 & 301,78 & 364,70 & 364,70 & $0,0060 *$ & 371,25 & 79,48 \\
\hline \multirow{2}{*}{ poloose } & po & 129,44 & 21,67 & 25,25 & 125,25 & 143,29 & 143,29 & 0,8583 & 138,14 & 34,53 \\
\hline & loose & 365,13 & 70,30 & 487,17 & 487,17 & 634,50 & 634,50 & $0,0005^{*}$ & 485,57 & 82,6 \\
\hline \multirow{4}{*}{ ponessee } & & 21,38 & 29,60 & 30,90 & 130,90 & 40,10 & 140,10 & 0,3469 & 126,14 & 49,84 \\
\hline & ne & 195,88 & 80,86 & 196,30 & 196,30 & 155,40 & 155,40 & 0,2149 & 167,57 & 51,74 \\
\hline & ssee & 327,50 & 54,41 & 353,80 & 353,80 & 435,80 & 435,80 & 0,0595 & 423,57 & 149,83 \\
\hline & pon & 190,40 & 24,24 & 94,30 & 194,30 & 186,50 & 186,50 & 0,8473 & 184,33 & 61,46 \\
\hline \multirow[t]{2}{*}{ pontalese } & ta & 170,20 & 45,88 & 173,40 & 173,40 & 168,80 & 168,80 & & 147,67 & 23,8 \\
\hline & lese & 42,11 & 62,34 & & 422 & & 474,30 & & & 70,11 \\
\hline \multirow{2}{*}{ ponteen } & pon & 204,22 & 27,95 & 33,27 & 233,27 & 238,22 & 238,22 & 0,0544 & 234,14 & 47,31 \\
\hline & teen & 310,78 & 64,39 & 377,45 & 377,45 & 437,67 & 437,67 & 0,0 & 403,57 & 61,64 \\
\hline \multirow{3}{*}{ porelee } & po & 142,70 & 27,58 & 31,00 & 131,00 & 174,33 & 174,33 & & 135,83 & 30,33 \\
\hline & re & 48,90 & 65,09 & 09 & 117,09 & &, 56 & & 17 & 27,18 \\
\hline & lee & & 73,49 & & 307 & 89 & 340 & & ,33 & 37,68 \\
\hline \multirow{2}{*}{ porsee } & por & & 45, & & & & & & & \\
\hline & see & 312,67 & 24,82 & 375,00 & 375,00 & 00 & 00 & & & \\
\hline \multirow{2}{*}{ releen } & $\mathrm{re}$ & 80,67 & 51,63 & 86,50 & 186,50 & 164,10 & 164,10 & 5481 & 156,29 & 54,61 \\
\hline & leen & 03,56 & 75,76 & 00 & 427,00 & 425,00 & 425,00 & $11^{*}$ & & 55,11 \\
\hline \multirow{2}{*}{ sadoon } & sa & & & & & & & & & \\
\hline & doon & 321,22 & 60,73 & 355,20 & 355,20 & 422,30 & 422,30 & $0,0234^{*}$ & 418,57 & 72,33 \\
\hline \multirow{2}{*}{ soloop } & so & 190,67 & 61,22 & 73,63 & 273,63 & 9,43 & 259,43 & $7^{*}$ & 248,71 & 41,45 \\
\hline & loop & & & & & & & & & \\
\hline \multirow{2}{*}{ tabaar } & ta & 151,40 & 49,67 & 30 & & 7,40 & 117,40 & 723 & 86 & 38,28 \\
\hline & baar & 373,40 & 91,29 & 409,20 & 409,20 & 466,50 & 466,50 & 738 & 378,71 & 56,17 \\
\hline \multirow{2}{*}{ tanleen } & $\tan$ & 243,67 & 42,81 & 3,80 & 288,80 & 252,40 & 252,40 & & 0 & 54,62 \\
\hline & leen & & & & & & & & $38 \varepsilon$ & \\
\hline \multirow{2}{*}{ tanloo } & $\tan$ & 249,67 & 38,64 & 77,55 & 277,55 & 6,11 & 326,11 & 0,0299* & & 69,64 \\
\hline & loo & 223,44 & 56,53 & 264,27 & 264,27 & 247,78 & 247,78 & 0,6286 & 328,14 & 45,71 \\
\hline \multirow{3}{*}{ tascreet } & tas & & 28,79 & & & 9,80 &, 80 & 85 & 89 & 64,08 \\
\hline & creet & 439,11 & 129,1 & & & 1,10 & 1,10 & & 400,11 & 56,85 \\
\hline & tas & 214,11 & 44,38 & 213,80 & 213,80 & 221,80 & 221,80 & 0,8697 & 251,14 & 68,06 \\
\hline \multirow[t]{3}{*}{ tasparoo } & pa & 244,22 & 38,78 & 240,10 & 240,10 & 193,40 & 193,40 & 0,0129 & 222,43 & 60,39 \\
\hline & roo & 197,89 & 52,27 & 298,10 & & 310,70 & 310,70 & & 239,14 & 61,26 \\
\hline & te & 109,89 & 20,47 & & 135,40 & 123,11 & 123,11 & 0,5997 & 133,71 & 26,49 \\
\hline \multirow[t]{2}{*}{ tenneree } & nne & 196,89 & 63,85 & 175,56 & 175,56 & 169,33 & 169,33 & 0,6609 & 159,86 & 49,48 \\
\hline & ree & 220,11 & 58,01 & 245,60 & & 294,56 & 294,56 & & 293,71 & 37,6 \\
\hline \multirow{2}{*}{ tolee } & to & 187,30 & 41,75 & 195,20 & 195,20 & 184,10 & 184,10 & 0,8952 & 204,43 & 41,02 \\
\hline & lee & 241,10 & 100,00 & 244,40 & 244,40 & 305,00 & 305,00 & 0,1817 & 297,29 & 75,91 \\
\hline \multirow{2}{*}{ toneen } & to & 167,10 & 43,23 & 172,60 & 172,60 & 154,00 & 154,00 & 0,8103 & 179,29 & 60,12 \\
\hline & neen & 281,60 & 65,76 & 359,10 & 359,10 & 432,90 & 432,90 & $0,0025^{*}$ & 403,86 & 59,61 \\
\hline
\end{tabular}




\subsubsection{Paroxítonos e Proparoxítonos}

Vejamos, então, as médias de duração nas palavras terminadas em núcleo simples, nas quais o padrão acentual esperado era o paroxítono ou o proparoxítono. A Tabela 64 a seguir apresenta as médias de duração por nível de proficiência em palavras reais. Percebe-se que a diferença de duração entre os níveis só foi estatisticamente significativa em duas palavras: accountant e lollipop. Pode-se observar que a sílaba $a$ - de accountant foi significativamente mais baixa nos níveis intermediário e avançado do que no nível básico, provavelmente porque, ao contrário dos informantes do nível básico, os falantes de nível intermediário e avançado podem ter produzido (corretamente) o schwa nesta sílaba, que é significativamente mais curto do que uma vogal plena. Na palavra lollipop, a sílaba -lli- também foi significativamente mais longa na produção dos informantes de nível básico, assim como as outras duas sílabas desta palavra, o que indica que os falantes de nível básico podem ter produzido a palavra inteira de forma mais lenta do que os informantes dos níveis mais avançados. Na maioria dos casos em que não houve diferença estatisticamente significativa entre os grupos, a duração da palavra como um todo é maior no nível básico do que nos níveis intermediário e avançado.

Tabela 64: Duração em palavras reais com padrão paroxítono ou proparoxítono por nível de proficiência

\begin{tabular}{|c|c|c|c|c|c|c|c|c|c|c|}
\hline \multicolumn{11}{|c|}{ Duração (em milissegundos) } \\
\hline \multirow{2}{*}{ Palavra } & \multirow{2}{*}{$\begin{array}{c}\text { Síla- } \\
\text { ba }\end{array}$} & \multicolumn{2}{|c|}{ Básico } & \multicolumn{2}{|c|}{ Intermediário } & \multicolumn{2}{|c|}{ Avançado } & \multirow{2}{*}{$\begin{array}{c}\text { p- } \\
\text { valor }\end{array}$} & \multicolumn{2}{|c|}{ Nativos } \\
\hline & & Média & DP & Média & DP & Média & DP & & Média & DP \\
\hline \multirow{3}{*}{ absent } & $\mathrm{ab}$ & 184,50 & 26,33 & 202,00 & 202,00 & 184,67 & 184,67 & 0,2733 & 202,29 & 20,78 \\
\hline & sent & 506,60 & 80,49 & 398,40 & 398,40 & 442,56 & 442,56 & 0,0726 & 307,86 & 29,48 \\
\hline & $\mathrm{a}$ & 119,00 & 42,97 & 67,11 & 67,11 & 62,70 & 62,70 & 0,0032 & 63,86 & 20,6 \\
\hline \multirow{3}{*}{$\begin{array}{c}\text { accoun- } \\
\text { tant }\end{array}$} & ccoun & 362,10 & 66,78 & 355,44 & 355,44 & 345,13 & 345,13 & 0,8641 & 276,14 & 23,01 \\
\hline & tant & 382,78 & 108,09 & 324,78 & 324,78 & 389,90 & 389,90 & 0,2443 & 272 & 59,55 \\
\hline & $\mathrm{a}$ & 117,00 & 21,73 & 108,50 & 108,50 & 109,80 & 109,80 & 0,4018 & 129,14 & 28,44 \\
\hline \multirow[t]{2}{*}{ apricot } & pri & 200,80 & & 195,40 & 195,40 & & & & & \\
\hline & $\cot$ & 391,56 & 49,18 & 394,50 & 394,50 & 384,30 & 384,30 & 0,9703 & 336,29 & 31,56 \\
\hline \multirow{2}{*}{ attic } & $\mathrm{a}$ & 130,40 & 18,86 & 154,00 & 154,00 & 125,10 & 125,10 & 0,0565 & 151,29 & 16,71 \\
\hline & ttic & 376,40 & 55,63 & 374,20 & 374,20 & 391,10 & 391,10 & 0,8792 & 261 & 30,58 \\
\hline$a w k-$ & aw & 216,10 & 104,13 & 175,40 & 175,40 & 136,50 & 136,50 & 0,1023 & 162,29 & 26,34 \\
\hline ward & kward & 615,22 & 204,28 & 577,80 & 577,80 & 496,40 & 496,40 & 0,3579 & 360,57 & 27,83 \\
\hline base- & base & 303,90 & 59,58 & 324,00 & 324,00 & 340,10 & 340,10 & 0,4649 & 251,43 & 15,73 \\
\hline
\end{tabular}




\begin{tabular}{|c|c|c|c|c|c|c|c|c|c|c|}
\hline ment & ment & 382,30 & 120,46 & 384,40 & 384,40 & 378,20 & 378,20 & 0,8666 & 268,43 & 51,93 \\
\hline \multirow{2}{*}{ blanket } & blan & 297,00 & 45,88 & 311,60 & 311,60 & 278,10 & 278,10 & 0,5155 & 214,86 & 52,51 \\
\hline & ket & 344,50 & 66,54 & 51,40 & 351,40 & 378,00 & 378,00 & 0,3502 & 00,43 & 46,43 \\
\hline \multirow{2}{*}{ bonnet } & bo & 200,70 & 41,95 & 223,20 & 223,20 & 212,70 & 212,70 & 0,6250 & 164,71 & 42,5 \\
\hline & nnet & 335,30 & 75,29 & 50,60 & 350,60 & 352,00 & 352,00 & 0,8929 & 278,71 & 72,38 \\
\hline \multirow{2}{*}{$\begin{array}{c}\text { break- } \\
\text { fast }\end{array}$} & break & 85,20 & 73,67 & 05,50 & & 266,90 & 266,90 & 0,3811 & 07,43 & 25,61 \\
\hline & fast & 523,40 & 172,17 & 31,70 & 431,70 & 461,30 & 461,30 & 0,4469 & 01,29 & 61,11 \\
\hline \multirow{2}{*}{ carrot } & ca & 209,00 & 28,35 & 207,33 & 207,33 & 11,56 & 211,56 & 0,9216 & 174,25 & 30,62 \\
\hline & rrot & 362,67 & 62,55 & 53,67 & 353,67 & 77,00 & 377,00 & 0,5683 & 272,13 & 56,01 \\
\hline \multirow{2}{*}{ frolic } & fro & 280,50 & 63,33 & 03,10 & 303,10 & 274,40 & 274,40 & 0,5116 & 241,57 & 42,78 \\
\hline & & 297,80 & 55,66 & 300,90 & 300,90 & 327,60 & 327,60 & 0,6653 & 304,71 & 15,25 \\
\hline \multirow{2}{*}{ husband } & hus & 278,90 & 39,82 & 52,30 & 252,30 & 248,90 & 248,90 & 0,2326 & 217,57 & 51,41 \\
\hline & band & 355,90 & 108,65 & 11,00 & 311,00 & 49,40 & 349,40 & 0,4197 & 302,29 & 48,66 \\
\hline \multirow{3}{*}{ lizard } & li & 213,10 & 30,23 & 11,20 & & & 204 & 393 & 8,86 & 16,12 \\
\hline & zard & 367,30 & 47,64 & 65,60 & 365,60 & 375,00 & 375,00 & 0,9580 & 311 & 43,6 \\
\hline & lo & 179,64 & 52,62 & 174,80 & 174,80 & 159,50 & 159,50 & 0,7121 & 175,57 & 26,89 \\
\hline \multirow[t]{2}{*}{ lollipop } & lli & 117,67 & 39,20 & 90,20 & 90,20 & 11,70 & 111,70 & 0,0363 & 109,43 & 17,58 \\
\hline & pop & 428,89 & 93,91 & 404,70 & 404,70 & 15,40 & 415,40 & 0,7113 & 341,86 & 49,98 \\
\hline \multirow{2}{*}{ loquat } & lo & 179,30 & 48,72 & 204,80 & 204,80 & 184,22 & 184,22 & 0,5069 & 65,71 & 0,7643 \\
\hline & quat & 464,75 & 87,21 & 492,30 & 492,30 & 492,00 & 492,00 & 0,5145 & 103,32 & 0,1536 \\
\hline \multirow{2}{*}{ mallard } & & & & & & & 230,40 & 0,7472 & & 872 \\
\hline & llard & 389,70 & 96,96 & 338,50 & 338,50 & 407,70 & 407,70 & 0,1211 & 45,23 & 0,0993 \\
\hline \multirow{2}{*}{ market } & mar & 246,56 & 42,13 & 241,30 & 241,30 & 233,60 & 233,60 & 0,7674 & 49,09 & 0,5757 \\
\hline & & 340,00 & 33 & & & & 10 & & & 016 \\
\hline \multirow{2}{*}{ muskrat } & mus & 296,10 & 71,73 & 308,40 & 308,40 & 277,00 & 277,00 & 0,7500 & 35,32 & 0,0299 \\
\hline & krat & 491,56 & 129,17 & 447,60 & 447,60 & 446,40 & 446,40 & 0,4854 & 32,43 & 0,0309 \\
\hline \multirow{2}{*}{ pageant } & & 184,80 & 32,58 & 190,30 & 190,30 & 196,50 & 196,50 & 0,7131 & 18,37 & 0,3722 \\
\hline & & 444,67 & 83,40 & 404,90 & 404,90 & 415,60 & 415,60 & 0,4986 & 57,91 & 0,0070 \\
\hline \multirow{2}{*}{ parrot } & & 167,50 & 23,59 & 177,70 & 177,70 & 166,80 & 166,80 & 0,8512 & 39,59 & 0,8920 \\
\hline & rrot & 384,10 & 66,03 & 351,10 & 351,10 & 386,90 & 386,90 & 0,3154 & 47,95 & 0,0002 \\
\hline \multirow{2}{*}{ rabbit } & $\mathrm{ra}$ & 219,80 & 43,08 & 230,50 & 230,50 & 221,10 & 221,10 & 0,6992 & 26,49 & 0,0417 \\
\hline & & 325,67 & 49,61 & 323,30 & 323,30 & 353,30 & 353,30 & 0,3087 & 57,18 & 0,0022 \\
\hline \multirow{2}{*}{ standard } & stan & 391,30 & 69,74 & 406,90 & 406,90 & 350,90 & 350,90 & 0,3352 & 28,4 & 0,3133 \\
\hline & & 307,20 & 108,15 & 315,10 & 315,10 & 296,60 & 296,60 & 0,9748 & 37,81 & 0,0417 \\
\hline \multirow{2}{*}{ wombat } & wom & 282,70 & 57,29 & 333,00 & 333,00 & 270,40 & 270,40 & 0,0613 & 36,71 & 0,0916 \\
\hline & & 357,90 & 67,92 & 369,50 & 369,50 & 414,80 & 414,80 & 0,1812 & 24,06 & 0,0036 \\
\hline
\end{tabular}

A Tabela 65 mostra, por fim, as médias de duração nos três níveis de proficiência nos logatomas em que o acento esperado era paroxítono ou proparoxítono. Percebe-se que, assim como nos casos de palavras reais, não houve diferença estatisticamente significativa em muitas palavras. Nas palavras bornet, carrit, lochanip e trialic, a duração na última sílaba foi estatisticamente maior na produção dos falantes de nível avançado 
do que nos outros dois níveis. Observa-se que, de maneira geral, a duração na penúltima sílaba dessas palavras também foi mais alta pelos falantes de nível avançado. Na palavra currant, a duração da penúltima sílaba também foi significativamente mais alta pelos falantes de nível avançado, assim como a antepenúltima sílaba de selantip, todas destacas em cinza.

Tabela 65: Duração em palavras logatomas com padrão paroxítono ou proparoxítono por nível de proficiência

\begin{tabular}{|c|c|c|c|c|c|c|c|c|c|c|}
\hline \multicolumn{11}{|c|}{ Duração (em milissegundos) } \\
\hline \multirow{2}{*}{ Palavra } & \multirow{2}{*}{ Sílaba } & \multicolumn{2}{|c|}{ Básico } & \multicolumn{2}{|c|}{ Intermediário } & \multicolumn{2}{|c|}{ Avançado } & \multirow{2}{*}{-valor } & \multicolumn{2}{|c|}{ Nativos } \\
\hline & & Média & DP & Média & DP & Média & DP & & Média & DP \\
\hline \multirow{3}{*}{ alosmic } & $\mathrm{a}$ & 104,80 & 17,42 & 123,80 & 123,80 & 106,30 & 106,30 & 0,3827 & 120,14 & 36,86 \\
\hline & los & 292,70 & 62,24 & 254,60 & 254,60 & 304,80 & 304,80 & & 300 & 80,11 \\
\hline & $\operatorname{mic}$ & 311,56 & 34,88 & & & & 380,00 & & & 38,36 \\
\hline \multirow{3}{*}{ anicot } & $\mathrm{a}$ & 103,70 & 30,28 & & 108 & 96,80 & 96,80 & & 117,43 & 33,25 \\
\hline & ni & 123,60 & 28,03 & & 116,80 & 116,00 & 116,00 & 0,8 & 115,57 & 20,6 \\
\hline & $\cot$ & 460,67 & 93,32 & & 449,70 & 468,80 & 468,80 & & 402 & 42,03 \\
\hline \multirow{2}{*}{ appit } & $\mathrm{a}$ & 123,50 & 35,91 & & & & & & & 39,28 \\
\hline & ppit & 382,56 & 65,82 & 392,30 & 392,30 & 458,70 & 458,70 & 26 & 309,71 & 23,69 \\
\hline \multirow{2}{*}{ blarket } & blar & 312,50 & 59,83 & & 00 & & 307,20 & & & 77,89 \\
\hline & ket & & 113,58 & & & & & & & \\
\hline \multirow{2}{*}{ bornet } & bor & 244,29 & 62,80 & 239,50 & 239,50 & 280,20 & 280,20 & 0,45 & 218,29 & 71,82 \\
\hline & net & 312,88 & 95,29 & 333,90 & 333,90 & 411,50 & 411,50 & 0,0 & 309,14 & 87,27 \\
\hline \multirow{2}{*}{ brantec } & bran & 280,60 & 79,78 & & $30 s$ & & 29 & & 258 & 73,48 \\
\hline & & & & & & & & & & \\
\hline \multirow{2}{*}{ callpid } & call & 205,20 & 34,03 & 235,60 & 235,60 & 253,50 & 253,50 & 0,1632 & 258,14 & 63,73 \\
\hline & pid & 402,10 & 82,10 & 407,5 & 407,50 & 423,40 & 423,40 & 579 & 342,43 & 37,79 \\
\hline \multirow{2}{*}{ carrit } & $\mathrm{ca}$ & & & & & & & & & \\
\hline & & 280,70 & 68,26 & 356,20 & 356,20 & 382,36 & 382,36 & & 32 & 55,19 \\
\hline \multirow{2}{*}{ crastip } & cras & 295,20 & 60,83 & 312,20 & 312,20 & 289,80 & 289,80 & 65 & 297,29 & 30,48 \\
\hline & & 337,11 & 82,45 & & & & 333,80 & & & 41,95 \\
\hline \multirow{2}{*}{ custand } & cus & 228,10 & 35,53 & 255,09 & 255,09 & 246,40 & 246,40 & 0,3761 & 234,29 & 52,88 \\
\hline & tand & 376,10 & 88,25 & 373,64 & 373,64 & 404,70 & 404,70 & 0,3463 & 349,43 & 69,92 \\
\hline \multirow{2}{*}{ draspid } & dras & 326,20 & 56,86 & 330,70 & 330,70 & 345,90 & 345,90 & 0,7320 & 311,86 & 51,44 \\
\hline & & 362,00 & 72,57 & 354,00 & 354,00 & 368,00 & 368,00 & 0,7594 & 291 & 23,25 \\
\hline \multirow{2}{*}{ dullpod } & dull & 238,10 & 52,52 & 254,70 & 254,70 & 243,60 & 243,60 & 0,4644 & 213,14 & 40,89 \\
\hline & pod & 436,44 & 38,17 & 422,80 & 422,80 & 444,50 & 444,50 & 0,6692 & 391,86 & 83,03 \\
\hline \multirow{2}{*}{ garment } & gar & 245,20 & 34,87 & 257,90 & 257,90 & 274,30 & 274,30 & 0,5875 & 217 & 51,45 \\
\hline & ment & 373,14 & 51,96 & 345,10 & 345,10 & 411,20 & 411,20 & 0,1058 & 277,67 & 82,2 \\
\hline \multirow{2}{*}{ lattap } & la & 194,70 & 48,28 & 201,90 & 201,90 & 204,50 & 204,50 & 0,9101 & 216,14 & 80,1 \\
\hline & ttap & 462,00 & 59,00 & 421,30 & 421,30 & 471,00 & 471,00 & 0,3431 & 326,86 & 79,02 \\
\hline
\end{tabular}




\begin{tabular}{|c|c|c|c|c|c|c|c|c|c|c|}
\hline \multirow{3}{*}{ lochanip } & lo & 06,40 & 53,72 & 218,60 & 218,60 & 187,80 & 187,80 & 0,7782 & 151,43 & 35,34 \\
\hline & cha & 58,70 & 63,88 & 31,40 & 231,40 & 209,50 & 209,50 & 0,2376 & 205,86 & 4,25 \\
\hline & nip & 39,80 & 54,86 & 59,90 & 359,90 & 408,20 & 408,20 & 0437 & 249,57 & 3,92 \\
\hline \multirow{2}{*}{ locust } & lo & 36,00 & 29,01 & 19,20 & 219,20 & 92,10 & 192,10 &, 2240 & 165 & 3,11 \\
\hline & cust & 42,33 & 08,23 & 71,60 & 71,60 & 00,20 & 500,20 & 0,7712 & 392,57 & 5,08 \\
\hline \multirow{2}{*}{ lurrent } & $\mathrm{lu}$ & 15,20 & 55,96 & 38,20 & 38,20 & 30,40 & 230,40 & 6579 & 181,29 & 79,85 \\
\hline & rrent & 375,22 & 54,05 & 387,60 & 387,60 & 439,60 & 439,60 & 0,0555 & 381,57 & 54,4 \\
\hline \multirow{2}{*}{ narpek } & nar & 58,60 & 50,69 & 75,30 & 275,30 & 288,40 & 288,40 & 587 & 79,83 & 77,1 \\
\hline & pek & 58,00 & 96,34 & 15,00 & 15,00 & 56,90 & 456,90 & 0,3341 & 338,17 & 79,34 \\
\hline \multirow{2}{*}{ pabloc } & pa & 140,80 & 40,81 & 35,00 & 135,00 & 58,89 & 158,89 & 0,5835 & 166,88 & 63,67 \\
\hline & bloc & 18,67 & 82,20 & 31,40 & 431,40 & 462,00 & 462,00 & 0,1451 & 413,13 & 74,58 \\
\hline \multirow{2}{*}{ pebbuck } & pe & 09,50 & 26,18 & 24,60 & 24 , & 135,10 & 135,10 & 550 & 139 & 29,26 \\
\hline & buck & 434,33 & 58,86 & 426,40 & 426,40 & 467,60 & 467,60 & 0,3668 & 374,33 & 24,2 \\
\hline \multirow{3}{*}{ petanip } & e & 94,30 & 29,37 & 14,60 & 14,60 & 109,30 & 109,30 & 0,9371 & 128,14 & 28,45 \\
\hline & ta & 224,60 & 104,88 & 11,00 & 0 & 10 & 10 & 065 & 86 & 64,1 \\
\hline & ip & & 84, & & & & & 28 & & 70,06 \\
\hline \multirow{2}{*}{ plantid } & plan & 229,80 & 35,45 & 261,80 & 261,80 & 253,00 & 253,00 & 396 & 271,14 & 61,09 \\
\hline & & 345,78 & 48,90 & 333,60 & 333,60 & 370,70 & 370,70 & 995 & 374,29 & 193,16 \\
\hline \multirow{2}{*}{ plittod } & pli & 162,20 & 26,76 & 6 & 6 & 20 & 173 & 61 & & 61,12 \\
\hline & ttod & 448,50 & 85,36 & 378,11 & 378,11 & 427,60 & 427,60 & 0,1386 & 391,57 & 80,29 \\
\hline \multirow{3}{*}{ poniard } & po & 149,33 & 19,77 & 151,50 & 151,50 & 153,70 & 153,70 & 0,9629 & 144,71 & 60,41 \\
\hline & ni & 153,44 & 30,23 & 55,30 & 55,30 & 54,00 & 154,00 & 307 & 127,4 & 24,41 \\
\hline & ard & 29,25 & 75,1 & 46,60 & 60 & 70 & 318 & 290 & 309,86 & 79,59 \\
\hline \multirow{2}{*}{ pullent } & $\mathrm{pu}$ & 58,10 & 29,55 & 157,64 & 157,64 & 165,50 & 165,50 & 0,8801 & 156 & 53,96 \\
\hline & llent & 398,67 & 60,68 & 360,27 & 360,27 & 422,30 & 422,30 & 0,0874 & 321,43 & 101,44 \\
\hline \multirow{3}{*}{ sankep } & & & 37, & 309,90 & 90 & 327,40 & 327,40 & & 14 & 39,7 \\
\hline & kep & 387,50 & 71,09 & 380,10 & 380,10 & 395,90 & 395,90 & 0,6644 & 296,43 & 59,23 \\
\hline & se & 193,20 & 25,25 & 245,20 & 245,20 & 228,40 & 228,40 & 0,0097 & 194,71 & 33,22 \\
\hline \multirow[t]{2}{*}{ selantip } & la & & 36 , & & & & & & & 56,49 \\
\hline & & 68,78 & 69,91 & 71,40 & 371 & 400,00 & 400,00 & 623 & 313,57 & 48,44 \\
\hline \multirow{2}{*}{ tanlip } & $\tan$ & 54,40 & 83,75 & 258,90 & 258,90 & 268,20 & 268,20 & 0,7326 & 261 & 50,27 \\
\hline & lip & 341,00 & 97,00 & 332,30 & 332,30 & 377,60 & 377,60 & 0,1629 & 302,71 & 91,55 \\
\hline \multirow{2}{*}{ taplop } & to & 72,60 & 98,31 & 268,40 & 268,40 & 253,10 & 253,10 & 0,7038 & 276,71 & 68,77 \\
\hline & lop & 381,30 & 60,96 & 339,90 & 339,90 & 360,60 & 360,60 & 0,2610 & 384,57 & 174,8 \\
\hline \multirow{2}{*}{ tarpec } & $\operatorname{tar}$ & 176,20 & 21,08 & 189,78 & 189,78 & 203,50 & 203,50 & 0,5657 & 226,43 & 36,91 \\
\hline & & 409,78 & 85,06 & 363,44 & 363,44 & 412,90 & 412,90 & 0,2114 & 346,43 & 38,4 \\
\hline \multirow{2}{*}{ trappid } & tra & 198,60 & 43,10 & 208,40 & 208,40 & 218,22 & 218,22 & 0,8005 & 225 & 45,43 \\
\hline & ppid & 342,22 & 55,52 & 350,90 & 350,90 & 378,22 & 378,22 & 0,4134 & 288,86 & 60,01 \\
\hline \multirow{2}{*}{ trialic } & tria & 264,20 & 64,00 & 320,80 & 320,80 & 299,70 & 299,70 & 0,0797 & 335,86 & 83,07 \\
\hline & lic & 282,11 & 46,30 & 321,80 & 321,80 & 366,40 & 366,40 & 0,0091 & 314,71 & 84,41 \\
\hline \multirow{2}{*}{ turnip } & & 192,50 & 33,85 & 197,10 & 197,10 & 191,30 & 191,30 & 0,9546 & 184,57 & 31,07 \\
\hline & & 297,00 & 84,17 & 373,90 & 373,90 & 345,90 & 345,90 & 0,1669 & 264,86 & 56,1 \\
\hline
\end{tabular}

Os resultados apresentados nesta seção serão discutidos em 6.4 a seguir. 


\subsection{Discussão}

Esta seção apresenta uma discussão dos resultados apresentados na Seção 6.3. Em 6.4.1 são discutidos os resultados referentes à verificação perceptual dos falantes nativos (grupo de controle) e, em 6.2.2 são discutidos os resultados referentes às verificações perceptual e acústica pelos falantes de inglês como L2.

\subsubsection{Falantes nativos}

Os resultados indicaram que a taxa de acertos pelos falantes nativos foi, de maneira geral, bastante alta. No caso de palavras reais, os informantes aplicaram o acento na posição esperada em 94\% dos casos. Em logatomas, a taxa de acertos também foi bastante alta, de $90,1 \%$. Isso indica que as palavras inventadas nesta pesquisa realmente possuem características de palavras existentes na língua inglesa.

Os resultados indicaram, também, que a proporção de acertos foi um pouco mais alta em palavras terminadas em núcleo ramificado, nas quais o padrão acentual esperado era o oxítono, do que em palavras terminadas em núcleo simples, nas quais o padrão esperado era o paroxítono ou o proparoxítono, inclusive em logatomas, o que mostra o quanto é clara a questão da duração no inglês.

A análise por informante mostrou que não houve uma variação significativa nas proporções de acerto pelos nativos, já que todos apresentaram taxas entre $83,9 \%$ e 97,6\% (incluindo palavras reais e logatomas). No caso da análise da relação entre sílaba e acento proposta neste capítulo, esse resultado corresponde ao esperado, já que não se trata de uma regra variável como a retração de acento (cf. Capítulo 5) ou uma regra cuja aplicação pode depender do contexto como a assimilação de vozeamento (cf. Capítulo 4).

\subsubsection{Falantes de inglês como L2}

Os resultados referentes aos 30 falantes de inglês como L2 indicaram que o padrão acentual em logatomas e palavras reais foi aplicado corretamente em $72,2 \%$ dos casos, e que o número de acertos aumenta conforme o avanço do nível de proficiência. 0 Gráfico 30, repetido a seguir, compara a taxa de aplicação pelos três níveis de 
proficiência e pelos falantes nativos, os quais, como vimos em 6.4.1, apresentaram 94\% de acertos.

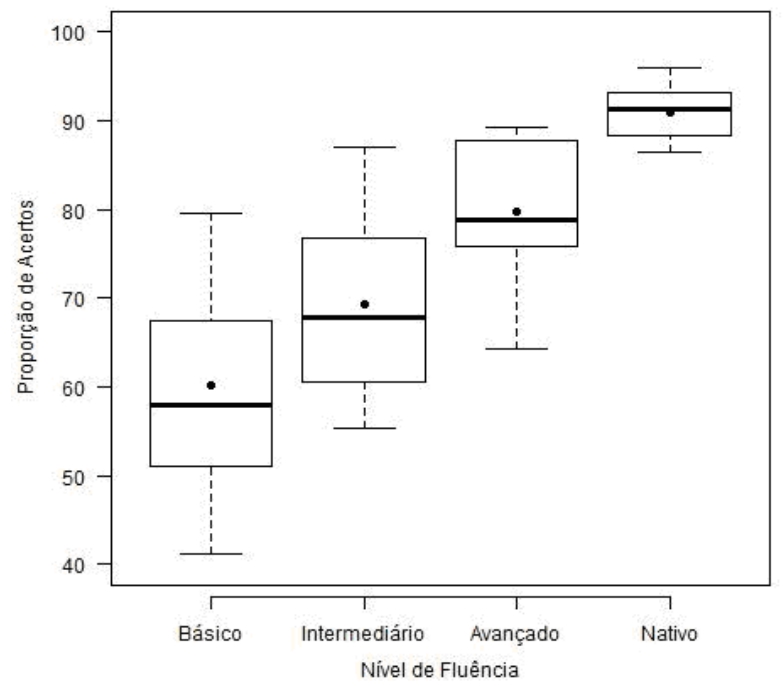

Gráfico 30: Sílaba e acento - acertos por Nível de Proficiência

Os resultados mostraram que, diferentemente dos falantes nativos, que apresentaram uma taxa de acerto um pouco maior em palavras terminadas em núcleo ramificado, nas quais o acento esperado era o oxítono, os falantes brasileiros apresentaram taxas de acerto mais altas em palavras terminadas em núcleo simples, nas quais o acento esperado era o paroxítono ou o proparoxítono. Dentre os três padrões acentuais controlados nesta pesquisa, a maior taxa de acertos foi registrada em palavras paroxítonas, com $82,9 \%$ de acerto, e a mais baixa em palavras oxítonas, com $62,8 \%$ de acertos. Os resultados mostraram, ainda, que as maiores taxas de acerto foram registradas em palavras reais cujo padrão acentual era o paroxítono (ex: RAbbit, CArrot) e as mais baixas em logatomas cujo padrão acentual esperado era o oxítono (ex: solOOP, lanDOO).

Resultados semelhantes foram encontrados na pesquisa de Post (2010) que, conforme mencionado na Seção 6.1.3, registrou muito mais erros em palavras oxítonas do que em paroxítonas. Assim como a autora, acreditamos que esse resultado seja uma indicação de que os falantes brasileiros tendem a recorrer ao padrão acentual menos marcado na língua materna, que, no caso do português, é o paroxítono (cf. Bisol, 1992).

Para verificar se o padrão oxítono passa a ser aplicado corretamente com mais frequência no nível avançado, realizamos o cruzamento entre as variáveis Padrão 
Acentual Esperado e Nível de Proficiência. 0 Gráfico 37 a seguir mostra que, nos três níveis de proficiência, o padrão paroxítono apresenta uma proporção de acertos significativamente mais alta do que o padrão oxítono. Observa-se que, nos níveis básico e intermediário, as proporções de acerto nos três padrões acentuais são bastante semelhantes, apesar de serem mais baixas no nível básico. No nível avançado, diferentemente dos outros dois níveis, a taxa de acertos em proparoxítonas é um pouco mais alta do que em paroxítonas, mas as oxítonas também são as que apresentaram a menor taxa de acertos.

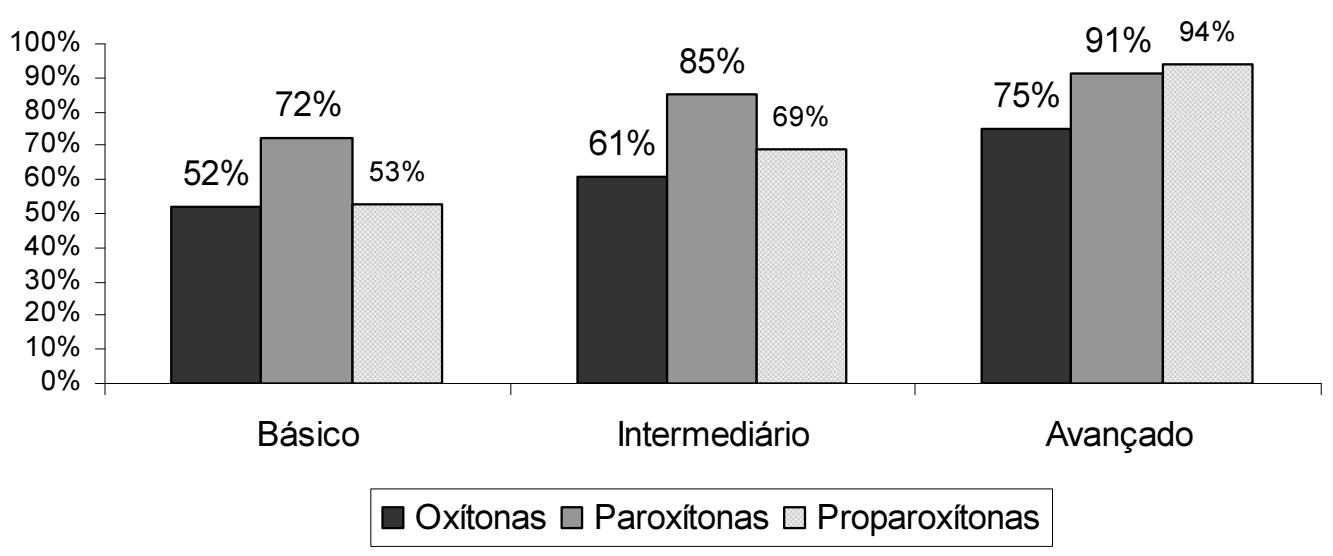

Gráfico 37: Acertos por Acento Esperado e Nível de Proficiência

Como a influência da L1 sobre a L2 é geralmente observada nos níveis iniciais, o fato de os falantes de nível avançado terem aplicado mais acertos em palavras paroxítonas do que em oxítonas poderia ser justificado pelo fato de que o padrão paroxítono também é o default na língua inglesa (cf. 6.1.2), e que esses falantes estariam, portanto, recorrendo ao padrão predominante na própria L2. Entretanto, conforme salienta Post (2010), o padrão paroxítono não ocorre em palavras terminadas em sílaba pesada, isto é, terminadas em vogal longa ou ditongo. Desse modo, o favorecimento do acerto pelo padrão paroxítono neste trabalho, assim como as estratégias de reparo apontadas em Post (2010), podem ser evidência de que, mesmo no nível avançado, há uma certa influência do padrão acentual da língua materna sobre a língua-alvo.

Os resultados também indicaram que o segmento da sílaba final foi estatisticamente significativo e que o acerto foi favorecido por palavras terminadas em [t], [d] e [k], nas quais o padrão esperado era o paroxítono. Sendo assim, apesar de a variável Padrão da Sílaba Final, cujos fatores eram núcleo simples ou núcleo ramificado, 
não ter sido estatisticamente relevante, fica claro que o acerto foi favorecido por palavras terminadas em núcleo simples, nas quais o padrão acentual era o paroxítono.

Assim como nos resultados dos falantes nativos, observou-se que os falantes de inglês como L2 apresentaram mais acertos em palavras reais do que em logatomas. Observou-se, também, que a inserção de epêntese ocorreu em apenas 79 casos (de 3683), principalmente no nível básico. Os casos de epêntese no nível intermediário ocorreram apenas nas palavras lanese, calonese, poloose e paneep, todas logatomas. Percebeu-se que, nas palavras lanese e calonese, as quais foram criadas a partir do padrão fonológico encontrado em palavras como police e Japanese, os informantes não reconheceram no padrão da escrita um padrão que remetesse às palavras reais que inspiraram a criação desses logatomas, e acabaram produzindo [la.'nc.zi] e [ka.lo.'ne.zi] em vez de [lə.'ni:s] e [ka.lo.'ni:s].

Consideremos, então, os resultados referentes à duração, os quais foram apresentados na Seção 6.3.3. Com relação às palavras oxítonas, os resultados indicaram que a média de duração na penúltima sílaba em palavras reais como baloon e bamboo e em logatomas como deleen, galeen e lanese foi significativamente mais alta na produção dos falantes brasileiros do que na dos nativos. Como foram constatados muitos casos de palavras em que a sílaba final também foi mais longa na produção de não nativos, isso poderia indicar, simplesmente, que os falantes nativos produzem as palavras de maneira mais rápida (fluente) e, por isso, apresentam valores de duração significativamente mais baixos do que os falantes brasileiros.

Entretanto, observamos diversos casos em que, enquanto a penúltima sílaba apresentou uma duração significativamente mais longa na fala de nativos, a última sílaba apresentou um valor mais baixo do que a média dos nativos, como nos casos de palavras reais como kangaroo e Chinese e de logatomas como poleen e tanloo. Sendo assim, nem todas as ocorrências de diferença significativa entre as médias de duração dos nativos e dos brasileiros ocorreram em decorrência do fato de os nativos produzirem as palavras de forma mais rápida e fluente, já que em diversos casos a duração na última sílaba é mais curtana produção dos brasileiros. Isso pode ser um indicativo de que, ao menos nessas palavras, os brasileiros produziram vogais curtas em vez de longas em posição final, o que acabou desfazendo o núcleo ramificado da sílaba final e alterando o acento que seria oxítono para paroxítono, conforme previsto na Seção 6.2. 
Os resultados separados por nível de proficiência parecem trazer mais evidências a respeito do desfazimento do núcleo ramificado pelos falantes brasileiros. Os resultados da Tabela 62 mostram que, nos 12 casos em que houve diferença significativa na duração da última sílaba, houve um aumento gradual em direção ao nível avançado. Em uma palavra como bamBO0, por exemplo, a sílaba -boo foi mais breve na produção dos falantes de nível básico, um pouco mais longa pelos falantes de nível intermediário e ainda mais longa pelos falantes de nível avançado. Esse resultado parece indicar que, pelo menos no que diz respeito à essas palavras, os falantes passam a produzir a vogal longa na última sílaba conforme o avanço do nível de proficiência, o que constitui o núcleo ramificado e atrai o acento no inglês, do mesmo modo que os falantes nativos. No nível básico a duração é mais breve porque os informantes tendem a produzir vogais curtas em vez de longas, o que mostra que, para esses informantes, essas palavras possuem núcleo simples.

Portanto, dois fatos podem ser observados a respeito das médias de duração em palavras oxítonas: 1) De modo geral, os falantes não nativos apresentam durações mais altas em todas as sílabas do que os falantes nativos, o que parece indicar que os nativos, por serem fluentes, produzem as palavras de maneira mais rápida; 2) Em determinadas palavras, a duração de sílabas finais com núcleo ramificado é significativamente mais longa na produção de falantes do nível avançado do que nos falantes de nível básico, o que pode indicar que, no decorrer da aquisição, os falantes aprendem a produzir vogais longas nas sílabas finais dessas palavras e atribuem o acento oxítono de maneira correta.

Com relação às palavras paroxítonas, observou-se que, de modo geral, a duração é mais longa na produção dos brasileiros do que na fala de nativos tanto na sílaba final quanto nas outras sílabas. Observou-se, também, que a duração de todas as sílabas no nível básico é mais longa do que no nível avançado, o que parece indicar que, neste caso, a duração é mais uma questão de "ser mais fluente" do que de atribuição do acento.

Os resultados referentes à relação entre sílaba e acento indicaram, portanto, que o nível de proficiência é um fator bastante relevante para a aplicação do acerto e que os falantes de nível avançado, que representam o estágio final da aquisição, apresentaram uma taxa de acertos bastante aproximada à dos falantes nativos. Observou-se, também, que, assim como no estudo de Post (2010), os informantes tiveram mais facilidade em adquirir o acento de paroxítonas do que de oxítonas terminadas em sílabas longas. 


\section{Capítulo 7}

\section{DISCUSSÃO}

A partir dos resultados apresentados e discutidos nos Capítulos 4, 5 e 6 pretendemos, no presente capítulo, discutir o papel da GU e da língua materna, o percurso de aquisição e o fator idade na aquisição de segunda língua à luz das hipóteses e predições de pesquisa concebidas no Capítulo 3.

Vimos no Capítulo 2 que diversas propostas a respeito da disponibilidade da GU e do estado inicial da gramática da L2 foram estabelecidas na literatura em aquisição de segunda língua. Todas as propostas descritas na presente pesquisa assumem que a GU permanece disponível e que a L1 influencia, de alguma forma, o processo de aquisição de L2, mas divergem a respeito do estado inicial da aquisição e do papel da GU durante o processo.

Para comparar o que as quatro maiores propostas que assumem o acesso à GU dizem a respeito do estado inicial, das etapas de desenvolvimento e do estágio final na aquisição de L2, apresentamos a seguir uma versão resumida do Quadro 3, apresentado no Capítulo 2. Pode-se observar que, dentre as quatro, apenas a Hipótese do Acesso Total/Sem Transferência, proposta por Epstein et al. (1996), rejeita a transferência da L1 para a L2. De acordo com essa proposta, os princípios e parâmetros da GU permanecem disponíveis na aquisição de L2 e o estado inicial da aquisição é constituído pela GU, assim como na aquisição de L1. Como vimos no Capítulo 2, as principais críticas contra esta hipótese dizem respeito à previsão de que os aprendizes de L2 adultos sempre atingiriam o nível de proficiência nativo, o que não condiz com as evidências encontradas na literatura em aquisição de segunda língua. As outras três propostas (Acesso Total/Transferência Total, Árvores Mínimas e Traços Indeterminados) assumem que há uma transferência da L1 para a L2, principalmente no estágio inicial, mas variam no que diz respeito à intensidade dessa transferência. Com relação ao estado estável (ou estágio final da aquisição), a Hipótese das Árvores Mínimas, a Hipótese dos Traços Indeterminados e a Hipótese do Acesso Total/Sem Transferência preveem a aquisição de uma gramática igual ou muito semelhante à fala nativa, enquanto a 
Hipótese do Acesso Total/ Transferência Total assume que, embora seja possível, não é sempre que se chega a um sistema tão semelhante à gramática da língua-alvo.

Quadro 17: Resumo das principais propostas sobre o papel da GU e da L1 na aquisição de L2

\begin{tabular}{|c|c|c|c|c|}
\hline & $\begin{array}{l}\text { Acesso Total/ } \\
\text { Transf. Total } \\
\end{array}$ & $\begin{array}{l}\text { Árvores } \\
\text { Mínimas }\end{array}$ & $\begin{array}{c}\text { Traços } \\
\text { Indeterminados } \\
\end{array}$ & $\begin{array}{c}\text { Acesso Total/ } \\
\text { Sem Transf. }\end{array}$ \\
\hline $\begin{array}{l}\text { ESTADO } \\
\text { INICIAL }\end{array}$ & $\begin{array}{l}\text { Transferência } \\
\text { forte. } \\
\text { O estado inicial é a } \\
\text { gramática da L1, mas } \\
\text { há acesso total à GU. } \\
\text { Estão disponíveis: } \\
\text { categorias funcionais } \\
\text { e lexicais da L1, traços } \\
\text { e força de traços } \\
\text { (feature strengtht). }\end{array}$ & $\begin{array}{l}\text { Transferência } \\
\text { parcial. } \\
\\
\text { Acesso indireto à } \\
\text { GU (via L1). } \\
\text { Categorias } \\
\text { funcionais da L1 } \\
\text { não estão } \\
\text { disponíveis, } \\
\text { somente as } \\
\text { lexicais. }\end{array}$ & $\begin{array}{l}\text { Transferência } \\
\text { fraca. } \\
\text { Categorias funcio- } \\
\text { nais e lexicais da L1 } \\
\text { estão disponíveis, } \\
\text { mas os valores das } \\
\text { categorias } \\
\text { funcionais são } \\
\text { indeterminados. }\end{array}$ & $\begin{array}{c}\text { Sem } \\
\text { transferência. } \\
\\
\text { Categorias } \\
\text { funcionais e } \\
\text { lexicais da L1, } \\
\text { traços e valores } \\
\text { dos traços. }\end{array}$ \\
\hline $\begin{array}{l}\text { DESENVOL- } \\
\text { VIMENTO }\end{array}$ & $\begin{array}{l}\text { Falantes de L1s di- } \\
\text { ferentes percorrem } \\
\text { caminhos diferentes. A } \\
\text { modificação de } \\
\text { parâmetros é possível, } \\
\text { assim como a } \\
\text { marcação de } \\
\text { parâmetros } \\
\text { inexistentes na L1. }\end{array}$ & $\begin{array}{l}\text { Emergência de } \\
\text { categorias } \\
\text { funcionais em } \\
\text { estágios, com base } \\
\text { no input da L2. }\end{array}$ & $\begin{array}{c}\text { Traços } \\
\text { indeterminados são } \\
\text { adquiridos no } \\
\text { decorrer do } \\
\text { processo. }\end{array}$ & $\begin{array}{l}\text { Nenhum desen- } \\
\text { volvimento } \\
\text { necessário em } \\
\text { propriedades } \\
\text { abstratas de } \\
\text { categorias } \\
\text { funcionais. }\end{array}$ \\
\hline $\begin{array}{l}\text { ESTADO } \\
\text { ESTÁVEL }\end{array}$ & $\begin{array}{l}\text { Aquisição total da } \\
\text { gramática da L2 é } \\
\text { possível, mas nem } \\
\text { sempre é alcançada }\end{array}$ & $\begin{array}{c}\text { Gramática igual } \\
\text { ou muito } \\
\text { semelhante à da } \\
\text { L2. } \\
\end{array}$ & $\begin{array}{l}\text { Gramática igual ou } \\
\text { muito semelhante à } \\
\text { da L2. }\end{array}$ & $\begin{array}{l}\text { Gramática igual } \\
\text { ou muito seme- } \\
\text { lhante à da L2. }\end{array}$ \\
\hline
\end{tabular}

Como se observa, toda a discussão baseia-se em dados de aquisição sintática, e até onde sabemos, não há trabalhos discutindo a validade destas propostas levando em conta a aquisição de regras fonológicas que podem ser influenciadas pela GU, pela L1, ou por nenhuma delas. ${ }^{48} \mathrm{~A}$ grande diferença está em que a fonologia funciona com unidades diferentes da sintaxe (por exemplo, não há como se discutir categorias funcionais vs. lexicais). Especificamente, o presente trabalho pretende contribuir para esta discussão investigando a aquisição de três fenômenos fonológicos do inglês pelos mesmos informantes brasileiros: a regra de assimilação de vozeamento, que existe tanto no inglês quanto no $\mathrm{PB}$, mas de maneira diferente e, portanto, trata-se de uma regra a ser modificada; a regra de retração de acento, que ocorre de maneira muito semelhante nas duas línguas e representa uma regra a ser transferida da L1 para a L2; e a relação entre

\footnotetext{
${ }^{48}$ Lembramos que Archibald (1992, 1993a, 1993b) discute apenas a questão da (re)marcação de parâmetros e do acesso à GU na aquisição de segunda língua.
} 
sílaba e acento, que é totalmente diferente no inglês e no PB e se dá através da marcação de parâmetros métricos. Além disso, pretendemos trazer para a discussão o papel do fator idade de início de aquisição (mesmo que aqui estejamos falando de aprendizado através de instrução formal e não de um processo semelhante ao percorrido pelas crianças para adquirir a primeira língua) e do nível de proficiência.

A análise da aquisição das regras de retração de acento e de assimilação de vozeamento permite verificar de que forma o sistema fonológico da L1 pode influenciar a aquisição de segunda língua. No caso da regra de retração de acento, a transferência da regra da L1 tem um papel facilitador na aquisição da L2, já que a regra ocorre de maneira muito semelhante no português e no inglês (como vimos no Capítulo 5, exceto pela distância entre os choques de acento). No que diz respeito à regra de assimilação de vozeamento, por outro lado, a transferência da regra da L1 não resulta necessariamente na produção correta, já que a direção de aplicação da regra é diferente nas duas línguas. A análise da relação entre sílaba e acento, por sua vez, permite verificar a possibilidade de marcar o parâmetro do acento da língua-alvo. Como vimos no Capítulo 1, ainda que os parâmetros sejam universais, a marcação para cada parâmetro varia de língua para língua e ocorre de maneira diferente no inglês e no português. Essas línguas diferem no que diz respeito ao peso silábico, já que, diferentemente do $\mathrm{PB}$, no inglês sílabas com núcleo ramificado são consideradas pesadas e sílabas com núcleo simples em final de palavra são consideradas leves. Sendo assim, para que os falantes brasileiros adquiram a regra de acento do inglês, é necessário que (re)marquem ${ }^{49}$ o parâmetro referente ao peso silábico do inglês.

Desse modo, caso os resultados mostrassem que o fenômeno adquirido com mais facilidade fosse a relação entre sílaba e acento, isso seria uma evidência de que o estado inicial da aquisição é caracterizado pela GU, que permitiu que a marcação do parâmetro do acento ocorresse antes da transferência da regra de retração de acento da L1. Caso a regra de retração de acento fosse adquirida com mais facilidade, isso significaria que o estado inicial da aquisição é caracterizado pela gramática da L1 e que haveria uma

\footnotetext{
${ }^{49}$ Embora seja assunto muito interessante, foge do escopo desta tese discutir se o que ocorre é uma marcação paramétrica (a partir do valor da GU) ou de uma remarcação do valor marcado pela L1. Isto porque, para que este teste fosse conduzido, seria necessário que o valor da GU fosse diferente do valor de L1. Como vimos, segundo Dresher \& Kaye (1990), na GU o valor default para peso silábico é 'não', mas o valor default para o que é pesado é 'rima'. Ocorre que 'rima' é também o valor desse parâmetro para o português. Assim, quando adquirindo o inglês, não é possível saber se o falante brasileiro está usando o valor da GU ou do português, já que se trata do mesmo valor.
} 
transferência positiva ${ }^{50}$ dessa regra para a L2. Por fim, caso a assimilação de vozeamento fosse adquirida com mais facilidade, isso significaria que nem a L1 e nem a GU foram fatores determinantes no processo de aquisição desses informantes, já que não se trata de um caso de marcação paramétrica ou de transferência (positiva) da L1 para a L2. Através da comparação entre a aquisição do vozeamento (que deve ser feita por modificação na regra existente em L1) e a aquisição do acento (que deve ser feita pela modificação no valor do parâmetro), é possível observar se é mais fácil a mudança de um valor paramétrico ou de uma regra fonológica.

O Quadro 18 a seguir, que já foi apresentado de forma mais detalhada no Capítulo 3, resume as previsões a respeito do papel da GU e da L1 enquanto facilitadores no estado inicial da aquisição de acordo com as possibilidades de aquisição dos três fenômenos em análise. Observa-se que, em determinadas possibilidades de aquisição, fatores como instrução explícita, motivação, quantidade e qualidade do input, entre outras variáveis que não foram controladas nesta pesquisa, podem ser tão relevantes quanto a L1 ou a GU durante o processo de aquisição.

Quadro 18: Resumo das previsões acerca da aquisição dos três processos

\begin{tabular}{|c|c|}
\hline POSSIBILIDADES DE AQUISIÇÃO & PAPEL DA GU E DA L1 \\
\hline $\begin{array}{c}\text { Retração de acento > assimilação de vozeamento, sílaba } \\
\text { e acento }\end{array}$ & L1 \\
\hline $\begin{array}{c}\text { Sílaba e acento > retração de acento, assimilação de } \\
\text { vozeamento }\end{array}$ & GU \\
\hline $\begin{array}{l}\text { Assimilação de vozeamento > retração de acento, } \\
\text { relação entre sílaba e acento. }\end{array}$ & Nem L1 nem GU \\
\hline $\begin{array}{c}\text { Retração de acento, sílaba e acento > assimilação de } \\
\text { vozeamento. }\end{array}$ & GU e L1 \\
\hline $\begin{array}{l}\text { Retração de acento, assimilação de vozeamento > sílaba } \\
\text { e acento. }\end{array}$ & L1 + outros fatores \\
\hline $\begin{array}{l}\text { Assimilação de vozeamento, sílaba e acento > retração } \\
\text { de acento }\end{array}$ & L1 não afeta o processo \\
\hline $\begin{array}{c}\text { Retração de acento, sílaba e acento > assimilação de } \\
\text { vozeamento }\end{array}$ & L1 e GU \\
\hline $\begin{array}{l}\text { Os três processos são adquiridos de forma semelhante, } \\
\text { não há mais fácil ou mais difícil. }\end{array}$ & GU, L1 + outros fatores \\
\hline
\end{tabular}

${ }^{50}$ Como vimos no Capítulo 2, a transferência positiva, também chamada de facilitação, ocorre quando a influência da L1 resulta em uma produção correta, enquanto a negativa (também conhecida como interferência), resulta em uma produção incorreta (cf. Gass e Selinker, 2009, p. 93). 
As seções a seguir discutem se as hipóteses levantadas no Capítulo 3 a respeito do papel da GU e da L1, do percurso de aquisição e do fator idade podem explicar os resultados reportados nos Capítulos 4, 5 e 6. Para facilitar a argumentação, as hipóteses não serão necessariamente discutidas na ordem que foram apresentadas no Capítulo 3.

\subsection{0 percurso de aquisição}

Com o objetivo de verificar o desenvolvimento dos três fenômenos investigados nesta pesquisa, analisamos as produções de falantes nos níveis básico, intermediário e avançado com a hipótese de que o tempo de estudo afeta a L2. Assim, a predição é que no nível avançado, os aprendizes apresentariam produções mais semelhantes ao falar nativo do que os de nível básico e intermediário, ou seja, teriam sido capazes de adquirir as duas regras em análise e, ainda, marcar o parâmetro do acento. Vejamos, então, os resultados referentes ao nível de proficiência em cada um dos fenômenos analisados.

Com relação à regra de assimilação de vozeamento, a qual é desencadeada pelo contexto precedente no inglês (ex: $\operatorname{dog}[z], J^{\circ} n^{\prime}[z]$ ) e pelo contexto seguinte no português (ex: me[z]mo, casa[z] amarelas), os resultados indicaram que a variável nível de proficiência foi estatisticamente significativa e que os falantes de nível intermediário foram os que apresentaram mais casos de vozeamento, com 33\% de fricativas vozeadas, seguidos dos falantes de nível avançado, com 27,33\%, e dos falantes de nível básico, com 16,5\%, conforme o Gráfico 37 a seguir (Gráfico 5 do Capítulo 4).

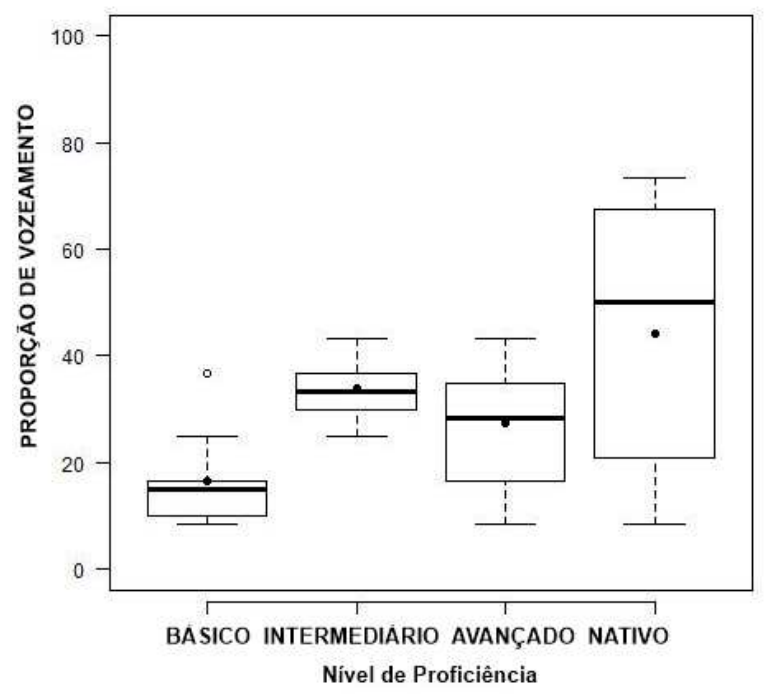

Gráfico 37: Vozeamento por nível de proficiência 
Contudo, como vimos no Capítulo 4, ficou claro que o nível de proficiência foi significativo apenas quando consideramos a taxa de aplicação do vozeamento tanto nos contextos em que o vozeamento poderia ser resultado de assimilação regressiva (ex: $\operatorname{dog}[z]$ around), quanto nos contextos em que só poderia ser resultado de assimilação progressiva (ex: many dog[z]). Se observarmos a taxa de aplicação do vozeamento especificamente nos casos que não permitiam a assimilação regressiva do português, ou seja, casos de fricativa seguida de consoante desvozeada ou de pausa, o vozeamento foi aplicado em apenas $0,6 \%$ dos dados (12/1023). Nesses contextos específicos, não houve um aumento na aplicação do vozeamento conforme o avanço do nível de proficiência, já que todos os níveis apresentaram uma taxa de vozeamento extremamente baixa, conforme o Gráfico 38 a seguir (Gráfico 13 do Capítulo 4).

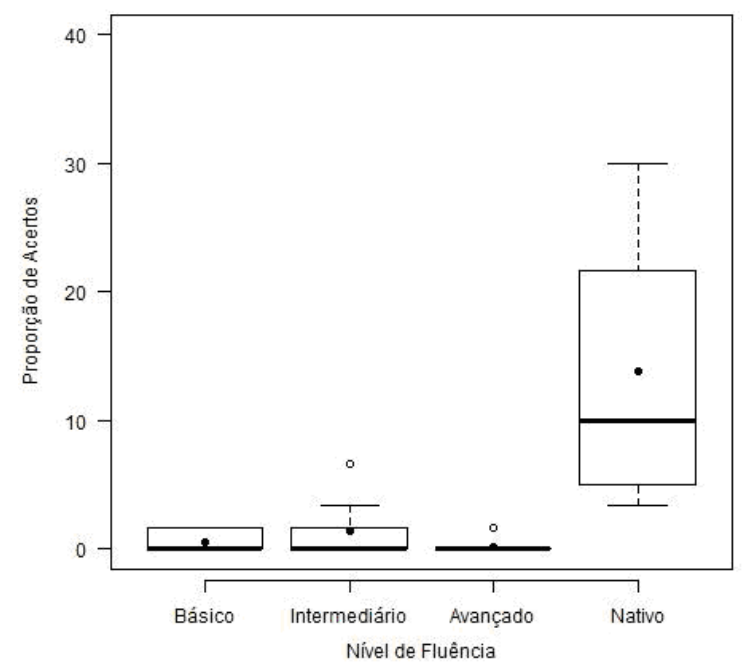

Gráfico 38: Aplicação do vozeamento em fricativas seguidas de pausa ou de consoante desvozeada por nível de proficiência

Como se observa neste gráfico, mesmo os falantes nativos aplicam muito pouco o processo. Ainda assim, a diferença entre a média de aplicação dos brasileiros, nos três níveis, e dos nativos, é sempre significativa. E no que respeita à comparação entre os diferentes níveis para os falantes brasileiros, não houve diferença estatística entre eles, até porque quase não houve aplicação do processo.

Desse modo, ainda que o nível intermediário tenha apresentado mais aplicações de vozeamento do que os níveis básico e avançado no Gráfico 37, não se pode afirmar que a regra do inglês foi adquirida em nenhum nível de proficiência se observarmos especificamente os casos que não permitiam a aplicação da regra regressiva do $\mathrm{PB}$, pois 
nem mesmo os falantes de nível avançado foram capazes de produzir o vozeamento do /s/ nesses contextos.

Com relação à retração de acento, por outro lado, observou-se um aumento na taxa de aplicação da regra conforme o avanço do nível de proficiência. Pode-se observar no Gráfico 39 a seguir (Gráfico 18 no Capítulo 5), que a média de aplicação da regra aumenta conforme o nível de proficiência e que alguns falantes de nível avançado apresentaram, inclusive, uma proporção de retração mais alta do que os falantes nativos. Percebe-se, também, que há bastante variação na proporção de retração de acento nos três níveis de proficiência, e que essa variação é menor no grupo de falantes nativos. No caso da retração de acento, pode-se dizer, portanto, que os falantes brasileiros apresentaram produções mais semelhantes ao falar nativo no estágio final da aquisição do que nos níveis iniciais, conforme o previsto.

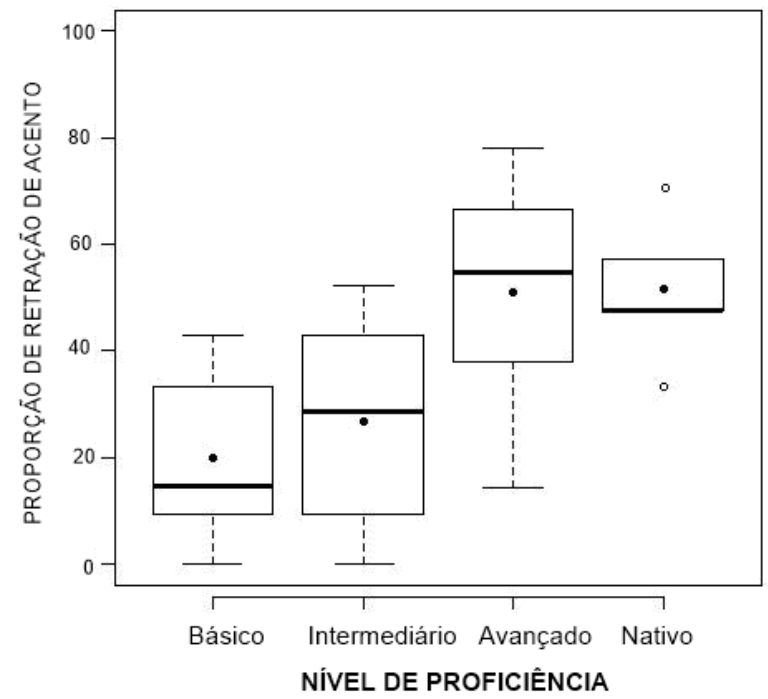

Gráfico 39: Retração de Acento por Nível de Proficiência

Por fim, os resultados referentes à relação entre sílaba e acento também indicam claramente um percurso de aquisição em direção ao falar nativo. Os resultados apontaram que os informantes de nível básico apresentaram a menor taxa de acertos, de 60,9\%, seguidos dos falantes de nível intermediário, com 72,4\% de acertos e dos informantes de nível avançado, com 83,3\% de acertos, o valor mais aproximado ao apresentado pelos nativos (94\%). 0 avanço gradual na proporção de acertos por nível de proficiência pode ser observado no Gráfico 40 a seguir (Gráfico 30 do Capítulo 6). 


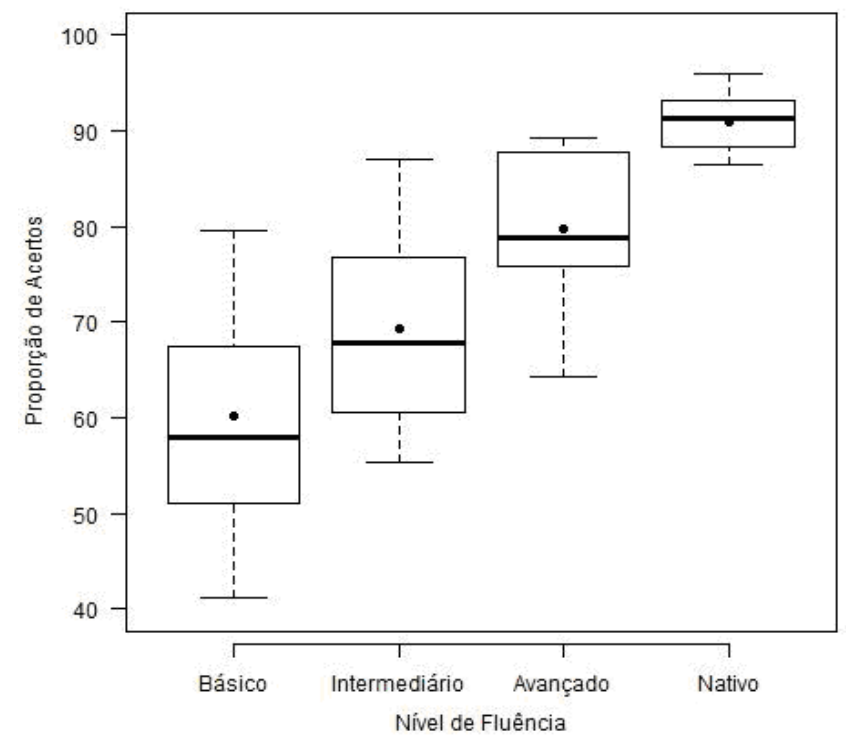

Gráfico 40: Sílaba e acento - acertos por Nível de Proficiência

Desse modo, a hipótese a respeito do nível de proficiência não pode ser completamente negada (não se pode negar a hipótese nula de que nível de proficiência não afetaria a aquisição), pois houve um avanço em direção ao falar nativo na aquisição da regra de retração de acento e da relação entre sílaba e acento, mas os resultados referentes à assimilação de vozeamento indicaram que a regra não foi adquirida em nenhum nível de proficiência. Esses resultados parecem indicar que o tempo de estudo pode afetar alguns fenômenos fonológicos, mas não temos, e há que se discutir o porquê.

\subsection{A influência da idade}

Vimos na Seção 2.3.1 que o fator idade é uma questão amplamente discutida na pesquisa em aquisição de L2, já que evidências apontam para o fato de que, quanto mais tarde o aprendiz for exposto a uma segunda língua, maior será a influência da L1 sobre a língua-alvo. Com o objetivo de verificar se a idade de início da aquisição teria alguma influência sobre a produção dos aprendizes na presente pesquisa, dividimos nossos informantes em dois grupos: falantes que iniciaram a aquisição do inglês antes dos 12 anos e falantes que iniciaram a aquisição após os 12 anos, com base na hipótese de que aqueles que iniciaram a aquisição mais jovens apresentariam produções mais semelhantes ao modo de falar nativo, conforme a Hipótese do Período Crítico (Lenneberg, 1967). 
Com relação à assimilação de vozeamento, houve uma tendência de os falantes que iniciaram a aquisição antes dos 12 anos aplicarem mais o vozeamento nos três níveis de proficiência (cf. Gráfico 10, Cap. 4), mas não se observa essa diferença quando consideramos especificamente os casos em que o vozeamento não poderia ser influenciado pela regra regressiva do PB, pois, como vimos, a proporção de vozeamento foi extremamente baixa nesses contextos. 0 Gráfico 41 a seguir (Gráfico 12 do Cap. 5) apresenta a proporção de vozeamento por idade de início da aquisição e por nível de proficiência nos contextos de fricativa seguida de pausa ou de consoante desvozeada, quando a regra do português não poderia ser aplicada. Como vimos, houve apenas 12 casos devozeamento nestes contextos, e o gráfico não indica nenhuma tendência de aplicação da regra em um ou outro grupo de idade.

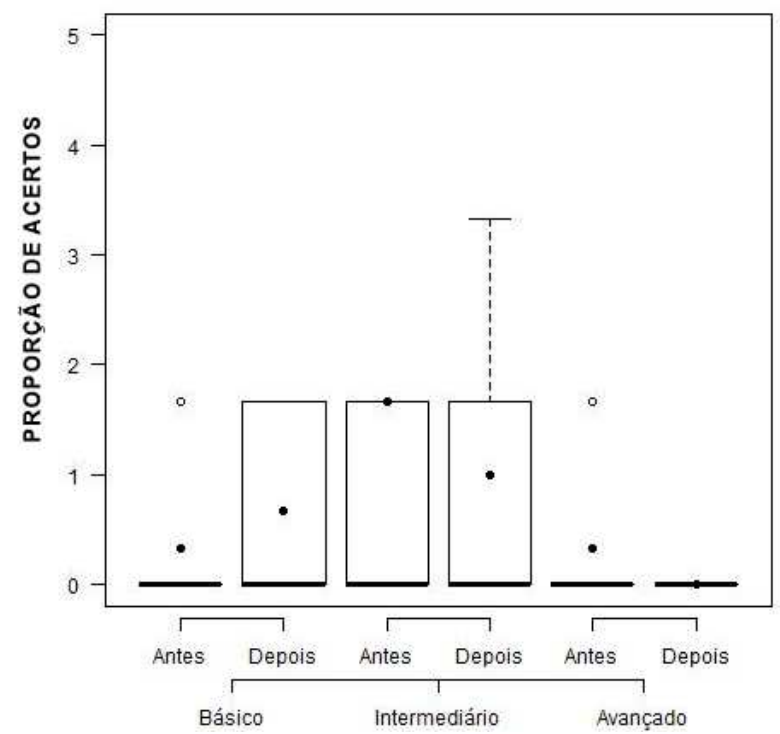

\section{Gráfico 41: Vozeamento por Idade de aquisição e Nível de Proficiência: contexto seguinte desvozeado ou pausa}

No que diz respeito à retração de acento, o fator idade de início da aquisição foi estatisticamente significativo e indicou que a aplicação da regra foi mais frequente nos dados dos informantes que iniciaram a aquisição antes dos 12 anos, o que seria uma evidência de que iniciar a aquisição da L2 antes da puberdade pode, sim, ter uma influência sobre a produção dos informantes. Essa tendência foi observada tanto no que concerne às taxas dos dois grupos de idade em comparação com a taxa dos falantes nativos, conforme Gráfico 42 a seguir (Gráfico 21 do Cap. 5), quanto com relação à aplicação da regra por grupo de idade em cada nível de proficiência, conforme o Gráfico 43 a seguir. 


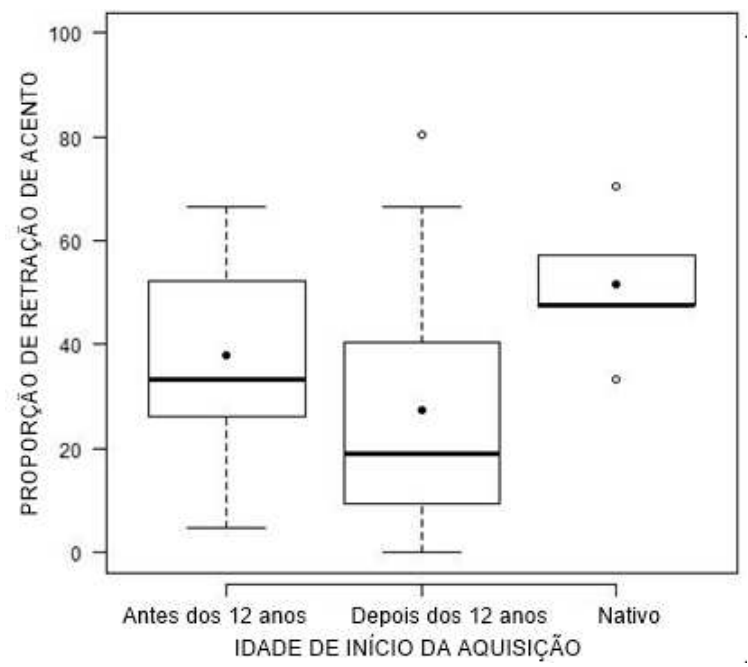

Gráfico 42: Retração de acento por Idade de início da aquisição

Observa-se que, nos três níveis de proficiência, os falantes que iniciaram a aquisição antes dos 12 anos apresentaram, em média, uma taxa de aplicação mais alta do que os que iniciaram a aquisição após os 12 anos.

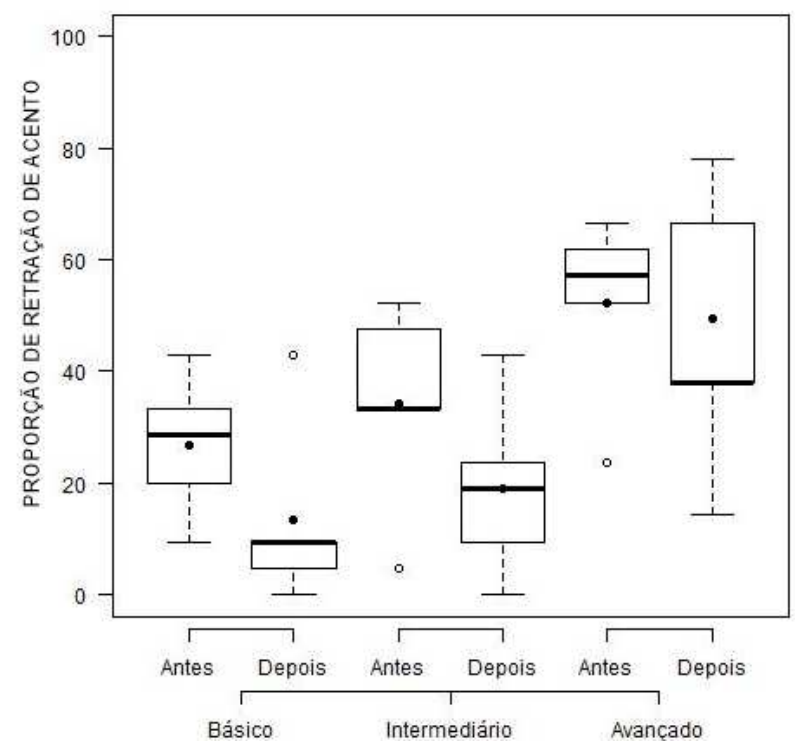

Gráfico 43: Retração por Idade de início da aquisição e nível de proficiência

Em resumo, a idade de início de aquisição mostrou-se um fator relevante para a retração de acento.

Vejamos, por fim, os resultados referentes ao fator idade na aquisição do acento. Se considerarmos a diferença na taxa geral de acertos entre os dois grupos de idade, percebemos que, ainda que o grupo que iniciou a aquisição antes dos 12 anos tenha 
apresentado uma média de acertos um pouco mais alta, a diferença entre os dois grupos não é significativa, conforme o Gráfico 44 a seguir (Gráfico 35 do Cap. 6).

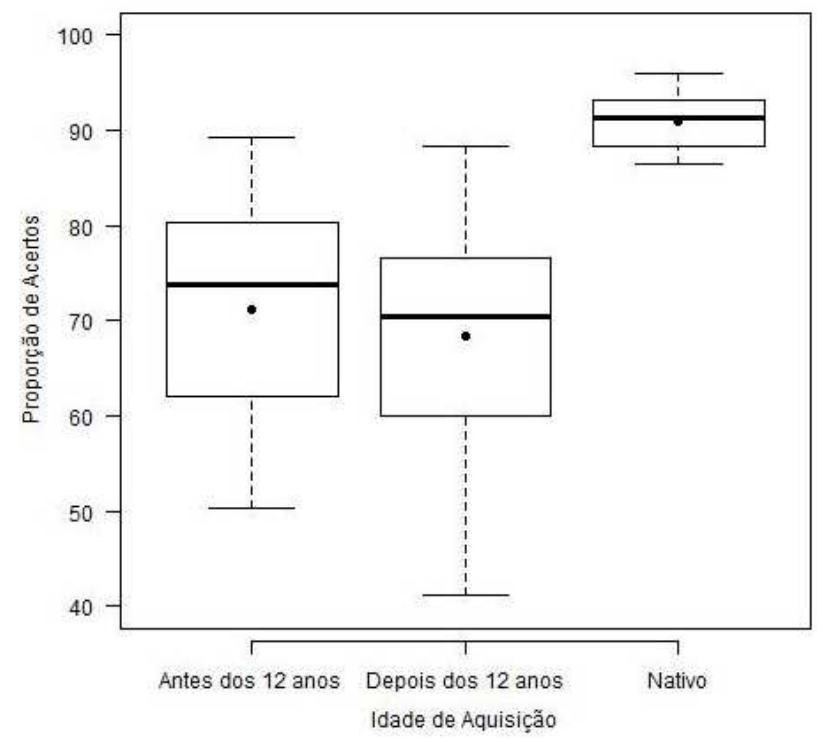

\section{Gráfico 44: Proporção de acertos por Idade de Início da Aquisição}

Quando observarmos os dois grupos de idade de início da aquisição separados por nível de proficiência, entretanto, percebe-se que a média de acertos nos níveis básico e intermediário pelos informantes que iniciaram a aquisição antes dos 12 anos é mais baixa do que a média dos que iniciaram após os 12 anos. Observa-se que o grupo de informantes no nível básico que iniciou a aquisição antes da puberdade é o que apresenta a maior variação entre os indivíduos, já que alguns informantes neste grupo tiveram taxas de acertos muito acima da média para este nível (cf. Seção 6.3.1.2). No nível intermediário, apesar de a média do grupo que iniciou a aquisição antes dos 12 anos ser mais baixa do que os que iniciaram após essa idade, observa-se que também há indivíduos que apresentaram taxas bastante acima da média e que este grupo também é bastante variado. 0 nível avançado, por fim, foi o único em que a média de acertos pelos informantes que iniciaram a aquisição antes dos 12 anos foi mais alta do que a dos que iniciaram após os 12 anos. Observa-se que, neste nível de proficiência, o grupo de falantes que iniciou a aquisição após os 12 anos é o mais homogêneo dentre todos os outros grupos, conforme o Gráfico 45 a seguir (Gráfico 36 do Cap. 6). 


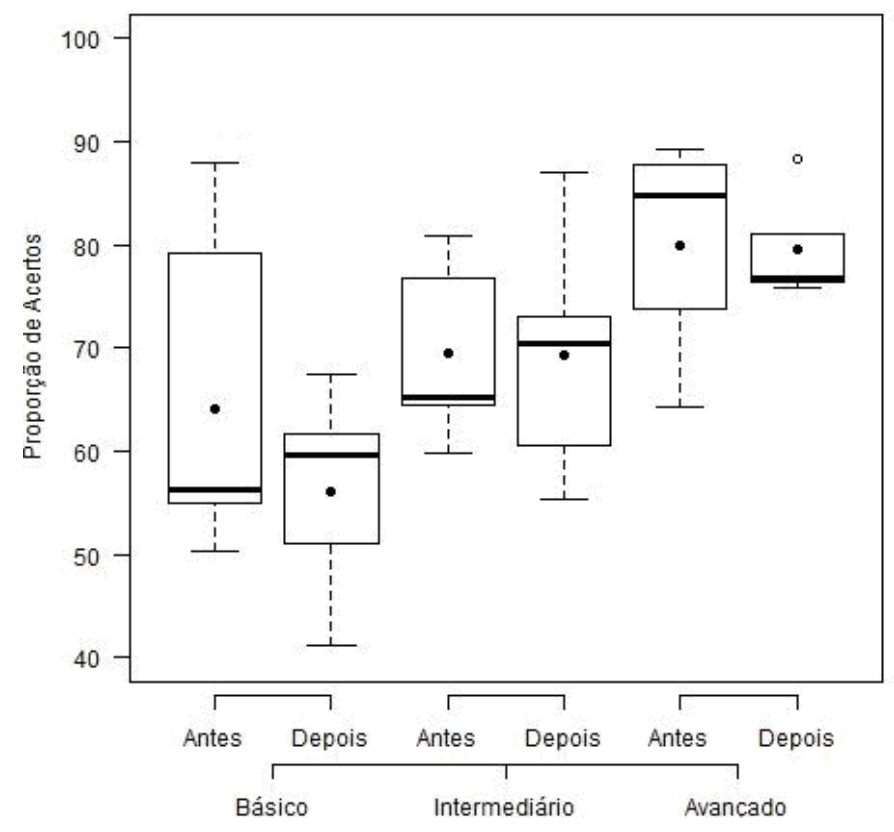

\section{Gráfico 45: Acertos por nível de proficiência e idade de início da aquisição}

Os resultados encontrados nesta pesquisa indicam, portanto, uma tendência de os informantes que iniciaram a aquisição mais jovens apresentarem produções mais semelhantes ao falar nativo somente no que diz respeito à regra de retração de acento. Com relação à regra de assimilação de vozeamento, as produções de vozeamento em contextos que não permitiam a regra do $\mathrm{PB}$ foram tão poucas que não é possível estabelecer qualquer generalização a respeito da influência da idade de início da aquisição. No que diz respeito à relação entre sílaba e acento, observa-se que no nível avançado os informantes que iniciaram a aquisição antes dos 12 anos apresentam produções mais semelhantes ao falar nativo, o que corroboraria nossa hipótese inicial. Entretanto, o mesmo não se observa para os níveis básico e intermediário, nos quais, diferentemente do esperado, os falantes que iniciaram a aquisição após a puberdade apresentaram uma média de acertos mais alta.

Portanto, não se pode negar a hipótese nula de que a idade de início da aquisição não afeta a aquisição de segunda língua, já que os informantes que iniciaram a aquisição antes da puberdade tiveram mais facilidade para adquirir a regra de retração de acento em todos os níveis de proficiência e falantes de nível avançado que iniciaram a aquisição antes dos 12 anos apresentaram uma taxa de acertos na relação entre sílaba e acento mais alta do que os que iniciaram a aquisição após essa faixa de idade. Tampouco podemos concluir que iniciar a aquisição da L2 antes da puberdade é um fator 
determinante para a aquisição de regras fonológicas e para a marcação de parâmetros porque os resultados não foram significativos nem para a regra de assimilação de vozeamento, que não foi adquirida em nenhum nível de proficiência, e nem para a marcação do parâmetro do acento nos níveis básico e intermediário. Os resultados são muito interessantes na medida em que, dentro da teoria gerativa por Princípios \& Parâmetros, o período crítico estabeleceria o momento até quando os parâmetros estariam disponíveis para (re)marcação. Como vimos, o resultado significativo foi encontrado na manutenção de um processo fonológico que já existia em L1. Logo, não se pode dizer que a idade estava afetando a aquisição deste processo. Em suma, para os dois fenômenos que não implicavam L1, o fator idade não se mostrou relevante.

\subsection{0 papel da Gramática Universal e da Língua Materna}

Vejamos, por fim, o que nossos resultados dizem a respeito da influência da Gramática Universal e da L1 no processo de aquisição de segunda língua. De acordo com nossa hipótese, a GU continuaria disponível durante a aquisição de L2 (cf. White, 2003, Meisel, 2011), o que permitiria a marcação do parâmetro do acento do inglês, mas a aquisição partiria da gramática da L1, o que explicaria a influência da L1 sobre a L2, principalmente nos níveis iniciais.

Para que se tenha uma visão geral da aquisição dos três processos, o Gráfico 32 a seguir apresenta a taxa de acertos pelos informantes brasileiros no nível avançado, que representam o estágio estável/final da aquisição, em comparação com os resultados dos falantes nativos.

Os resultados indicam que, dentre os três processos, a relação entre sílaba e acento apresentou a taxa de acertos mais alta tanto pelos falantes de nível avançado quanto pelos falantes nativos (83,3\% e 92,2\%, respectivamente), seguida da retração de acento, com aplicação de 43,9\% pelos falantes de nível avançado e 50,6\% pelos falantes nativos e, por último, pela assimilação de vozeamento, com apenas 0,5\% de aplicação pelos falantes de nível avançado e 27,3\% pelos falantes nativos (especificamente nos contextos que não permitiam a assimilação regressiva). 


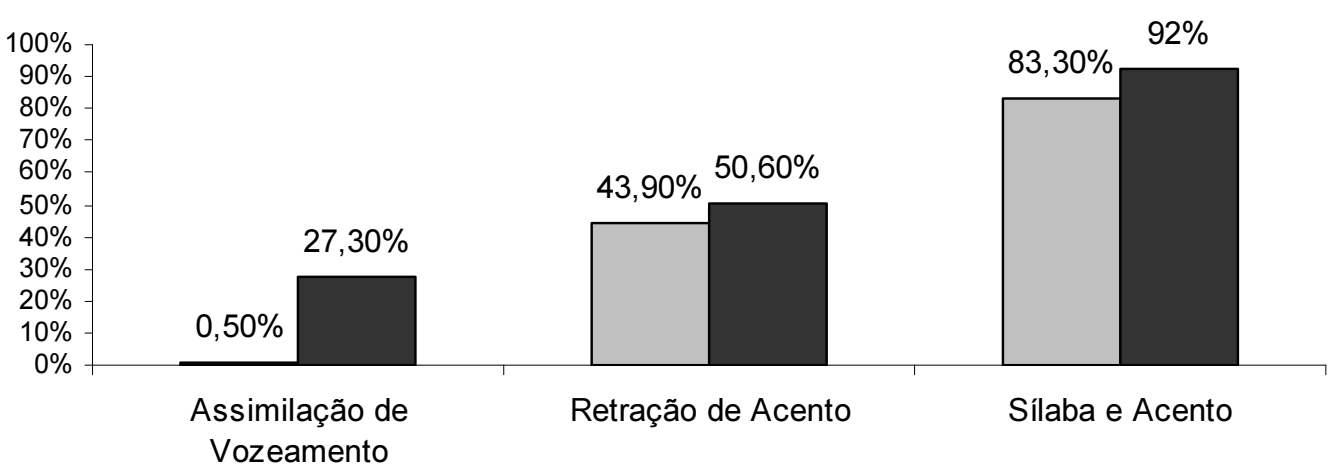

Falantes de Nível Avançado $\square$ Nativos

Gráfico 46: Acertos por falantes de nível avançado e falantes nativos nos três fenômenos

Apesar de a maior taxa de acertos por falantes brasileiros ter sido encontrada na relação entre sílaba e acento, observa-se que a retração de acento foi a regra que apresentou as taxas mais aproximadas entre os falantes de nível avançado e os falantes nativos, com uma diferença de apenas $6,7 \%$, contra $8,9 \%$ de diferença entre falantes avançados e nativos na relação entre sílaba e acento e $26,8 \%$ de diferença na regra de assimilação de vozeamento.

Esse resultado deixa claro que dentre os três fenômenos investigados a assimilação de vozeamento progressiva foi a regra mais difícil de ser adquirida pelos informantes desta pesquisa, o que confirma a nossa predição a respeito da aquisição dos três fenômenos (Cf. Cap. 3) de que a modificação de uma regra (i.e., assimilação de vozeamento) seria mais difícil do que transferir uma regra (i.e., retração de acento) ou (re)marcar de um parâmetro (i.e. sílaba e acento).

Com relação à regra de retração de acento e à relação entre sílaba e acento, se considerarmos a proximidade entre as taxas de aplicação dos falantes de nível avançado, que representam o estágio estável/final da aquisição, e os falantes nativos como o principal critério para verificar qual dos três processos foi adquirido com mais facilidade pelos informantes nesta pesquisa, concluímos que foi a regra de retração de acento. Entretanto, se considerarmos apenas a taxa de acertos como critério para definirmos qual fenômeno foi adquirido com mais facilidade pelos falantes brasileiros, chegamos à conclusão de que foi sílaba e acento, pois foi o que apresentou a taxa de acertos mais alta no nível avançado. Quando observamos os resultados referentes ao nível básico, que representa o estágio inicial da aquisição, observamos que a relação entre sílaba e acento também apresentou a maior taxa de acertos: os informantes de nível básico aplicaram o 
acento corretamente em 60,9\% dos casos, contra 17,5\% de aplicação da regra de retração de acento e praticamente nenhuma aplicação da assimilação de vozeamento progressiva.

Esses resultados poderiam ser evidência de que, assim como na aquisição de L1, a aquisição de segunda língua parte da Gramática Universal, a qual permitiu que a marcação do parâmetro do acento ocorresse antes da transferência da regra de retração de acento e da modificação da regra de assimilação de vozeamento, já que a proporção de acertos do acento foi a mais alta dentre os três fenômenos tanto no estágio inicial (nível básico) quanto no estágio final (nível avançado) da aquisição. Entretanto, antes de chegarmos a alguma conclusão a respeito do papel da GU e da L1 sobre a aquisição de L2, é importante considerarmos a natureza de cada um desses processos.

Primeiramente, é importante lembrar que a aplicação das regras de retração de acento e de assimilação de vozeamento depende do contexto. No caso da retração de acento, para que a regra seja aplicada é necessário que o choque acentual esteja dentro do domínio da frase fonológica, tanto no inglês como no PB. Por isso, as sequências de choque acentual em nosso experimento de coleta foram incluídas em frases fonológicas do mesmo tamanho e no mesmo tipo de frase veículo, o que descartaria a influência dos contextos prosódico e sintático sobre a retração (cf. 5.2.1). Entretanto, além dessa especificidade do domínio prosódico, a aplicação da regra depende de fatores como a velocidade de fala, a fluência e uma não preocupação em falar "corretamente", já que a fala cuidadosa e em velocidade mais lenta gera mais fronteiras fonológicas e pode bloquear a aplicação da regra. Dado que os informantes de nível básico ainda não são capazes de realizar a leitura das frases de forma fluente, é natural que tenham apresentado taxas de aplicação da retração de acento mais baixas do que os informantes dos níveis intermediário e avançado, já que a regra foi bloqueada pela leitura mais pausada e cautelosa característica deste nível. 0 fato de os falantes de nível básico terem apresentado uma taxa de retração de acento relativamente baixa não pode, portanto, ser usado como justificativa para afirmar que a L1 não estava operando no início da aquisição.

Outro fato a ser destacado sobre a retração de acento é que a regra é variável inclusive na fala nativa. Conforme já mencionado, se observarmos a proporção de aplicação da regra pelos falantes de nível avançado e pelos falantes nativos, percebemos que são as taxas mais próximas dentre os três processos investigados $(43,9 \%$ e $50 \%$, 
respectivamente). Isso indica que, assim que os informantes brasileiros conseguem produzir as frases fluentemente, a regra é transferida da L1 e aplicada de maneira muito semelhante à produção dos falantes nativos do inglês, tanto no que diz respeito à quantidade quanto no que diz respeito aos contextos em que a regra é aplicada. 51

Com relação à regra de assimilação de vozeamento, vimos que os falantes brasileiros não adquiriram a regra progressiva, nem mesmo no nível avançado - o que indicou que modificar uma regra fonológica foi o mais difícil dentre os três pontos analisados. Mas, além da não aquisição da regra do inglês, há outro fator importante a ser considerado nesta análise: o fato de o vozeamento pelos falantes brasileiros ter sido motivado pelo contexto seguinte. Se observarmos os dados da Tabela 5 (Cap. 4), podemos perceber que o vozeamento do /s/ na fala dos brasileiros foi motivado pelo contexto seguinte em $97 \%$ dos casos, o que indica que o vozeamento ocorreu quase categoricamente por causa da transferência da regra de assimilação regressiva, do português, para o inglês. Os resultados da Tabela 10 (Cap. 4) indicam que o vozeamento foi influenciado pelo contexto seguinte em todos os níveis: no nível básico, houve 49\% de vozeamento quando o contexto seguinte era vozeado; no nível intermediário, 65,6\%; e, no nível avançado, 56\%. A taxa de aplicação mais baixa pelos falantes de nível básico, neste caso, pode ter sido influenciada pelo mesmo motivo que houve menos retração de acento neste nível: é possível que os informantes tenham produzido as sentenças de forma mais lenta e cautelosa, o que resultou na criação de mais fronteiras entre palavras e consequentemente mais bloqueios da regra do português. No nível intermediário, houve mais casos de vozeamento porque os falantes já são capazes de realizar a leitura das frases de maneira contínua, o que permitiu uma aplicação mais alta da regra regressiva, do PB. Por fim, o fato de os falantes de nível avançado terem aplicado uma taxa de vozeamento mais baixa do que o nível intermediário nesses contextos pode indicar o início de uma consciência de que a regra do português não deve ser aplicada categoricamente no inglês, ainda que esses mesmos informantes não tenham sido capazes de produzir a regra do inglês nos contextos seguidos de pausa ou de consoante surda.

Os resultados discutidos até aqui mostram, portanto, que houve transferência da L1 para a L2 tanto na regra de retração de acento quanto na regra de assimilação de

${ }^{51}$ Até onde sabemos, não há estudos que mostrem a proporção de aplicação deste processo no português brasileiro, de forma que não é possível saber se há alguma modificação de quantidade de aplicação em L2 em relação à L1. 
vozeamento nos três níveis de proficiência, o que confirma a influência da língua materna na aquisição de regras fonológicas da L2 tanto no início da aquisição quanto durante o processo. Resta entendermos o que os resultados referentes à relação entre sílaba e acento, que se dá através de marcação paramétrica, nos dizem a respeito do papel da GU e da língua materna no processo de aquisição.

Vimos que os falantes brasileiros de nível avançado acertaram o padrão acentual das palavras do inglês em $83,3 \%$ dos casos, a taxa geral mais alta dentre os três fenômenos analisados (comparada a 43,9\% em retração de acento e 0,5\% em assimilação de vozeamento progressiva nos contextos que não permitiam a regra do português). Contudo, é importante salientar que os falantes nativos também apresentaram uma taxa de acerto maior no experimento que testava a relação entre sílaba e acento, com 92,2\% de acertos (comparado a 50\% em retração de acento e 44\% em assimilação de vozeamento), o que ressalta o caráter variável das duas regras discutidas acima em contraste com a aplicação quase categórica do acerto na relação entre sílaba e acento. Isso é um ponto importante para questionarmos se a relação entre sílaba e acento apresentou as taxas de acertos mais altas tanto no nível básico quanto no avançado por causa da influência da GU, que permitiu que a marcação do parâmetro ocorresse antes da transferência da L1, ou se as taxas foram mais altas simplesmente porque não é um fenômeno variável como retração de acento, por exemplo.

Outro fator que merece ser frisado com relação à sílaba e acento é o tipo de palavra que favoreceu acerto pelos brasileiros. 0 Gráfico 47 a seguir (Gráf. 37 do Cap. 6) mostra que em todos os níveis de proficiência houve mais acertos nas em que o acento esperado era o paroxítono do que naquelas em que o acento esperado era o oxítono.

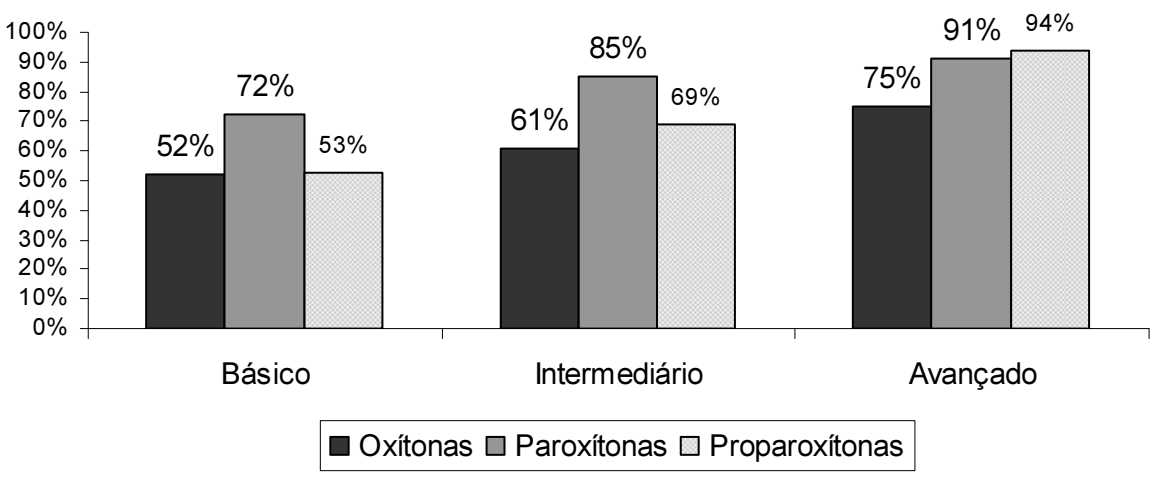

Gráfico 47: Acertos por Acento Esperado e Nível de Proficiência 
Esse resultado evidencia, primeiramente, que os falantes aprenderam parte da regra de acentuação do inglês, pois, desde o nível básico, entenderam que sílaba com rima ramificada (CVC) em posição final não atrai o acento no inglês. Outro ponto a ser destacado é a preferência pelo padrão paroxítono, o mais comum no PB. Mesmo nos casos em que houve aplicação de epêntese, nos quais era esperado que o padrão acentual fosse alterado, o padrão paroxítono da palavra foi mantido, ainda que na sílaba errada, na maioria dos casos (ex: ['ræ.bıt] $\rightarrow$ ['ræ.bi.tfi], cf. Seção 6.4.2). No caso de palavras terminadas em núcleo ramificado, a taxa de acertos foi mais baixa nos três níveis de proficiência. Isso indica que, apesar de os informantes, em sua maioria, terem compreendido que sílaba CVC não atrai o acento, acabaram errando com mais frequência os padrões CVV e CVVC, que constituem sílabas pesadas no inglês. Observamos que este fato aconteceu quanto havia vogais longas envolvidas (em comparação com casos em que o núcleo era preenchido por um ditongo), e nossa hipótese é de que os falantes não são capazes de distinguir vogais longas de vogais breves, o que pode ser evidenciado através da não distinção na produção destas vogais (ver os resultados para verificação acústica na Seção 6.3.3). Consequentemente, houve uma tendência de aplicação do acento paroxítono em palavras que deveriam ser produzidas com acento oxítono, inclusive naquelas que se assemelham a vocábulos existentes no português (ex: bamBOO $\rightarrow$ BAMboo). Esse resultado indica que, inclusive no caso da relação entre sílaba e acento, a taxa de acertos pode ter sido influenciada por algum tipo de transferência da L1, já que o padrão paroxítono, que apresentou a maior taxa de acertos nos dados dos brasileiros, é o predominante no PB.

Sendo assim, observa-se a influência do PB na aquisição dos três fenômenos estudados desde o nível básico até o nível avançado, uma evidência de que a gramática da L2 é construída a partir da gramática da língua materna. Nossos resultados também apontaram que os informantes de nível avançado foram capazes de mudar o conceito de peso das sílabas finais, que no PB é caracterizado pela rima ramificada e no inglês pelo núcleo ramificado. Isso é uma evidência de que, apesar de o estado inicial da aquisição de L2 ser caracterizado pela gramática da L1, a GU permite a marcação de parâmetros da língua-alvo no decorrer do processo de aquisição, inclusive no caso de aprendizes adultos. Esses resultados vão ao encontro das pesquisas de Archibald (1992, 1993a, 1993b), as quais indicaram que falantes de polonês, de espanhol e de húngaro foram 
capazes de marcar o parâmetro do acento do inglês, apesar de também terem apresentado influência de suas respectivas línguas maternas (Cf. Capítulo 2).

Com relação às propostas sobre a influência da GU e da L1 nos estágios da aquisição de L2 apresentadas na Seção 2.3 e resumidas no Quadro 3, nossos resultados parecem estar mais próximos do que é previsto pela Hipótese do Acesso Total/Transferência Total (Schwartz e Sprouse, 1996), tanto no que diz repeito ao estado inicial, composto pela gramática da L1 e com acesso total à GU, quanto no que diz respeito ao estágio final, pois a proposta prevê que a aquisição total da gramática da L2 é possível, mas nem sempre é alcançada. Entretanto, mais pesquisas precisam ser desenvolvidas para verificar que tipo de influência esse acesso total à GU pode exercer sobre a aquisição de segunda língua.

Vimos que, dentre os três processos investigados, a regra de retração de acento, adquirida através da transferência da L1, e a relação entre sílaba e acento, adquirida pela marcação de parâmetros através do input da L2, foram adquiridas com mais facilidade do que a regra de assimilação de vozeamento, que não tem apoio nem na L1 e nem na GU. Observou-se, também, que a modificação da regra de assimilação de vozeamento foi mais difícil do que modificar o valor do parâmetro do acento, o que indica que a mudança de um valor paramétrico é mais fácil que a mudança de uma regra fonológica existente na L1. Os resultados desta pesquisa mostram, portanto, que o processo de aquisição fonológica de segunda língua é influenciado tanto pela Gramática Universal, que permite a (re)marcação paramétrica a partir do input da língua alvo, quanto pela língua materna, que se manifesta na L2 através de transferência positiva ou negativa, o que faz com que regras que não contam com apoio nem da GU e nem da L1 sejam os fenômenos mais difíceis de serem adquiridos. 


\section{CONSIDERAÇÕES FINAIS}

A presente pesquisa teve como objetivo investigar o papel da língua materna (L1) e da Gramática Universal (GU) na aquisição do inglês por falantes de português brasileiro através da análise de três regras fonológicas: a relação entre sílaba e acento, que é adquirida através da marcação de parâmetros métricos; a retração de acento, que representa uma regra a ser transferida da L1 para a L2; e regra de assimilação de vozeamento, que existe em ambas as línguas, mas de maneira diferente e, portanto, trata-se de uma regra a ser modificada.

Existe na literatura em aquisição de segunda língua uma discussão a respeito da disponibilidade da GU, da possibilidade de (re)marcar um parâmetro através do input da L2 e do estado inicial da gramática da segunda língua. Estudos em aquisição de L2 propõem que o aprendizado pode ocorrer com acesso direto à GU, sem transferência da L1 (Epstein et al, 1996), com acesso à GU, mas através da L1 (Schwartz e Sprouse, 1996, Vainikka e Young-Scholten 1994, Eubank 1993) ou sem acesso nenhum à GU (Clahsen \& Muysken, 1996). Entretanto, a grande maioria desses trabalhos baseia-se em dados de aquisição sintática, e até onde sabemos, não há trabalhos discutindo a validade destas propostas através de regras fonológicas que podem ser influenciadas pela GU, pela L1, ou por nem uma, nem outra.

Esta investigação permite compreender a influência da GU e da L1 na aquisição de L2 porque, se os resultados mostrassem que a relação entre a sílaba e acento fosse a regra mais fácil de ser adquirida, isso seria uma evidência de que o estado inicial da aquisição é caracterizado pela GU, que permitiu a (re)marcação do parâmetro do acento do inglês. Se a retração de acento fosse adquirida com mais facilidade, isso significaria que o estado inicial da aquisição é a gramática da L1 e que haveria uma transferência (positiva) dessa regra para a L2. Finalmente, se a regra de assimilação de vozeamento fosse adquirida com mais facilidade, isso seria uma evidência de que nem a L1 e nem a GU foram os fatores facilitadores no processo de aquisição desses informantes.

Após apresentarmos um panorama da pesquisa em aquisição de primeira e segunda língua no paradigma gerativo nos Capítulos 1 e 2, apresentamos as hipóteses que nortearam a investigação dos três fenômenos em análise nesta pesquisa. A primeira era a de que a GU continuaria disponível durante a aquisição de L2 (cf. White, 2003; 
Meisel, 2001), mas que a aquisição partiria da gramática da língua materna, o que explicaria a influência da L1 sobre a L2, principalmente nos níveis iniciais. Essa hipótese nos levou à predição de que a regra mais difícil de ser adquirida seria a assimilação de vozeamento, que não conta com o apoio nem da L1 e nem da GU. Nossa segunda hipótese era a de que o nível de proficiência seria relevante para a aquisição das três regras em análise, o que nos levou à predição de que os falantes de nível avançado apresentariam produções mais semelhantes ao falar nativo do que os falantes dos níveis básico e intermediário. E a terceira e última hipótese era a de que existe um período crítico que afeta a aquisição de L2, o que nos levou à predição de que os falantes que iniciaram a aquisição do inglês antes dos 12 anos apresentariam produções mais semelhantes ao modo de falar nativo, conforme a Hipótese do Período Crítico (Lenneberg, 1967).

A amostra foi composta por 30 falantes brasileiros de inglês como L2 divididos em três níveis de proficiência - básico, intermediário e avançado -, além de 7 falantes nativos, que constituíram o grupo de controle. Para a coleta foram utilizados 3 experimentos, um para cada fenômeno, o que totalizou 9.248 dados.

Os dados referentes à assimilação de vozeamento foram transcritos a partir da verificação acústica do vozeamento da fricativa /z/ com base na barra de sonoridade, na presença de pulsos glotais e na curva de F0, que é contínua em fricativas sonoras e interrompida em fricativas surdas. A classificação dos dados referentes à sílaba e acento e à retração de acento, por sua vez, foi realizada em duas etapas: uma verificação perceptual e uma verificação acústica. Optou-se pela combinação entre esses dois tipos de verificação principalmente porque, conforme apontado nos estudos de Grabe e Warren (1995) e Levey (1999), muitas vezes a retração de acento é percebida ainda que não haja evidências acústicas que indiquem a aplicação da regra. Para a verificação perceptual, foram utilizados os mesmos procedimentos aplicados por Levey (1999) e Stander (2007): primeiramente, a própria pesquisadora sinalizou o acento em cada palavra e, para assegurar a confiabilidade dessa classificação, solicitou-se que outra pessoa, com extenso conhecimento dos aspectos fonético-fonológicos da língua inglesa, realizasse o mesmo procedimento. Nos casos de discordância, as palavras eram ouvidas novamente até que se chegasse a um consenso a respeito das sílabas acentuadas. Para a verificação acústica das duas regras que envolviam a aquisição do acento, foi utilizado 
um script do Praat que apontou, entre outras informações, as medidas de duração (em milissegundos) e do pico de F0 (pitch) de cada sílaba.

Os resultados referentes à aquisição da regra de assimilação de vozeamento progressiva do inglês, que ocorre em decorrência do contexto precedente (ex: $\operatorname{dog}[z])$, mostraram que a aplicação do vozeamento foi favorecida por segmentos vozeados no contexto seguinte, uma evidência de que foi o vozeamento do contexto seguinte, e não do precedente, que influenciou a produção de fricativas vozeadas nos contextos em análise. Isso é confirmado se considerarmos que o vozeamento foi aplicado em apenas 0,6\% dos casos de fricativa seguida de consoante desvozeada ou de pausa (12/1121), contextos em que a assimilação regressiva do português, que ocorre em decorrência de segmentos vozeados no contexto seguinte, não poderia ocorrer. Os resultados indicaram, portanto, que a assimilação de vozeamento progressiva do /s/ no inglês não foi adquirida em nenhum nível de proficiência, e que houve uma transferência da regra regressiva da L1 para a L2. Conforme discutido na Seção 4.4.3, o fato de a assimilação progressiva ser uma regra marcada e de o contraste entre [s] e [z] em posição de final de palavra ser alofônico no português e, portanto, pouco saliente para os falantes brasileiros, parecem ser fatores relevantes para explicar os resultados encontrados.

Os resultados referentes à verificação perceptual da retração de acento indicaram que a regra foi aplicada em 21,7\% dos casos pelos falantes brasileiros (somando-se os três níveis de proficiência) e em $50 \%$ dos casos pelos falantes nativos. Observou-se que a retração passa a ser mais frequente conforme o avanço do nível de proficiência, já que os falantes de nível avançado aplicaram $43,9 \%$ de retração, valor bastante aproximado ao dos nativos (50\%), seguidos dos falantes de nível intermediário, com 24,8\% de retração e, por fim, pelos falantes de nível básico, com 17,5\% de aplicação da regra. Conforme apontado na Seção 5.4.2, acreditamos que a regra tenha sido pouco aplicada no nível básico porque esses informantes nem sempre são capazes de realizar a leitura das frases de modo natural, sem pausas, o que acaba bloqueando a aplicação da regra. Os resultados também mostraram que, assim como os falantes nativos, os falantes brasileiros aplicaram uma proporção de retração muito aproximada em contextos com sequência de choque de acentos primários (ex: bamBOO BRAcelets) e nos casos em que havia uma sílaba átona entre os dois acentos (ex: bamBOO maTErials). Com relação aos correlatos acústicos, observou-se que palavras lidas isoladamente apresentaram durações mais longas do que palavras lidas em contexto de frase com choque ou sem 
choque tanto na produção dos nativos quanto na dos falantes de inglês como L2 e que o pico de F0 e a duração não foram fatores decisivos para a produção das palavras em contextos de choque, sem choque e de palavra isolada. Os resultados referentes à regra de retração de acento indicaram, portanto, diversas semelhanças entre os resultados dos falantes nativos e dos falantes não nativos tanto do ponto de vista da percepção quanto no ponto de vista acústico. Desse modo, consideramos que, principalmente no nível avançado, a regra de retração de acento do inglês e todas as suas particularidades foi transferida do PB para o inglês.

Os resultados referentes à verificação perceptual da relação entre sílaba e acento, por fim, indicaram que os falantes nativos aplicaram o padrão acentual esperado (acerto) em palavras reais e logatomas em 92,2\% dos dados e que os falantes brasileiros (somando-se os três níveis de proficiência) aplicaram o padrão acentual esperado em $72,2 \%$ dos casos. Assim como na regra de retração de acento, o nível de proficiência foi um fator importante para a aquisição do padrão acentual do inglês, já que se observou um aumento na proporção de acertos conforme o avanço do nível de proficiência: os falantes de nível básico apresentaram 60,9\% de acertos, os falantes de nível intermediário apresentaram $72,4 \%$ de acertos e os falantes de nível avançado apresentaram $83,3 \%$ de acertos, o valor mais aproximado ao dos falantes nativos $(92,2 \%)$. No caso dos falantes nativos, os resultados indicaram que a proporção de acertos foi um pouco mais alta em palavras terminadas em núcleo ramificado, nas quais o padrão acentual esperado era o oxítono, do que em palavras terminadas em núcleo simples, nas quais o padrão esperado era o paroxítono ou o proparoxítono (inclusive em logatomas, o que mostra o quanto é clara a questão da duração no inglês). Ao contrário dos falantes nativos, os falantes brasileiros apresentaram taxas de acerto mais altas em palavras terminadas em núcleo simples, nas quais o acento esperado era o paroxítono ou o proparoxítono. Dentre os três padrões acentuais controlados nesta pesquisa, a maior taxa de acertos foi registrada em palavras paroxítonas, com 82,9\% de acerto, e a mais baixa em palavras oxítonas, com $62,8 \%$ de acertos. Os resultados mostraram que as maiores taxas de acerto foram registradas em palavras reais cujo padrão acentual era o paroxítono (ex: RAbbit, CArrot) e as mais baixas em logatomas cujo padrão acentual esperado era o oxítono (ex: solOOP, lanDOO). Mostramos que resultados semelhantes foram encontrados na pesquisa de Post (2010), que registrou mais erros em palavras oxítonas do que em paroxítonas, o padrão predominante no PB (cf. Cintra, 1997). 
Observou-se, portanto, a influência do PB na aquisição dos três fenômenos estudados desde o nível básico até o nível avançado: no caso da assimilação de vozeamento progressiva do inglês, observou-se a aplicação da regra regressiva do português; no caso da retração de acento, que ocorre de maneira semelhante nas duas línguas, a regra da L1 foi transferida para a L2 assim que os falantes se tornam capazes de produzir sentenças com naturalidade (i.e. nível avançado), ainda que de forma variável, assim como os falantes nativos; e no caso da relação entre sílaba e acento, os falantes tiveram mais facilidade em adquirir o padrão paroxítono, que é o padrão predominante na língua portuguesa (cf. Cintra, 1997), enquanto tiveram dificuldade em adquirir a distinção entre vogais curtas e longas, que não existe no PB. Esse resultado é uma evidência de que a gramática da L2 é construída a partir da gramática da língua materna, o que sustenta a nossa primeira hipótese.

Dentre os três processos investigados, a regra de retração de acento, adquirida através da transferência da $\mathrm{L} 1$, e a relação entre sílaba e acento, adquirida pela (re)marcação de parâmetros, foram adquiridas com mais facilidade do que a regra de assimilação de vozeamento, que não tem apoio nem na L1 e nem na GU. Isso indica que o processo de aquisição fonológica de segunda língua é influenciado tanto pela Gramática Universal, que permite a (re)marcação paramétrica a partir do input da língua alvo, quanto pela língua materna, que se manifesta na L2 através de transferência positiva ou negativa, o que faz com que regras que não contam com apoio nem da GU e nem da L1 sejam os fenômenos mais difíceis de serem adquiridos.

Com relação à hipótese a respeito da influência do nível de proficiência, observou-se um avanço em direção ao falar nativo na aquisição da regra de retração de acento e na relação entre sílaba e acento, mas os resultados referentes à assimilação de vozeamento indicaram que a regra não foi adquirida em nenhum nível de proficiência. Esses resultados indicam que o nível de proficiência pode afetar a aquisição de alguns, mas não todos, os fenômenos fonológicos da L2.

Por fim, no que diz respeito à hipótese referente à influência da idade, não se pode negar a hipótese nula de que a idade de início da aquisição não afeta a aquisição de segunda língua, pois os informantes que iniciaram a aquisição antes dos 12 anos tiveram mais facilidade para adquirir a regra de retração de acento em todos os níveis de proficiência e falantes de nível avançado que iniciaram a aquisição antes dos 12 anos apresentaram uma taxa de acertos mais alta do que os que iniciaram a aquisição após 
essa faixa de idade na relação entre sílaba e acento. Entretanto, nossos resultados não permitem a conclusão de que iniciar a aquisição da L2 antes da puberdade seja um fator decisivo para a aquisição de regras fonológicas e para a marcação de parâmetros porque os resultados não foram significativos nem para a regra de assimilação de vozeamento, que não foi adquirida em nenhum nível de proficiência, e nem para a marcação do parâmetro do acento nos níveis básico e intermediário. Em suma, para os dois fenômenos que não implicavam L1, o fator idade não se mostrou relevante.

Outro ponto a ser destacado é que, apesar dos procedimentos criteriosos para o nivelamento dos informantes, observou-se bastante variação individual nos três fenômenos analisados. Com relação às regras de retração de acento e de assimilação de vozeamento, que são dependentes do contexto, essa variação pode ter sido influenciada por fatores como velocidade e registro de fala, já que a maneira cautelosa com que alguns falantes não nativos realizaram a leitura das frases pode ter bloqueado sua aplicação. No caso da relação entre sílaba e acento, entretanto, a variação individual não pode estar relacionada a fatores relacionados ao contexto. Nesse caso, é possível que fatores relacionados à motivação, à quantidade e à qualidade da exposição à língua-alvo e ao "filtro afetivo" (Krashen 1985, p.3) estejam influenciando essas diferenças individuais.

0 fato de o nível de proficiência e a idade de início da aquisição afetarem a aquisição de alguns fenômenos fonológicos, mas não outros, além da variação individual observada dentro do mesmo nível de proficiência são questões interessantes que ficam como desdobramentos para pesquisas futuras. 


\section{REFERÊNCIAS}

ABAURRE-GNERRE, M. B. Processos fonológicos segmentais como índices de padrões Prosódicos diversos nos estilos formal e casual do português do Brasil. Caderno de Estudos Lingüísticos, n. 2, p. 23-34, 1981.

ABOUSALH, E. Resolução de choques de acento no português brasileiro: elementos para uma reflexão sobre a interface sintaxe/ fonologia. Dissertação de mestrado. Campinas: Instituto de Estudos da Linguagem, 1997.

ADGER, David. Core Syntax: A Minimalist Approach. 2002.

ANGELOU, Maya. Stress. In: The Sounds of Language: An Introduction to Phonetics and Phonology, First Edition. Elizabeth C. Zsiga. Blackwell Publishing Ltda, 2013.

ARCHIBALD, J. Transfer of L1 parameter settings: some empirical evidence from Polish metrics. Canadian Journal of Linguistics 37, 301-39, 1992

. Language learnability and L2 phonology: the acquisition of metrical

parameters. Dordrecht: Kluwer, 1993a

The learnability of English metrical parameters by adult Spanish

speakers. International Review of Applied Linguistics 31, 129-42, 1993b:

(ed). Phonological Acquisition and Phonological Theory. (1ª publicação

em 1995). Nova Iorque: Psychology Press, 2014.

AYOUN, Dalila. Parameter Setting in Language Acquisition. (2 ${ }^{\mathrm{a}}$ ed.). London \& New York: Continuum Press, 2005.

BARBOSA, P. A estrutura rítmica da frase revelada por aspectos de produção e percepção da fala. Manuscrito referente à comunicação do XLIII Seminário do GEL-São Paulo, 1995

. Syllable-timing in Brazilian Portuguese: uma crítica a Roy Major. In:

D.E.L.T.A., v.16, n. 2, p. 369-402, 2000.

Explaining Brazilian Portuguese resistance to stress shift with a coupledoscillator model of speech rhythm production. Em: Cadernos de Estudos Lingüísticos, 43, 71-92. Campinas, 2002.

BARBOSA, P.; MADUREIRA, S. Manual de Fonética Acústica Experimental: Aplicações a Dados do Português. São Paulo: Editora Cortez, 2015.

BIALISTOK, E. e HAKUTA, K. Confounded age: Linguistic and cognitive factors in age differences for second language acquisition. In: BIRDSONG, D. (ed.). Second language acquisition and the critical period hypothesis. Mahwah, NJ: Lawrence Erlbaum Associates, 1999. 
BIRDSONG, D. Age and second language acquisition and processing: A selective overview. Language Learning, v.56, n.1, p. 9-49, 2006.

BISOL, Leda. O ditongo na perspectiva da fonologia atual. D.E.L.T.A, 1989, vol. 5, n.2: 185224.

BOERSMA, Paul; WEENINK, David. Praat: doing phonetics by computer. (Versão 5.0.47) [Programa Computacional]. 2006. Disponível em: www.praat.org.

BOLINGER, D. Two kinds of vowels, two kinds of rhythm. Bloomington, IN: Indiana University Linguistics Club, 1986

BONGAERTS, T., MERMEN, S. e VAN DER SLIK, F. Authenticity of pronunciation in naturalistic second language acquisition: the case of very advanced late learners of Dutch as a second language. Studia Linguistica, v.54, n.2, p.298-308, 2000.

BROMBERGER, S. HALLE, M. Why Phonology is Different. Linguistic Inquiry, 20. p. 61-70, 1989.

BROSELOW, E. e Y. KANG. Second language phonology and speech. In J. Herschensohn and M. Young-Scholten (eds.) The Cambridge Handbook of Second Language Acquisition, 529-554. Cambridge, MA: Cambridge University Press, 2013

BROWN, R. A first language. Cambridge, MA: Harvard University Press, 1973.

CARROLL, J. B. The Carroll Model: A 25-Year Retrospective and Prospective View, Educational Researcher, 18 (1) 26-31, 1989.

CHOMSKY, N. Syntactic Structures. The Hague: Mouton, 1957

. Aspects of the Theory of Syntax. Cambridge, MA: MIT Press, 1965

Principles and parameters in syntactic theory. In: HORNSTEIN, N.;

LIGHTFOOT, D. (Ed.). Explanation in Linguistics: the logical problem of language acquisition. London: Longman, 1981. p. 32-75.

1986

. Knowledge of Language: its origin, nature and use. Nova Iorque: Praeger,

The Minimalist Program. MIT Press, 1995.

. Novos Horizontes do Estudo da Linguagem. DELTA [online], v. 13, p. 51-74,

1997.

CINTRA, G. Distribuição de padrões acentuais no vocábulo em português. Em:

Confluência vol. 5. n. 3 83-92 ed. Unesp Assis, 197 
CLARK, R. On the relationship between the input data and parameter setting. In Proceedings of NELS 19, 48-62. GLSA, University of Massachusetts, Amherst, 1989.

CLASHEN, H. Learnability theory and the problem of development". In: J. Weissenborn, H. Goodluck e T. Roeper (eds.) Theoretical issues in language acquisition: continuity and change in development. New Jersey, Hove \& London: LEA Publ. Hillsdale, 1992.

CLAHSEN, H. \& MUYSKEN, P. How adult second language learning differs from child first language development. Behavioral and Brain Sciences, v.19, p.721-723, 1996.

COLLISCHONN, G. A Sílaba em Português. Em: BISOL, L. Introdução a estudos de fonologia do português brasileiro. Porto Alegre: EDIPUCRS, 2005. 296 p.

A epêntese vocálica no português do sul do Brasil. In: BISOL, L.;

BRESCANCINI, C. Fonologia e Variação: recortes do português brasileiro. Porto Alegre: EDIPUCRS, 2003.

COOPER, W. E.; EADY, S. J. Metrical phonology in speech production. Journal of Memory and Language. 25. 369-384, 1986

CORDER, S.P. The significance of learners' errors. International Review of Applied Linguistics, 5, 161-170, 1967.

COUNCIL OF EUROPE. Common European Framework of Reference for Languages: learning, teaching, assessment. Cambridge: Cambridge University Press , 2001.

CYRINO, S. M. Objeto nulo do português do Brasil: um estudo sintático-diacrônico. Tese (Doutorado em Ciências). Campinas: Unicamp, 1994.

CURTISS, Susan. Genie: Psycholinguistic Study of a Modern-day "Wild Child". London: Academic Press Inc., 1977.

DE VILLIERS, J.; DE VILLIERS, P. A cross-sectional study of the acquisition of grammatical morphemes in child speech, Journal of Psycholinguistic Research 2: 267-78, 1973.

DRESHER, E. \& J.D. KAYE, A computer learning model for metrical phonology. Cognition 34:137-195, 1990.

DRESHER, E. On the Acquisition of Phonological Representations. In William Sakas, ed., Proceedings of the First Workshop on Psycho-computational Models of Human Language Acquisition, 41-48, 2004.

DULAY, H.C.; BURT, M.K. Natural sequences in child second language acquisition, Language Learning 24: 37-54, 1974.

ECKMAN, F. R. Markedness and the contrastive analysis hypothesis. Language Learning 27: 315-330, 1977. 
ECKMAN, F. Typological Markedness and Second Language Phonology." In Phonology and Second Language Acquisition, edited by Jette G. Hansen Edwards and Mary L. Zampini. Philadelphia, PA: John Benjamins Publishing Company, 2008.

EPSTEIN, S.; FLYNN, S. \& MARTOHARDJONO, G. Second language acquisition: Theoretical and experimental issues in contemporary research. Behavioral and Brain Sciences, v.19, p. 677-714, 1996.

EUBANK, L. On the transfer of parametric values in L2 development. Language Acquisition 3:183-208, 1993.

FERGUSON, C. Absence of copula and the notion of simplicity: A study of normal speech, baby talk, foreigner talk and pidgins; in D. Hymes (ed.): Pidgination and Creolization of Languages. Cambridge: Cambridge University Press, p. 141-50, 1971.

FERREIRA, L. High initial tones and plateaux in Spanish and Brazilian Portuguese neutral declaratives: Consequences to the relevance of F0, duration and vowel quality as stress correlates. Tese (Doutorado em Linguística) - University of Illinois at UrbanaChampaign, Urbana, 2008.

FLEGE, J. E. Second Language Speech Learning: Theory, findings, and problems. In: STRANGE, W. (ed.). Speech perception and linguistic experience: Issues in cross-language research. Timonium, MD: York Press, 1995, p. 233-277.

FIKKERT, Paula. On the acquisition of prosodic structure. Doctoral dissertation 6, Holland Institute of Generative Linguistics (HIL), Leiden University. The Hague: Holland Academic Graphics, 1994

FRIES, C. C. Teaching and learning English as a foreign language. Ann Arbor: University of Michigan Press., 1945.

FLYNN, S. (1996). A parameter-setting approach to second language acquisition. In W. C. Ritchie \& T. K. Bhatia (Eds.) Handbook of second language acquisition, p. 121-158. San Diego: Academic Press.

FOUGERON, C.; KEATING, P. Articulatory strengthening at edges of prosodic domains. Journal of the Acoustic Society of America, v. 101, n.6, p. 3728-3740, 1997.

FROMKIN, V., RODMAN, R. \& HYAMS, N. An introduction to language. 7a ed. Boston: Thomson Wadsworth, 2003. 620p.

FRY, D.B. Experiments in the perception of stress. Language and Speech, 1, 126-152, 1958

GARCIA, G. Aquisição de acento primário em inglês por falantes de português: uma análise de derivações com sufixos não neutros via algoritmo de aprendizagem gradual GLA. Dissertação de mestrado. Porto Alegre: UFRGS, 2012, 
GASS, S. L2 acquisition and linguistic theory: The role of language transfer. In W. Ritchie \& T. Bhatia (Eds.), Handbook of second language acquisition (pp.317-345). New York: Academic PresS, 1996.

GASS, Suzan M. \& SELINKER, Larry. Second Language Acquisition: An Introductory Course. Hillsdale, NJ: Lawrence Erlbaum Associates, 2008. 357p.

GAYER, Juliana E. L.; COLLISCHONN, G. Análise variacionista da resolução de choque de acento. Revista Virtual de Estudos da Linguagem - ReVEL. Vol. 5, n. 9, agosto de 2007.

GOLDSTEIN, L.; CHITORAN, I.; SELKIRK, E. Syllable structure as coupled oscillator modes: Evidence from Georgian vs. Tashlhiyt Berber. ICPhS 16. 2153-2156, 2007.

GRABE, E. ; WARREN, P. Stress Shift: Do Speakers Do It or Do Listeners Hear It?, In B. Connell and A. Arvaniti [Ed.], Papers in Laboratory Phonology IV, 1995

GUY, Gregory e ZILLES, Ana. Sociolingüística Quantitativa - Instrumental de Análise. São Paulo: Parábola, 2007.

HALLE, M. \& VERGNAUD, J. An essay on stress. (Current Studies in Linguistics 15. Cambridge, Mass.: MIT Press, 1987.

HAYES, Bruce. A metrical theory of stress rules. Tese de doutorado. Departamento de Linguística, MIT, Cambridge, MA, 1980.

1982. . Extrametricality and English Stress. Linguistic Inquiry 13, p. 227-276, The Phonology of Rhythm in English. Linguistic Inquiry, Vol. 15, n. 1, 1984, pp. 33-54.

The prosodic hierarchy in meter. In Paul Kiparsky and Gilbert Youmans, eds., Rhythm and Meter. Orlando: Academic Press, 1989, 201-260.

Metrical stress theory: Principles and case studies. Chicago: The University of Chicago Press, 1995.

HORA, D. da. A palatalização das oclusivas dentais: variação e representação não linear. Tese (Doutorado em Linguística Aplicada) - Faculdade de Letras, Pontifícia Universidade Católica do Rio Grande do Sul, Porto Alegre, 1990.

HYAMS, N. Language Acquisition and the Theory of parameters. Dordrecht: Reidel, 1986.

.The theory of parameters and syntactic development.In: Roeper and E. Williams (eds.), Parameter Setting, p. 1-22. Dordrecht: Reidel, 1987

INGRAM, David. The Acquisition of Negative Constraints, the OCP, and Underspecified Representations. In: ARCHIBALD, J. (ed.). Phonological Acquisition and Phonological Theory. New York: Psychology Press, 2014 (p. 63-80) 
ITÔ, Junko. Syllable theory in prosodic phonology. Tese (Doutorado, PhD) - University of Massachussetts, 1986

JAKOBSON, R., Child Language, Aphasia and Phonological Universals, 1941

JAMES, Alan. Second Language Phonology. In: Jordens, P. \& Lalleman, J. Investigating Second Language Acquisition. Walter de Gruiter, New York, 1996 (p.293 - 320)

JOHNSON, K. Acoustic and auditory phonetics. 2ª ed. Oxford: Blackwell, 2003.

KANNO, K. The acquisition of null and overt pronominals in Japanese by English speakers. Second Language Research 13, P. 265-287, 1997.

KAYE, J. Why this Article is not about the Acquisition of Phonology. Working Papers in Linguistics and Phonetic, 1997.

KIMBALL, A. COLE, J. Avoidance of Stress Clash in Perception of American English Proceedings of Speech Prosody 7, Dublin, Ireland, 2014

KLEIN, E. \& MARTOHARDJONO, G. Investigating second language grammars: Some conceptual and methodological issues in generative SLA research. In: KLEIN, E. \& MARTOHARDJONO, G. (Eds.) The development of second language grammars: A generative approach. Amsterdam: John Benjamins, 1999

KRASHEN, S. D. Second Language Acquisition and Second Language Learning. Pergamon Press Inc., 1981

KUHL, P. K.. Early Language Acquisition: Cracking the Speech Code. Nature Reviews Neuroscience, 5, 2004, p. 831-843

LADO, R. Linguistics across cultures. Ann Arbor: University of Michigan Press, 1957.

LEE, S.H. Morfologia e Fonologia Lexical do Português Brasileiro. Tese de Doutorado; Campinas, UNICAMP, 1995.

LENNEBERG, E. The biological foundations of language. Wiley and Sons: New York, 1967.

LEVIN, J.; FOX, J. A. Estatística para ciências humanas. 9a ed. São Paulo: Pearson. Prentice Hall, 2004.

LEVEY, S. LAWRENCE, R. Stress clash: Frequency and strategies of resolution. Acoustical Society of America Journal, Volume 111, Issue 5, pp. 2476-2476 (2002)

LIBERMAN, M. \& PRINCE, A. On stress and linguistic rhythm. Linguistic Inquiry, 8, 249336, 1977. Disponível em: http://idiom.ucsd.edu/ bakovic/211B/Liberman-Prince1977.pdf, acessado em 30/05/2013. 
LIGHTFOOT, D. The language lottery: toward a Biology of Grammars. Cambridge: MIT Press, 1982.

LOMBARDI, L. Positional faithfulness and voicing assimilation in Optimality Theory, in Natural Language and Linguistic Theory 17, 1999, 267-302.

LONG, M. H. Maturational Constraints on Language Development. Studies in Second Language Acquisition, v.12, n.3, p251-85, 1990.

LUST, Barbara. Child language acquisition and growth. Cambridge: Cambridge University Press, 2006.

MADUREIRA, Sandra . An acoustic study of sequences of words with adjacent primarystressed syllables: does stress shift occur in Brazilian Portuguese?. Cadernos de Estudos Lingüísticos (UNICAMP), Campinas, v. 43, p. 109-126, 2002.

MAJOR, R. Stress and rhythm in Brazilian Portuguese. In: KOIKE, D. A.; MACEDO, D. P. (Orgs.). Romance Linguistics: The Portuguese Context. Westport, Connecticut; London: Bergin Garvey, 1992, p. 3-30.

Foreign accent: The ontogeny and phylogeny of second language phonology. Mahwah,NJ: Lawrence Erlbaum Associates, 2001.

MAGALHÃES, José. Caracterização dos Processos Assimilatórios no Português Brasileiro. Fórum Linguístico, Florianópolis, v. 11, n. 1, p.97-105, jan./mar. 2014.

MARTIN, A.; PEPERKAMP, S. Speech Perception and Phonology. Em: M. van Oostendorp, C. Ewen, E. Hume \& K. Rice (eds.) Companion to

Phonology. Hoboken, N.J. : Wiley-Blackwell., 2011

MASSINI, G. Acento e ritmo. São Paulo: Contexto, 1992.

MATTOS, A.M.A. A hipótese da gramática universal e a aquisição de segunda língua. Rev. Est. ling., Belo Horizonte, v.9, n.2, p.51-71, jul./dez. 2000

MATTOSO CÂMARA Jr., J. Estrutura da Língua Portuguesa. Petrópolis: Vozes, 1972.

MEISEL, J. First And Second Language Acquisition: Parallels And Differences. Cambridge: CUP, 2011.

MENDES, C. F. The perception of the English -s morpheme by Brazilian EFL learners. Dissertação de Metsrado, UFSC, 2017.

MESTER, Armin and Junko Ito. 'Feature predictability and underspecification: Palatal prosody in Japanese mimetics.' Language 65: 258- 93, 1989

MOYER, Alene. Ultimate attainment in L2 phonology. Studies in Second Language Acquisition, 21, 81-108, 1999. 
NESPOR, Marina \& VOGEL, Irene. Prosodic Phonology. Dordrecht: Foris Publications, 1986. 327p.

NEWTON, C.; WELLS, B. Between-word junctures in early multiword speech. Journal of Child Language. n. 29, p. 275-299. 2002

OHALA, J. J. The origin of sound patterns in vocal tract constraints. In ${ }^{1}$ he production of speech (P. MacNeilage, editor), pp. 189-216. New York: Springer-Verlag, 1983

PEPERKAMP, S. A typological study of stress 'deafness'. In C. Gussenhoven \& N. Warner (Eds.), Laboratory Phonology 7 (pp. 203-240), 2001.

PÉREZ-LEROUX, A.; GLASS, W. OPC effects in the L2 acquisition of Spanish. In: PÉREZLEROUX, A.; GLASS, W. (eds.). Contemporary perspectives on the acquisition of Spanish. Vol. 1: Developing Grammars (p. 149-165). Somerville, MA: Cascadilla Press, 1997.

PINKER, S. Language learnability and language development. Cambridge, MA: Harvard University Press, 1984.

PLATZACK, C. The Initial Hypothesis of Syntax. À minimalist perspective on language acquisition and attrition. in : Clahsen on Language Acquisition. Amsterdam : Benjamins, 1996.

POST, A. Estratégias de Reparo na Atribuição do acento primário do inglês por falantes nativos de PB. Dissertação (Mestrado). Santa Maria: UFSM, 2010

RADFORD, A. Syntactic theory and the acquisition of English syntax. Oxford: Basil Backwell, 1990.

REETZ, Henning e JONGMAN, Allard. Phonetics: transcription, production, acoustics and perception. Oxford: Wiley-Blackwell, 2009. 316p.

RICE, Keren . Markedness in phonology. In Paul de Lacy (ed.) The Cambridge Handbook of Phonology. Cambridge University Press, ch.4, 2007.

ROCA, I.; JOHNSON, W. A course in phonology. Oxford: Blackwell, 1999.

ROACH, Peter. English Phonetics and Phonology: A practical course. $3^{\underline{a}}$ ed. Cambridge: Cambridge University Press, 2000. 286p.

SANDALO, Filomena; TRUCKENBRODT, Hubert. Some Notes on Phonological Phrasing in Brazilian Portuguese. Em: Phonological Answers: MIT Working Papers in Linguistics 42: 285-310, 2002.

SANKOFF, David. Variable rules. In: AMMON, Ulrich, DTTMAR, Norbert e MATTEIR, Klaus J. (eds.) Sociolinguistics: an international handbook of the science language and society. New York: Walter de Gruyter, 1988, p. 984-998. 
SANTOS, Raquel. Aquisição do acento primário no português do Brasil. Tese (Doutorado em Linguística). São Paulo: USP, 2001.

. Categorias Sintáticas Vazias e Retração de Acento em Português

Brasileiro. DELTA [online]. 2002, vol.18, n.1, pp. 67-86

A aquisição da linguagem. FIORIN, José Luiz (org.) Introdução à

Linguística: I. objetos teóricos. São Paulo: Contexto, 2002.

SANTOS, R. S.; LEAL, E. G. Os domínios prosódicos e a duração de sílaba no português brasileiro. Revista da ABRALIN, Florianópolis, v.5, n.1, p.143-167, 2008.

SELKIRK, Elisabeth. The syllable, The structure of phonological representations (part II), H. van der Hulst \& N. Smith (eds.). Dordrecht: Foris, 1982. 337-83.

Phonology and Syntax: The Relation between Sound and Structure.

Massachussetts: The MIT Press, 1984.476p.

SCARPA, E. e SILVA, L. Choques de acento e interferências rítmicas do português brasileito na aquisição de inglês como L2: considerações preliminares. Prolíngua (João Pessoa) , v. 8, p. 93, 2013.

SCHACHTER, J. Testing a proposed universal. In: GASS, S., SCHACHTER, J. (eds.) Linguistic perspectives on second language acquisition. London: Cambridge, 1989.

SCHWARTZ, B. D. \& SPROUSE, R. L2 cognitive states and the full transfer/full access model. Second Language Research, v. 12, 40-72, 1996.

SCHREUDER, M. \& GILBERS, D. Restructuring the melodic content of feet. In: Phonologica (Proceedings of the 9th International Phonology Meeting, 2002

SELKIRK, Elizabeth O. Sentence Prosody: Intonation, Stress, and Phrasing. In: GOLDSMITH, John (ed.). The handbook of phonological theory. Cambridge (UK): Blackwell, 1995. 986 p.

SELINKER, L. Interlanguage. International Review of Applied Linguistics, p.209-30,1972.

SILVA, C.C. Aquisição da Regra de Assimilação do Vozeamento em Português Brasileiro. Série: Produção Acadêmica Premiada. São Paulo: FFLCH/ USP, 2010.

SILVA Jr. Interferências rítmicas do português no inglês como L2: o choque acentual. Tese (Doutorado em Linguística). João Pessoa: Universidade Federal da Paraíba, 2013

SKINNER, B. F. Verbal Behavior. Cambridge, MA: B. F. Skinner Foundation, 1957

SPINASSÉ, Karen P. Os conceitos Língua Materna, Segunda Língua e Língua Estrangeira e os falantes de línguas alóctones minoritárias no Sul do Brasil. Revista Contingentia, Vol. 1, 2006, p. 01-10 
SMITH, C. The devoicing of /z/ in American English: effects of local and prosodic context. Journal of Phonetics (1997) 25, 471-500, 1997.

STAMPE, David. A dissertation on natural phonology. Tese de Doutorado, Universidade de Chicago, EUA, 1973.

STANDER, L. A aquisição do acento primário em inglês como LE: o caso das palavras sufixadas à luz da Teoria da Otimidade. Dissertação de mestrado. Pelotas: UCPel, 2007.

TARALLO, F. A Pesquisa Sociolingüística. 4ª ed. São Paulo: Ática, 1994. 96p.

TARONE, Elaine. Some influences on the syllable structure of interlanguage phonology. IRAL, International Review of Applied Linguistics in Language Teaching 18: 139-152, 1980

TENANI, L. Fonologia Prosódica. Em: Fonologia, Fonologias: uma introdução. São Paulo: Editora Contexto, 2017.

TRUBETZKOY, N. Princípios de Fonologia. In Travaux du Cercle Linguistique de Prague 7, 1939.

VAINIKKA, A. \& YOUNG-SCHOLTEN. M. Access to X'-Theory--Evidence from Turkish and Korean adults learning German, in B.Schwartz \& T.Hoekstra (eds) Language Acquisition Studies in Generative Grammar, John Benjamins, Amsterdam.(p.265-316), 1994.

WEINREICH, U. Languages in contact. New York: LinguisticCircle of New York, 1953.

WHITE, L. The pro-drop parameter in adult second language acquisition. Language Learning 35: 47-65, 1985.

Second language acquisition and universal grammar. Cambridge: CUP, 2003

XAVIER, G. Teoria Gerativa e Aquisição da linguagem. Tese (Doutorado em Linguística). Campinas, Universidade Estadual de Campinas, 2006.

YAVAs, Mehmet. Applied English Phonology. Malden: Blackwell Publishers, 2006. 245p.

YUAN, B. The status of thematic verbs in the second language acquisition of Chinese. Second Language Research 17: 248-172, 2001.

ZANFRA, M. Phonological context as a trigger of voicing change: a study on the production of English /s/ and /z/ in word-final position by Brazilians. Dissertação de Mestrado. UFSC, 2013.

ZEC, Draga. Sonority constraints on syllable structure. Phonology 12.85-129, 1995.

ZIMMER, Márcia Cristina.; SILVEIRA, Rosane \& ALVES, Ubiratã Kickhöfel. Pronunciation Instruction for Brazilians: Bringing Theory and Practice Together. Newcastle: Cambridge Scholars Publishing, 2009. 


\section{ANEXOS}

\section{ANEXO 1: Ficha Social}

Este questionário tem por objetivo registrar os dados dos informantes que participarão desta pesquisa. Muito obrigada pela sua participação, ela é muito importante!

1)Nome:

2) Idade e data de nascimento:

3) Cidade de nascimento:

4) Escolaridade:

5) Profissão:

6) Nível de inglês: ( ) básico ( ) intermediário ( ) avançado

7) Com quantos anos você começou a aprender inglês? De que maneira (escola, curso de inglês, etc.)?

Ainda estuda? Sim ( ) Não ( )

Há quanto tempo você estuda inglês?

8) Você já teve a oportunidade de morar em país de língua inglesa? Sim ( ) Não ( ) Se a resposta anterior foi positiva, por quanto tempo?

Em qual país?

Estudou inglês nos país estrangeiro? Por quanto tempo?

9) Você tem contato com a língua inglesa fora da sala de aula? Se a resposta for positiva, especifique.

10) Você já teve aulas de pronúncia de língua estrangeira? Comente.

11) Você fala alguma outra língua estrangeira? Qual?

Desde quando?

Data: / / Informante no : 


\section{ANEXO 2: Termo de Consentimento Livre e Esclarecido}

Prezado participante:

Você está sendo convidado a participar de uma pesquisa na área de Aquisição de Segunda Língua que eu, Carina Silva Fragozo, estou conduzindo nesses anos de 20132017 como estudante de doutorado da Universidade de São Paulo, sob orientação da Prof ${ }^{\text {a }}$ Dr ${ }^{\text {a }}$ Raquel Santana Santos.

A participação neste estudo poderá ser interrompida a qualquer momento se você assim desejar. Sua participação não acarretará custos para você e não será disponível nenhuma compensação financeira adicional.

Título da pesquisa: "Aquisição Fonológica de Segunda Língua e a Teoria Gerativa" Descrição da pesquisa: 0 objetivo principal desta pesquisa é investigar se é possível que o falante de uma língua estrangeira consiga atingir um nível de proficiência semelhante ao de um falante nativo através da análise de palavras e frases produzidas por falantes brasileiros de inglês como língua estrangeira.

\section{Por que isso é importante?}

Através desta pesquisa, será possível prever e explicar dificuldades na pronúncia do inglês por falantes brasileiros e compreender o processo de aquisição de uma língua estrangeira.

\section{o que vai acontecer?}

Você será gravado durante a execução de três tarefas. Nas três tarefas, você deverá ler uma lista de palavras e frases em inglês. A gravação será realizada com um microfone em um pedestal de mesa e deverá durar cerca de 30 minutos.

Privacidade: Seu nome não será mencionado em nenhum material escrito nesta pesquisa. Ele será identificado apenas por uma numeração e o seu nível de proficiência.

Benefícios: Você estará contribuindo (e muito!) para o ensino de pronúncia do inglês para falantes brasileiros. Se você desejar, ao término da pesquisa, lhe enviarei por escrito, com linguagem clara e de forma acessível, os resultados obtidos na tese!

Riscos: A probabilidade de ocorrência de eventos desfavoráveis, prejudiciais ou desconfortáveis pode ser considerada baixa, devido à natureza e ao método de coleta dos dados: sua tarefa consiste na leitura de palavras e frases. Os riscos a que serão submetidos os participantes no processo de gravação dos áudios podem envolver casos de timidez ou inibição por parte do falante diante da pesquisadora. Os demais riscos envolvidos na pesquisa podem ser considerados naturais, ou seja, aqueles que o participante já possui e enfrenta em seu cotidiano.

Então, tenha certeza de que no curso da pesquisa você terá os seguintes direitos: a) garantia de esclarecimento e resposta a qualquer pergunta; b) liberdade de abandonar a pesquisa a qualquer momento, sem prejuízo para si; c) garantia de que caso haja algum dano a sua pessoa, decorrente da participação nesta pesquisa, os prejuízos serão assumidos pelos pesquisadores. Caso haja despesas decorrentes da participação nesta pesquisa, as mesmas serão absorvidas pelo pesquisador. Nos casos de dúvidas você deverá falar com a pesquisadora, a fim de resolver seu problema.

Divulgação dos resultados: A pesquisa será publicada no site http://www.teses.usp.br/ em 2017. Caso deseje, você receberá por email um aviso sobre essa publicação, para conhecer os resultados finais e o conhecimento que a sua participação auxiliaram a gerar.

Email para contato:

Deseja receber um e-mail com os resultados da pesquisa? ( ) Sim ( ) Não 
Abaixo estão os meios de contato meus, da minha orientadora e do Comitê de Ética em Pesquisa com Seres Humanos da USP. Você pode tirar suas dúvidas sobre esse estudo a qualquer momento. Uma via deste Termo de Consentimento vai ficar com você para possíveis consultas e/ou dúvidas posteriores.

Agradeço antecipadamente pela sua participação!

\section{ANEXO 3 \\ AVALIAÇÃo ORAL DO NÍVEL A2 (BÁSICO)}

\begin{tabular}{|c|c|c|c|}
\hline A2 & Grammar and Vocabulary & Pronunciation & Interactive Communication \\
\hline 5 & $\begin{array}{l}\text { Shows a good degree of control of simple } \\
\text { grammatical forms. } \\
\text { Uses a range of appropriate vocabulary } \\
\text { when talking about everyday situations. }\end{array}$ & $\begin{array}{l}\text { Is mostly intelligible, and has some control } \\
\text { of phonological features at both utterance } \\
\text { and word levels. }\end{array}$ & $\begin{array}{l}\text { Maintains simple exchanges. } \\
\text { Requires very little prompting and support. }\end{array}$ \\
\hline 4 & \multicolumn{3}{|c|}{ Performonce shores features of Bands 3 and 5.} \\
\hline 3 & $\begin{array}{l}\text { Shows sufficient control of simple } \\
\text { grammatical forms. } \\
\text { Uses appropriate vocabulary to talk about } \\
\text { everyday situations. }\end{array}$ & $\begin{array}{l}\text { Is mostly intelligible, despite limited control } \\
\text { of phonological features. }\end{array}$ & $\begin{array}{l}\text { Maintains simple exchanges, despite some } \\
\text { difficulty. } \\
\text { Requires prompting and support. }\end{array}$ \\
\hline 2 & \multicolumn{3}{|c|}{ Performance shares features of Bands 1 and 3.} \\
\hline 1 & $\begin{array}{l}\text { Shows only limited control of a few } \\
\text { grammatical forms. } \\
\text { Uses a vocabulary of isolated words and } \\
\text { phrases. }\end{array}$ & $\begin{array}{l}\text { Has very limited control of phonological } \\
\text { features and is often unintelligible. }\end{array}$ & $\begin{array}{l}\text { Has considerable difficulty maintaining } \\
\text { simple exchanges. } \\
\text { Requires additional prompting and support. }\end{array}$ \\
\hline 0 & \multicolumn{3}{|c|}{ Performance bejow Band 1.} \\
\hline
\end{tabular}

\begin{tabular}{|c|c|}
\hline A2 & Global Achievement \\
\hline \multirow[t]{2}{*}{5} & Handes communication in evenyday situations, despite hesitation. \\
\hline & $\begin{array}{l}\text { Constructs longer utterances but is not able to use complex language except } \\
\text { in well-rehearsed utterances. }\end{array}$ \\
\hline 4 & Performance shares features of Bands 3 and 5 . \\
\hline \multirow[t]{2}{*}{3} & Comeys basic meaning in very familiar evenyday situations. \\
\hline & $\begin{array}{l}\text { Produces utterances which tend to be very short - woeds or phrases - with } \\
\text { frequent hesitation and pauses. }\end{array}$ \\
\hline 2 & Performance shares features of Bands 1 and 3 \\
\hline \multirow[t]{2}{*}{1} & $\begin{array}{l}\text { Has difficulty conveying basic meaning even in very familiar everyday } \\
\text { situations. }\end{array}$ \\
\hline & $\begin{array}{l}\text { Responses are imited to short phrases } \alpha \text { isolated worts with frequent } \\
\text { hesitation and pauses. }\end{array}$ \\
\hline 0 & Performance below Bandl \\
\hline
\end{tabular}

